\author{
UNIVERSIDADE DE BRASÍLIA \\ FACULDADE DE TECNOLOGIA \\ PROGRAMA DE PÓS-GRADUAÇÃO EM GEOTECNIA
}

\title{
ESTUDOS LABORATORIAIS E AVALIAÇÃO ESTRUTURAL DE UM PAVIMENTO ASFÁLTICO CONSTRUIIDO COM MISTURAS DE SOLO TROPICAL, FOSFOGESSO E CAL
}

\section{DANIEL ARTHUR NNANG METOGO}

ORIENTADOR: LUIS FERNANDO MARTINS RIBEIRO, DSc. CO-ORIENTADORA: LILIAN RIBEIRO DE REZENDE, DSc.

TESE DE DOUTORADO EM GEOTECNIA

Publicação: G.TD - 112/15

Brasília, DF, 14 Outubro de 2015 
UNIVERSIDADE DE BRASÍLIA

FACULDADE DE TECNOLOGIA

PROGRAMA DE PÓS-GRADUAÇÃO EM GEOTECNIA

\section{ESTUDOS LABORATORIAIS E AVALIAÇÃO \\ ESTRUTURAL DE UM PAVIMENTO ASFÁLTICO \\ CONSTRUÍDO COM MISTURAS DE SOLO TROPICAL, FOSFOGESSO E CAL}

*.

\section{DANIEL ARTHUR NNANG METOGO}

TESE DE DOUTORADO SUBMETIDA AO DEPARTAMENTO DE ENGENHARIA CIVIL E AMBIENTAL DA UNIVERSIDADE DE BRASÍLIA COMO PARTE DOS REQUISITOS NECESSÁRIOS PARA A OBTENÇÃO DO GRAU DE DOUTOR EM GEOTECNIA.

\section{APROVADA POR:}

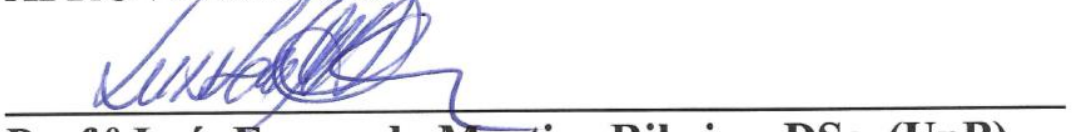

Prof. $^{\circ}$ Luís Fernando Martins Ribeiro, DSc. (UnB)

(Orientador)

$$
\text { Alex B Pariera }
$$

Prof. $^{\circ}$ Alexandre Benetti Parreira, DSc. (USP/São Carlos) (Examinador externo)

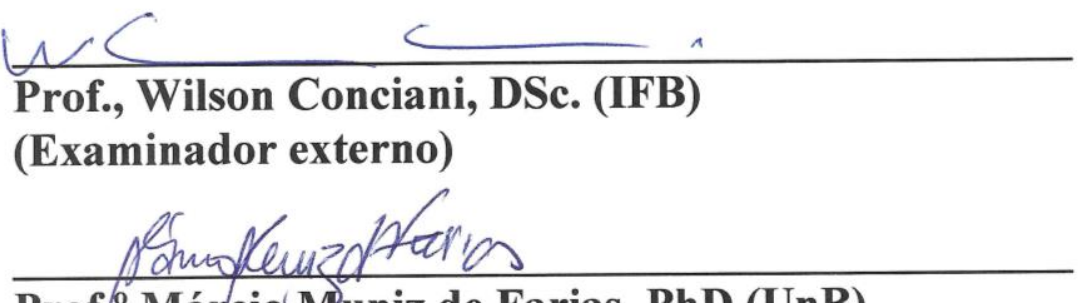

Prof. ${ }^{\circ}$ Márcio Muniz de Farias, PhD (UnB)

(Exáminador interno)

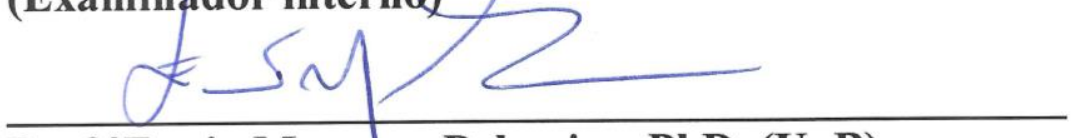

Prof. ${ }^{\circ}$ Ennio Marques Palmeira, PhD. (UnB)

(Examinador interno)

Brasília - DF, 14 Outubro de 2015 


\section{FICHA CATALOGRÁFICA}

\section{METOGO, DANIEL ARTHUR NNANG}

Estudos Laboratoriais e Avaliação Estrutural de um Pavimento Asfáltico Construído com Misturas de Solo Tropical, Fosfogesso e Cal [Distrito Federal] 2015.

xii, 207 p., 297 mm (ENC/FT/UnB, Doutor, Geotecnia, 2015)

Tese de Doutorado - Universidade de Brasília. Faculdade de Tecnologia.

Departamento de Engenharia Civil
1. Fosfogesso
2. Solo tropical.
3. Cal.
4. Avaliação estrutural
I. ENC/FT/UnB
II. Título (série)

\section{REFERÊNCIA BIBLIOGRÁFICA}

METOGO, D.A.N. (2015). Estudos Laboratoriais e Avaliação Estrutural de um Pavimento Asfáltico Construído com Misturas de Solo Tropical, Fosfogesso e Cal. Tese de Doutorado, Publicação G.TD-112/15, Departamento de Engenharia Civil e Ambiental, Universidade de Brasília, Brasília, DF, 207 p.

\section{CESSÃO DE DIREITOS}

NOME DO AUTOR: Daniel Arthur Nnang Metogo, TÍTULO DA TESE DE DOUTORADO: Estudos Laboratoriais e Avaliação Estrutural de um Pavimento Asfáltico Construído com Misturas de Solo Tropical, Fosfogesso e Cal.

GRAU: Doutor

ANO: 2015

É concedida à Universidade de Brasília a permissão para reproduzir cópias desta tese de doutorado e para emprestar ou vender tais cópias somente para propósitos acadêmicos e científicos. O autor reserva outros direitos de publicação e nenhuma parte desta tese de doutorado pode ser reproduzida sem a autorização por escrito do autor.

Daniel Arthur Nnang Metogo,

QE 40, Rua 15, Lote 52, Apartamento 104, Polos de Modas, Guará II CEP: 71070-515 - Brasília/DF-Brasil. 
Dedico este trabalho ao meu pai e também engenheiro civil, Akono Nnang Charles Albert, in memória (1960 - 2013). Saudade Eterna. E a minha mãe, Ngo Mbok Naomie Caroline. 


\section{AGRADECIMENTOS}

Aos meus pais, pelos enormes sacrifícios, os conselhos, as orientações, o grande amor e a confiança.

Aos meus irmãos, todos mais novos que sempre me incentivaram nos estudos e para quem tento ser uma referência acadêmica.

ÀDivânia Neves Terência pelo companheirismo e compressão nessa longa travessia.

Um agradecimento especialaos meus orientadores, o Professor Luís Fernando Martins Ribeiro e a Professora Lilian Ribeiro de Rezende pela confiança depositada em mim e pelo crescimento acadêmico que me proporcionaram através das suas dicas, correções, sugestões e orientações.

A maior parte dos ensaios de campo desta tese não seria concretizada se não fosse pela Professora Márcia Mascarenhas da UFG que viabilizou financeiramente a realização dessas investigações com as verbas dos projetos de pesquisa da FAPEG. Estou-lhe muito grato.

Ao colegiado de professores do Programa de Pós-Graduação em Geotecnia pelos ensinamentos, a disponibilidade para tirar as dúvidas e a confiança depositada em mim no ato da minha admissão no programa.Uma saudação particular aos coordenadores do programa que ocuparam o cargo durante minha permanência no departamento, são os professores Manoel Porfírio Cordão Neto, Hernán Eduardo Martínez Carvajal e Gregório Luís Silva Araújo por toda a atenção dada nesse período.

Aos Professores Washington Peres Núñezda UFRGS, José Camapum de Carvalho,Manoel Porfírio Cordão Neto, pelas contribuições na minha qualificação.

Ao Professor Marcio Muniz de Farias que possibilitou a realização dos ensaios triaxiais dinâmicos no INFRALAB e com quem tirei várias dúvidas de pavimentação.

Á Professor Edi Mendes Guimarães que possibilitou a realização dos ensaios de difratometria de raio-x no seu laboratório no Instituto de Geociência da Universidade de Brasília e a toda sua equipe pelo suporte técnico.

Aos meus colegas da geotecnia pelas trocas de ideias, dicas e orientações quanto à utilização dos equipamentos de laboratório. Um agradecimentoespecial aos colegas de laboratório Iván, Alejandra Maria Gómez Jimenez, ClaúdiaMaricela Gómez Muñetón, Janaina Tatto, Leonardo Ramos e Silva, FerneyQuinõnes Siqueira, Jaime Ebando, Marcus Vinicius, Marcelo Llano, Alexander Rojas.

Aos colegas Tubal Matos e Luis Abel Sozinho que gentilmente me hospedaram quando cheguei em Brasília.

Ao colega Bernardo pela sua disponibilidade para irmos a Catalão coletar as amostras de fosfogesso e solo. Uma viagem que nunca me esquecerei de tanto que rimos nessa estrada. Valeu pela força Bernadão. 
Ao Thiago Freitas, aluno de iniciação científica que me apoiou muito tanto durante a coleta das amostras em Catalão como nos ensaios em laboratório. Desejo-lhe tudo de bom na sua vida acadêmica. Não tenho a mínima dúvida será um ótimo profissional.

A minha amiga e parceira de pesquisa Michelle Marques com quem realizei diversos ensaios de campo. Era Panda aqui DCP ali, piadas para cá rizadas para lá e mais e mais ensaios. Bons momentos que ficam gravados para sempre.

Ao João Junior técnico da UFG que sempre me apoiou na realização dos ensaios de campo, desde a época do mestrado. Estou-lhe infinitamente grato. Muito do que sei hoje sobre os ensaios geotécnicos lhe devo.

Ao Alexandre Garcia, amigo de longas datas que em diversas ocasiões e na medida das suas possibilidades, conseguia para mim um caminhão para a realização dos ensaios de campo.

Aos meus colegas de trabalho Maria Célia, Cláudia e Edgar pela compreensão e o incentivo na reta final da tese.

Á Prefeitura de Aparecida de Goiânia, através da sua secretaria de obras e especialmente, através o engenheiro Odon Cleber pelo apoio incondicional nesta pesquisa deste seu início em 2009.

A empresa Anglo-American Ltda. pelo fornecimento do fosfogesso utilizado nesta pesquisa.

Á CAPES e ao CNPq pelas bolsas de estudo.

A toda a comunidade dos estudantes africanos em Brasília, Timothée, Martin Fonkoua, Virginia, Alberto, Gaudêncio, Luzibety, Zito, Zico, Gilberto entre outros, pela amizade, irmandade e incentivo mútuo nos estudos. Ao Professor Ivair dos Santos, pelas nossas lutas cotidianas em prol a nossa comunidade estudantil.

Enfim, a todos que, direta ou indiretamente, contribuíram para realização deste trabalho. 


\section{RESUMO}

A mineração ocupa um lugar de destaque no Brasil em termo de geração de riquezas. No entanto, a exploração mineira tem ocasionado uma grande preocupação ambiental, destacando-seo gerenciamento dos resíduos sólidos gerados pelo processo de beneficiamento mineral. No caso específico da indústria de fertilizante, cujo principal subproduto é o fosfogesso, as preocupações ambientais e econômicas são significativas devido à dificuldade de disposição desse subproduto. Diante isso, o aproveitamento do fosfogesso como matéria prima em outros ramos da indústria, apresenta-se como uma alternativa viável em detrimento à sua estocagem. Por outro lado, verifica-se a escassez dos materiais granulares tradicionalmente utilizados em pavimentação. $\mathrm{O}$ afastamento das jazidas dos centros urbanos e as dificuldades decorrentes da obtenção das licenças de exploração tornam cada vez mais inviável a utilização desses materiais em pavimentação. Essa dupla problemática leva ao estudo de viabilização do fosfogesso como material alternativo para pavimentos de baixo custo. Pesquisas nesse sentido iniciaram em 2007 na Universidade Federal de Goiás e foram estendidos à Universidade Brasília. Esta tese é parte do trabalho que vem se desenvolvendo nessas instituições e constitui-se da ampliação dos estudos laboratórios de misturas de solo fino tropical, fosfogesso e cal em vista sua utilização em pavimentos de baixo custo. Procurase também uma forma de controlar a etringita, mineral expansivo formado durante o processo de hidratação desses três materiais. Além disso, é realizado um acompanhamento do desempenho estruturalde uma pista experimental construída em 2009 no município de Aparecida de Goiânia (GO) com misturas de 80\%solo + 20\%fosfogesso, 80\%solo $+11 \%$ fosfogesso+9\%cal, $91 \%$ solo+9\%cal e $100 \%$ cascalho para fins comparativos. Para tanto, recorreu-se aos ensaios de viga Benkelman, prova de carga sobre placa e DCP em cinco períodos da vida do pavimento. Na última campanha, também foi realizado um levantamento visual e em seguida, uma quantificação dos defeitos de superfície do pavimento. Como conclusão tem-se que misturas com até $20 \%$ de fosfogesso e $6 \%$ de cal podem ser utilizados em pavimentação de baixo custo sem risco. Recomenda-se, no entanto que não seja utilizado de forma alguma em período chuvoso em função da possiblidade de formação da etringita. Jámisturas com teores elevados devem ser evitadas.Em campo, verificou-se um desempenho estrutural satisfatório dos trechos analisados em todas as etapas. Entretanto, maior atenção deve ser levada para o trecho $80 \%$ solo+20\%fosfogesso, pois, esse geralmente apresentou desempenho inferior quando comparado aos demais.Atualmente a pista apresenta alguns defeitos de superfície, principalmente relacionados às intervenções humanas do que próprio processo natural de degradação do pavimento.

Palavras-Chaves: Fosfogesso.Solo tropical.Cal. Avaliação estrutural. 


\section{ABSTRACT}

Mining occupies a prominent place in Brazil in terms of wealth generation. However, exploration of minerals has caused great environmental concern with particular emphasis on the management of solid waste generated by mineral processing. In the specific case of the fertilizer industry whose main by product is phosphogypsum, environmental and economic concerns are significant due to the difficulty in disposing this by product. In relation to this, the reuse of phosphogypsum as a raw material in other industrial sectors presents itself as a viable alternative to the detriment of its storage. On the other hand, the shortage of granular materials traditionally used in paving is verified. The great distance of quarries from urban centers and the difficulties arising from the acquisition of the operating licenses makes the use of these materials in paving impossible. These two problems lead to the study of the viability of phosphogypsum as an alternative material for low cost pavements. Research in this field began in 2007 at the Federal University of Goias and was extended to the University Of Brasilia. This thesis is a part a task which has been developed in these institutions and is a part of an extension of laboratory studies of fine tropical soil mixtures, phosphogypsum and lime in the view of its usage in low cost pavements. It also looks for a way of controlling ettringite, an expansive mineral formed during the hydration process of these three materials. Besides that, there is a monitoring of a structural performance of an experimental track built in 2009 in the municipality of Aparecida de Goiania (GO) with mixtures of $80 \%$ soil $+20 \%$ phosphogypsum, $80 \%$ soil $+11 \%$ phosphogypsum $+9 \%$ lime, $91 \%$ soil $+9 \%$ lime and $100 \%$ gravel for comparative purposes. For this purpose, Benkelmanbeam tests were used, plate load test and DCP in five life spans of the pavement. During the last monitoring, there was a visual survey and consequently, a quantification of the defects of the pavement's surface area. As a conclusion, mixtures with up to $20 \%$ of phosphogysum and $6 \%$ lime may be used in low cost pavements without risk. However, it is recommended that it shouldn't be used in a rainy period because of the formation of ettringite. Mixtures with high levels should be avoided. In the study field, satisfactory structural performance was found. However, great attention should be paid to the $80 \%$ soil $+20 \%$ phosphogypsum segment because this one generally presented lower performance when compared with the others. Currently, the track presents some surface defects mainly related to human interventions other than the natural degradation process.

Keywords:Phosphogypsum.Tropical Soil.Lime. Estrutural performance. 


\section{RESUMÉ}

L'industrie minière occupe um espace de choix au Brésil en terme de geration de richesses. Cependant, l'exploitation minière provoque de grandes préoccupations envirronnementales, parmi lesquelles s'évidencie la gestion des rejets solides issues du processus de traitement mineral. Dans le cas spécifique de l'industrie de fertilisants, dont le principal sous-produit est le phosphogypse, il existe de grandes préoccupations environnementales et économiques quant à son stockage. Face à cette situation, l'utilisation du phosphogypse comme matière première dans d'autres secteurs industriels se présente comme une alternative viable. D'autre part, on observe la rarification des gissements des materiaux granulaires généralement utilisés en construction routière. L'éloignement de ces gisements des centres urbains, en plus des difficultés d'obtention des licences d'exploitation rend de plus en plus ces matériaux inacessibles pour les projets routiers. Cette double problématique conduit aux études d'utilisation du phosphogypse comme matériau alternatif pour la constrution de chaussées économiques. Des recherches dans ce sens ont débutées à 1'Université Fédérale de Goiás en 2007 et se sont étendues à 1`Université de Brasília. Cette thèse fait partie de ces recherches et est constituée par une élargissement des tests de laboratoire sur les mélanges de sols fins tropicaux, phophogypse et chaux en vue de leur utilisation en chaussées économiques. En plus, on cherche une méthode simple mais éficace pour controler la formation de l'étringitte, un minéral expansif issu du processus d'hydratation des trois materiaux. Aditionellement, il a été realisé un accompagnement des performances struturelles d'une piste experimentale constuite en 2009 dans la municipalité de Aparecida de Goiânia (GO) avec les mélanges de $80 \%$ sol $+20 \%$ phosphogypse, $80 \%$ sol $+11 \%$ phosphogypse+9\% chaux, $91 \%$ sol+9\%chaux et de $100 \%$ de grave lateritique, pour servir de comparant. Á cet effet, les essais de poutre Benkelman, chargement statique et DCP ont été realisés pendant cinq périodes de vie de la chaussée. Comme conclusion, on observe que les mélanges avec jusqu'à $20 \%$ de phophogypse et $6 \%$ de chaux peuvent être utilisées sans grand souci en chaussées économiques. Cependant, il est fortement recommendé que leur aplication ne se fasse pas en saison de pluie pour limiter au máximum les risques de formation de l'étringitte. Les mélanges avec des teneurs plus élévées doivent être évités. Au chantier, il a été verifiée un bon comportement struturel sur tous les tronçons analisés pendant toutes les étapes d'essai. Cependant, un regard plus attentif doit être porté sur le tronçon 80\%sol+20\%phosphogypse, car, en général, celui-ci a présenté des performances plus basses losque comparé aux autres. Actuellement, la piste experimentale présente certaines deteriorations de surperficie, principalement relationnées aux interventions humaines plutôt qu'aux processus naturels de dégradation de chaussée.

Mots-clefs : $\quad$ Phosphogypse. Sol tropical.Chaux. Évaluation struturelle. 


\section{ÍNDICE}

\section{CAPÍTULO 1}

1 - INTRODUÇÃO...................................................................................24

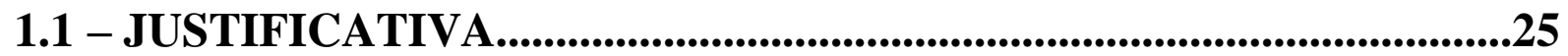

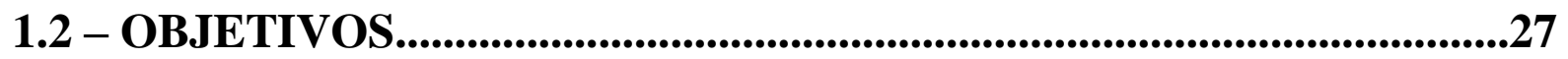

1.2.1 - OBJETIVO PRINCIPAL............................................................................................27

1.2.2 - OBJETIVOS ESPECÍFICOS............................................................................27

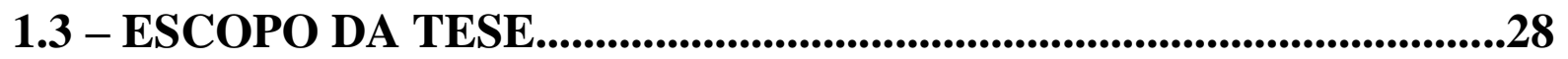

CAPÍTULO 2

2 - REVISÃO BIBLIOGRÁFICA.......................................................29

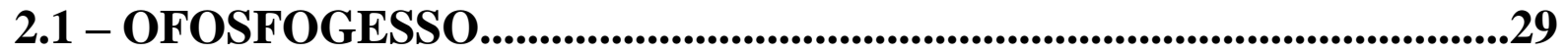

2.1.1 - DEFINIÇÕ ÕES.....................................................................................................29

2.1.2 - ROCHAS FOSFÁTICAS.........................................................................31

2.1.3 - ÁCIDO SULFÚRICO E ÁCIDO FOSFÓRICO....................................................34

2.1.4 - PROCESSOS DE FORMAÇÃO DO FOSFOGESSO.....................................................36

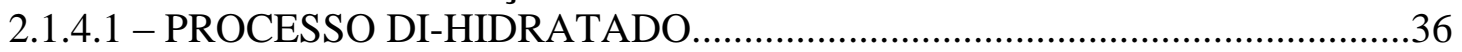

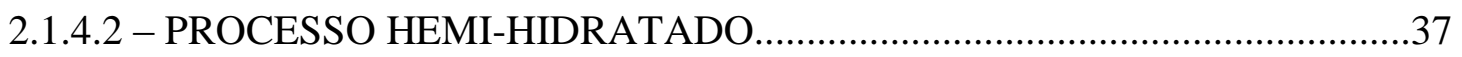

2.1.4.3 - PROCESSOS HEMI-DIHIDRATADOS …………......................................38

2.1.5 - CARACTERÍSTICAS DO FOSFOGESSO....................................................................39

2.1.5.1 - CARACTERÍSTICAS QUÍMICAS..........................................................40

2.1.5.2 - CARACTERÍSTICAS RADIOATIVAS...................................................4

2.1.5.3 - CARACTERÍSTICAS FÍSICAS...............................................................43

2.1.6 - DISPOSIÇÃO FINAL E IMPACTOS AMBIENTAIS DO FOSFOGESSO..........45

2.1.6.1 - CONTAMINAÇÃO ATMOSFÉRICA......................................................45

2.1.6.2 - CONTAMINAÇÃO DOS SOLOS E DAS ÁGUAS SUBTERRÂNEAS.....47

2.1.7 - UTILIZAÇÃO DO FOSFOGESSO...........................................................................50

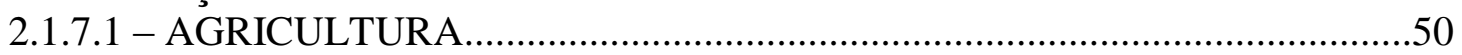

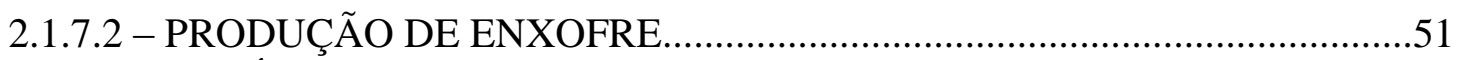

2.1.7.3 - INDÚSTRIA CIMENTEIRA..............................................................52

2.1.7.4 - CONSTRUÇÃO CIVIL.........................................................................52

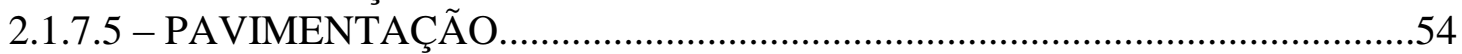

2.2 - SOLOS TROPICAIS E PAVIMENTAÇÃO DE BAIXO CUSTO.......59

2.2.1 - DEFINIÇÕES.....................................................................................................................59

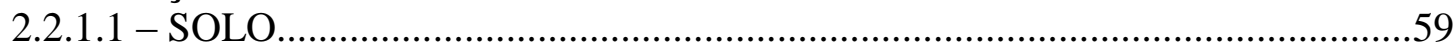

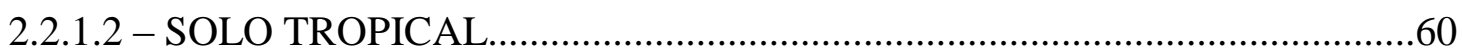

2.2.2 - METODOLOGIA MCT.........................................................................................63

2.2.3 - UTILIZAÇÃO DOS SOLOS TROPICIAIS EM PAVIMENTAÇÃO

DE BAIXO CUSTO..............................................................................................................68

2.2.4 - ESTABILIZÇÃO QUÍMICA DOS SOLOS COM CAL..............................................71 
2.3 - AVALIAÇÃ̃O DOS PAVIMENTOS ASFÁLTICOS.............................73

2.3.1 - AVALIAÇÃO FUNCIONAL DOS PAVIMENTOS.....................................................74

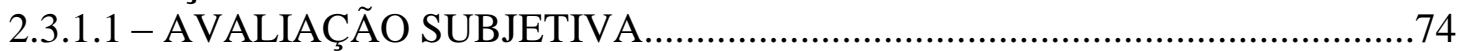

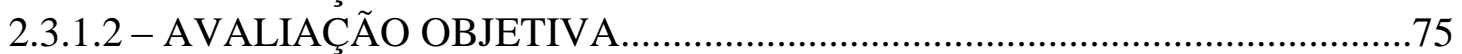

2.3.2 - AVALIAÇÃO ESTRUTURAL DOS PAVIMENTOS.................................................84

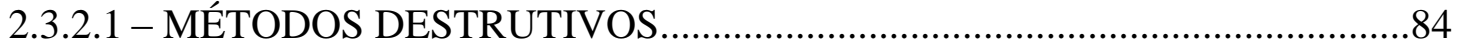

2.3.2.2 - MÉTODOS SEMIDESTRUTIVOS...........................................................85

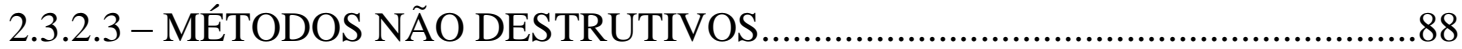

2.3.3. RETRONÁLISE DE PAVIMENTOS....................................................................95

\section{CAPÍTULO 3}

3 - METODOLOGIA...............................................................97

3.1 - MATERIAIS...........................................................................................97

3.2 - MÉTODOS.......................................................................................100

3.2.1 - ENSAIOS DE LABORATÓRIO_................................................................100

3.2.1.1 - ENSAIOS DE CARACTERIZAÇÃO.....................................................101

3.2.1.2 - ENSAIOS DA METODOLOGIA MCT ......................................................102

3.2.1.3 - ENSAIOS DE COMPACTAÇÃO MINI-PROCTOR, EXPANSÃO E

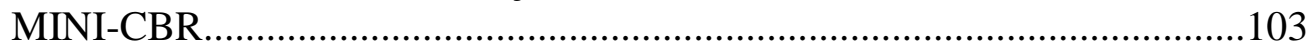

3.2.1.4 - ENSAIOS DE COMPRESSÃO SIMPLES................................................104

3.2.1.5 - ENSAIOS PARA DETERMINAÇÃO DOS MÓDULOS DE

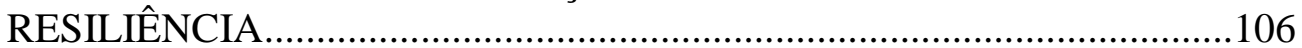

3.2.2 - ENSAIOS DE CAMPO....................................................................................................109

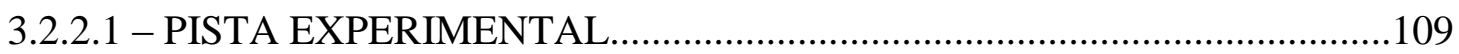

3.2.2.2 - ENSAIOS DE VIGA BENKELMAN....................................................110

3.2.2.3 - ENSAIOS DE PROVA DE CARGA ESTÁTICA.........................................111

3.2.2.4 - ENSAIOS DE PENETROMETRO DINÂMICO DE CONE - DCP...........112

3.2.2.5 - LEVANTAMENTO DOS DEFEITOS SUPERFICIAIS DO PAVIMENTO.

\section{CAPÍTULO 4}

4 - RESULTADOS E ANÁLISES................................................115

4.1 - ENSAIOS DE LABORATÓRIO.........................................................115

4.1.1 - ENSAIOS DE CARACTERIZAÇÃO.............................................................115

4.1.1.1 - ANÁLISES GRANULOMÉTRICAS......................................................115

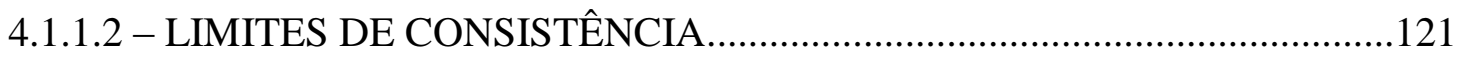

4.1.1.3- CLASSIFICAÇÕES SUCS E TRB............................................................123

4.1.1.4 - MASSA ESPECÍFICA DOS GRÃOS.......................................................123

4.1.2 - METODOLOGIA MCT...............................................................................................124

4.1.2.1 - CLASSIFICAÇÃO MCT..........................................................................124

4.1.2.2 - MINI-PROCTOR ................................................................................ 125

4.1.2.3 - MINI - CBR E EXPANSÃO...............................................................129

4.1.3 - POTENCIAL HIDROGENIÔNICO........................................................................151

4.1.4 - DIFRATOMETRIA DE RAIOS-X.....................................................................152 
4.1.5 - RESITÊNCIAS À COMPRESSÃO SIMPLES..........................................................154

4.1.6 - MÓDULOS DE RESILIÊNCIA.................................................................................155

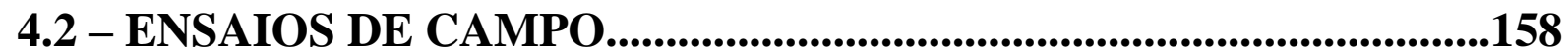

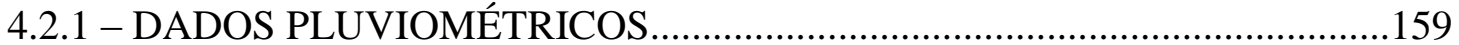

4.2.2 - ENSAIOS DE VIGA BENKELMAN..................................................................160

4.2.3 - ENSAIOS DE PROVA DE CARGA SOBRE PLACA....................................177

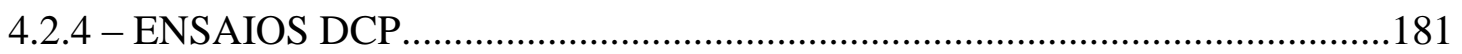

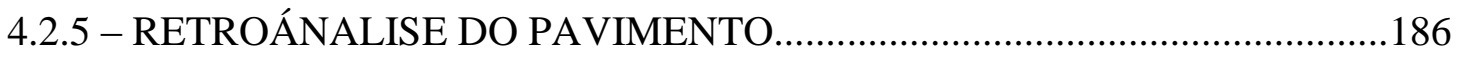

4.2.6 - AVALIAÇÃO FUNCIONAL DO PAVIMENTO_.........................................189

\section{CAPÍTULO 5}

5 - CONSIDERAÇÕES FINAIS.............................................192

5.1 - CONCLUSÕES. 192

5.1.1 - ENSAIOS DE LABORATÓRIO...........................................................................192

5.1.2 - ENSAIOS DE CAMPO.....................................................................................................193

5.2 - SUGESTÕES PARA PESQUISAS FUTURAS...................................196

REFERÊNCIAS BIBLIOGRÁFICAS..............................................197 


\section{LISTA DE TABELAS}

Tabela 2.1. Composição química dos fosfogessosdihidratados produzidos na Turquia (Degirmenci et al., 2006), China (Ming et al.,2008), Polônia (Wolicka, 2008), Brasil (Castilhos et al., 1998) eTunisia (Felfoulet al., 2002) 40

Tabela 2.2. Resultados das características químicas do extrato lixiviado das amostras (modificado de Mesquita, 2007).

Tabela 2.3. Ensaios da sistemática MCT e fenômenos correlacionados - Associação com os defeitos construtivos na base (modificado de Nogami\&Villibor, 2009).....64

Tabela 2.4. Avaliação das propriedades obtidas dos ensaios de Mini-CBR e Expansão (modificado de Villibor\&Nogami, 2009)..................................................68

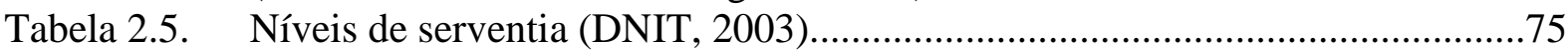

Tabela 2.6. Resume dos defeitos - Codificação e Classificação de acordo com a norma DNIT 005/2003- TER (DNIT, 2003. Modificado)............................................81

Tabela 2.7. Condição do pavimento em função do IGG (DNIT, 2006)...............................82

Tabela 2.8. Correlações existentes na literatura técnica entre o CBR e o DCP (Silva Jr.,

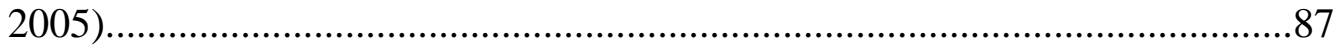

Tabela 2.9. Critério para avaliação estrutural de acordo com a norma DNER - PRO 011/79

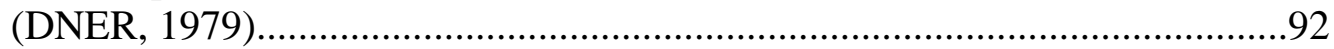

Tabela 2.10. Valores de fatores de correção sazonal (DNER, 1979).................................93

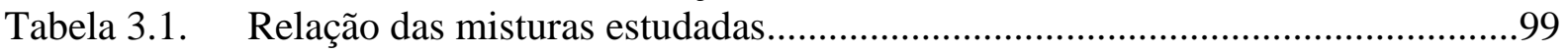

Tabela 4.1. Frações e parâmetros granulométricos do solo...............................................115

Tabela 4.2. Frações e parâmetros granulométricos do solo, fosfogesso e cal.....................117

Tabela 4.3. Frações granulométricas das misturas.......................................................117

Tabela 4.4. Parâmetros granulométricos das misturas...................................................118

Tabela 4.5. Valores obtidos dos ensaios de limites de consistência.................................121

Tabela 4.6. Classificação dos materiais de acordo com a TRB e o SUCS.........................123

Tabela 4.7. Valores de massa específica dos grãos para as diferentes misturas.................124

Tabela 4.8. Parâmetros de obtidos da metodologia MCT para a classificação do solo.....125

Tabela 4.9. Parâmetros obtidos dos ensaios de compactação mini-Proctor........................126

Tabela 4.10. Resultados dos ensaios de Mini-CBR sem imersão, com imersão e com cura de 7 dias e imersão

Tabela 4.11. Resistências à compressão simples do solo e das misturas com $20 \%$ fosfogesso em kPa.

Tabela 4.12. Parâmetros obtidos dos ensaios de módulo de resiliência calibrados para o

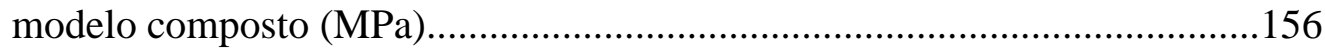

Tabela 4.13. Estrutura do pavimento considerado para as simulações..............................156

Tabela 4.14. Resultados obtidos das simulações..............................................................157

Tabela 4.15. Avaliação estrutural do trecho 80Solo+20Fosfogesso em todas etapas de

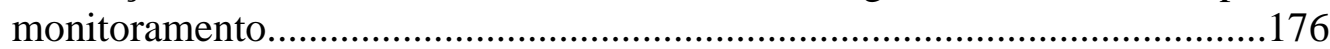

Tabela 4.16. Avaliação estrutural do trecho 80 Solo+11Fosfogesso+9Cal em todas etapas de

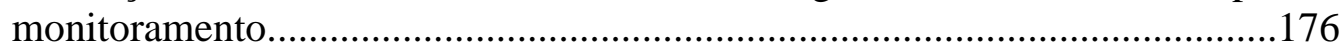

Tabela 4.17. Avaliação estrutural do trecho 91Solo+9Cal em todas etapas de

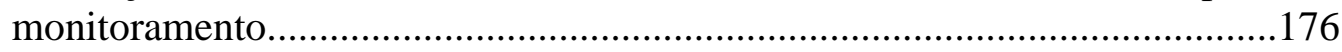

Tabela 4.18. Avaliação estrutural do trecho 100Cascalho em todas etapas de

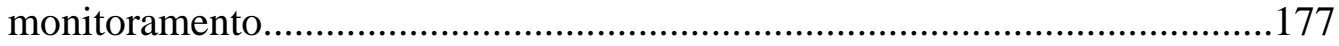

Tabela 4.19. Média dos deslocamentos máximos obtidos dos ensaios de prova de carga...179 Tabela 4.20. Médias dos deslocamentos correspondente a um carregamento de 560kPa...179 
Tabela 4.21. Módulos de reação de placa em MPa/m......................................................179

Tabela 4.22. Espessuras médias das primeiras camadas e índices de penetração médios

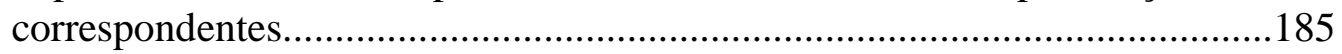

Tabela 4.23. Resumo das bacias de deslocamentos médias dos trechos na $7^{\mathrm{a}}$ etapa de

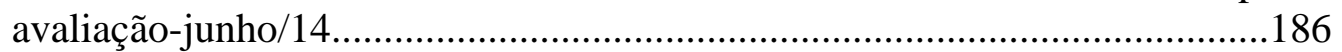

Tabela 4.24. Módulos retronalisados com o programa BAKFAA para os trechos em estudo 188

Tabela 4.25. Levantamento do estado de superfície e cálculo dos índices de gravidade global pelas normas DNIT-005/2003-TER e DNIT 006/2003-PRO nos trechos solo+fosfogesso e solo+fosfogesso+cal......

Tabela 4.26. Levantamento do estado de superfície e cálculo dos índices de gravidade global pelas normas DNIT-005/2003-TER e DNIT 006/2003-PRO nos trechos solo+cal e cascalho. 


\section{LISTA DE FIGURAS}

Figura 2.1. As potenciais jazidas de rochas fosfáticas no mundo (modificado de Zapata \& Roy, 2004)..... 32

Figura 2.2. Série de decaimento da ${ }^{238} \mathrm{U}$ (Modificado de Tosaka, 2008)............................42

Figura 2.3. Série de decaimento do ${ }^{232} \mathrm{Th}$ (Modificado de Tosaka, 2008)..........................43

Figura 2.4. Imagem de microscopia eletrônica de varredura (MEV)..................................45

Figura 2.5. Etapas da construção da pista experimental. (a) Fornecimento do fosfogesso em campo. (b) Medições radiométricas. (c) Preparo do subleito. (d) Preparo da camada de base. (e) Mistura com cal. (f) Mistura do solo com fosfogesso. (g) Imprimação das camadas de base. (h) Aplicação do pré-misturado a frio. ( i) e j) Aspectos finais da pista experimental. (Metogo,

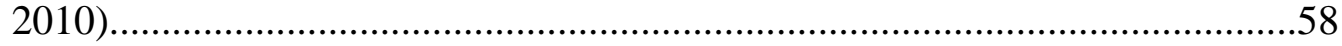

Figura 2.6. Corte rodoviário, com camada laterítica sobrejacente a uma camada saprolítica de origem sedimentar, com as correspondentes micro-fábricas (Villiboret al., 2009).

Figura 2.7. Ocorrência dos solos de comportamento laterítico no território brasileiro (modificado de Villiboret al.,2009).....

Figura 2.8. Dispositivo para compactação e controle altura dos corpos de prova na metodologia MCT (Villibor\&Nogami, 2009)............................................65

Figura 2.9. Exemplo de curvas de deformabilidade (Villiibor\&Nogami, 2009)..............66

Figura 2.10. Exemplo de famílias de curvas de compactação(Villiibor\&Nogami, 2009)...66

Figura 2.11. Ensaio de perda por imersão(Villiibor\&Nogami, 2009).............................66

Figura 2.12. Gráfico de classificação dos solos tropicais de acordo com a metodologia MCT......

Figura 2.13. Variação da serventia com o tráfego ou com o tempo decorrido da utilização da via (Bernucci, 2008).

Figura 2.14. Faixas de variação do IRI dependendo do caso e situação considerados (Sayers\&Karamilhas, 1998 modificado por Bernucci, et al.2008) 76

Figura 2.15. Exemplo de funcionamento do disptick para levantamento das irregularidades do pavimento (Pavement-Interactive, 2007).....

Figura 2.16. Princípio de funcionamento de um equipamento tipo-resposta (Bernucci, et al.,2008)

.77

Figura 2.17. Perfilometros de alta velocidade. (a) APL (Technologies nouvelles, 2012). (b) Pavement Scanner. Fonte :Dynatest.

Figura 2.18. Representação esquemática dos defeitos ocorrentes na superfície dos pavimentos flexíveis e semirrígidos (modificado de DNIT, 2003).

Figura 2.19. Métodos destrutivos para avaliação estrutural de pavimentos. a) Frasco de areia após abertura de trincheira. Fonte: Dynatest. b) Extração de corpo de prova em estrutura de pavimento com sonda rotativa (TCE-SC, 2014) .85

Figura 2.20. Equipamento DCP. (a) Desmontado. Fonte: Jet- Materials. (b) Em uso. Fonte:

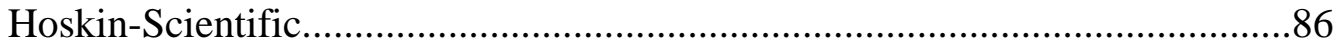

Figura 2.21. Exemplos de gráficos obtidos do ensaio DCP. (a) Curva DCP. (b) Diagrama estrutural. (Alves, 2002). 
Figura 2.22. Equipamento PANDA. (a) Desmontado e dentro da sua mala. (b) Utilizado em campo. Fonte: Sol-Solution. (c) Exemplo de perfil obtido com o Panda. (AFNOR, 2000). .88

Figura 2.23. Esquema de montagem do ensaio de prova de carga sobre um pavimento. Fonte: Betoteste.

Figura 2.24. Ensaio de viga Benkelman. a) Esquema da viga Benkelman convencional. b) Posicionamento da viga para execução do ensaio..... .90

Figura 2.25. Modelos de FaillingWeightDeflectometer. a) FWD Dynatest. Fonte Dynatest. b) Modelo Kuab. Fonte Kuab........................................................................94

Figura 2.26. Bacia de deslocamento típica obtida com o FWD. Fonte: Dynatest.................94 Figura 2.27. Execução do ensaio com o deflectômetro. Fonte: Geneq Inc............................95 Figura 3.1. Aspetos do fosfogesso: (a) Logo após a coleta; (b) Após secagem em laboratório. 97

Figura 3.2. Localização do ponto de coleta dos solos e da área de geração do fosfogesso. (Google Maps, 2015)......................................................................................98

Figura 3.3. Processo de coleta das amostras de solo nas margens da rodovia GO-330 em Catalão. a) Retirada da camada vegetal. b)Coleta da amostra..........................98

Figura 3.4. Solo, fofogesso, cal e misturas estudadas na primeira fase dos ensaios..........100

Figura 3.5. Equipamentos utilizados para os ensaios de caracterização (a) Granulômetro a laser MICROTRAC S3500; (b) PENTAPYC 5200e. 101

Figura 3.6. Execução dos ensaios de medição de pH: (a)Preparação das amostras; (b)pHmetro digital. 101

Figura 3.7. Execução dos ensaios de difratometria de raios-X: (a) Equipamento de difratometria de raio-X da marca RIGAKU; (b) Tratamento dos dados.

Figura 3.8. Ensaios da classificação MCT. (a) Compactação Mini-MCV; (b) Perda de massa por imersão.............................................................................102

Figura 3.9. Ensaios a) Expansão. b) Mini-CBR com imersão..........................................104

Figura 3.10. Ensaios de compressão simples: (a) Moldagem dos corpos de prova; (b) Armazeneamento dos corpos de prova para cura; (c) Realização do ensaio de compressão simples. 106

Figura 3.11. Etapas do ensaio triaxial dinâmico: (a) Instalação do corpo de prova na base do equipamento; (b) Instalação da membrana; (c) Corpo de prova montado e pronto para o ensaio; (d) Rompimento do corpo de prova; (e) Corpo de prova rompido (f) Corpo de prova rompido................................................................108

Figura 3.12. Tela de entrada e saída do equipamento do triaxial dinâmico ELE.................108 Figura 3.13. Localização da pista experimental, $16^{\circ} 44^{\prime} 45.21^{\prime \prime} \mathrm{S}-4^{\circ} 15^{\prime} 28.35^{\prime \prime} \mathrm{W}$ (Google Maps, 2015). 109

Figura 3.14. Croqui esquemático da estrutura do pavimento analisado (Metogo, 2010).

Figura 3.15. Localização das estacas para os ensaios de viga Benkelman.........................111

Figura 3.16. Execução dos ensaios de viga Benkelman:(a)Posicionamento da viga; (b) Leitura dos deslocamentos da ponta de ensaio da viga..................................111

Figura 3.17. Localização das estacas para os ensaios de prova de carga estática.................112 Figura 3.18. Execução dos ensaios de prova de carga estática: (a)Posicionamento do macaco; (b) Leitura dos deslocamentos...........................................................112

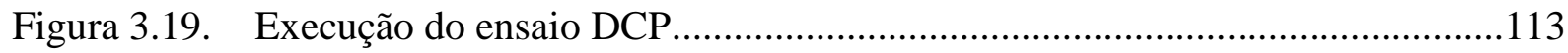

Figura 3.20. Defeitos superficiais levantados em campo em junho de 2014: (a) Trincas longitudinais em trilhas; (b)Trincas tipo couro de jacaré; (c)Trinca 
longitudinal; (d) Emendas; (e) Afundamento na trilha de roda interna, trinca longitudinal, remendo; (f) Panela; (g) Instalação da rede de esgoto; (h) Escavação transversal para passagem de

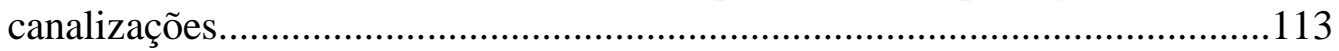

Figura 4.1. Distribuição granulométrica do solo com e sem defloculante.........................116 Figura 4.2. Sistema de 3 laser utilizado pelo MICROTRAC S3500...............................118 Figura 4.3. Curvas granulométricas sem defloculante e sem ultrassom dos materiais (a) $\mathrm{S}=$ Solo, $\mathrm{FG}=$ fosfogesso e $\mathrm{CH}=\mathrm{Cal}$, (b) GII-1, 2, 3, 4, 5 e 6, (c) GII-7, 8, 9, 10, 11 e 12

Figura 4.4. Curvas granulométricas sem defloculante e sem ultrassom dos materiais (d) GII-13, 14, 15, 16, 17 e 18 (e) GII-19, 20, 21, 22, 23 e 24 (f) GII-25, 26, 27, 28,29 e 30 .

Figura 4.5. Variação dos limites de consistência. (a) Variação dos limites de liquidez com o teor de cal. (b) Variação dos limites de liquidez com o teor de fosfogesso. (c) Variação dos limites de plasticidade com o teor de cal. (d) Variação dos limites de plasticidade com o teor de fosfogesso. (e) Variação dos índices de plasticidade com o teor de cal. (f) Variação dos índices de plasticidade com o teor de fosfogesso. 122

Figura 4.6. Classificação MCT.(a) Curvas de deformabilidade (b) Família de curvas de compactação (c) Curva de perda de massa por imersão (d) Gráfico da classificação MCT para o solo estudado......................................................125

Figura 4.7. Variação das umidades ótimas e $\gamma_{\text {dmax }}$ :(a) e (c) com $\%$ de fosfogesso (b) e (d) com \% de Cal............................................................................................126

Figura 4.8. Curvas de compactação Mini-Proctor e de saturação dos materiais em função dos teores de fosfogesso. 127

Figura 4.9. Curvas de compactação Mini-Proctor e de saturação dos materiais em função dos teores da cal...... 128

Figura 4.10. Curvas obtidas dos ensaios de Mini-CBR com e sem imersão, Expansão com imersão imediata e com imersão após 7 dias de cura (a) GI-1 (b) GI-2 .........131

Figura 4.11. Curvas obtidas dos ensaios de Mini-CBR com e sem imersão, Expansão com imersão imediata e com imersão após 7 dias de cura (a) GI-3 (b) GI-4 ..........132

Figura 4.12. Curvas obtidas dos ensaios de Mini-CBR com e sem imersão, Expansão com imersão imediata e com imersão após 7 dias de cura (a) GI-5 (b) GI-6.........133

Figura 4.13. Curvas obtidas dos ensaios de Mini-CBR com e sem imersão e com imersão após 7 dias de cura; Expansão com imersão imediata e com imersão após 7 dias de cura (a) GII-1 (b) GII-2.

Figura 4.14. Curvas obtidas dos ensaios de Mini-CBR com e sem imersão e com imersão após 7 dias de cura; Expansão com imersão imediata e com imersão após 7 dias de cura (a) GII-3 (b) GII-4. 135

Figura 4.15. Curvas obtidas dos ensaios de Mini-CBR com e sem imersão e com imersão após 7 dias de cura; Expansão com imersão imediata e com imersão após 7 dias de cura (a) GII-5 (b) GII-6.

Figura 4.16. Curvas obtidas dos ensaios de Mini-CBR com e sem imersão e com imersão após 7 dias de cura; Expansão com imersão imediata e com imersão após 7 dias de cura (a) GII-7 (b) GII-8.

Figura 4.17. Curvas obtidas dos ensaios de Mini-CBR com e sem imersão e com imersão após 7 dias de cura; Expansão com imersão imediata e com imersão após 7 dias de cura (a) GII-9 (b) GII-10. 138 
Figura 4.18. Curvas obtidas dos ensaios de Mini-CBR com e sem imersão e com imersão após 7 dias de cura; Expansão com imersão imediata e com imersão após 7 dias de cura (a) GII-11 (b) GII-12

Figura 4.19. Curvas obtidas dos ensaios de Mini-CBR com e sem imersão e com imersão após 7 dias de cura; Expansão com imersão imediata e com imersão após 7 dias de cura (a) GII-13 (b) GII-14.

Figura 4.20. Curvas obtidas dos ensaios de Mini-CBR com e sem imersão e com imersão após 7 dias de cura; Expansão com imersão imediata e com imersão após 7 dias de cura (a) GII-15 (b) GII-16.

Figura 4.21. Curvas obtidas dos ensaios de Mini-CBR com e sem imersão e com imersão após 7 dias de cura; Expansão com imersão imediata e com imersão após 7 dias de cura (a) GII-17 (b) GII-18.

Figura 4.22. Curvas obtidas dos ensaios de Mini-CBR com e sem imersão e com imersão após 7 dias de cura; Expansão com imersão imediata e com imersão após 7 dias de cura (a) GII-19 (b) GII-20.

Figura 4.23. Curvas obtidas dos ensaios de Mini-CBR com e sem imersão e com imersão após 7 dias de cura; Expansão com imersão imediata e com imersão após 7 dias de cura (a) GII-21 (b) GII-22.

Figura 4.24. Curvas obtidas dos ensaios de Mini-CBR com e sem imersão e com imersão após 7 dias de cura; Expansão com imersão imediata e com imersão após 7 dias de cura (a) GII-23 (b) GII-24.

Figura 4.25. Curvas obtidas dos ensaios de Mini-CBR com e sem imersão e com imersão após 7 dias de cura; Expansão com imersão imediata e com imersão após 7 dias de cura (a) GII-25 (b) GII-26.

Figura 4.26. Curvas obtidas dos ensaios de Mini-CBR com e sem imersão e com imersão após 7 dias de cura; Expansão com imersão imediata e com imersão após 7 dias de cura (a) GII-27 (b) GII-28

Figura 4.27. Curvas obtidas dos ensaios de Mini-CBR com e sem imersão e com imersão após 7 dias de cura; Expansão com imersão imediata e com imersão após 7 dias de cura (a) GII-29 (b) GII-30

Figura 4.28. Variação dos valores de Mini-CBR com e sem imersão e com imersão após 7 dias de cura em função do teor de fosfogesso.

Figura 4.29. Variação dos valores de Mini-CBR com e sem imersão e com imersão após 7 dias de cura em função do teor de cal.

Figura 4.30. Variação dos valores de $\mathrm{pH}$ com água e $\mathrm{KCl}$. a) e b) em função do teor de fosfogesso. c) e d) em função do teor de cal.

Figura 4.31. Difratogramas obtidos dos ensaios de difratometria de raio-x. a) Amostra de solo. b) Fosfogesso. 152

Figura 4.32. Difratogramas obtidos dos ensaios de difratometria de raio-x: GII-1, GII-2. GII-3, GII-4, GII-12, GII-16, GII-22 e GII-30. 153

Figura 4.33. Evolução da resistência à compressão das misturas. a) Com o teor de cal. b) Com o tempo de cura. 154

Figura 4.34. Tela de entradas de dados e saídas de resultados do programa AEMC..........156 Figura 4.35. Comparação dos parâmetros de deformabilidade das amostras. a) Uz: Deflexão elástica no topo do revestimento. b)Ez: Deformação vertical no topo do subleito.

Figura 4.36. Comparação do desempenho dos materiais. a) Módulos resilientes das simulações. b) Números de eixos padrão - $\mathrm{N}$ obtidos dos modelos DNER-PRO 11/79 e Dormon\& Metcaff-1965. 
Figura 4.37. Gráficos de precipitação referentes ao local da pista experimental. a) Outubro 2009. b) Maio 2010. c) Outubro 2010. d) Junho 2011. e) Novembro 2011. f) Novembro 2012. g) Junho 2014. 159

Figura 4.38. Gráfico de fator de correção da deflexão em função da temperatura do revestimento asfáltico (DER-SP, 2006)....................................................160

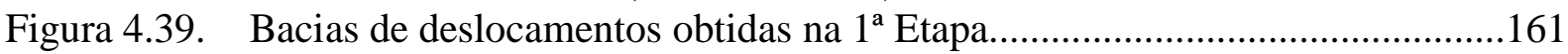

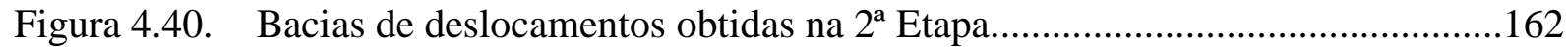

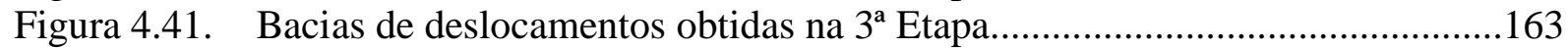

Figura 4.42. Bacias de deslocamentos obtidas na $4^{\text {a }}$ Etapa..............................................164

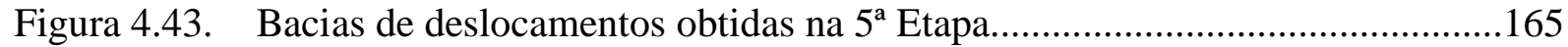

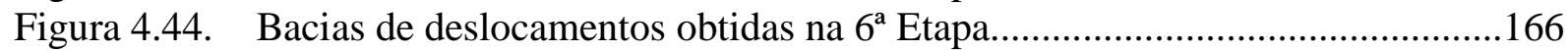

Figura 4.45. Bacias de deslocamentos obtidas na $7^{\text {a }}$ Etapa..............................................167

Figura 4.46. Deflectogramas e raios de curvaturas obtidos na $1^{\mathrm{a}}$ Etapa. Outubro de 2009.168

Figura 4.47. Deflectogramas e raios de curvaturas obtidos na $2^{\text {a }}$ Etapa. Maio de 2010......169

Figura 4.48. Deflectogramas e raios de curvaturas obtidos na $3^{\text {a }}$ Etapa. Outubro de 2010.170

Figura 4.49. Deflectogramas e raios de curvaturas obtidos na $4^{a}$ Etapa. Junho de 2011....171

Figura 4.50. Deflectogramas e raios de curvaturas obtidos na $5^{\text {a }}$ Etapa. Novembro de

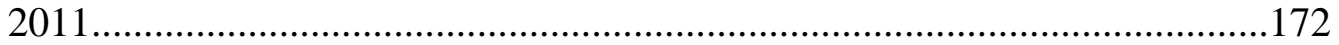

Figura 4.51. Deflectogramas e raios de curvaturas obtidos na $6^{\mathrm{a}}$ Etapa. Novembro de

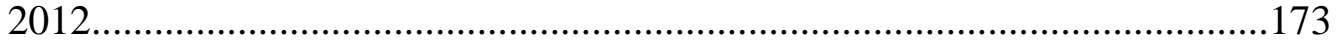

Figura 4.52. Deflectogramas e raios de curvaturas obtidos na $7^{\mathrm{a}}$ Etapa. Junho de $2014 \ldots . .174$ Figura 4.53. Bacias de deslocamentos médias obtidas para cada trecho em todas as etapas de avaliação do pavimento..........................................................................175

Figura 4.54. Curvas de deformações médias dos trechos nas diferentes etapas de

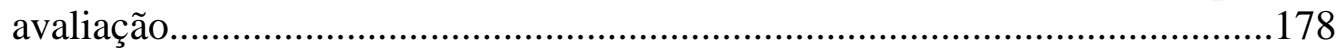

Figura 4.55. Média dos deslocamentos máximos obtidos dos ensaios de prova de carga...179

Figura 4.56. Taxas de recuperação elásticas do pavimento em relação a deformação

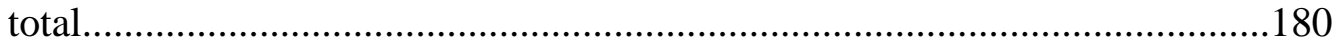

Figura 4.57. Módulos de reação da placa em MPa/m...................................................180

Figura 4.58. Módulos de reação elásticos da placa em MPa/m.......................................180

Figura 4.59. Índices de penetração do DCP nos trechos nas $1^{\mathrm{a}}$ e $2^{\mathrm{a}}$ etapas.......................182

Figura 4.60. Índices de penetração do DCP nos trechos nas $4^{\mathrm{a}}$ e $5^{\mathrm{a}}$ etapas.......................183

Figura 4.61. Índices de penetração do DCP nos trechos nas $6^{a}$ e $7^{\mathrm{a}}$ etapas......................184

Figura 4.62. Índices de penetração médios dos materiais por etapa....................................185

Figura 4.63. Tela de entrada dos dados iniciais para retroanálises no BAKFAA - Caso do trecho 80Solo+20Fosfogesso..................................................................187

Figura 4.64. Tela do BAKFAA com os resultados da retroanálise - Caso do trecho 80Solo+20Fosfogesso. 187

Figura 4.65. Resultados obtidos das retroanálises com o programa BAKFAA para os trechos em estudo. 188 


\section{LISTA DE SIMBOLOS, NOMENCLATURAS E ABREVIATURAS}

\section{AASHTO}

ABNT

AI

ASTM

$\mathrm{BE}$

$\mathrm{BD}$

BPL

CBR

$\mathrm{CH}$

CNEN

$\mathrm{CP}$

$\mathrm{CRCN}-\mathrm{CO}$

DCP

DER/SP

DER/PR

DNER

DNIT

EPA

EUA

FG

FIPR

GO

IP

IPT

INMET

LCPC

$\mathrm{LG}^{\prime}$

LVDTs

MCT

$\mathrm{MCV}$

ME

MEV

ML

MR

NBR

NP

SAFL

SI

SC
"American Association of State Highway and Transportation Officials"

Associação Brasileira de Normas Técnicas

"Asphalt Institute"

"American Society for Testing and Materials"

Bordo Esquerdo

Bordo Direito

"Bone Phophate of Lime"

CaliforniaBearingRatio

Cal Hidratada

Unidade da Comissão Nacional de Energia Nuclear

Corpo de Prova

Centro Regional de Ciências Nucleares do Centro Oeste,

Penetrômetro dinâmico de cone

Departamento de Estradas e Rodagem de São Paulo

Departamento de Estradas e Rodagem do Paraná.

Departamento Nacional de Estradas e Rodagem.

Departamento Nacional de Infraestrutura de Transportes

"Environmental ProtectionAgency"

Estados Unidos da América

Fosfogesso

"Florida Institute of PhosphoreReserch"

Goiás

Índice de plasticidade;

Instituto de Pesquisas Tecnológicas

Instituto Nacional de Meteorologia

"Laboratoire Central des Ponts et Chaussée"

Solo Argiloso Lateritíco

"Linear Variable Differential Transformers"

Miniatura, Compactado, Tropical

"MoistureConditionValue"

Método de Ensaio

Microscopia Eletrônica de Varredura

"MoLowliquidlimit"

Módulo Resiliente

Normas Brasileiras

Não Plástico

Solos Arenosos Finos Lateríticos

Sistema Internacional

"Sand Clay" 


\begin{tabular}{|c|c|}
\hline $\mathrm{SC}$ & Santa Catarina \\
\hline SP & São Paulo \\
\hline SPC & "Stabilized Phosphogypsum with Cement" \\
\hline STD & Sólidos Totais Dissolvidos \\
\hline SUCS & Sistema de Classificação Unificado de Solos \\
\hline TRB & "TransportationResearchBoard" \\
\hline UCOS & Umedecimento Compactação e Secagem \\
\hline UFG & Universidade Federal de Goiás \\
\hline USEPA & "U.S. Environmental Protection Agency" \\
\hline VDM & Volume Diário Médio \\
\hline \multicolumn{2}{|c|}{$\left(\mathrm{Ca}_{10-\mathrm{x}-\mathrm{y}} \mathrm{Na}_{\mathrm{x}} \mathrm{Mg}_{\mathrm{y}}(\mathrm{PO} 4)_{6-\mathrm{z}}(\mathrm{CO} 3)_{\mathrm{z}} \mathrm{F}_{0.4 \mathrm{z}} \mathrm{F}_{2}\right) \quad$ Francolita } \\
\hline$\left(\mathrm{NH}_{4}\right)_{2} \mathrm{HPO}_{4}$ & Fosfatos de diamônio \\
\hline $\mathrm{H}_{2} \mathrm{PO}_{4}^{-}, \mathrm{HPO}_{4}^{-2} \cdot, \mathrm{PO}_{4}^{-3}$ & Íons fosfatos \\
\hline${ }^{10} \mathrm{Be}$ & Berílio 10 \\
\hline${ }^{14} \mathrm{C}$ & Carbono 14 \\
\hline${ }^{210} \mathrm{~Pb}$ & Chumbo 210 \\
\hline${ }^{222} \mathrm{Rn}$ & Radônio 222 \\
\hline${ }^{226} \mathrm{Ra}$ & Rádio \\
\hline${ }^{232} \mathrm{Th}$ & Tório 232 \\
\hline${ }^{234} U$ & Urânio 234 \\
\hline${ }^{238} \mathrm{U}$ & Urânio 238 \\
\hline${ }^{26} \mathrm{Al}$ & Alumínio 26 \\
\hline${ }^{40} \mathrm{P}$ & Potássio 40 \\
\hline Al & Alumínio \\
\hline $\mathrm{Al}_{2} \mathrm{O}_{3}$ & Óxido de alumínio \\
\hline As & Arsênico \\
\hline $\mathrm{Bq}$ & Becquerel \\
\hline $\mathrm{Bq} / \mathrm{kg}$ & Becquerel por quilograma \\
\hline $\mathrm{Bq} / \mathrm{m}^{2} / \mathrm{s}$ & Becquerel por metro quadrado por segundo \\
\hline $\mathrm{Bq} / \mathrm{m}^{3}$ & Becquerel por metro cúbico \\
\hline$c^{\prime}$ & $\begin{array}{l}\text { Coeficiente angular da reta assimilável à curva } \\
\text { deformabilidade com Mini-MCV }=10\end{array}$ \\
\hline $\mathrm{C}_{3} \mathrm{~A}$ & Complexo alumínio \\
\hline $\mathrm{Ca}\left(\mathrm{H}_{2} \mathrm{PO}_{4}\right)_{2}$ & Fosfato monocálcio \\
\hline $\mathrm{Ca}(\mathrm{OH})_{2} \mathrm{Mg}(\mathrm{OH})_{2}$ & Cal dolomíticadihidratada \\
\hline $\mathrm{Ca}(\mathrm{OH})_{2} \mathrm{MgO}$ & Cal dolomíticamonohidratada \\
\hline $\mathrm{Ca}_{10}\left(\mathrm{PO}_{4}\right)_{6}(\mathrm{OH})_{2}$ & Hidroxiapatita \\
\hline $\mathrm{Ca}_{10}\left(\mathrm{PO}_{4}\right) 6 \mathrm{~F}_{2}$ & Fluroapatita \\
\hline $\mathrm{Ca}_{10}\left(\mathrm{PO}_{4}, \mathrm{CO}_{3}\right)_{6}(\mathrm{OH})_{2}$ & Carbonato-hidroxiapatita \\
\hline $\mathrm{Ca}_{2}\left(\mathrm{HPO}_{4}\right)_{2}$ & Fosfato bicálcio \\
\hline $\mathrm{Ca}^{2+}-$ & Íon cálcio \\
\hline $\mathrm{Ca}_{3}(\mathrm{PO} 4)_{2}$ & Fosfato tricálcio \\
\hline $\mathrm{CaO}$ & Óxido de cálcio \\
\hline $\mathrm{CaO} .(\mathrm{OH})_{2}$ & Cal cálcica hidratada \\
\hline $\mathrm{CaS}$ & Sulfeto de cálcio \\
\hline $\mathrm{CaSO}_{4}$ & Sulfato de cálcio ou gesso natural \\
\hline $\mathrm{CaSO}_{4} \cdot 2 \mathrm{H}_{2} \mathrm{O}$ & Sulfato de cálcio dihidratado \\
\hline
\end{tabular}




\begin{tabular}{|c|c|}
\hline $\mathrm{CaSO}_{4} \cdot 2 \mathrm{nH}_{2} \mathrm{O}$ & Fosfogesso \\
\hline $\mathrm{Cd}$ & Cádmio \\
\hline $\mathrm{Ci}$ & Curie \\
\hline $\mathrm{cm}$ & Centímetro \\
\hline $\mathrm{cm} / \mathrm{s}$ & Centímetro por segundo \\
\hline $\mathrm{CO}_{2}$ & Dióxido de carbono \\
\hline $\mathrm{Cr}$ & Cromo \\
\hline $\mathrm{Cu}$ & Cobre \\
\hline$d^{\prime}$ & $\begin{array}{l}\text { Inclinação da parte do ramo seco da curva de compactação } \\
\text { correspondente a } 12 \text { golpes }\end{array}$ \\
\hline $\mathrm{D}_{0}$ & Deformação real do pavimento no ponto de prova \\
\hline $\mathrm{D}_{25}$ & $\begin{array}{l}\text { Deformação obtida quando a carga está localizada a } 25 \\
\text { cm do ponto de prova }\end{array}$ \\
\hline $\mathrm{D}_{560 \mathrm{kPa}}$ & $\begin{array}{l}\text { Deslocamento correspondente a uma pressão de } 560 \mathrm{kPa} \text { no } \\
\text { ensaio de prova de carga }\end{array}$ \\
\hline DAP & Fosfatos de diamônio \\
\hline$D_{\text {elástíco }}$ & Deslocamento recuperado \\
\hline $\mathrm{D}_{\max }$ & Deslocamento máximo no ensaio de prova de carga \\
\hline Dmax & $\begin{array}{l}\text { Limite superior de aceitação dos deslocamentos no ensaio de } \\
\text { viga }\end{array}$ \\
\hline Dmédio & Deslocamentos médios por seção \\
\hline Dmim & $\begin{array}{l}\text { Limite inferior de aceitação dos deslocamentos no ensaio de } \\
\text { viga }\end{array}$ \\
\hline $\mathrm{DN}$ & Índice de penetração do penetrômetro dinâmico de cone \\
\hline $\mathrm{D}_{\text {plástico }}$ & Deslocamento não recuperado \\
\hline $\mathrm{e}^{\prime}$ & Índice de classificação MCT \\
\hline Exp. & Expansão \\
\hline $\mathrm{F}^{-}$ & Íon fluoreto \\
\hline $\mathrm{Fe}$ & Ferro \\
\hline $\mathrm{Fe}_{2} \mathrm{O}_{3}$ & Óxido de ferro \\
\hline $\mathrm{g} / \mathrm{cm}^{3}$ & Grama por centímetro cúbico \\
\hline $\mathrm{g} / \mathrm{l}$ & Grama por litro \\
\hline $\mathrm{H}_{2} \mathrm{O}$ & Água \\
\hline $\mathrm{H}_{2} \mathrm{~S}$ & Sulfeto de hidrogênio \\
\hline $\mathrm{H}_{2} \mathrm{SO}_{4}$ & Ácido sulfúrico \\
\hline $\mathrm{H}_{3} \mathrm{PO}_{4}-$ & Ácido fosfórico \\
\hline $\mathrm{HF}$ & Ácido fluorídrico \\
\hline $\mathrm{K}$ & Potássio \\
\hline $\mathrm{k}_{1}, \mathrm{k}_{2}, \mathrm{k}_{3}$ & Parâmetros dos modelos de modulo de resiliência \\
\hline $\mathrm{K}_{2} \mathrm{O}$ & Óxido de potássio \\
\hline $\mathrm{KCl}$ & Cloreto de potássio \\
\hline $\mathrm{kN} / \mathrm{m}^{3}$ & Quilonewton por metro cúbico \\
\hline $\mathrm{kPa}$ & Quilopascal \\
\hline $\mathrm{k}_{\text {placa }}$ & Coeficientes de reação da placa \\
\hline $\mathrm{k}_{\text {viga }}$ & Módulo de reação vertical da viga \\
\hline $\mathrm{m}$ & Metro \\
\hline $\mathrm{m}^{2}$ & Metro quadrado \\
\hline MAP & Fosfatos de monoamônio \\
\hline
\end{tabular}




\begin{tabular}{|c|c|}
\hline $\mathrm{Mg}$ & Magnésio \\
\hline $\min$ & Minuto \\
\hline $\mathrm{mm}$ & Milímetro \\
\hline $\mathrm{mm} /$ golpe & Milímetro por golpe \\
\hline $\mathrm{Mn}$ & Manganês \\
\hline $\mathrm{MPa}$ & Megapascal \\
\hline $\mathrm{N}$ & Azoto ou nitrogênio \\
\hline $\mathrm{N} / \mathrm{mm}^{2}$ & Newton por milímetro quadrado \\
\hline $\mathrm{Na}_{2} \mathrm{O}$ & Óxido de sódio \\
\hline $\mathrm{Na}_{2} \mathrm{SiF}_{6}$ & Fluorosilicato de sódio \\
\hline $\mathrm{Na}_{3} \mathrm{AlF}_{6}$ & Hexafluoraluminato de sódio \\
\hline $\mathrm{Na}_{5} \mathrm{P}_{3} \mathrm{O}_{10}$ & Tripolifosfato de sódio \\
\hline $\mathrm{NaCl}$ & Cloreto de sódio \\
\hline $\mathrm{NaF}$ & Fluoreto de sódio \\
\hline $\mathrm{NH}_{3}$ & Amônia \\
\hline $\mathrm{NH}_{4} \mathrm{H}_{2} \mathrm{PO}_{4}$ & Fosfato de monamônio \\
\hline $\mathrm{N}^{\mathrm{O}}$ & Número \\
\hline $\mathrm{O}_{2}$ & Dióxido \\
\hline${ }^{\circ} \mathrm{C}$ & Grau Celsius \\
\hline${ }^{\circ} \mathrm{F}$ & Graus Fahrenheit \\
\hline $\mathrm{P}$ & Fosfato \\
\hline $\mathrm{P}_{2} \mathrm{O}_{5}$ & Pentóxido de fósforo \\
\hline $\mathrm{Pb}$ & Chumbo \\
\hline $\mathrm{pCi} / \mathrm{m}^{2} / \mathrm{s}$ & Pico Curie por metro quadrado por segundo \\
\hline $\mathrm{pH}$ & Potencial Hidrogênio \\
\hline $\mathrm{Pi}$ & Perda de massa por imersão expressa em porcentagem \\
\hline $\mathrm{R}_{0}$ & Raio de curvatura \\
\hline$S$ & Enxofre \\
\hline $\mathrm{Si}$ & Silício \\
\hline $\mathrm{SiF}_{4}$ & Tetrafluoreto de silício \\
\hline $\mathrm{SO}_{2}$ & Dióxido de sulfato \\
\hline $\mathrm{SO}_{3}$ & Trióxido de enxofre \\
\hline $\mathrm{Sr}$ & Grau de saturação \\
\hline $\mathrm{t}$ & Tonelada \\
\hline $\mathrm{U}$ & Urânio \\
\hline $\mathrm{W}$ & Umidade \\
\hline $\mathrm{w}_{\mathrm{L}}$ & Limite de liquidez \\
\hline $\mathrm{w}_{\mathrm{ot}}$ & Umidade ótima \\
\hline $\mathrm{W}_{\mathrm{P}}$ & Limite de plasticidade \\
\hline $\mathrm{Zn}$ & Zinco \\
\hline$\gamma_{\text {dmax }}$ & Peso específico aparente seco máximo \\
\hline$\Delta \mathrm{w}$ & Variação de umidade \\
\hline$\theta$ & Somatório das tensões principais \\
\hline$\mu \mathrm{g} / \mathrm{kg}$ & Micro grama por quilograma \\
\hline$\mu \mathrm{m}$ & Micrometro \\
\hline$\mu \mathrm{Sv} / \mathrm{h}$ & Microsievens por hora \\
\hline$\sigma$ & Desvio padrão \\
\hline$\sigma_{3}$ & Tensão confinante \\
\hline$\sigma_{\mathrm{d}}$ & Tensão desvio \\
\hline
\end{tabular}




\section{CAPÍTULO 1}

\section{1 - INTRODUÇÃO}

A mineração ocupa um lugar de destaque no Brasil, sendo ela um dos principais impulsionadores do seu crescimento econômico. De acordo com Farias \& Coelho (2002), o subsolo brasileiro ainda possui importantes depósitos minerais, fato que possibilita um futuro promissor da atividade mineral nesse país. No entanto, a exploração mineira tem ocasionado uma grande preocupação ambiental, destacando-se a gestão e o gerenciamento dos resíduos sólidos gerados pelo processo de beneficiamento mineral. No caso específico da indústria de fertilizante, cujo principal subproduto gerado é o fosfogesso, as preocupações ambientais também são significativas devido à dificuldade de gestão desse subproduto. Devido ao volume de rejeitos gerados, as pilhas localizadas nas plantas industriais são perceptíveis e, consequentemente, surgem dificuldades de dispô-los adequadamente. A presença desses depósitos traz, por um lado, preocupações ambientais devido aos riscos de contaminação dos solos, dos lençóis freáticos e das emissões radioativas e, por outro, problemas econômicos relacionados aos custos envolvidos com sua manutenção e com a extensão das áreas de deposição. Diante desses diversos problemas, o aproveitamento do fosfogesso como matéria prima em outros ramos da indústria, apresenta-se como uma alternativa viável em detrimento à sua estocagem.

Assim como a atividade mineira, a qualidade e extensão da malha rodoviária contribuem significativamente, tanto com o desenvolvimento econômico do país como com a qualidade de vida das populações. No entanto, a prática rodoviária vem enfrentando grandes dificuldades para encontrar áreas de empréstimo de materiais granulares naturais tradicionalmente utilizados em camadas de pavimento. Essa situação se torna ainda mais grave, visto a necessidade de empregar quantidades cada vez maiores desses materiais na construção de estradas, para satisfazer as necessidades relacionadas ao crescimento urbano, econômico e industrial. Nas regiões tropicais, recorre-se comumente ao cascalho laterítico para construção das camadas de base e sub-base de pavimentos asfálticos. Entretanto, devido 
à escassez desses materiais, as jazidas estão localizadas em regiões cada vez mais distantes das obras viárias e, particularmente, dos grandes centros urbanos. Ainda quando encontradas, sua exploração está geralmente condicionada às restrições ambientais. Esses fatos vêm inviabilizando ambiental e economicamente o uso do cascalho nas construções rodoviárias. Por esse motivo, torna-se necessário o desenvolvimento de pesquisas no sentido de encontrar materiais alternativos tecnicamente viáveis e ambientalmente corretos para uso em obras viárias.

A dupla problemática do reaproveitamento dos resíduos sólidos oriundos da indústria de fertilizante e a escassez dos materiais granulares leva à proposta de usar o fosfogesso como material alternativo em construção de pavimentos asfálticos. Os trabalhos pioneiros nesse sentido foram implementados pelo Laboratoire Central des Ponts et Chaussées - LCPC na França e pela Florida Institute of Phosphore Research - FIPR nos Estados Unidos, no final da década de 70. No Brasil, os estudos sobre o uso do fosfogesso em pavimentação iniciaramse na Universidade de São Paulo em 1995 (Parreira et al., 2003). Desde então, vários outros trabalhos foram elaborados e ainda estão sendo realizados, procurando sempre as melhores possibilidades de uso deste resíduo em pavimentação ou outras obras geotécnicas (Matos, 2011). Trabalhos anteriores mostraram que o fosfogesso dihidratado sozinho não apresenta características técnicas mínimas para ser utilizado em camada de pavimento, mesmo de baixo volume de tráfego (Mesquita, 2007; Rufo,2009). Por esse motivo, esse resíduo deve ser estabilizado quimicamente ou então usado como estabilizante físíco em solo fino ou arenoso.

\section{1- JUSTIFICATIVA}

No estado de Goiás, estão localizadas grandes empresas produtoras de fertilizante do Brasil. A grande quantidade de fosfogesso produzida por essas mineradoras gera problemas ambientais e econômicos relacionados com seu armazenamento. Isso torna necessário realizar estudos sobre as possíveis utilizações desse material em engenharia civil. Pesquisas no sentido de usar o fosfogesso em pavimentação vêm sendo realizadas na Universidade de Federal de Goiás (UFG) desde 2007 e, mais recentemente, na Universidade de Brasília (UnB). A primeira pesquisa focou-se em ensaios de laboratório para determinar as propriedades geotécnicas e avaliar os riscos de contaminação de misturas de solos tropicais da região de 
Goiânia com 20, 50 e $80 \%$ de fosfogesso (Mesquita, 2007). Desse estudo, foi observado que a mistura com $20 \%$ de fosfogesso poderia ser utilizada para construção de camadas de sub-base e até de base de pavimento asfáltico. Na mesma sequência, o trabalho de Faria (2007) mostrou um ganho considerável de resistência dessa mistura quando estabilizada com cal. Com base nos precedentes trabalhos, Rufo (2009) analisou o comportamento de outras misturas de solo tropical com 9\% de fosfogesso, estabilizadas com 9\% de cal hidratada do tipo CHI. Para tanto, a pesquisadora utilizou um solo da região de Catalão (GO), visto que a viabilidade econômica do reaproveitamento do resíduo é justificada se esse rejeito é reutilizado próximo ao local onde é produzido. A autora apontou a inviabilidade técnica da estabilização química com cal das misturas do solo fino escolhido com o fosfogesso. Essa conclusão foi obtida a partir dos valores altos de expansão (18,5 a 29,6\%) das misturas quando imersas na água, além de baixos valores de $\operatorname{CBR}(1,3$ a 2,4\%). Ainda para essas misturas, foram observados elevados índices de plasticidade (26 a 38\%). Acredita-se que tal comportamento é devido à formação de um mineral expansivo chamado etringita $\left(\mathrm{Ca}_{6} \mathrm{Al}_{2}\left(\mathrm{SO}_{4}\right)_{3}(\mathrm{OH})_{12}, 26 \mathrm{H}_{2} \mathrm{O}\right)$, a partir da reação de hidratação dos três materiais envolvidos. Em seguida, Metogo (2009) realizou testes rápidos com misturas de diferentes de solos com fosfogesso estabilizadas com cal e cimento. Esses ensaios se limitaram apenas aos limites de consistência. Os resultados mostraram variações significativas dos índices de plasticidade das misturas em função dos solos utilizados.

Nos estudos de Metogo (2010), as misturas solo fino + fosfogesso, solo fino+fosfogesso+cal, solo fino+cal e o cascalho foram analisadas primeiramente em laboratório e em seguida, utilizadas na construção das camadas de base de uma pista de experimental de pavimento asfáltico em Aparecida de Goiânia (GO). O solo utilizado foi coletado próximo ao local de execução da pista experimental e as dosagens foram feitas baseando-se nos estudos já referenciados. Ensaios de controle tecnológico e de avaliação estrutural do pavimento em campo foram realizados durante a construção, seis e dozes meses após abertura ao tráfego. Observou-se que, tanto em laboratório como em campo, a mistura como 80\% de solo fino, $11 \%$ de fosfogesso estabilizada com $9 \%$ de cal foi a que apresentou melhor comportamento mecânico, indicando ser uma alternativa viável ao uso do cascalho. No entanto, essa mistura foi a que apresentou a maior expansão $(1,05 \%)$. Apesar de bem inferior àquela observada por Rufo (2009), os danos provocados pela expansão dessa mistura depois de uma noite de chuva foram verificados durante a execução da pista experimental (Metogo, 2010). De forma geral, 
os resultados dessa pesquisa mostraram o potencial de uso das misturas solo, fosfogesso, cal em pavimentação. Entretanto, para sua total viabilização, ainda é preciso entender e controlar melhor o fenômeno de formação da etringita. Por outro lado, tendo em conta a utilização pioneira dessas misturas em campo, é prescritível continuar o monitoramento estrutural da pista experimental, para obter maiores dados de campo e, acompanhar e entender melhor o comportamento mecanístico desses materiais com o suporte de ferramentas numéricas na perspectiva de um melhor aproveitamento futuro desses materiais.

\section{2 - OBJETIVOS}

\subsection{1 - OBJETIVO PRINCIPAL}

Esta tese é a continuação das investigações iniciadas por Metogo (2010) e tem como objetivo principal aprofundar, em laboratório, nos estudos sobre misturas de fosfogesso dihidratado com solo tropical estabilizado ou não com cal, em vista sua utilização em camada de base ou sub-base. A pesquisa foca, também, na avaliação estrutural contínua e no levantamento de defeitos de superfície já existentes na pista experimental executada em 2009 no município de Aparecida de Goiânia (GO) com essas misturas. Dessa avaliação, são retirados parâmetros necessários para retroanálises da pista experimental e consequente entendimento do comportamento estrutural dessas misturas.

\subsection{2 - OBJETIVOS ESPECÍFICOS}

Como objetivos específicos têm-se:

- Caracterizar adequadamente os materiais utilizados na pesquisa;

- Ampliar os estudos do comportamento mecânico das misturas solo fino tropical, fosfogesso dihidratado e cal;

- Estudar detalhadamente os processos de cimentação das misturas de solos finos lateríticos com fosfogesso estabilizadas com cal;

- Entender melhor o processo de formação da etringita a fim de melhor controlar seu aparecimento e, dessa forma, limitar a expansão dessas misturas;

- Determinar as características resilientes das misturas solo, fosfogesso e cal; 


\section{3 - ESCOPO DA TESE}

Para melhor expor os estudos e resultados obtidos nesta investigação e suas análises, esta tese foi subdivida em cinco capítulos. O presente capítulo, o primeiro, é introdutório e apresenta os aspectos gerais desta pesquisa, sua justificativa e contextualização, seus objetivos gerais e específicos. O Capítulo 2 constitui a uma revisão bibliográfica e trata de assuntos pertinentes ao fosfogesso, aos solos tropicais e sua utilização em pavimentos de baixo custo e às técnicas de estabilização química de solos com cal. Ainda apresenta conceitos e métodos de avaliação funcional e estrutural dos pavimentos asfálticos e noções sobre a retroanálise de pavimentos asfálticos, sem deixar de apresentar brevemente alguns programas computacionais geralmente utilizados para essa tarefa. No Capítulo 3 é apresentada a metodologia norteadora desta pesquisa, assim como os materiais e misturas utilizados. O Capítulo 4 apresenta e discute os resultados obtidos em laboratório e em campo, assim como os oriundos das retroanálises do pavimento. As considerações finais, conclusões sobre este trabalho e as sugestões para pesquisas futuras encontram-se no Capítulo 5. 


\section{2 - REVISÃO BIBLIOGRÁFICA}

Neste capítulo são apresentadas as definições, as principais características, as questões ambientais relacionadas com o fosfogesso e suas possíveis aplicações. Essas informações tornam-se importantes para que se conheça melhor o resíduo sólido estudado nesta pesquisa. Em seguida são apresentados alguns conceitos sobre os solos tropicais, a metodologia MCT e sua aplicabilidade no contexto da pavimentação de baixo custo. São também discutidos os aspetos pertinentes à estabilização dos solos com cal e à formação da etringita em misturas de solo, fosfogesso e cal. Um panorama sobre os procedimentos para avaliação funcional e estrutural de pavimentos asfálticos e os equipamentos utilizados para essa finalidade também são apresentados. O capítulo conclui-se com a apresentação dos aspectos relevantes sobre a retroanálise de pavimentos asfálticos e alguns programas computacionais utilizados para essa finalidade.

\section{1 - O FOSFOGESSO}

\subsection{1 - DEFINIÇÕES}

O fosfato $(\mathrm{P})$, azoto ou nitrogênio $(\mathrm{N})$ e potássio $(\mathrm{K})$ são três elementos químicos importantes para o crescimento das plantas. Apesar de serem abundantes na natureza, esses elementos não se encontram sempre em níveis de concentração nos solos disponíveis para as plantas. Por esse motivo, os solos devem ser periodicamente reabastecidos. $\mathrm{O}$ uso de fertilizante é o método mais utilizado para suprir essa necessidade. Destacam-se assim, de acordo com os elementos químicos predominantes, os fertilizantes fosfáticos, azotados e potássicos (Moughli, 2000). O potássio provém de depósitos subterrâneos ou marítimos, constituídos de misturas de cloreto de sódio e de potássio $(\mathrm{NaCl}, \mathrm{KCl})$. $\mathrm{Na}$ indústria de fertilizantes, o azoto presente na atmosfera é fixado quimicamente para formar a amônia $\left(\mathrm{NH}_{3}\right)$ (Moughli, 2000). Para obtenção dos fosfatos, as rochas fosfáticas são as principais matérias primas. 
Ainda de acordo com Moughli (2000), apesar dos fosfatos presentes nos fertilizantes serem estimados em termo de teor de pentóxido de fósforo $\left(\mathrm{P}_{2} \mathrm{O}_{5}\right)$, essa molécula não se encontra nos fertilizantes e nem participa da nutrição das plantas. Nos adubos, os fósforos são presentes geralmente na forma de fosfatos de cálcio $\left(\mathrm{Ca}_{3}\left(\mathrm{PO}_{4}\right)_{2}\right.$ ou $\left.\mathrm{Ca}\left(\mathrm{H}_{2} \mathrm{PO}_{4}\right)_{2}\right)$ ou de amônio $\left(\mathrm{NH}_{4} \mathrm{H}_{2} \mathrm{PO}_{4}\right.$ ou $\left.(\mathrm{NH} 4)_{2} \mathrm{HPO}_{4}\right)$. Já no solo, essas substâncias são absorvidas pelas plantas nas formas de íons $\mathrm{H}_{2} \mathrm{PO}_{4}^{-}$ou $\mathrm{HPO}_{4}^{-2}$ dependendo do $\mathrm{pH}$ do solo. $\mathrm{O}$ ácido fosfórico $\left(\mathrm{H}_{3} \mathrm{PO}_{4}\right)$ é a principal matéria prima para fabricação dos fosfatos de cálcio e de amônio e por extensão, dos fertilizantes fosfáticos. A sua produção advém de dois processos distintos. No primeiro processo obtém-se o fósforo elementar por meio da redução térmica do fosfato de cálcio em forno elétrico, o qual é posteriormente oxidado e absorvido em água, resultando o ácido fosfórico. O segundo processo, por via úmida, é baseado na reação do ácido sulfúrico com o concentrado fosfático. Esse último é o mais utilizado no mundo (Souza, 2001; Claude, 2005).

O fosfogesso $\left(\mathrm{CaSO}_{4} \cdot 2 n \mathrm{H}_{2} \mathrm{O}\right)$ é o principal subproduto da reação de ataque da rocha fosfática pelo ácido sulfúrico $\left(\mathrm{H}_{2} \mathrm{SO}_{4}\right)$ durante o processo de fabricação do ácido fosfórico por via úmida. Esse resíduo pode existir sob três formas, dependendo do valor do número $n$ de moléculas de água presentes nos cristais de fosfogesso (Parreira et al,. 2003). Apesar de ser constituído principalmente pelo sulfato de cálcio, o fosfogesso possui várias impurezas tais como $\mathrm{P}_{2} \mathrm{O}_{5}, \mathrm{~F}^{-}, \mathrm{Al}, \mathrm{P}, \mathrm{Si}, \mathrm{Fe}, \mathrm{Mg}$ e matérias orgânicas (Degirmenci et al., 2006; Min et al., 2007), além de metais pesados como o $\mathrm{Cu}, \mathrm{Cd}, \mathrm{Zn}, \mathrm{U}$ e radioativos tipo ${ }^{238} \mathrm{U},{ }^{234} \mathrm{U},{ }^{226} \mathrm{Ra}$, ${ }^{210} \mathrm{~Pb}$ e ${ }^{222} \mathrm{Rn}$ (Castilhos et al., 1998; Masri, et al., 2004). Quando a indústria de fertilizante produz uma tonelada de pentóxido de fosfato $\left(\mathrm{P}_{2} \mathrm{O}_{5}\right)$, ela gera entre 4 a 6 toneladas de fosfogesso (Kouloheris, 1980; Helena \& Recki, 1984). As grandes quantidades de fosfogesso obtidas nesse processo tem sido um problema para as indústrias, por causa da sua disposição final e das eventuais poluições ao meio ambiente. Kouloheris (1980) relata que as primeiras formas de gerenciamento desse resíduo consistiam no seu bombeamento diretamente no mar, aproveitando a alta solubilidade do fosfogesso nas águas salinas. Devido à produção cada vez maior de fosfogesso, esse método foi progressivamente substituído pelo seu armazenamento em depósitos sobre o solo (Lloyd Jr., 1985). De acordo com Parreira et al. (2003), a produção mundial de fosfogesso é de 180 milhões de toneladas por ano. No Brasil, os estoques de fosfogesso passaram de 50 a 150 milhões de toneladas entre 1991 e 2007, e uma produção anual de 5,4 milhões de toneladas nos últimos anos (Mazzilli \& Saueia, 1997; Kanno et al., 2008; Fernandes \& Luz, 2010). Os problemas de disposição final do fosfogesso levam cada 
vez mais pesquisadores a buscarem soluções econômicas e ambientalmente aceitáveis para seu reuso. Entretanto, o reaproveitamento desse resíduo vem sendo bastante limitado por causa das suas impurezas e da abundância de depósitos de gesso natural $\left(\mathrm{CaSO}_{4}\right)$, material de mesma composição química, mas sem impurezas. Dois fatores determinam o tipo e a quantidade de impurezas do fosfogesso: a origem da rocha fosfática e o processo de produção do ácido fosfórico. Esses assuntos serão discutidos mais detalhadamente a seguir.

\subsection{2 - ROCHAS FOSFÁTICAS}

O termo rocha fosfática, embora seja considerado impreciso, é globalmente aceito para designar os materiais geológicos que contêm uma quantidade adequada de minerais fosfáticos para o uso comercial (Straaten, 2002). A mesma expressão é utilizada para se referir aos produtos industriais de alta concentração em fósforo (McClellan \& Kauwenbergh, 2004). Os concentrados fosfáticos são comercializados expressos sob a forma de pentóxido de fósforo $\left(\mathrm{P}_{2} \mathrm{O}_{5}\right)$ ou fosfato tricálcio $\left(\mathrm{Ca}_{3}\left(\mathrm{PO}_{4}\right)_{2}\right)$, também conhecido como Bone Phophate of Lime BPL (Souza, 2001). Além do mineral principal contendo o fósforo, as jazidas de rochas fosfáticas contêm minerais acessórios ou impurezas de ganga que ainda podem se encontrar no mineral fosfático enriquecido (Zapata \& Roy, 2004).

As maiores reservas mundiais de rochas fosfáticas estão localizadas no Marrocos e nos Estados Unidos. Cerca de 40 países produzem os concentrados fosfáticos, mas apenas 12 países são responsáveis por $92 \%$ da produção mundial. Essa produção é liderada pelos Estados Unidos com 33 a 34\% do total da produção, e é seguido pela China, Marrocos e Rússia (Better, 1999; Zapata \& Roy, 2004). O parque industrial de fosfatos brasileiro ocupa a $8^{a}$ colocação dentre os produtores mundiais de concentrado de rocha fosfática com $3,4 \%$ de participação (Souza, 2001). A Figura 2.1 mostra as potenciais jazidas de rochas fosfáticas no mundo. As reservas totais de rochas fosfáticas brasileiras são estimadas a quatro bilhões de toneladas. Em termos de $\mathrm{P}_{2} \mathrm{O}_{5}$, elas representam cerca de $1 \%$ das reservas mundiais (Cekinski et al., 1990). Esse patrimônio fosfático está distribuído nos estados produtores de Minas Gerais com 73,8\%, Goiás com 8,3\% e São Paulo com 7,3\%, que juntos participam com $89,4 \%$ das reservas totais do país, seguido dos estados de Santa Catarina, Pernambuco, Bahia e Paraíba, com os 10,6\% restantes (Souza, 2001). 


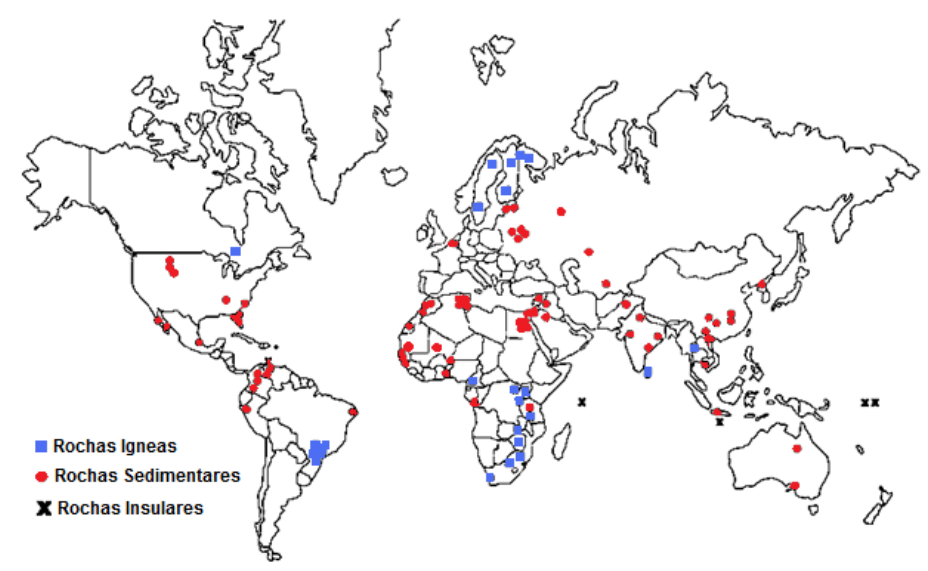

Figura 2.1 As potenciais jazidas de rochas fosfáticas no mundo (modificado de Zapata \& Roy, 2004).

A indústria de fertilizantes consume cerca de $90 \%$ da produção mundial de rocha fosfática. O restante é utilizado diretamente como fertilizante, ou para a produção de complementos alimentares para animais, produtos alimentares, ou ainda para a fabricação dos fósforos elementares e seus derivados como o tripolifosfato de sódio $\left(\mathrm{Na}_{5} \mathrm{P}_{3} \mathrm{O}_{10}\right)$, componente importante para os detergentes (Zapata \& Roy, 2004; Jasinski, 2006).

De acordo com Straaten (2002), existem cinco tipos de depósitos de rochas fosfáticas no mundo: marinhos de origem sedimentar, ígnea, metamórficos, biogenéticos e os depósitos resultantes de um processo de intemperismo. Os depósitos sedimentares são utilizados para produzir mais de $80 \%$ das rochas fosfáticas (UNIDO \& IFDC, 1998). McClellan \& Kauwenbergh (2004) estimam que os depósitos ígneos foram responsáveis por 10 a $20 \%$ da produção mundial de rochas fosfáticas entre 1994 e 2004. Esses dados corroboram com Souza (2001) que afirma que esses dois depósitos são os mais importantes de ponto de vista econômico comparados, por exemplo, aos depósitos biogenéticos, que são concentrações orgânicas nitrogenadas, originadas pelos dejetos de aves. Dependendo das suas origens, as rochas fosfáticas apresentam grandes diferenças do ponto de vista mineralógico, da textura e das características químicas (UNIDO \& IFDC, 1998). Do ponto de vista mineralógico, a apatita representa o principal grupo dos mais de 200 minerais fosfáticos conhecidos. Este se encontra principalmente nas rochas primares sedimentares, metamórficas e ígneas. Porém, pode ser observado também nas rochas que sofreram intemperismo (Straaten, 2002). O grupo das apatitas se subdivide em:

- Fluroapatitas, $\left(\mathrm{Ca}_{10}\left(\mathrm{PO}_{4}\right)_{6} \mathrm{~F}_{2}\right)$, presente nas rochas ígneas e metamórficas; 
- Hidroxiapatita $\left(\mathrm{Ca}_{10}\left(\mathrm{PO}_{4}\right)_{6}(\mathrm{OH})_{2}\right)$, frequente nos depósitos ígneos, metamórficos mas também nos biogenéticos;

- Carbonato-hidroxiapatita $\left(\mathrm{Ca}_{10}\left(\mathrm{PO}_{4}, \mathrm{CO}_{3}\right)_{6}(\mathrm{OH})_{2}\right)$, presente principalmente nas ilhas e cavernas sob forma de produtos da decomposição de aves e morcegos;

- Francolita (Ca10-x-yNax $\left.\mathrm{Mg}_{y}\left(\mathrm{PO}_{4}\right)_{6-z}\left(\mathrm{CO}_{3}\right)_{z} \mathrm{~F}_{0.4 z} \mathrm{~F}_{2}\right)$, encontrada majoritariamente nos depósitos marinhos.

Cerca de $80 \%$ das jazidas fosfatadas naturais do Brasil são em geral, de origem ígnea com presença acentuada de rocha carbonática e micáceos com baixo teor de $\mathrm{P}_{2} \mathrm{O}_{5}$ (Souza, 2001). As rochas destes complexos ígneos, sujeitas às alterações intempéricas superficiais são decompostas, promovendo um enriquecimento residual das apatitas, pela solubilização dos minerais associados (carbonatos das rochas, olivinas, piroxênios e biotitas das rochas ultrabásicas). Assim sendo, é necessário distinguir nas jazidas de origem ígneas as rochas frescas que se encontram em profundidade e as rochas alteradas da superfície, onde ocorreu o citado enriquecimento residual, dando origem ao denominado minério oxidado (Cekinski et al., 1990). Segundo Cekinski et al. (1990) e Souza (2001), os depósitos fosfáticos brasileiros de origem ígnea são localizados em Araxá (MG), Tapira (MG), Catalão (GO), Ouvidor (GO), Ipanema (SP), Serrote (SP), Anitápolis (SC), Jacupiranga (SP), Cajati (SP) e Maicuru (PA).

Depósitos de origem sedimentar também ocorrem no país, nos estados do Nordeste, principalmente em Pernambuco (Olinda), Bahia (Irecê) podendo ser ainda encontrado em locais de outros estados, como Minas Gerais nos municípios de Lagamar e Patos de Minas e no oeste matogrossense. Essas rochas se constituem em camadas, níveis ou extratos, mais ou menos uniformes, correspondentes ao acúmulo de fosfatos de precipitação química, com ou sem ajuda de microrganismos em fundos de lagos ou mares (Cekinski et al., 1990; Souza, 2001). Tem-se conhecimento ainda de jazidas de concentração residual em Anitápolis (SC), Pirocaua e Trauira no Maranhão e do tipo guano em Fernando de Noronha (Souza, 2001).

Em função do baixo teor de $\mathrm{P}_{2} \mathrm{O}_{5}$ das rochas brasileiras, existe a necessidade de que sejam beneficiadas para se obter concentrados fosfáticos com teor de fósforo adequado ao processamento químico subsequente (Cekinski et al.,1990). O processo de beneficiamento das rochas fosfáticas inicia-se pelas operações de lavra, transporte por caminhões ou estradas de ferro e britagem. Esta é executada em duas fases e tem como objetivo a redução granulométrica do minério até o diâmetro máximo em torno de $32 \mathrm{~mm}$. Depois, o material 
britado é estocado em pilhas de homogeneização. Por seguinte, esse é submetido aos processos de moagem, classificação e deslamagem cujos objetivos são fragmentar o material em finas partículas, separar as partículas por tamanho, particularmente de diâmetro menor a $20 \mu \mathrm{m}$, através de hidrociclones. Na próxima etapa, são adicionados vários reagentes coletores e depressores ao material em suspensão. Essa é a fase de condicionamento. A polpa assim condicionada é submetida à flotação, cujo objetivo é alcançar a maior concentração possível dos compostos de fósforo pela separação de outros compostos diluentes. O processo de flotação se baseia no comportamento físico-químico das superfícies das partículas minerais presentes numa suspensão aquosa. A polpa final da operação de flotação é submetida a uma operação de espessamento por um processo de desaguamento e a seguir é encaminhada à filtração, num filtro a vácuo. $\mathrm{O}$ material de saída do filtro, com uma umidade em torno de $10 \%$, é submetido à secagem. Na maioria dos casos, o produto final de umidade quase nula contém entre 36 e 38\% de $\mathrm{P}_{2} \mathrm{O}_{5}$ (Cekinski et al., 1990; PORMIN, 2008). Em seguida, esse produto final é submetido às reações de ataque pelo ácido sulfúrico no processo de produção do ácido fosfórico. Dessas reações é gerado o subproduto chamado fosfogesso como apresentado nos próximos parágrafos.

\subsection{3 - ÁCIDO SULFÚRICO E ÁCIDO FOSFÓRICO}

O ácido sulfúrico é uma das principais matérias primas da fabricação dos fertilizantes fosfatados. De acordo com Norfalco (2007), sua produção mundial é de 190 milhões de toneladas por ano. Cerca de $58 \%$ dessa produção é utilizada na geração de fertilizantes. Temse ainda que $65 \%$ da produção mundial desse ácido é feita a partir do enxofre elementar, $16 \%$ da pirita e $19 \%$ de outras fontes. Em geral, o ácido sulfúrico é produzido a partir da oxidação catalítica do dióxido de sulfato $\left(\mathrm{SO}_{2}\right)$ em trióxido de enxofre $\left(\mathrm{SO}_{3}\right)$, o qual vai ser combinado com água para formar o ácido sulfúrico $\left(\mathrm{H}_{2} \mathrm{SO}_{4}\right)$ (UNIDO \& IFDC, 1998).

O ácido fosfático $\left(\mathrm{H}_{3} \mathrm{PO}_{4}\right)$ por sua vez, é utilizado pela indústria de fertilizante principalmente para a produção dos fosfatos mono (MAP) e diamônio (DAP) (UNIDO \& IFDC, 1998). Existem basicamente dois processos para produção do ácido fosfórico, por via térmica ou úmida. O primeiro é principalmente utilizado para a fabricação do fósforo elementar que, depois serve na produção de um ácido fosfórico não utilizado, na maioria das vezes, na fabricação de fertilizante. O processo por via úmida é o método mais empregado para 
produção do ácido fosfático utilizado pelas indústrias de fertilizantes. Esse consiste principalmente no ataque da rocha fosfática pelo ácido sulfúrico (Cekinski et al., 1990; UNIDO \& IFDC, 1998). Considerando a fluroapatita como o principal mineral da rocha fosfática, a fórmula dessa reação pode ser escrita conforme apresentado na Equação 2.1:

$$
\mathrm{Ca}_{10}\left(\mathrm{PO}_{4}\right)_{6} \mathrm{~F}_{2}+10 \mathrm{H}_{2} \mathrm{SO}_{4}+10 \mathrm{nH}_{2} \mathrm{O} \rightarrow 10 \mathrm{CaSO}_{4} \mathrm{nH}_{2} \mathrm{O}+6 \mathrm{H}_{3} \mathrm{PO}_{4}+2 \mathrm{HF}
$$

Onde:

$$
\begin{aligned}
& \mathrm{Ca}_{10}\left(\mathrm{PO}_{4}\right)_{6} \mathrm{~F}_{2}=\text { Flurapatita. } \\
& \mathrm{H}_{2} \mathrm{SO}_{4}=\text { Ácido sulfúrico. } \\
& \mathrm{H}_{2} \mathrm{O}=\text { Água. } \\
& \mathrm{CaSO}_{4} \mathrm{nH}_{2} \mathrm{O}=\text { Fosfogesso. } \\
& \mathrm{H}_{3} \mathrm{PO}_{4}=\text { Ácido fosfático. } \\
& \mathrm{HF}=\text { Ácido fluorídrico. }
\end{aligned}
$$

Dependendo do tipo de processo de hidratação utilizados para a produção do ácido fosfático, o número $n$ de moléculas de água no fosfogesso pode ser igual a $0,1 / 2$ ou 2 . A Equação 2.1 representa na realidade o resultado de dois estágios. No primeiro, o ácido fosfórico, geralmente um reciclado, reage com a apatita formando o fosfato monocálcico. No segundo, o fosfato monocálcico é atacado pelo ácido sulfúrico para produzir o ácido fosfórico e um resíduo na forma de sulfato de cálcio chamado fosfogesso. Esses estágios não requerem necessariamente que as duas reações sejam reversíveis e podem normalmente ocorrer simultaneamente no mesmo reator (UNIDO \& IFDC, 1998). Além do ácido fosfático e do fosfogesso, é gerado o ácido fluorídrico (HF), líquido incolor, corrosivo e muito tóxico, utilizado nos processos de purificação dos alumínios e urânios (Rauber \& Kupferschmidt, 2006). O ácido fluorídrico formado reage com o silício e outras impurezas da rocha fosfática (N, K, Mg e Al) para produzir os fluorosilicatos e outros compostos complexos (UNIDO \& IFDC, 1998).

As reações de ataque da rocha pelo ácido sulfúrico podem ser realizadas por meio de três processos distintos, originando como subprodutos os fosfogessos di-hidratado, hemi-hidratado e anidro. O grau de hidratação é principalmente controlado pela temperatura e a concentração do ácido. Não existe, atualmente, um desenvolvimento comercial do processo anidro, porque 
este requer temperaturas muito altas que geram enormes problemas de corrosão e maiores gastos enérgicos (UNIDO \& IFDC, 1998). Os processos de formação do fosfogesso são melhores descritos a seguir.

\subsection{4 - PROCESSOS DE FORMAÇÃO DO FOSFOGESSO}

\subsubsection{1 - PROCESSO DI-HIDRATADO}

Por causa da sua relativa simplicidade, o processo di-hidratado é o mais usado no mundo. Segundo Cekinski et al.(1990), esse é o mais difundido no Brasil. Nessa forma de produção de fosfogesso, as reações de ataque desenvolvem-se em temperaturas entre 70 a $85^{\circ} \mathrm{C}$, podendo ser consideradas baixas quando comparadas aos demais processos. Além de apresentar uma grande flexibilidade por usar vários tipos de rochas fosfáticas, esse processo tem como vantagens o menor investimento inicial e um baixo custo operacional. Com esse método, é possível produzir um fosfato do qual o urânio pode ser extraído. A produção de fosfogesso seco é de cerca 4,9 toneladas por tonelada de $\mathrm{P}_{2} \mathrm{O}_{5}$ produzido. Entretanto, o processo di-hidratado tem como maior desvantagem o fato de produzir o fosfogesso com maior teor de impurezas, além da menor produtividade, situada entre 28 e $30 \%$ em $\mathrm{P}_{2} \mathrm{O}_{5}$ (Kouloheris, 1980).

Nesse processo, a rocha fosfática moída é pré-misturada com um reciclado de ácido fosfático fraco. Depois um ácido sulfúrico forte é adicionado à precedente mistura, provocando uma reação exotérmica acompanhada da evaporação da água e da volatilização dos tetrafluoreto de silício $\left(\mathrm{SiF}_{4}\right)$ e ácido fluorídrico $(\mathrm{HF})$. Geralmente, essa reação é realizada num reator dotado de um sistema de resfriamento a vácuo. Esse sistema serve para controlar a temperatura da reação (entre 70 a $85^{\circ} \mathrm{C}$ ) e permitir que o $\mathrm{SiF}_{4}$ e $\mathrm{HF}$ possam ser recuperados no estado líquido e utilizados para outras finalidades. Depois da reação, a mistura é deixada em repouso por um período de 1,5 a 12 horas. Essa etapa permite a cristalização do sulfato de cálcio. A polpa resultante dessa fase contém $29 \%$ de $\mathrm{P}_{2} \mathrm{O}_{5}$ e 38 a $40 \%$ de matéria sólida. Em seguida, essa polpa é levada para um filtro. Esse filtro tem como função separar o fosfogesso do ácido fosfórico, assim como os demais materiais insolúveis, da forma mais eficiente e econômica possível. Durante o processo de filtragem, o ácido fosfórico é primeiramente coletado pela aplicação de um sistema de aspiração a vácuo e segue para a estocagem. Sua concentração é de 28 a $30 \%$ de $\mathrm{P}_{2} \mathrm{O}_{5}$. Esse ácido pode ser submetido a um processo de evaporação para 
aumentar sua concentração de forma a atingir 50 a $54 \%$ de $\mathrm{P}_{2} \mathrm{O}_{5}$. A polpa é lavada duas a três vezes para completar a extração de ácido fosfórico (fraco) do subproduto sólido. Esse subproduto é um fosfogesso di-hidratado $\left(\mathrm{CaSO}_{4} \cdot 2 \mathrm{H}_{2} \mathrm{O}\right)$. A última lavagem é feita com água limpa e o fosfogesso gerado é armazenado em depósitos. Várias soluções fracas de ácido fosfático são coletadas nas seções de lavagem. A última é utilizada para a lavagem da etapa anterior. A solução obtida na primeira etapa é finalmente redirecionada para o reator onde é misturada novamente com a rocha fosfática moída e o processo reinicia-se (UNIDO \& IFDC, 1998).

\subsubsection{2 - PROCESSO HEMI-HIDRATADO}

Kouloheris (1980) reporta que o processo hemi-hidratado é muito empregado na Europa, no Japão e na África. Esse processo ocorre em duas fases distintas. Portanto, é necessário que haja uma separação do reator em dois compartimentos. A razão volumétrica entre os tanques de reação é de 2:1. A primeira zona de reação ainda é dividida em dois compartimentos idênticos $1 \mathrm{~A}$ e $1 \mathrm{~B}$. A rocha fosfática é colocada no compartimento $1 \mathrm{~A}$. O ácido sulfúrico e o ácido fosfático fraco proveniente da filtragem são colocados no reator 2. A polpa contida nesse reator é reciclada, depois resfriada e enviada para o compartimento 1A. A rocha fosfática presente nesse compartimento reage com íons sulfatos em condições controladas. A polpa do tanque 1A é encaminhada para o tanque 1B. O calor liberado é removido por um sistema de resfriamento a vácuo de forma a manter a temperatura de reação entre 98 a $100^{\circ} \mathrm{C}$. $\mathrm{O}$ ácido fosfático obtido cujo teor em $\mathrm{P}_{2} \mathrm{O}_{5}$ situa-se entre 40 a $50 \%$ é separado do fosfogesso hemi-hidratado por um filtro a vácuo horizontal. O ácido extraído da filtragem é diretamente armazenado e já pode ser utilizado como concentrado fosfático, sem precisar passar por uma fase de clarificação, de remoção de sólidos ou de evaporação. Por seguinte, a polpa é submetida a três estágios de lavagem. Da mesma forma que no processo di-hidratado, na última lavagem é utilizada uma água limpa. O filtrado dessa etapa contém uma baixa concentração em ácido e é utilizado para a lavagem anterior. A solução recolhida na primeira lavagem é redirecionada para o reator 2. O fosfogesso hemi-hidratado gerado pelo processo é armazenado em pilhas (UNIDO \& IFDC, 1998).

Por não necessitar de uma fase de evaporação, esse processo apresenta a vantagem de eliminar os gastos para a aquisição e a manutenção de um equipamento suplementar para a evaporação. Como outra vantagem, observa-se que o processo hemi-hidratado produz um 
ácido mais puro, além de permitir um melhor aproveitamento da rocha fosfática. Para uma tonelada de $\mathrm{P}_{2} \mathrm{O}_{5}$, são produzidas 4,3 toneladas de fosfogesso. É importante ressaltar que, esse processo é mais rápido do que o precedente (UNIDO \& IFDC, 1998). Apesar do seu bom rendimento, o processo hemi-hidratado apresenta algumas desvantagens que provavelmente limitam sua popularidade em comparação ao processo di-hidratado. Dentre estas, observa-se que os cristais hemi-hidratados são mais finos que os di-hidratados, o que dificulta bastante a filtragem da polpa hemi-hidratada. Nesse processo, a retenção do ácido fosfático na polpa, tanto na sua forma solúvel quanto cristalizada, é maior por causa de uma concentração em $\mathrm{P}_{2} \mathrm{O}_{5}$ mais elevada. Isso conduz a uma maior perda em ácido ou a maiores gastos em água de filtragem. Por outro lado, o fosfogesso hemi-hidratado, por ser uma forma de sulfato de cálcio instável, tende sempre a se transformar em fosfogesso di-hidratado antes da filtragem. Essa situação é ainda mais grave durante a lavagem por causa da hidratação do fosfogesso, o que gera problemas no dimensionamento dos equipamentos. Enfim, por causa das altas temperaturas envolvidas nas reações e da elevada concentração de $\mathrm{P}_{2} \mathrm{O}_{5}$, ocorre uma maior corrosão dos equipamentos, em particular dos agitadores e das bombas (UNIDO \& IFDC, 1998).

\subsubsection{3 - PROCESSOS HEMI-DIHIDRATADOS}

Existem genericamente três processos hemi-dihidratados: sem filtração intermediária, com filtração intermediária e di-hidratado/hemi-hidratado. Em geral, esses processos tiram proveito das vantagens dos processos di-hidratado e hemi-hidratado. O processo hemidihidratado sem fase de filtração intermediária ou hemi-hidratado com cristalização é amplamente utilizado nos países da Ásia oriental e Oceania. O formato das plantas desse processo é parecido ao do processo di-hidratado. A diferença é que o reator onde ocorre o ataque funciona nas condições que permitem a formação de um fosfogesso hemi-hidratado. Os reatores seguintes funcionam de forma a favorecer a geração de um fosfogesso dihidratado por hidratação do hemi-hidratado. O objetivo dessa fase é obter cristais dihidratados durante a filtragem. O ácido fosfórico produzido é ligeiramente menos concentrado do que o obtido no processo di-hidratado, mas o fosfogesso produzido é mais puro e, portanto, de maior uso como material de construção ou na indústria cimenteira. Esse processo apresenta uma vantagem importante para países onde os recursos em gesso natural são escassos como no Japão. O custo elevado e a complexidade desse processo são suas principais desvantagens (UNIDO \& IFDC, 1998). 
No processo hemi-hidratado com filtragem intermediária, a primeira fase é idêntica ao processo hemi-hidratado sem filtração, incluindo a recuperação do ácido fosfático por filtragem. Depois dessa fase, o fosfogesso hemi-hidratado é descarregado do filtro e depois enviado para os tanques de agitação. As operações são controladas de forma a garantir a transformação total do fosfogesso hemi-hidratado em di-hidratado, assim como sua cristalização. A fase de transformação é acelerada pela adição de uma pequena quantidade de ácido sulfúrico na polpa. Quase todo o $\mathrm{P}_{2} \mathrm{O}_{5}$ precipitado com o fosfogesso hemi-hidratado é liberado na fase líquida. Por seguinte, o fosfogesso di-hidratado é filtrado e a polpa lavada com a água do processo. $\mathrm{O}$ filtrado e o $\mathrm{P}_{2} \mathrm{O}_{5}$ recuperado são redirecionados para o estágio de reação hemi-hidratada e usados como água da última lavagem. A filtragem intermediária aumenta o custo e a complexidade da produção, mas essa desvantagem é compensada pela eliminação da fase de concentração por causa do alto teor de $\mathrm{P}_{2} \mathrm{O}_{5}$ situada em torno de $40 \%$. O fosfogesso obtido é mais puro do que o obtido no processo di-hidratado e hemi-hidratado e pode ser utilizado na produção dos materiais de construção (UNIDO \& IFDC, 1998).

Já no processo di-hidratado/hemi-hidratado, as primeiras reações são realizadas nas condições di-hidratadas, sem intenção de produzir um ácido fosfórico de alta concentração porque as etapas sucessivas de desidratação necessitam entre 20 a $30 \%$ de $\mathrm{P}_{2} \mathrm{O}_{5}$ e 10 a $20 \%$ de $\mathrm{H}_{2} \mathrm{SO}_{4}$. Uma centrífuga é instalada junto com o filtro para produzir uma fina espessura de polpa de fosfogesso e corrigir as concentrações. No final do processo, é possível produzir um ácido sulfúrico com $35 \%$ de $\mathrm{P}_{2} \mathrm{O}_{5}$, comparado ao máximo de $32 \%$ obtido no processo di-hidratado. Esse processo apresenta as mesmas vantagens e desvantagens que os hemi-hidratado-dihidratado, exceto o fato que o fosfogesso hemi-hidratado produzido tem uma maior aplicabilidade (UNIDO \& IFDC, 1998).

\subsection{5 - CARACTERÍSTICAS DO FOSFOGESSO}

As características do fosfogesso dependem da natureza das rochas fosfáticas, do tipo de processo de produção do ácido fosfático, da eficiência da planta, do método de disposição, da idade, da localização e do tamanho das áreas onde este está estocado (Tayibi et al., 2009). As principais características que podem ser avaliadas são as químicas, as radioativas e as físicas. 


\subsubsection{1 - CARACTERÍSTICAS QUÍMICAS}

Rutherford et al. (1995) alertam que é necessário entender a composição química do fosfogesso para uma completa avaliação dos seus impactos ambientais, um melhor planejamento do seu armazenamento e suas possíveis utilizações. Na sua forma mais comum, o fosfogesso é majoritariamente construído pelo sulfato de cálcio di-hidratado $\left(\mathrm{CaSO}_{4} \cdot 2 \mathrm{H}_{2} \mathrm{O}\right)$ e contém certas impurezas. Essas são, principalmente, constituídas por matérias orgânicas, resíduos de ácidos fosfático e sulfúrico, fluoretos, ferro $(\mathrm{Fe})$, metais pesados como o arsênico (As), cádmio $(\mathrm{Cd})$, cromo $(\mathrm{Cr})$, chumbo $(\mathrm{Pb})$, manganês $(\mathrm{Mn})$ e radionuclídeos (Berish, 1990; Kumar, 2002). A natureza química dessas impurezas está relacionada, primeiramente, com a composição da rocha fosfática utilizada na fabricação do ácido fosfórico, das condições de reação com o ácido sulfúrico, de separação dos produtos e dos equipamentos utilizados (Rutherford et al., 1995; Castilhos et al., 1998). A Tabela 2.1 apresenta a composição química de fosfogessos di-hidratados produzidos em algumas regiões do planeta: Balikesir na Turquia (Degirmenci et al., 2006), Guizhou Wengfu na China (Min et al., 2008), Wizów na Polônia (Wolicka, 2008), Catalão no Brasil (Castilhos et al., 1998) e Sfax na Tunísia (Felfoul et al., 2002). Observa-se que independentemente da região, o fosfogesso di-hidratado apresenta praticamente a mesma constituição química, marcada pela predominância do óxido de cálcio $(\mathrm{CaO})$ e trióxido de enxofre $\left(\mathrm{SO}_{3}\right)$.

Tabela 2.1. Composição química dos fosfogessos dihidratados produzidos na Turquia (Degirmenci et al., 2006), China (Ming et al.,2008), Polônia (Wolicka, 2008), Brasil (Castilhos et al., 1998) e Tunisia (Felfoul et al., 2002).

\begin{tabular}{lccccc}
\hline \multirow{2}{*}{ Compostos } & \multicolumn{3}{c}{ Teor $(\%)$} & Brasil & Tunísia \\
\cline { 2 - 6 } & Turquia & China & Polônia & Bra & 0,50 \\
$\mathrm{SiO}_{2}$ & 3,44 & 1,25 & 0,65 & 0,64 & 32,50 \\
$\mathrm{CaO}$ & 32,04 & 29,05 & 29,6 & 38,15 & 44,00 \\
$\mathrm{SO}_{3}$ & 44,67 & 42,19 & 42,2 & 49,36 & 0,10 \\
$\mathrm{Al}_{2} \mathrm{O}_{3}$ & 0,88 & 0,43 & 0,2 & 0,59 & 0,10 \\
$\mathrm{Fe}_{2} \mathrm{O}_{3}$ & 0,32 & 0,21 & 0,14 & 0,35 & 0,65 \\
$\mathrm{P}_{2} \mathrm{O}_{5}$ & 0,5 & 3,5 & 2,2 & 0,00 & - \\
$\mathrm{Na}_{2} \mathrm{O}+\mathrm{K}_{2} \mathrm{O}$ & 0,13 & 0,51 & 0,50 & 0,18 & 1,20 \\
$\mathrm{~F}$ & 0,79 & - & 0,50 & 10,73 & 20,95 \\
Outras impurezas & 17,23 & 22,86 & 24,01 & & \\
\hline
\end{tabular}

De acordo com Felfoul et al. (2002) e Ajam et al.(2009), as impurezas do fosfogesso podem ser classificadas em dois grupos:

- Impurezas solúveis: são os sais ou ácidos não eliminados na fase de lavagem do processo de produção do ácido fosfórico. Nesse grupo, encontram-se principalmente o $\mathrm{P}_{2} \mathrm{O}_{5}$ e os 
fluoretos solúveis. Esses ácidos são responsáveis pelo $\mathrm{pH}$ relativamente baixo do fosfogesso.

- Impurezas insolúveis: são constituídas pelos minerais não transformados durante a reação de ataque (silício, carbono orgânico, resíduo da decomposição de espécies vivas) e dos compostos obtidos por reações secundárias $\left(\mathrm{P}_{2} \mathrm{O}_{5}\right.$ cristalizado, oligoelementos e, principalmente, os metais pesados).

A presença de impurezas no fosfogesso vem limitando seu reaproveitamento em diversas áreas, além de apresentar potenciais riscos ambientais. De acordo com Singh (2005), as impurezas mais prejudiciais para uma aplicação direta do fosfogesso em construção civil são os $\mathrm{P}_{2} \mathrm{O}_{5}\left(\mathrm{Ca}\left(\mathrm{H}_{2} \mathrm{PO}_{4}\right)_{2}, \mathrm{Ca}_{2}\left(\mathrm{HPO}_{4}\right)_{2}\right.$ e $\left.\mathrm{Ca}_{3}\left(\mathrm{PO}_{4}\right)_{2}\right)$, os flúores $\left(\mathrm{NaF}, \mathrm{Na}_{2} \mathrm{SiF}_{6}\right.$ e $\left.\mathrm{Na}_{3} \mathrm{AlF}_{6}\right)$ e as matérias orgânicas. Os teores de metais pesados nos fosfogessos são geralmente baixos, porém quando esses são encontrados em nível de concentrações acima das recomendações técnicas, tornam-se poluentes oferecendo riscos de contaminação de solos e mananciais de água que estejam próximos dos depósitos de fosfogesso (Castilhos et al., 1998; Rufo, 2009). De todas as impurezas do fosfogesso, os radionuclídeos são provavelmente os mais preocupantes do ponto de vista ambiental.

\subsubsection{2 - CARACTERÍSTICAS RADIOATIVAS}

A radioatividade é um fenômeno natural durante o qual os núcleos atômicos instáveis chamados radioisótopos se desintegram espontaneamente liberando energia em diversas formas de radiações para se transformar em núcleo atômico mais estável e perdendo assim uma parte da sua massa. As radiações emitidas podem ser de raios alfa (liberação de carga elétrica positiva), beta (carga negativa) ou gama (radiação eletromagnética). Até 1964, o Curie (Ci) era a principal unidade radioativa. Um Curie corresponde ao número de desintegração de um grama de rádio $(\mathrm{Ra})$ puro. Isso equivale a cerca de $3,7 \times 10^{10}$ desintegrações atômicas por segundo. Atualmente, essa unidade é substituída pelo Becquerel (Bq) que representa uma desintegração por segundo. Consequentemente, $1 \mathrm{Ci}=3,7 \times 10^{10} \mathrm{~Bq}$. A atividade de uma amostra radioativa é definida como seu número de desintegração por segundo. No Sistema Internacional (SI) o Becquerel é a unidade de medida da atividade radioativa.

Existem duas principais fontes radioativas naturais: as partículas cósmicas de altas energias que são filtradas pela atmosfera e os radionuclídeos originados da crosta terrestre 
(UNSCEAR, 2000). Dos radionuclídeos de origem cósmica os mais abundantes são ${ }^{14} \mathrm{C},{ }^{10} \mathrm{Be}$ e ${ }^{26} \mathrm{Al}$ enquanto na costa terrestre, os mais comuns são o potássio-40 $\left({ }^{40} \mathrm{P}\right)$ e os radioisótopos das séries naturais do urânio, actínio e tório, assim como os núcleos mães ${ }^{235} \mathrm{U},{ }^{238} \mathrm{U}$ e ${ }^{232} \mathrm{Th}$ e os seus produtos sucessivos de decaimento alfa ou beta (Azouazi et al., 2001). As rochas fosfáticas apresentam naturalmente uma alta radioatividade e provém principalmente, dos radionuclídeos ${ }^{238} \mathrm{U}$ e ${ }^{232} \mathrm{Th}$ e seus produtos de decaimento (Tayibi et al., 2009). As Figuras 2.2 e 2.3 mostram, respectivamente, as séries de decaimento do ${ }^{238} \mathrm{U}$ e ${ }^{232} \mathrm{Th}$. Durante o processo de ataque da rocha fosfática pelo ácido sulfúrico, o equilíbrio radioativo da rocha é rompido e ocorre uma redistribuição dos radionuclídeos entre o ácido fosfórico e o fosfogesso: cerca de $80 \%$ de ${ }^{226} \mathrm{Ra}$ concentra-se no fosfogesso enquanto $86 \%$ de ${ }^{238} \mathrm{U}$ e $70 \%$ de ${ }^{232}$ Th orientam-se para o ácido fosfórico (Berish, 1990; Rutherford et al., 1995; Tayibi et al., 2009). Afifi et al. (2009) mostraram que a radioatividade do fosfogesso é, principalmente, devida ao radionuclídeos ${ }^{226} \mathrm{Ra}$ e ${ }^{210} \mathrm{~Pb}$. De acordo com Rutherford et al. (1995), o rádio-226 com 1690 anos de meia vida é a maior fonte radioativa do fosfogesso a longo prazo. O gás radônio-222, seu primeiro produto na série de decaimento, é a causa da maior preocupação para saúde humana do uso do fosfogesso, pois sua inalação foi associada ao desenvolvimento de doenças cancerígenas.

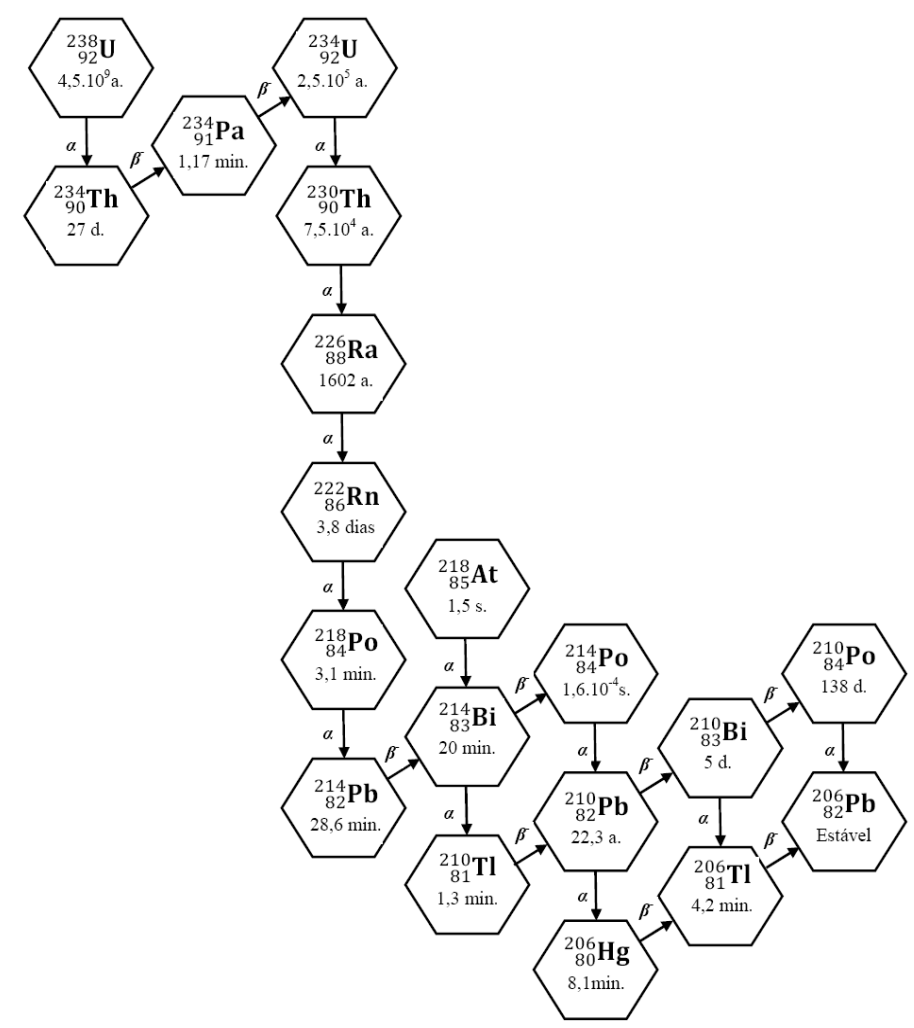

Figura 2.2. Série de decaimento da ${ }^{238} \mathrm{U}$ (Modificado de Tosaka, 2008) 


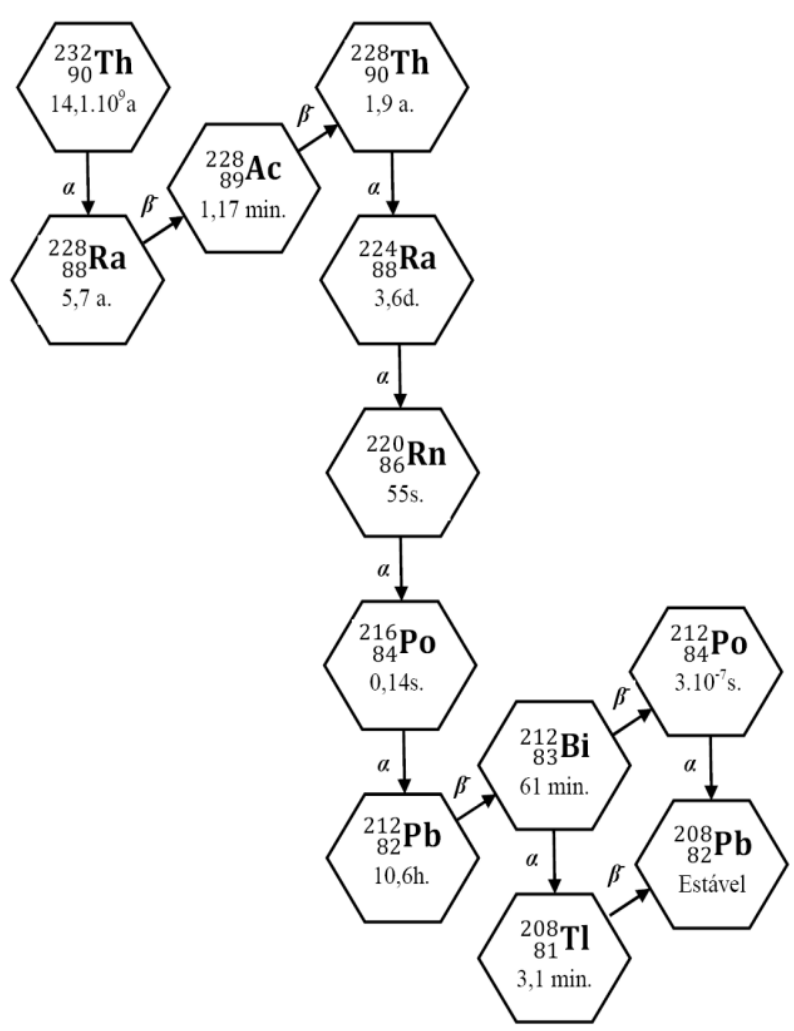

Figura 2.3. Série de decaimento do ${ }^{232} \mathrm{Th}$ (Modificado de Tosaka, 2008)

\subsubsection{3 - CARACTERÍSTICAS FÍSICAS}

O fosfogesso é um resíduo sólido, poeirento e geralmente de cor amarela. Recente produzido, seu teor de umidade situa-se entre 25 e 30\% (UNIDO \& IFDC, 1998). Uma vez que o fosfogesso é depositado, essa umidade varia de acordo com o tipo de estocagem (a úmido ou a seco), a idade das pilhas, as condições meteorológicas do local e de drenagem das áreas de armazenamento (Silva et al., 2002; Tayibi et al., 2009).

A condutividade hidráulica vertical nas pilhas de fosfogesso varia entre $1 \times 10^{-5}$ e $2 \times 10^{-5} \mathrm{~m} / \mathrm{s}$ (Rouis et al.1990; Tayibi et al. 2009; Ajam et al., 2009). O ensaio de permeabilidade realizado por Rufo (2009) com o fosfogesso de Catalão (GO) compactado nos seus valores de umidade ótima e peso específico aparente seco máximo, mostrou que este apresenta uma condutividade hidráulica de $2,4 \times 10^{-6} \mathrm{~m} / \mathrm{s}$. Esse valor foi confirmado por Matos (2011) para o mesmo material. A solubilidade do fosfogesso depende do $\mathrm{pH}$ da água em que está imerso. Numa água desmineralizada, essa solubilidade está em torno de 2,4g/l (Felfoul et al., 2002). Os resultados dos ensaios feitos por Castilhos et al.(1998) e Mesquita (2007) com o 
fosfogesso produzido na região de Catalão $(\mathrm{GO})$, mostraram que a sua solubilidade varia entre 2,4 e 2,8 g/l. Segundo Tayibi et al. (2009), essa propriedade do fosfogesso é aproximadamente igual a 4,1g/l em águas salgadas.

As medidas feitas por Rutherford et al. (1995) nas pilhas de fosfogesso da Flórida e do Idaho nos Estados Unidos e, do Togo na África, assim como os resultados obtidos por Silva et al. (2002) com o fosfogesso de Catalão no Brasil mostraram que o $\mathrm{pH}$ do fosfogesso varia entre 2,7 e 5,6. Isso faz do fosfogesso um material não corrosivo e portanto, não perigoso de acordo com as normas NBR 10.004 da Associação Brasileira de Normas Técnicas (ABNT, 2004a) e da U.S. Environmental Protection Agency - USEPA (USEPA, 2009). Essas normas definem como perigoso todo material de $\mathrm{pH}$ inferior ou igual a 2,0 ou superior ou igual a 12,5. Ressalta-se ainda que o $\mathrm{pH}$ do fosfogesso geralmente aumenta com a idade da pilha. $\mathrm{O}$ fosfogesso analisado por Mesquita (2007) apresentou um pH de 6,8.

Os valores de massa específica dos grãos de fosfogesso encontrados na literatura internacional variam entre 2,3 e 2,5 g/cm ${ }^{3}$ (Chang et al., 1989; Felfoul et al., 2002; Tayibi et al., 2009). Segundo Silva et al. (2002), Dueñas et al. (2007) e Tayibi et al. (2009), a massa especifica aparente do fosfogesso varia entre 0,9 e $1,7 \mathrm{~g} / \mathrm{cm}^{3}$.

De acordo com Chang, Ching e Ho (1989), Felfoul et al. (2002), Ajam et al. (2009) e Tayibi et al. (2009), o fosfogesso tem uma granulometria fina e pode ser classificado como silte, por apresentar a maioria das suas partículas com diâmetros situados entre $250 \mu \mathrm{m}$ e $45 \mu \mathrm{m}$. Além disso, conforme observado por Mesquita (2007), Rufo (2009), Metogo (2010) e Matos (2011) quando é realizado o ensaio de sedimentação com o uso do defloculante hexametafosfato de sódio, ocorre um pequeno aumento no teor de argila e uma diminuição no teor da fração silte e areia.

A morfologia do fosfogesso mostra que esse resíduo é essencialmente constituído por cristais tabulares de sulfato de cálcio di-hidratado, cujo comprimento varia entre 10 e $300 \mu \mathrm{m}$ com média situada entre 50 e $60 \mu \mathrm{m}$ e uma relação largura/comprimento em torno de 1/8 (Castilhos et al.,1998; Felfoul et al., 2002; Ajam et al., 2009; Tayibi et al., 2009). Nota-se também a presença de pequenas partículas (diâmetro inferior a $10 \mu \mathrm{m}$ ), sendo a maioria delas presas na superfície dos cristais de sulfato de cálcio. Essas partículas são principalmente impurezas 
contidas no fosfogesso (Castilhos et al., 1998). A Figura 2.4 mostra a microscopia eletrônica de varredura (MEV) de um fosfogesso produzido na região de Sfax na Tunísia, onde é possível observar a existência dos cristais e das impurezas. Os ensaios feitos por Castilhos et al. (1998), Degirmenci et al.(2007) e Mesquita (2007) indicaram que o fosfogesso é um material não plástico.

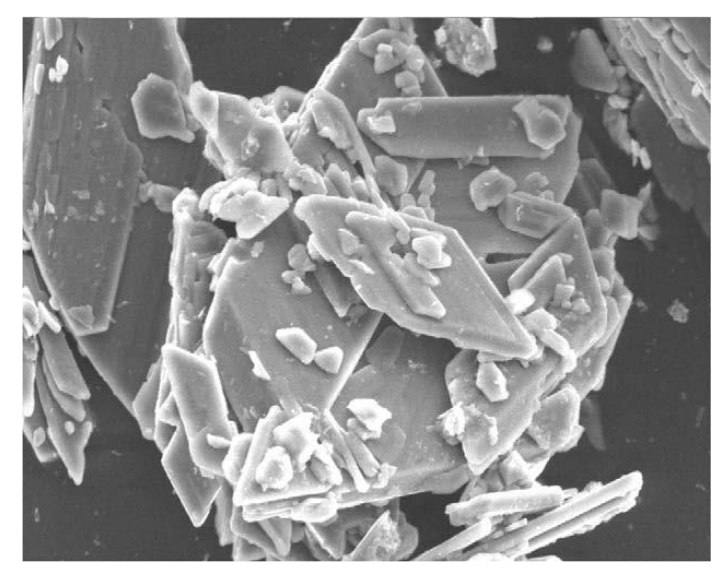

Figura 2.4 Imagem de microscopia eletrônica de varredura (MEV) de um fosfogesso produzido na região de Sfax na Tunísia. Escala: $\longleftarrow 100 \mu \mathrm{m}$ (Ajam et al., 2009).

\subsection{6 - DISPOSIÇÃO FINAL E IMPACTOS AMBIENTAIS DO FOSFOGESSO}

As enormes produções de fosfogesso vêm tornando sua gestão cada vez mais problemática para as indústrias de fertilizantes. Camichael (1988) estima que apenas $15 \%$ da produção mundial de fosfogesso é reprocessada, $28 \%$ é despejada nas águas e $58 \%$ é estocada em depósitos (pilhas). O armazenamento do fosfogesso em plataformas terrestres e sem nenhum tratamento prévio necessita de grandes áreas além de causar sérios riscos de contaminação ambiental dos solos, das águas, da atmosfera e consequentemente para a saúde humana (Berish, 1990; Tayibi et al. 2009).

\subsubsection{1 - CONTAMINAÇÃO ATMOSFÉRICA}

Segundo Berish (1990), existem dois principais mecanismos de liberação no ar dos radionuclídeos provenientes das pilhas de fosfogesso: a difusão do gás ${ }^{222} \mathrm{Rn}$ e a suspensão das partículas de radionuclídeos devido ao tráfego dos veículos e ao vento. A quantidade de radônio liberada por uma pilha de fosfogesso depende de vários fatores: a atividade específica do ${ }^{226} \mathrm{Ra}$ no fosfogesso, a quantidade de radônio liberada por unidade de ${ }^{226} \mathrm{Ra}$ produzida, a pressão atmosférica, o coeficiente de difusão do radônio no fosfogesso (incluindo o teor de umidade e a porosidade), a superfície da pilha, a cobertura vegetal e as condições climáticas. 
O teor de umidade elevado ou a presença de água na superfície da pilha reduz consideravelmente a velocidade de exalação do ${ }^{222} \mathrm{Rn}$. Essa exalação não é uniforme na superfície de uma mesma pilha por causa da não uniformidade da distribuição do ${ }^{226} \mathrm{Ra}$ na pilha (Windham \& Horton, 1980; Berish 1990).

Dueñas et al. (2007) analisaram a exalação do ${ }^{222} \mathrm{Rn}$ das pilhas de fosfogesso ativas, restauradas e não restauradas da região de Huelva na Espanha. O processo de restauração deuse pela cobertura das pilhas de fosfogesso por uma camada de solo de $25 \mathrm{~cm}$ de espessura, seguido por revegetação da mesma. As medidas foram efetuadas durante 24 horas. Nas pilhas ativas, foi medida uma exalação de $0,523 \mathrm{~Bq} / \mathrm{m}^{2} / \mathrm{s}$. Esse valor foi duas vezes maior que os obtidos para as pilhas não restauradas $\left(0,262 \mathrm{~Bq} / \mathrm{m}^{2} / \mathrm{s}\right)$ e oito vezes para as restauradas $(0,065$ $\mathrm{Bq} / \mathrm{m}^{2} / \mathrm{s}$ ). Nas pilhas de fosfogesso de Catalão no Brasil, Silva et al. (2002) mostraram que a exalação do ${ }^{222} \mathrm{Rn}$ variava entre $0,35 \mathrm{~Bq} / \mathrm{m}^{2} / \mathrm{s}$ e $0,69 \mathrm{~Bq} / \mathrm{m}^{2} / \mathrm{s}$. Todos esses valores foram inferiores a $0,74 \mathrm{~Bq} / \mathrm{m}^{2} / \mathrm{s}$, limite máximo permitido pela USEPA (2009).

Rabi \& Mohamad (2006) modelaram e simularam numericamente os fluxos de calor nas pilhas de fosfogesso a fim de determinar sua influência na liberação do gás ${ }^{222} \mathrm{Rn}$ na atmosfera. A pilha foi modelada em duas dimensões, na forma de retângulo e com porosidade e permeabilidade constantes. Os pesquisadores aplicaram os conceitos de Darcy - Brinkman Boussinesq para avaliar os fluxos de ar nas pilhas. As temperaturas do terreno abaixo das pilhas foram consideradas constantes e admitiu-se que aumentavam exponencialmente quando esse terreno era exposto à pressão atmosférica. Esse estudo mostrou que os movimentos de convecção natural do calor que ocorrem nas pilhas de fosfogesso influenciam pouco no fluxo de emanação do ${ }^{222} \mathrm{Rn}$ na atmosfera.

Jang et al. (2005) desenvolveram um modelo matemático para estimar a emanação do ${ }^{222} \mathrm{Rn}$ provenientes de alvenarias feitas a base de fosfogesso e prever o seu impacto sobre a saúde de moradores de uma peça de $1 \mathrm{~m}^{3}$ construída com esses materiais. As medidas foram feitas com base em dois tipos de alvenaria de espessuras e atividade de ${ }^{222} \mathrm{Rn}$ diferentes: FG1 (2,2 cm e $259 \mathrm{~Bq} / \mathrm{kg})$ e FG2 (3,7 cm e $289 \mathrm{~Bq} / \mathrm{kg})$. As medidas foram efetuadas durante 133 horas para o FG1 e 144 horas para o FG2. Os resultados estimados pelo modelo para o FG1 foi de $77,7 \mathrm{~Bq} / \mathrm{m}^{3}$ e a exalação medida foi $78,07 \mathrm{~Bq} / \mathrm{m}^{3}$. Para o FG2 os valores obtidos pelo modelo e por medição foram respectivamente $139,12 \mathrm{~Bq} / \mathrm{m}^{3}$ e $136,16 \mathrm{~Bq} / \mathrm{m}^{3}$. Esses resultados 
mostraram a boa eficiência do modelo proposto. Nesse mesmo sentido, estudos realizados por Máduar et al., (2011) mostram que casas construídas com placas de fosfogessos produzidos no Brasil não apresentam riscos radioativos adicionais à saúde dos ocupantes.

Roessler (1990) estudou a emanação de ${ }^{222} \mathrm{Rn}$ em pavimentos asfálticos construídos com fosfogesso estabilizado com cimento (SPC) e misturas de fosfogesso com areia, cascalho e granito. O fosfogesso foi misturado nas proporções de 20,40 e $80 \%$ e foi construído um trecho com $100 \%$ de SPC. As pistas foram revestidas por um concreto betuminoso usinado a quente. As medições foram realizadas em onze seções. Os resultados obtidos mostraram que a emissões radioativas das camadas de base foram proporcionais ao teor de fosfogesso nas misturas da seguinte forma: $20 \%$ de FG $\left(1 \mathrm{pCi} / \mathrm{m}^{2} / \mathrm{s}\right), 40 \%\left(2 \mathrm{pCi} / \mathrm{m}^{2} / \mathrm{s}\right)$ e $80 \%\left(4 \mathrm{pCi} / \mathrm{m}^{2} / \mathrm{s}\right)$. Com $100 \%$ de fosfogesso estabilizado com cimento (SPG) foi medida uma radiação de apenas $1 \mathrm{pCi} / \mathrm{m}^{2} / \mathrm{s}$. Para os aterros de $60 \mathrm{~cm}$ de espessuras, a emanação de ${ }^{222} \mathrm{Rn}$ variou de 2 a $4 \mathrm{pCi} / \mathrm{m}^{2} / \mathrm{s}$. Esses valores são inferiores aos limites prescritos pela EPA (20pCi $\left./ \mathrm{m}^{2} / \mathrm{s}\right)$. Roessler (1990) afirma que o revestimento reduz o fluxo radioativo proveniente das bases. Porém, as medidas de exalação de ${ }^{222} \mathrm{Rn}$ feitas na superfície do revestimento foram mais elevadas do que esperado. Essa situação levou o autor a questionar o potencial radioativo do concreto asfáltico utilizado na pista, já que esse parâmetro não foi medido antes da sua aplicação. Observações semelhantes foram feitas nos estudos de Metogo (2010) em pista experimental construída com misturas de solo fino, fosfogesso e cal e permitiram concluir que a utilização de fosfogesso em camadas de base de pavimento asfáltico não oferece riscos ao meio ambiente e à população.

\subsubsection{2 - CONTAMINAÇÃO DOS SOLOS E DAS ÁGUAS SUBTERRÂNEAS}

A segunda preocupação ambiental com as pilhas de fosfogesso é a contaminação dos solos, das águas subterrâneas e marinhas por lixiviação das impurezas do fosfogesso (Berish, 1990). Essa preocupação levou vários pesquisadores a avaliarem as características de lixiviação das diferentes impurezas do fosfogesso. Foi nesse sentido que Haridasan et al. (2002) estudaram a lixiviação ${ }^{226} \mathrm{Ra}$ das amostras de fosfogesso da região de Kochi na Índia, utilizando como líquido lixiviador a água destilada $(\mathrm{pH}=6,0)$ e águas de chuvas $(\mathrm{pH}=5,0$ a 5,8). A atividade inicial do ${ }^{226} \mathrm{Ra}$ nas amostras era de $8,5 \mathrm{~Bq} / \mathrm{l}$. Os resultados mostraram que o ${ }^{226} \mathrm{Ra}$ é menos lixiviado pela água de chuva $(0,09-0,28 \mathrm{~Bq} / \mathrm{l})$ do que pela água destilada $(0,08-0,38 \mathrm{~Bq} / \mathrm{l})$. Os autores estimaram que a atividade total do ${ }^{226}$ Ra na água de chuva foi de $18 \%$ e de $24 \%$ na 
água destilada. Esse último valor é próximo do encontrado por Azouazi et al. (2001) com o fosfogesso da região de Khourigba no Marrocos, isto é 26\%. Haridasan et al.(2002) explicam que essa diferença é devida à presença na água de chuva dos íons de sulfato provenientes da atmosfera. Observou-se que a maioria das taxas de lixiviação ${ }^{226} \mathrm{Ra}$ determinadas foram maiores que o limite permitido pela Bureau of Indian Drinking Water Standards $(0,1 \mathrm{~Bq} / \mathrm{l})$. Porém, ficaram abaixo do limite indicado pela Organização Mundial da Saúde (1 Bq/l). Esse fato é confirmado com o estudo do fosfogesso de Khourigba cuja atividade do ${ }^{226} \mathrm{Ra}$ lixiviado é de 0,2 Bq/1 (Azouazi e al., 2001).

Burnett e Elzeman (2001) estudaram o processo de migração dos radionuclídeos e outras impurezas nas pilhas de fosfogesso da Flórida e no seu redor. Para isso, foram cavados 70 poços de monitoramento em volta das pilhas até atingir o aquífero superficial e 11 poços em cima da pilha de fosfogesso mais antiga. Os pesquisadores observaram que os fluidos extraídos dos poços da pilha antiga tinham baixo valor de $\mathrm{pH}(2,43 \pm 0,10)$, uma alta concentração iônica e uma quantidade elevada de Sólidos Totais Dissolvidos (STD) estimada em $18700 \pm 2300 \mu \mathrm{g} / \mathrm{kg}$. Já para os poços em volta das pilhas, os valores de $\mathrm{pH}$ eram mais elevados $(6,33 \pm 0,65)$ com uma menor quantidade de STD $(3300 \mu \mathrm{g} / \mathrm{kg})$, sendo esses valores mais próximos das propriedades das águas subterrâneas normais. Os autores ainda notaram que as concentrações de alguns componentes como $\mathrm{SiO}_{2}, \mathrm{PO}_{4}^{-3}$ e $\mathrm{F}^{-}$eram muito mais elevadas na pilha do que no aquífero. A concentração de $\mathrm{F}^{-}$na pilha, por exemplo, é mais de 1900 vezes maior do que no aquífero superficial. Isso mostra que a contaminação das águas subterrâneas pelos ácidos do fosfogesso é muito baixa. Do ponto de vista radioquímico, os poços da pilha apresentaram atividades excepcionalmente elevada de ${ }^{238} \mathrm{U}(10-17 \mathrm{~Bq} / \mathrm{l})$, ${ }^{222} \mathrm{Rn}(300-1200 \mathrm{~Bq} / \mathrm{l})$ e ${ }^{210} \mathrm{~Pb}(7-70 \mathrm{~Bq} / \mathrm{l})$ em comparação à água aquífera. Além disso, os autores observaram que atividade do ${ }^{226} \mathrm{Ra}$ na pilha $(0,1-0,2 \mathrm{~Bq} / \mathrm{l})$ é menor que na maioria dos poços em volta e ligeiramente mais elevada que nas águas aquíferas normais. Esse resultado permitiu afirmar que as pilhas de fosfogesso não são as fontes dos ${ }^{226}$ Ra presentes nas águas aquíferas superficiais.

O estudo da lixiviação do $\mathrm{Cd}, \mathrm{Cu}, \mathrm{U}$, e $\mathrm{Zn}$ do fosfogesso da Síria foi realizado por Masri et al. (2004). No ensaio de lixiviação contínua durante 60 minutos com água destilada, $50 \%$ dos elementos $\mathrm{Cd}, \mathrm{Cu}$ e $\mathrm{Zn}$ foram dissolvidos, enquanto essa porcentagem foi de $20 \%$ para o U. Já quando foram realizadas medidas sucessivas entre os intervalos de tempo variando de 10 a 
120 minutos, o $\mathrm{Zn}$ apresentou a maior susceptibilidade à lixiviação com uma taxa de transferência de 97\%. Na ordem decrescente, seguem o Cu (68\%), Cd (57\%) e U (31\%). Realizando o ensaio com uma solução ácida, esses autores concluíram que os elementos se dissolveram na seguinte sequência: U(31\%), Cd(25\%), $\mathrm{Zn}(10 \%)$ e $\mathrm{Cu}(10 \%)$. Aumentando a acidez da solução lixiviadora com adição de $\mathrm{H}_{2} \mathrm{SO}_{4}$ houve aumento da solubilidade dos diferentes elementos.

Com foco na aplicação do fosfogesso em pavimentação, Mesquita (2007) estudou a lixiviação de alguns metais pesados nas misturas de um fosfogesso de Catalão (GO) e do solo tropical de Goiânia (GO) de acordo com a norma NBR 10.005 (ABNT, 2004b). Além do fosfogesso e do solo, as misturas analisadas foram definidas da seguinte forma:

- Mistura A: 50\% Solo + 50\% Fosfogesso;

- Mistura B: $80 \%$ Solo + 20\% Fosfogesso;

- Mistura C: $20 \%$ Solo + 80\% Fosfogesso.

A Tabela 2.2 mostra os resultados obtidos nesse ensaio. Observa-se que esses resultados se encontram dentre dos limites especificados pela norma NBR 10.004 (ABNT, 2004c).

Tabela 2.2. Resultados das características químicas do extrato lixiviado das amostras estudadas (modificado de Mesquita, 2007)

\begin{tabular}{lccccccc}
\hline \multirow{2}{*}{ Parâmetros } & $\begin{array}{c}\text { Limites } \\
\text { máximos pela } \\
\text { NBR 1004 }\end{array}$ & \multicolumn{2}{c}{ Resultados das características químicas do lixiviado (mg/l) } & \multirow{2}{*}{ L.D (mg/l) } \\
\cline { 3 - 6 } & Fosfogesso & Solo & Mistura A & Mistura B & Mistura C & \\
\hline Arsênico & 1,0 & $<0,20$ & $<0,20$ & $<0,20$ & $<0,20$ & $<0,20$ & $<0,20$ \\
Bário & 70,0 & $<0,10$ & $<0,10$ & $<0,10$ & $<0,10$ & $<0,10$ & $<0,10$ \\
Cádmio & 0,5 & $<0,05$ & 0,05 & 0,05 & 0,06 & 0,05 & 0,05 \\
Chumbo & 1,0 & $<0,20$ & 0,24 & 0,37 & $<0,20$ & $<0,20$ & $<0,20$ \\
Cromo Total & 5,0 & $<0,20$ & $<0,20$ & $<0,20$ & $<0,20$ & $<0,20$ & 0,2 \\
Mercúrio & 0,1 & $<0,10$ & $<0,10$ & $<0,10$ & $<0,10$ & $<0,10$ & 0,1 \\
Prata & 5,0 & $<0,05$ & $<0,05$ & $<0,05$ & $<0,05$ & $<0,05$ & 0,05 \\
Selênio & 1,0 & $<0,20$ & $<0,20$ & $<0,20$ & $<0,20$ & $<0,20$ & 0,2 \\
Fluoretos & 150,0 & 4,36 & $<0,10$ & 10,1 & 6,87 & 15,4 & 1 \\
\hline
\end{tabular}

Obs. L.D. Limites de Detecção/ abaixo da sensibilidade analítica, resultados obtidos considerando-se massa (peso) para a análise igual a 2 (duas) gramas e a sensibilidade dos equipamentos utilizados.

Nifong \& Harris (1993) monitoraram o comportamento ambiental das pistas experimentais a base de fosfogesso dos municípios de Polk e Columbia nos Estados Unidos. Durante dois anos e meio foi analisada a qualidade das águas subterrâneas, a atividade do ${ }^{222} \mathrm{Ra}$ no solo e 
sua exalação no ar. Desses estudos, os autores concluíram que o impacto ambiental em longo prazo da utilização do fosfogesso em pavimentação é mínimo.

\subsection{7 - UTILIZAÇÃO DO FOSFOGESSO}

Os problemas relacionados ao armazenamento do fosfogesso e seus potenciais riscos ambientais incentivaram pesquisadores a buscarem aplicações econômicas e ambientalmente corretas desse subproduto. Por ser construído majoritariamente de sulfato de cálcio hidratado, o fosfogesso tem despertado interesse cada vez maior em vários ramos da atividade industrial, em particular na agricultura, indústria de enxofre e do cimento, na construção civil e em geotecnia. Em algumas delas, a utilização do fosfogesso tem apresentado limitações técnicas quando não submetido a um processo de purificação. A seguir são apresentados alguns detalhes dessas utilizações.

\subsubsection{1 - AGRICULTURA}

Nessa área, os solos básicos (com teor elevado de sódio) são considerados problemáticos, pois tendem a endurecer, limitando assim a penetração das águas de chuvas assim como o desenvolvimento das raízes das plantas. Para tornar os solos menos básicos, é comum utilizar o fosfogesso. Uma vez adicionado, o fosfogesso aumenta a porosidade do solo e facilita de fato, a infiltração da água. Essa propriedade é também válida para tratar os solos altamente intemperizados e os de regiões áridas. O fosfogesso pode também ser utilizado nas regiões onde a irrigação é feita com águas salgadas para lavar os excessos de sais e, impedir que os solos se tornem básicos. Essa técnica foi utilizada, por exemplo, na Holanda, para recuperar os solos salgados deixados após a construção de diques para fins agrícolas (Lloyd, 1985; Sumner et al., 1986). Além disso, o fosfogesso pode ser utilizado para reduzir a quantidade de alumínio nos solos ácidos (Sumner et al.,1986). Por outro lado, é possível utilizar o fosfogesso para reduzir a concentração de alguns íons metálicos no solo por um mecanismo de fixação ou de promoção das condições que favorecem a lixiviação desses íons. Essa alternativa é valiosa principalmente nas regiões onde as práticas agrícolas e de fertilização conduziram a uma intoxicação das plantas por causa de altas concentrações iônicas no solo (Lloyd, 1985). O fosfogesso é também utilizado como fonte de enxofre e cálcio para as plantas, sendo que esses elementos são de grande importância para seu crescimento. $\mathrm{O}$ 
enxofre é assimilável pelas plantas em forma de molécula de sulfato e sua presença não altera o pH no solo.

Apesar do grande potencial de uso do fosfogesso na agricultura, alguns problemas dificultam seu emprego. Geralmente, esse subproduto encontra-se úmido, o que dificulta bastante sua manipulação. Quando seco, seu manejo é melhorado, mas sua viabilidade econômica é reduzida. Por outro lado, por conter radionuclídeos, existe a preocupação de serem absorvidos pelas plantas e, por conseguinte, transmitidos ao ser humano. No Brasil, a recente resolução CNEN 179/14 de novembro de 2014 (CNEN, 2014a) regulamenta, entre outros, a utilização do fosfogesso na agricultura. Essa resolução estabelece como nível de dispensa para o uso do fosfogesso nesse ramo o valor limite de $1000 \mathrm{~Bq} / \mathrm{kg}$ para concentração de atividade de rádio226 ou rádio-228, para cada radionuclídeo.

\subsubsection{2 - PRODUÇÃO DE ENXOFRE}

A conversão do fosfogesso em enxofre é, sem dúvida, de grande interesse para as indústrias de fertilizantes porque possibilita a produção posterior do ácido sulfúrico, importante insumo para a fabricação dos adubos. Esse interesse vem motivando alguns pesquisadores a elaborarem novas técnicas para a produção do enxofre a partir do fosfogesso. Segundo Lloyd (1985), todos os processos de produção do enxofre a partir do fosfogesso necessitam, no mínimo, de um combustível para aquecer o fosfogesso durante a reação e uma fonte de carbono para reagir com esse resíduo. As reações básicas para produzir o enxofre nessas condições estão apresentadas nas Equações 2.2 a 2.5:

$$
\begin{aligned}
& \mathrm{CaSO}_{2}+2 \mathrm{C} \rightarrow \mathrm{CaS}+2 \mathrm{CO}_{2} \\
& \mathrm{CaS}+\mathrm{H}_{2} \mathrm{O}+\mathrm{CO}_{2} \rightarrow \mathrm{CaCO}_{3}+2 \mathrm{H}_{2} \mathrm{~S} \\
& 2 \mathrm{H}_{2} \mathrm{~S}+3 \mathrm{O}_{2} \rightarrow 2 \mathrm{SO}_{2}+2 \mathrm{H}_{2} \mathrm{O} \\
& 2 \mathrm{H}_{2} \mathrm{~S}+\mathrm{SO}_{2} \rightarrow 3 \mathrm{~S}+2 \mathrm{H}_{2} \mathrm{O}
\end{aligned}
$$

A Equação 2.2 descreve a tratamento térmico do fosfogesso. O sulfeto de cálcio $(\mathrm{CaS})$ sólido presente no reator é imerso numa água em ebulição, onde reage com o dióxido de carbono (Equação 2.3). Por seguinte, o sulfeto de hidrogênio $\left(\mathrm{H}_{2} \mathrm{~S}\right)$ obtido é queimado pelo dióxido (Equação 2.4). Finalmente, o sulfeto de hidrogênio reage com o dióxido de sulfato para produzir o enxofre (Equação 2.5). 


\subsubsection{3 - INDÚSTRIA CIMENTEIRA}

Exceto por suas impurezas, o fosfogesso di-hidratado $\left(\mathrm{CaSO}_{4} 2 \mathrm{H}_{2} \mathrm{O}\right)$ apresenta a mesma composição química que o gesso natural. Nesse sentido, o fosfogesso di-hidratado é de uso comum como aditivo na indústria cimenteira. Por esse motivo, a substituição do gesso natural por esse subproduto vem sendo pesquisada cada vez mais. Quanto mais escassas as jazidas de gesso próximas às usinas de fertilizantes, maior o interesse para tais investigações. Nesse ramo, por exemplo, Kacimi et al. (2006) observaram que a adição do $10 \%$ de fosfogesso ao cimento permite a clinquerização total do cimento com temperaturas menores, $1200^{\circ} \mathrm{C}$ ao invés de $1470^{\circ} \mathrm{C}$ como ocorre no processo tradicional. Isso torna o processo $25 \%$ mais eficiente e aumenta a vida útil dos fornos. Além disso, foi observado que, em comparação ao método tradicional, a utilização do fosfogesso preservou perfeitamente a estrutura cristalina da fase silicata, o que contribuiu para o aumento das propriedades físicas e mecânicas do cimento.

Mun et al. (2007) experimentaram um cimento não convencional a base de mistura fosfogesso (di-hidratado e anidro), resíduos de cal e escórias granuladas de alto-forno, um subproduto da indústria metalúrgica. Primeiramente, o fosfogesso foi lavado por $0,5 \%$ de leite de cal a $20^{\circ} \mathrm{C}$ durante $5 \mathrm{~min}$. Em seguida, o fosfogesso foi desidratado a $80^{\circ} \mathrm{C}$. Depois, uma parte deste foi calcinada a $450^{\circ} \mathrm{C}$ para o transformar em anidro. Os materiais obtidos foram misturados com a escória granulada do alto-forno para formar o cimento não convencional. Para os cimentos feitos com fosfogesso di-hidratado ou resíduos de cal, foram observadas baixas resistências iniciais e elevadas resistências finais. Quando não é necessário obter grandes resistências iniciais, essas misturas são economicamente viáveis em comparação com aquelas realizadas com o fosfogesso anidro. Foi observado também que, embora as resistências iniciais à compressão obtidas com o cimento não convencional fossem muito semelhantes às encontradas com o cimento Portland convencional, as resistências finais foram atingidas com idade maior devido às reações continuas entre a escória e o fosfogesso.

\subsubsection{4 - CONSTRUÇÃO CIVIL}

Diversos produtos e misturas de materiais foram estudadas por pesquisadores para fins de construção civil. Para limitar os efeitos deletérios das impurezas tanto sobre a qualidade dos materiais obtidos quanto para a saúde humana, o fosfogesso foi, na maioria dos casos, submetido a um processo de purificação antes do seu uso. Hoje no Brasil, a resolução CNEN 
$\mathrm{n}^{\mathrm{o}}$ 189/15 de agosto 2015 (CNEN, 2015) regulamenta a utilização do fosfogesso na construção civil.

Nesse mesmo propósito, Kumar (2002) investigou as propriedades mecânicas das misturas de cinzas volantes, cal e fosfogesso calcinado visando sua utilização na fabricação de alvenarias de baixos custos. Depois da moldagem, as alvenarias foram deixadas em cura durante uma semana para que ganhassem resistência necessária para suas manipulações. Em seguida, foram submetidas a um teste de durabilidade. Para isso, foram colocadas num ambiente agressivo de solução de sulfato a $25 \pm 2^{\circ} \mathrm{C}$. Algumas amostras de composições idênticas foram curadas na temperatura ambiente $\left(23 \pm 2^{\circ} \mathrm{C}\right)$ e outras a $50^{\circ} \mathrm{C}$. Um dia antes de serem submetidos ao ensaio de compressão simples, as amostras foram retiradas da água. As amostras foram ensaiadas depois de tempos de cura de 24, 48, 72 e 96 dias. Para as amostras curadas na temperatura ambiente, foi observado um aumento da resistência com o tempo de cura. Porém, as maiores variações de resistências foram observadas apenas nos primeiros dias. Para uma proporção fixa de cinzas volantes, foi observado um aumento da resistência com o aumento do teor de fosfogesso. Foi verificado também que as resistências à compressão das alvenarias diminuíam com o aumento do teor de cinzas volantes. Porém, a resistência à compressão das amostras com maior concentração de cinzas volantes (5,9 $\mathrm{N} / \mathrm{mm}^{2}$ ) foi superior ao limite exigido para tijolos de argilas na Índia $\left(3,5 \mathrm{~N} / \mathrm{mm}^{2}\right)$. Para o mesmo tempo de cura, as alvenarias curadas a $50^{\circ} \mathrm{C}$ apresentaram melhor desempenho em comparação às curadas na temperaturas ambiente. As alvenarias com maior teor de fosfogesso apresentaram uma melhor durabilidade. Isso possibilita o uso de tais elementos nas fachadas. Resultados parecidos foram obtidos por Min et al. (2008).

Ajam et al. (2009) estudaram a incorporação do fosfogesso na fabricação de tijolos a base de argila. $\mathrm{O}$ objetivo dessa pesquisa era substituir a areia tradicionalmente misturada à argila para produzir esse tipo de tijolo. O fosfogesso foi adicionado nas proporções de 5, 15, 30 e $40 \%$. Foi realizada uma mistura com $10 \%$ de areia e de $15 \%$ de fosfogesso para limitar as trincas e os riscos radioativos do produto. Os tijolos foram aquecidos até $850^{\circ} \mathrm{C}$ durante 14 horas. No final do processo, os autores observaram que apenas a mistura com $40 \%$ de fosfogesso trincou. Também foi realizado um teste de absorção de água. Nesse teste foi observado um aumento do coeficiente de absorção com o teor de fosfogesso. Entretanto, o valor máximo obtido $(13,4 \%)$ foi inferior ao limite das normas tunisianas $(15 \%)$. Da mesma 
forma, todos os tijolos apresentaram uma resistência maior que o limite de 2,5 MPa permitido pelas referidas normas. Esse estudo validou a aplicação desse tipo de produto na construção civil. Porém, os autores recomendam que sejam preferencialmente utilizados os tijolos com mistura de fosfogesso (15\%), areia (10\%) e argila (75\%) de forma a limitar os riscos de trincas.

No Brasil, Kanno et al. (2008) desenvolveram um método para transformar o fosfogesso em produto cerâmico de elevada resistência à compressão. Esse método, chamado Umedecimento Compactação e Secagem - UCOS consiste em submeter o fosfogesso a uma fase de prétratamento (desidratação) durante a qual ele é aquecido até as condições hemi-hidratadas. Por seguinte, o fosfogesso hemi-hidratado obtido é umedecido e colocado num molde no qual é submetido a uma compressão. O molde pode ser de diversos formatos, dependendo da aplicação que se pretende dar ao produto final. A compressão faz com que as partículas de fosfogesso se aglomerem e formem um corpo rígido e resistente. O tempo de compressão é de alguns minutos e, em seguida, o material é retirado dos moldes para secagem e uso. Essa fase leva em torno de 30 minutos. Esse método permite que o fosfogesso seja utilizado em construção civil até como elemento estrutural, já que as resistências obtidas (90 MPa) foram superiores aos valores médios encontrados para o concreto (50 MPa).

Ferrari (2012) por sua vez estudou misturas de fosfogesso com resíduos da produção de cal e areia de extração de ouro para a formação de novos materiais de construção civil. Os resultados obtidos pelos ensaios de resistência à compressão simples atingiram o valor de 8,3 MPa no terceiro dia de cura e de 13,5 MPa no nono dia. A mistura apresentou coeficiente de resistência à água de $0,95 \%$ aos 28 dias, absorção de água de 8,6\% e valores de dilatação no terceiro dia de $1 \%$ e 1,5\% após um ano e meio de cura. A autora conclui que esses valores satisfizeram as exigências da NBR 7.170 (ABNT, 1983) para tijolos maciços de classes A, B e C e blocos cerâmicos de classes 15 e 25 . Outros estudos bem sucedidos e promissores para a utilização do fosfogesso na construção civil foram realizados por Zhou et al. (2012), Yang et al. (2013) e Zhou et al. (2014).

\subsubsection{5 - PAVIMENTAÇÃO}

Por ser uma área da indústria da construção que emprega enormes quantidades de materiais, a introdução do fosfogesso em pavimentação sempre despertou muitos interesses. Os trabalhos 
pioneiros nessa linha foram implementados pelo Laboratoire Central des Ponts et Chaussées - LCPC na França e pelo Florida Institute of Phosphore Research - FIPR nos Estados Unidos, no final da década 70. No Brasil, os estudos sobre o uso do fosfogesso em pavimentação iniciaram-se na Universidade de São Paulo, em 1995 (Parreira et al., 2003). Aplicado sozinho, o fosfogesso di-hidratado apresenta características geotécnicas ruins além de grande sensibilidade a água.

Os trabalhos realizados por Parreira et al. (2003) tiveram como objetivo avaliar a influência do tipo de cimento na resistência à compressão simples e expansão das misturas de fosfogesso estabilizado com cimento visando sua utilização na construção de pavimentos. Para isso, foram utilizados cimentos com diferentes teores de $\mathrm{C}_{3} \mathrm{~A}$ : CP III-40 (2,4\% $\left.\mathrm{C}_{3} \mathrm{~A}\right)$, CP II E-32 $\left(5,0 \% \mathrm{C}_{3} \mathrm{~A}\right)$ e $\mathrm{CP}$ V-ARI $\left(7,5 \% \mathrm{C}_{3} \mathrm{~A}\right)$. As amostras foram compactadas com as energias Proctor normal e modificado e por seguinte, curadas durante 1, 3, 7, 28 e 84 dias na temperatura de $24^{\circ} \mathrm{C}$ e umidade relativa igual a $100 \%$. Os resultados dessa pesquisa mostraram que as resistências à compressão das misturas aumentam com o teor de cimento, o tempo de cura e a energia de compactação. Foi observado que as amostras compactadas na energia modificada apresentaram resistências até $130 \%$ maiores que para aquelas compactadas na energia normal. Os autores verificaram que o aumento da porcentagem de $\mathrm{C}_{3} \mathrm{~A}$ nos cimentos reduz a resistência das misturas com o tempo de cura. Os valores de resistência obtidos foram aproximadamente iguais à metade dos obtidos para as misturas tradicionais de solo lateritíco estabilizado com cimento. Quanto à expansão, os resultados mostraram que as energias de compactação não apresentam uma importância significativa nas misturas. $\mathrm{O}$ aumento do teor de $\mathrm{C}_{3} \mathrm{~A}$ nos cimentos reduziu a expansão das amostras. Os autores ressaltam que as expansões medidas foram da mesma ordem de grandeza que as dos materiais tradicionalmente utilizados em pavimentação.

Degirmenci et al. (2007) estudaram a estabilização de dois solos turcos com fosfogesso, cimento e cinzas volantes. As misturas foram curadas durante dois dias numa temperatura de $21^{\circ} \mathrm{C}$. Foi observado que as estabilizações com cimento, e com cimento e fosfogesso reduziram a plasticidade e aumentaram os limites de liquidez dos solos. As densidades secas aparentes máximas aumentaram com o teor de cimento e de fosfogesso, enquanto a umidade ótima diminuiu. Já para os solos estabilizados com cinzas volantes foi notada uma diminuição significativa da plasticidade apenas para o solo altamente plástico. Por outro lado, as 
densidades secas aparentes e as umidades ótimas diminuíram com o aumento das cinzas volantes e do fosfogesso. Quanto à resistência à compressão simples, os valores obtidos para as misturas foram todos superiores aos do solo não estabilizado. Além disso, foi percebido o aumento da resistência à compressão com o aumento do teor de cimento.

O trabalho de Shen et al. (2007) investigou as características mecânicas das misturas fosfogesso, cinzas volantes e cal visando sua utilização na construção das camadas de bases de pavimentos semi-rígidos. O estudo tinha o objetivo de comparar o desempenho de tais misturas com as de cinzas volantes-cal e solo-cimento tradicionalmente utilizadas em pavimentação na China. Para os ensaios de compressão, as misturas foram moldadas num molde cilíndrico e depois, deixadas em cura em sacos plásticos na temperatura de $25 \pm 2^{\circ} \mathrm{C}$. As amostras foram imersas em água 24 horas antes da realização do ensaio. Os resultados permitiram observar que as misturas solo-cimento são as que apresentaram as piores resistências à compressão simples para todas as idades. As misturas de fosfogesso, cinzas volantes e cal tiveram as maiores resistências para todas as idades. Além disso, essas misturas apresentaram as maiores resistências iniciais.

Na Flórida (EUA), Kenlay \& Chang (1988) e Ho et al. (1988) testaram pistas a base de misturas de fosfogesso e areia. Os autores apontaram a facilidade de trabalhar com essas misturas além do fato que de apresentarem resistências superiores às das misturas de argila com areia tradicionalmente utilizadas. Recentemente, Cuadri et al. (2014) deram início aos estudos referentes à utilização do fosfogesso como modificador de cimento asfáltico petróleo. No estudo, a adição desse subproduto ao betume melhorou significativamente a viscosidade do ligante quando comparado com o gesso comercial nas mesmas. Os autores explicam que este tipo de comportamento é devido a novas ligações fortes envolvendo impurezas de fosfatos presentes no fosfogesso, o que não ocorre com o gesso comercial.

Contribuindo para o uso do fosfogesso na prática rodoviária brasileira, Mesquita (2007) estudou as misturas de solos tropicais finos da região de Goiânia-GO com um fosfogesso dihidratado produzido no município de Catalão-GO. A autora observou que as misturas com $80 \%$ de solo e $20 \%$ de fosfogesso apresentavam melhores resistências e podiam ser utilizadas na construção de aterros, camadas de reforço de subleito até sub-base de pavimentos. $\mathrm{O}$ trabalho de Faria (2007) mostrou que a adição da cal às referidas misturas aumentava 
consideravelmente suas resistências. Contudo, ao checar a viabilidade mecânica dessas misturas com um solo argiloso plástico da região de Catalão-GO, Rufo (2009) observou que havia formação de etringita $\left(\mathrm{Ca}_{6} \mathrm{Al}_{2}\left(\mathrm{SO}_{4}\right)_{3}(\mathrm{OH})_{12}, 26 \mathrm{H}_{2} \mathrm{O}\right)$ acompanhada de uma queda de resistência e de um aumento exagerado da expansão (18,5 a 29,5\%) e dos limites de consistência ao acrescentar água na mistura de solo-fosfogesso-cal. Esses resultados inviabilizaram o uso de solos plásticos nas referidas misturas. Metogo (2010) iniciou a avaliação do comportamento estrutural de misturas de fosfogesso, solo tropical da região de Aparecida de Goiânia-GO e cal CH-III, quando utilizadas em camadas de base de pavimento asfáltico em uma pista experimental. Para tanto, o autor realizou ensaios de laboratório para caracterizar as misturas a serem executadas em campo. Em seguida, foi construída uma pista experimental constituída por quatro subtrechos com misturas solo $(80 \%)+$ fosfogesso $(20 \%)$, solo $(80 \%)+$ fosfogesso $(11 \%)+$ cal $(9 \%)$, solo $(91 \%)+$ cal $(9 \%)$ e cascalho $(100 \%)$ compondo a camada de base. Esse último é o material tradicionalmente utilizado na região e para tanto, serviu de referência para os demais. Durante a construção dessa pista, foram realizados ensaios de frasco de areia e speedy para o controle de compactação dos materiais em campo, ensaios de Viga Benkelman para determinar as bacias de descolamentos dos trechos estudados e ensaios de prova de carga sobre placa para determinar as deformações das camadas quando sujeitas a carregamentos estáticos. Também foram realizados ensaios de Penetromêtro Dinâmico de Cone (DCP) para avaliar as resistências de ponta das camadas e inferir sobre as espessuras das mesmas. Ainda foram realizadas medições radiométricas para monitorar o impacto do fosfogesso ao meio ambiente no que diz respeito ao seu comportamento radiativo. A Figura 2.5 apresenta algumas etapas de construção da pista experimental. Para entender melhor o comportamento da pista experimental, uma segunda etapa de ensaios de campo foi realizada seis meses após a liberação do tráfego. Metogo (2010) observou-se que tanto em laboratório como em campo, a mistura solo (80\%) + fosfogesso $(11 \%)$ + cal (9\%) foi que apresentou os melhores desempenhos mecânicos, podendo, assim, ser utilizada em substituição ao cascalho para construção de pavimento de baixos custos. Porém, devem ser adotados cuidados para controlar a expansão dessa mistura devido à formação da etringita, como mencionado anteriormente. Por se tratar de um material novo, tornou-se imprescindível aprofundar os estudos laboratoriais sobre esse material e continuar o monitoramento dessa pista a longo prazo. 
Universidade de Brasília

Departamento de Engenharia Civil / FT

Programa de Pós-Graduação em Geotecnia
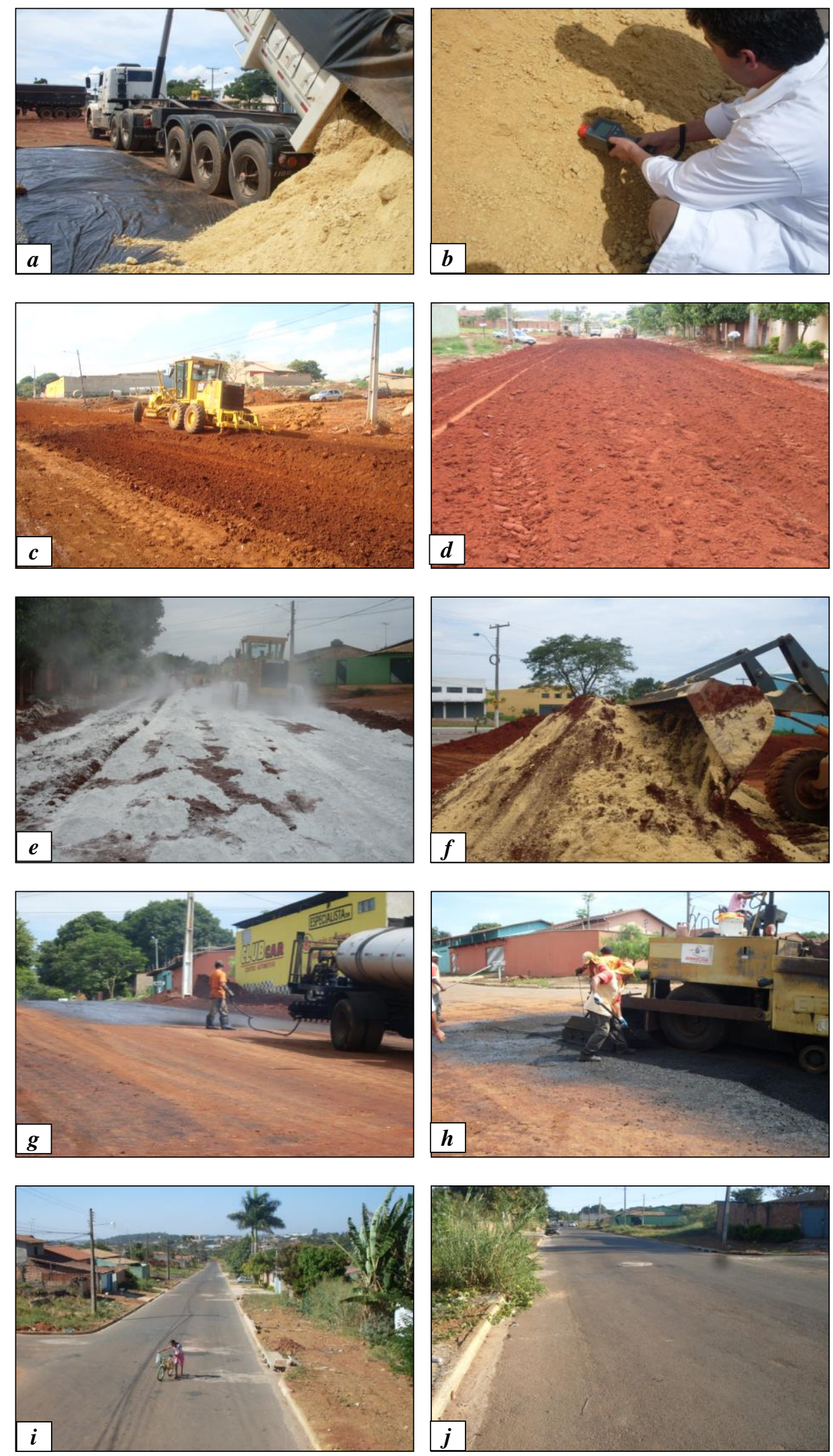

Figura 2.5 - Etapas da construção da pista experimental. (a) Fornecimento do fosfogesso em campo. (b)

Medições radiométricas. (c) Preparo do subleito. (d) Preparo da camada de base. (e) Mistura com cal. (f) Mistura do solo com fosfogesso. (g) Imprimação das camadas de base. (h) Aplicação do pré-misturado a frio. ( i) e j) Aspectos finais da pista experimental. (Metogo, 2010). 


\section{2- SOLOS TROPICAIS E PAVIMENTAÇÃO DE BAIXO CUSTO}

As técnicas rodoviárias utilizadas em pavimentação nos países em desenvolvimento são, geralmente, originárias de países já desenvolvidos. No Brasil, de maneira geral, os órgãos responsáveis pela construção de pavimentos seguem o que recomendam as normas e instruções do Departamento Nacional de Infraestrutura de Transportes - DNIT, as quais, por sua vez, se baseiam nas normas de instituições norte-americanas, tais como: American Association of State Highway and Transportation Officials - AASHTO, American Society for Testing and Materials - ASTM, Asphalt Institute - AI e Portland Cement Association - PCA. Essas normas resultaram, basicamente, de estudos do comportamento de rodovias e pistas experimentais situadas nos Estados Unidos da América e envolvem fixação de condições empíricas válidas para os ambientes e solos mais representativos daquele país. Nelas não se consideram, portanto, as particularidades relacionadas com as condições e com os solos mais frequentes no Brasil, onde, tanto os solos quanto os climas predominantes, podem ser englobados, genericamente, como do tipo "tropical úmido" (Villibor \& Nogami, 2009). Por esse motivo, vêm se encontrando várias discrepâncias entre as previsões efetuadas com a aplicação dos princípios dessas normas e procedimento e o real comportamento dos solos nas obras (Nogami \& Villibor, 1995). Esses solos eram considerados inapropriados pelos critérios tradicionais, o que levou à necessidade de se desenvolverem critérios mais apropriados, não relacionados demasiadamente aos fatores pedológicos e nem em propriedades e índices tradicionais, porém, mais ligados às propriedades mecânicas e hidráulicas dos solos compactados. Isso proporcionou o desenvolvimento de uma nova metodologia, no inicio da década de 80, que passou a ser dominada Metodologia MCT (Miniatura, Compactado, Tropical) e que inclui também nova proposta de classificação de solos tropicais.

\subsubsection{DEFINIÇÕES}

\subsubsection{SOLO}

O entendimento do que é um solo pode variar em função do ponto de vista a ser considerado: geológico, pedológico, da agronomia ou da geotecnia. último caso, cabe a definição proposta por Nogami \& Villibor (1995) que identificam o solo como material natural não consolidado, isto é, constituído de grãos separáveis por processos mecânicos ou hidráulicos relativamente suaves, com dispersão em água com o uso de aparelho dispersor de laboratório, e que podem 
ser escavados por equipamentos comuns de terraplanagem como pá carregadeira, ou motoescavotransportadora. O solo constitui a parte mais superficial da costa terrestre.

\subsubsection{SOLO TROPICAL}

Ainda segundo Nogami e Vilibor (1995), solo tropical é aquele que apresenta peculiaridades de comportamento e propriedades, relativamente aos solos não tropicais, em decorrência da atuação no mesmo de processos geológicos ou pedológicos, típicos das regiões tropicais úmidas. Os solos tropicais são agrupados em duas grandes classes:

- Os solos lateríticos (later, do latim: tijolo), são solos superficiais, típicos das partes bem drenadas das regiões tropicais úmidas, resultante de uma transformação da parte superior do subsolo pela atuação do intemperismo, por processo denominado laterização. Várias peculiaridades associam-se ao processo de laterização sendo, as mais importantes do ponto de vista tecnológico, o enriquecimento no solo de óxidos hidratados de ferro ou alumínio, e a permanência de caulinita como argilomineral predominante e quase exclusivo. Esses minerais conferem aos solos de comportamentos lateríticos coloração típica: vermelho, amarelo, marrom e alaranjado (Villibor et al., 2009);

- Os solos saprolíticos (sapro, do grego: podre), são aqueles que resultam da decomposição ou desagregação in situ da rocha matriz pela ação das intempéries (chuvas, insolação, geadas) e mantêm, de maneira nítida, a estrutura da rocha que lhe deu origem. São genuinamente residuais, isto é, derivam de uma rocha matriz, e as partículas que os constituem permanecem no mesmo lugar em que se encontravam em estado pétreo. Os solos saprolíticos constituem, portanto, a parte subjacente à camada do solo superficial laterítico aparecendo na superfície do terreno, somente por causa de obras executadas pelo homem ou erosões. Esses solos são heterogêneos e constituídos por uma mineralogia complexa contendo minerais ainda em fase de decomposição. São designados também de solos residuais jovens, em contraste com os solos superficiais lateríticos, considerados maduros (Villibor et al., 2009).

A Figura 2.6 ilustra um perfil de corte rodoviário no qual aparece a delimitação entre horizontes laterítico e saprolítico. Pode-se observar a grande suscetibilidade do horizonte saprolítico à erosão, característica que limita bastante sua utilização rodoviária. Na Figura 2.7 é ilustrada a ocorrência dos solos de comportamento laterítico no Brasil. Nela percebe-se uma predominância dos solos lateríticos sobre os saprolíticos. Por esses dois motivos, será dada uma maior ênfase sobre os solos lateríticos neste trabalho. 


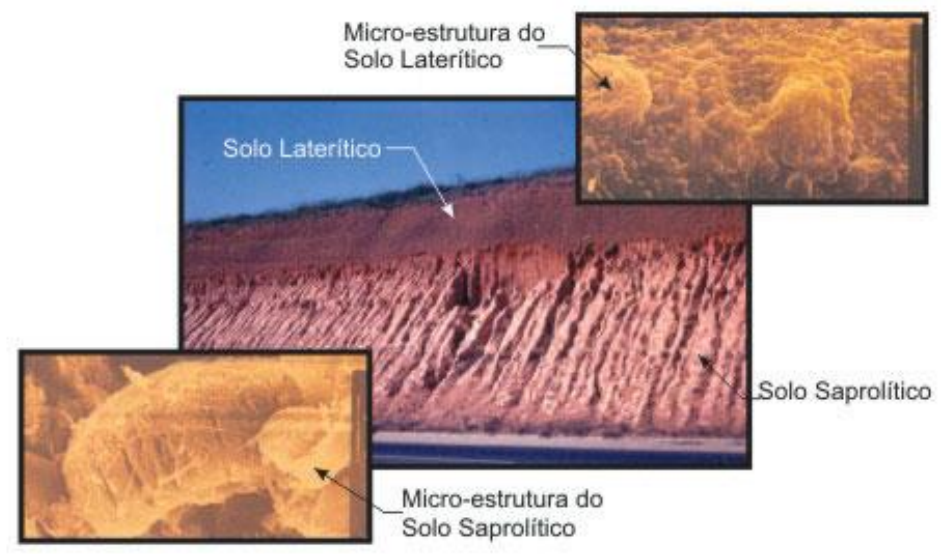

Figura 2.6. Corte rodoviário, com camada laterítica sobrejacente a uma camada saprolítica de origem sedimentar, com as correspondentes micro-fábricas (Villibor et al., 2009).

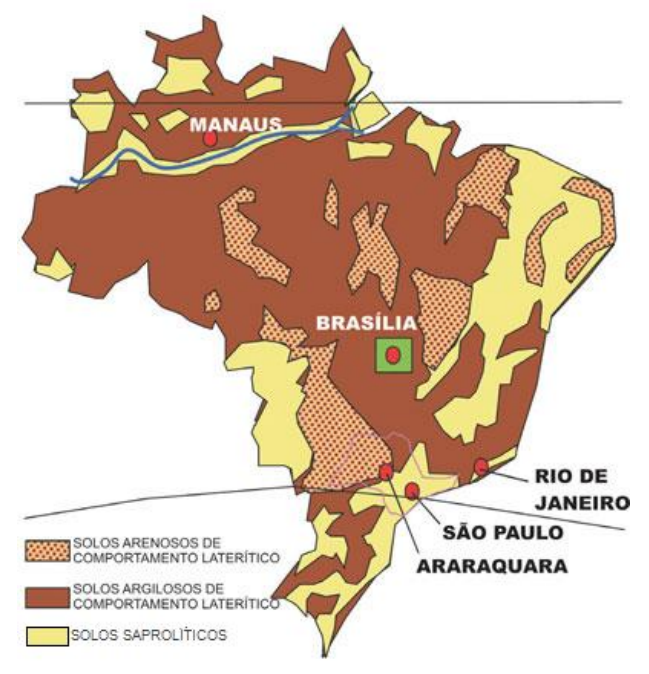

Figura 2.7. Ocorrência dos solos de comportamento laterítico no território brasileiro (modificado de Villibor et al., 2009).

Os solos lateríticos constituem perfis naturais caracterizados pedologicamente por conterem horizontes A e B podendo atingir espessuras de uma dezena de metros. Existem três tipos de ocorrência de solos lateríticos: os latossolos, os solos podzólicos e as terras roxas estruturadas. De acordo com os interesses geotécnicos, nos latossolos observa-se pequena diferença entre os horizontes, assim como elevada porosidade aparente, elevada permeabilidade, agregações geralmente bem desenvolvidas, variedade granulométrica, desde argila até areia argilosa. Já nos solos podzólicos, a diferenciação de horizontes é bastante nítida, podendo-se distinguir horizonte orgânico ou vegetal que se sobrepõe a um horizonte nitidamente mais rico em argila. Esse horizonte argiloso prejudica frequentemente as condições de drenagem dos solos podzólicos. A granulometria nesse tipo de ocorrência 
evoluía desde as variedades arenosas até as argilosas. Por sua parte, as terras roxas estruturadas apresentam diferenças pouco nítidas entre os horizontes, no que se refere principalmente à cor. O horizonte apresenta uma granulometria tipicamente argilosa.

A mineralogia dos solos lateríticos é relativamente simples, sendo esta constituída na sua grande maioria pelo o quartzo. Esse mineral encontra-se quase sempre de maneira dominante nas frações de areia e pedregulho desses solos e imprime ao solo propriedades e comportamentos decorrentes de suas peculiaridades: elevada resistência à compressão, elevado módulo de elasticidade, elevada dureza, massa específica absoluta em torno de $2,65 \mathrm{~g} / \mathrm{cm}^{3}$, elevada estabilidade química. Além do quartzo, destacam-se outros minerais, genericamente chamados de minerais pesados, dos quais pode-se citar: magnetita, ilmenita, turmalina, zircão, etc. Ainda na fração pedregulho, pode-se notar a presença de concreções lateríticas, principalmente constituídas por óxidos hidratados de fero ou alumínio (Nogami \& Villibor, 1995).

De acordo com Idalíra (2007), na fração argila dos solos lateríticos encontra-se constituintes minerais, como argilominerais, óxidos e hidróxidos de ferro ou alumínio e constituintes orgânicos. $\mathrm{O}$ argilomineral predominante nesses solos é a caulinita, de estrutura atômica 1:1, ou seja, formada por repetição sucessiva de pacotes constituídos de uma camada tetraedros de sílica e de uma camada de alumina ligados por uma forca atômica do tipo ponte hidrogênio. Esse tipo de ligação proporciona ao argilomineral pequena atividade coloidal, que nos solos lateríticos é ainda reduzida pela associação com óxidos e hidróxidos de ferro e alumínio. Os óxidos, apesar de possuírem elevada superfície de especifica e reduzidas dimensões, não são plásticos, ou são muito pouco plásticos, não expansivos e possuem uma capacidade de troca catiônica desprezível nas condições de $\mathrm{pH}$ predominantes nos solos. Além disso, os óxidos de ferro e alumino possuem propriedades cimentantes, auxiliando na formação de agregados e concreções lateríticas.

Segundo Nogami \& Villibor (1995), os solos de mesma granulometria, constituição e classificação geotécnicas podem ter comportamentos bem diferentes de acordo com as suas partículas de fábrica, isto é, da disposição espacial dos seus constituintes sólidos, dos seus vazios e das suas superfícies de descontinuidades. Nos solos lateríticos, a macrofábrica (fábrica observada a olho nu) é homogênea, isto é, não se distingue um desenho especial quando à distribuição dos grãos. A peculiaridade geotécnica mais notável dos solos lateríticos 
está na permanência da resistência dessa macrofábrica mesmo após molhagem ou umedecimento. Isso faz com que os solos mantenham elevada porosidade aparente e permeabilidade quando são submetidos ao aumento de umidade (por imersão em água ou molhagem pelas chuvas) no seu estado natural. Além disso, observa-se a permanência dos torrões na fração areia do solo, resistência à compressão e ao cisalhamento muito mais acima da prevista pelos índices físicos tradicionais assim como maior facilidade a se prestar às misturas com água ou estabilizantes químicos.

Essas diferentes peculiaridades vêm inviabilizando os parâmetros obtidos pelos métodos tradicionais, quando esses são utilizados para classificar os solos lateríticos. De acordo com Rezende (2003), geralmente, quando se aplicam essas normas verifica-se através de ensaios de laboratório (granulometria, limites de liquidez e de plasticidade, Índice de Suporte Califórnia - ISC) que o solo laterítico não é indicado para a utilização em pavimentação. No entanto, com a realização de pesquisas, a utilização desse material em campo e a determinação de novos parâmetros por meio da metodologia MCT e dos módulos resilientes, tem-se verificado o seu bom desempenho. Por esse motivo, maior atenção deve ser dada a esses parâmetros.

\subsubsection{METODOLOGIA MCT}

Tendo em vista as peculiaridades dos solos tropicais quando comparados aos solos do hemisfério norte, Nogami (1981) desenvolveu na sua tese de doutorado uma nova sistemática para a classificação dos solos tropicais para fins rodoviárias denominada Metodologia MCT. Essa metodologia se caracteriza pela utilização de corpos de prova cilíndricos, de dimensões reduzidas, com diâmetros de $50 \mathrm{~mm}$ de altura igual ou próximo dessa medida. Por esse motivo foram designados de "Miniatura" com a abreviação (M). Como, basicamente, são obtidos corpos de provas em laboratório por compactação $(C)$ e a sistemática foi desenvolvida para solos tropicais (T), usa-se a abreviatura MCT. A metodologia MCT é recomendada para estudos de solos tropicais que passam integralmente, ou têm pequena fração retida (menos de $10 \%$ ), na peneira de malha quadrada de abertura 2,00 mm (Nogami \& Villibor, 2009). A compactação dos corpos de prova é feita de acordo com o procedimento desenvolvido na Iowa State University e no Departamento de Estradas e Rodagem do estado de São Paulo, que utiliza basicamente o processo dinâmico desenvolvido pela referente instituição. Desde sua formulação no início da década de oitenta até nos dias atuais, várias modificações foram 
introduzidas nos detalhes executivos dos ensaios e, além disso, foram desenvolvidos métodos de ensaios apropriados, com corpos de prova específicos para determinação dos valores de outros parâmetros como: infiltrabilidade d’água, permeabilidade, contração por secagem, penetração da imprimadura betuminosa entre outros (Nogami \& Villibor, 2009). Na Tabela 2.3 estão resumidos os ensaios da sistemática MCT assim como os fenômenos físicos correlacionados.

Tabela 2.3. Ensaios da sistemática MCT e fenômenos correlacionados - Associação com os defeitos construtivos na base (modificado de Nogami \&Villibor, 2009).

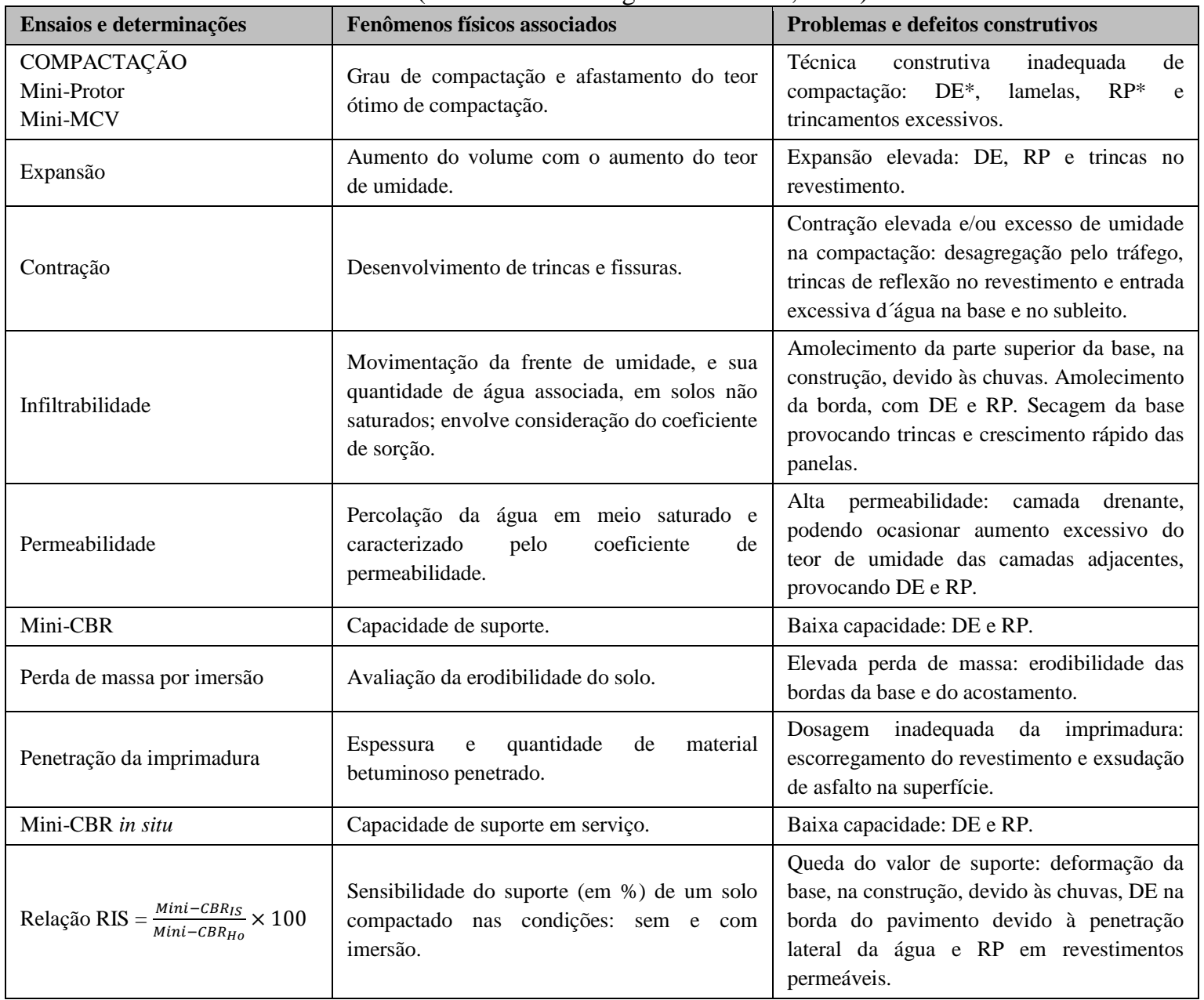

NB. DE=Deformação Excessiva do pavimento. RP=Ruptura do pavimento. Mini-CBRis=Mini-CBR imerso, sem sobrecarga. Mini-CBR $\mathrm{Ho}_{\mathrm{o}}$ na umidade ótima de compactação.

Apesar da sua habilidade em caracterizar melhor os solos tropicais em vista sua utilização em pavimentação, observa-se que os ensaios da metodologia MCT ainda são bastante desconhecidos e raramente utilizados em meios rodoviários. Por esse motivo, ainda necessitam maior divulgação. A seguir são brevemente apresentados os ensaios da sistemática MCT pertinentes ao estudo desenvolvido nesta tese. 
- Ensaio de compactação Mini-MCV. É um ensaio de compactação com diferentes energias que utiliza corpos de prova de $50 \mathrm{~mm}$ de diâmetro. Para esse ensaio é utilizado o mesmo dispositivo apresentado na Figura 2.8. O processo de compactação consiste em aplicar ao corpo de prova, com um determinado teor de umidade, um número crescente de golpes seguindo a série de golpes proposta por Parson: 1,2,3,4,6,8,12,..n...,4n. Durante esse processo de compactação são realizadas medidas de altura do corpo de prova para determinação das massas específicas aparentes secas. A compactação termina quando não há mais acréscimo sensível na densidade do solo, isto é, quando a diferença entre altura do corpo de prova para a séria de " $4 \mathrm{n}$ " golpes e a de " $\mathrm{n}$ " golpes correspondente for é inferior a $2 \mathrm{~mm}$, quando atingido o limite de 256 golpes, ou então, quando ocorrer exsudação da água de mistura. Para cada teor de umidade de compactação, é traçada uma curva de deformabilidade ou também chamada curva de Mini-MCV. No fim do ensaio, obtém-se também uma família de curvas de compactação em função das energias aplicadas. O ensaio de compactação Mini-MCV fornece dois parâmetros fundamentais para a classificação dos solos segundo a metodologia MCT. O coeficiente angular c' correspondente ao Mini-MCV=10 e o coeficiente d', que é a inclinação, medida nas proximidades da massa específica aparente seca máxima, da parte retilínea do ramo seco da curava de compactação correspondente a 12 golpes no ensaio. Nas Figuras 2.9 e 2.10 estão apresentados alguns exemplos de curvas de deformabilidade e famílias de curvas de compactação.

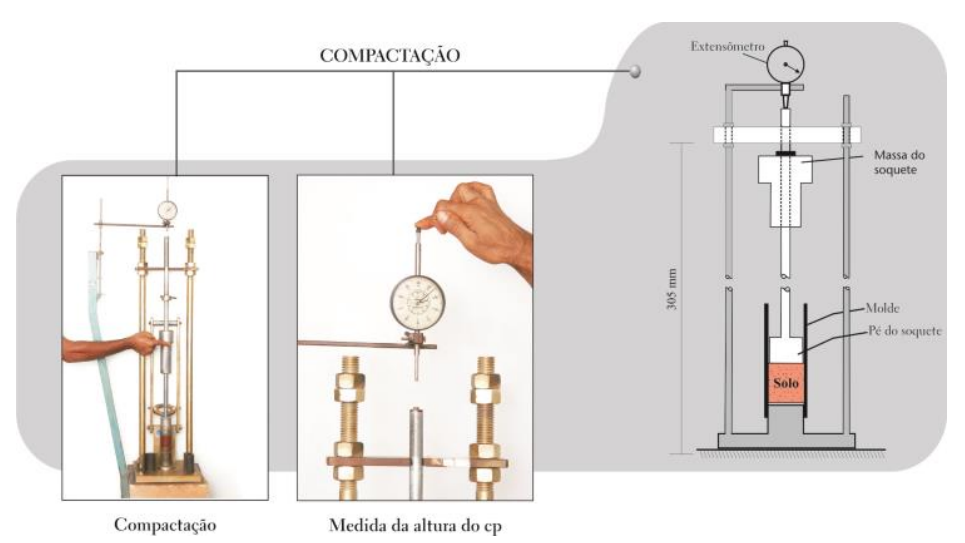

Figura 2.8. Dispositivo para compactação e controle altura dos corpos de prova na metodologia MCT (Villibor \& Nogami, 2009). 


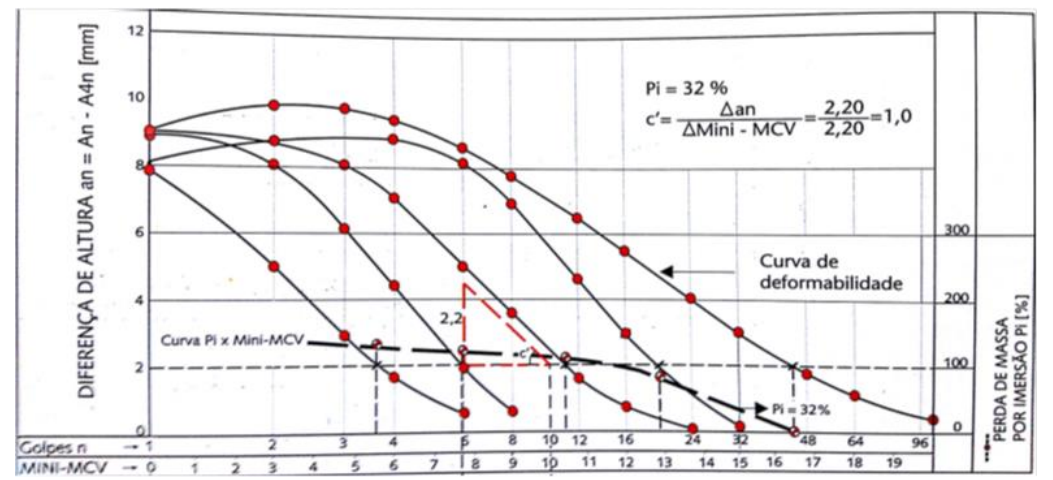

Figura 2.9.Exemplo de curvas de deformabilidade (Villiibor \& Nogami, 2009).

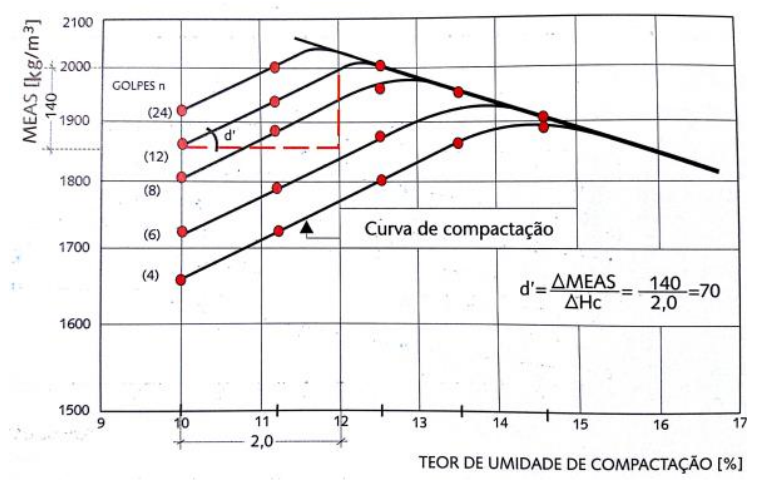

Figura 2.10. Exemplo de famílias de curvas de compactação (Villibor \& Nogami, 2009).

- Ensaio de perda de massa por imersão. Para a execução desse ensaio, os corpos de prova são compactados segundo o método Mini-MCV e somente são aproveitados aqueles que apresentarem uma curva de deformabilidade completa. Os corpos de prova escolhidos são então extraídos apenas parcialmente, de forma que fiquem expostos, exatamente, $10 \mathrm{~mm}$ da sua parte inferior. A seguir, os corpos de prova são imersos em água por 24 horas conforme mostra a Figura 2.11. Passado esse tempo, é determina-se as massas desprendidas e é calculada a perda de massa por imersão "Pi". Esse parâmetro também é utilizado para a classificação dos solos tropicais de acordo com a metodologia MCT conforme descrito nas próximas linhas.

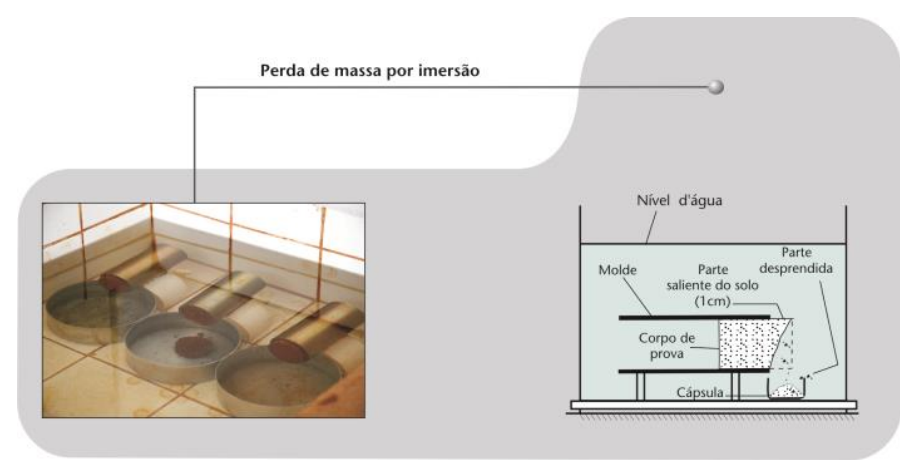

Figura 2.11. Ensaio de perda por imersão (Villibor \& Nogami, 2009). 
- Classificação MCT. Esta classificação permite a verificação do comportamento laterítico, ou não, dos solos e dá subsídios à avaliação das propriedades mecânicas e hidráulicasdos solos típicos dos climas tropicais úmidos. Para tanto, utiliza-se inicialmente o coeficiente de inclinação d'obtido do ensaio de compactação Mini-MCV e a perda de massa por imersão $P i$ para calcular índice de laterização e' a partir da Equação (2.6). Em seguida, de posse do índice $\mathrm{e}^{\prime}$ e o coeficiente angular $\mathrm{c}^{\prime}$, determina-se a classificação MCT do solo utilizando o gráfico ilustrado na Figura 2.12.

$$
e^{\prime}=\sqrt[3]{\frac{P i}{100}+\frac{20}{d^{\prime}}}
$$

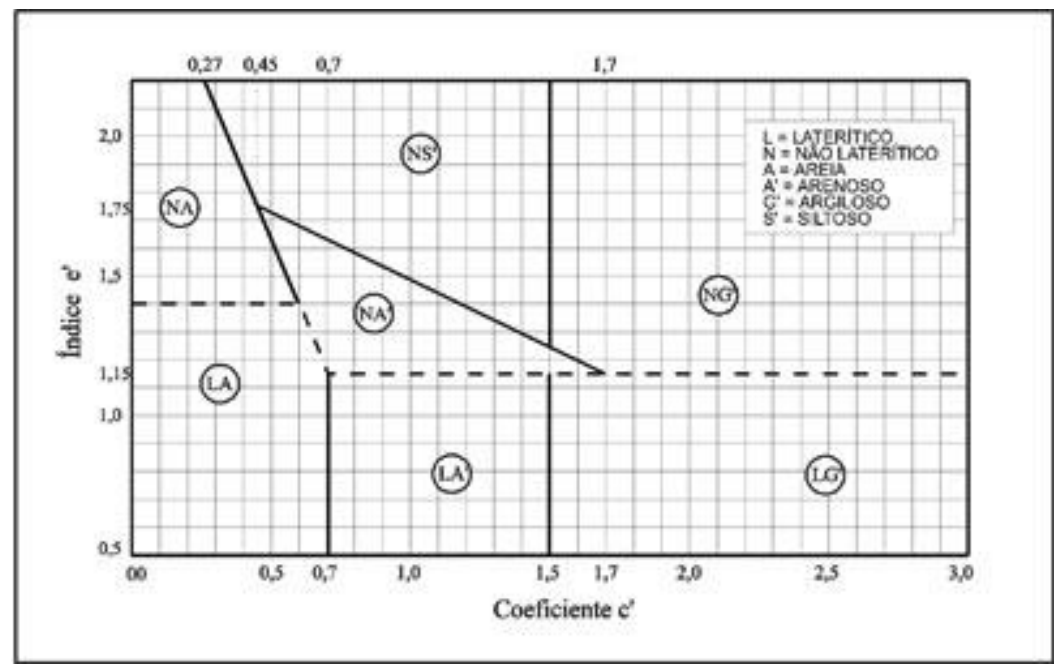

Figura2.12. Gráfico de classificação dos solos tropicais de acordo com a metodologia MCT.

- Ensaio de compactação Mini-Protor. Para esse ensaio é somente utilizado a fração do solo que passa na peneira de $2,00 \mathrm{~mm}$. Todas as amostras devem ser secas previamente ao ar. Utilizam-se, sempre, amostras virgens para cada ponto da curva de compactação. Então são separadas cinco alíquotas de material de aproximadamente $200 \mathrm{~g}$. A uniformização do teor de umidade de compactação é feita após a adição da água em cada alíquota de solo e homogeneização. Antes de iniciar a compactação, conserva-se a mesma é em repouso, pelo menos 12 horas em recipiente hermético para garantir o total umedecimento do solo. Para a compactação usam-se dois tipos de soquete: o leve com $2,27 \mathrm{~kg}$ e o pesado de $4,50 \mathrm{~kg}$. Para reproduzir as condições de energia normal, aplica-se 5 golpes de cada lado do corpo de prova, com o soquete leve, em uma camada apenas e, para a energia intermediária, de maior interesse para as camadas de base, aplicam-se 6 golpes de cada lado, com o soquete pesado. 
Os corpos de prova de prova oriundos desse processo de compactação atingem uma altura de $50 \pm 1 \mathrm{~mm}$, sem arrasamento. Para a determinação da altura de cada corpo de prova, utiliza-se um dispositivo de ensaio munido de um extensômetro que fornece seu valor aproximado de 0,1 mm conforme apresentado anteriormente na Figura 2.7.

- Ensaios de Mini-CBR e Expansão. O procedimento para esse ensaio é semelhante ao do ensaio tradicional CBR. No entanto, os corpos de prova utilizados são os provenientes do ensaio de compactação Mini-Protor e os valores de Mini-CBR são obtidos a partir das penetrações de $0,84 \mathrm{~mm}$ e $1,70 \mathrm{~mm}$ de um pistão de $16 \mathrm{~mm}$ de diâmetro nos corpos de prova. A velocidade de penetração do pistão é mantida a $1,25 \mathrm{~mm} / \mathrm{mim}$. O ensaio Mini-CBR pode ser realizado com ou sem imersão. A partir dessas duas situações de ensaio, é possível determinar a perda de suporte por imersão do solo, parâmetro conhecido como RIS. A expansão do solo é medida 24 horas após a imersão dos corpos de prova utilizados no ensaio Mini-CBR. A partir dos resultados obtidos desses ensaios, é possível caracterizar o comportamento dos solos conforme orientam Villibor \& Nogami (2009) na Tabela 2.4.

Tabela 2.4. Avaliação das propriedades obtidas dos ensaios de Mini-CBR e Expansão (modificado de Villibor \& Nogami, 2009).

\begin{tabular}{|l|c|c|}
\hline \multicolumn{1}{|c|}{ Propriedade } & Valor & Classificação \\
\hline \multirow{4}{*}{ Suporte Mini-CBR (\%) com sobrecarga padrão. } & $>30$ & Muito Elevado \\
\cline { 2 - 3 } & 12 a 30 & Elevado \\
\cline { 2 - 3 } & 4 a 12 & Médio \\
\cline { 2 - 3 } & $<4$ & Baixo \\
\hline \multirow{3}{*}{ Perda de suporte Mini-CBR por imersão (\%) } & $>70$ & Elevada \\
\cline { 2 - 3 } & 40 a 70 & Média \\
\cline { 2 - 3 } Expansão (\%) & $<40$ & Baixa \\
\hline \multirow{3}{*}{ Elevada } \\
\cline { 2 - 3 }
\end{tabular}

\subsection{3 - UTILIZAÇÃO DOS SOLOS TROPICIAIS EM PAVIMENTAÇÃO DE BAIXO}

\section{CUSTO}

Segundo Villibor et al.(2009), um pavimento é considerado de baixo custo quando utiliza bases constituídas de solos locais in natura, ou em misturas, com custos substancialmente inferiores à bases convencionais, revestimento betuminoso esbelto do tipo tratamento superficial ou concreto betuminoso usinado a quente, com espessura máxima de $3 \mathrm{~cm}$ e é 
dimensionado para atender os tráfegos urbanos, de muito leve a leve com um volume diário médio (VDM) inferior a 1500 veículos, com máximo 30\% de veículos comerciais, e com $\mathrm{N}<5.10^{6}$ solicitações do eixo simples padrão de $80 \mathrm{kN}$. No Brasil, há uma predominância dos solos lateríticos arenosos e argilosos, sendo que esses representam $65 \%$ dos solos encontrados no território nacional. Essa grande ocorrência e o melhor entendimento das peculiaridades desses solos potencializam seu uso para pavimentação de baixo custo.

De acordo com Nogami \& Villibor (1995), o melhor aproveitamento dos solos lateríticos de granulação fina (argilosos ou arenosos), em camadas de pavimentos ocorreu no estado de São Paulo na década 50, quando foram utilizados em reforço de subleito. Na mesma época, o engenheiro Francisco Pacheco e Silva, da então Seção de Solos do Instituto de Pesquisas Tecnológicas (IPT), orientou a primeira tentativa experimental da utilização de uma argila laterítica compactada em camada de base de pavimento. Essa camada foi protegida em seus lados por pintura betuminosa e mostrou um bom desempenho até vinte anos após sua execução, quando comparada com camadas vigentes naquela época e essencialmente constituídas de pedra britada. A primeira utilização dos solos arenosos finos lateríticos (SAFL) como base de pavimento data de maio 1967. Esse fato ocorreu com a construção de dois trechos como variantes de trânsito, de aproximadamente $300 \mathrm{~m}$ cada, na via Washington Luis (SP-310), nas proximidades de Araraquara, no interior de São Paulo (Corea et al. ${ }^{1}, 1972$ apud Nogami \& Villibor, 1995). Essas variantes foram revestidas de tratamento superficial simples e teriam um funcionamento de apenas três meses e meio até a construção do trecho definitivo. Após o término desse prazo, constatou-se que as variantes estavam em perfeitas condições. Villibor et al. (2009) ressaltam ainda que trechos inicialmente projetados como proteção à terraplanagem (entre eles, Cambaratiba - Borborema, Ibitinga-Itápolis e Itajobi Novo Horizonte) e construídos em 1974/75 funcionaram sem grandes problemas, como estradas pavimentadas, até meados da década de oitenta. Neles ocorreram apenas defeitos inerentes ao tipo de pavimento adotado (tratamento superficial delgado). Tendo em vista o excelente comportamento apresentado nos trechos experimentais, a base de SAFL começou a ser empregada como parte integrante da estrutura de pavimentos econômicos, em substituição às bases convencionais, geralmente constituídas de material britado, pedregulho ou solo cimento. Atualmente, já foram executados aproximadamente $12.300 \mathrm{~km}$ de rodoviária

${ }^{1}$ CORRÊAA, F. C.; VILLIBOR, D. F.; GRANDE, G., Utilização de solos finos estabilizados na execução de bases. II reunião das organizações rodoviárias. Brasília. 1972. 
vicinais com bases de SAFL, cujos $8.000 \mathrm{~km}$ apenas no estado de São Paulo. Em termos de vias urbanas, já foram construídos mais de 12 milhões de $\mathrm{m} 2$ de bases em SAFL no território nacional (Villibor et al., 2009). Com relação às argilas lateríticas, Villibor et al. (2009) acrescentam que um dos primeiros trechos experimentais utilizando esses materiais em base foi o acesso norte de Campinas à Via Anhanguera (SP-330), executado no início da década 50. Nesse trecho, a base foi envelopada com pintura betuminosa. Mais tarde, no Plano de Pavimentação de 1958 do Departamento de Estradas e Rodagem de São Paulo (DER/SP), foram executadas em grande escala sub-base e reforços de subleito com uso de argilas lateríticas. A construção de trechos experimentais com uso de argilas lateríticas foi retomada a partir de meados da década de 80 nos estados de São Paulo e Paraná. Hoje na cidade de Jaú em São Paulo, estima-se que o total de ruas pavimentadas com base de argila laterítica atinge mais de $500.000 \mathrm{~m}^{2}$.

Nos últimos anos, vem sendo investigada cada vez mais a utilização dos solos finos lateríticos em pavimentação na região central do Brasil. Com exemplos, Rezende (1999) estudou em laboratório, solos finos da região de do Distrito Federal e misturas desses solos com cal (2, 3 e $6 \%$ de cal hidratada). Em seguida, a autora analisou o comportamento estrutural de trechos experimentais, onde esses materiais foram utilizados nas camadas de base e sub-base. Esses materiais apresentaram comportamentos satisfatórios tanto em laboratório como em campo. Essas observações ainda foram confirmadas por Pessoa (2012) que acompanhou o desempenho funcional e estrutural dessas pistas durante quatro anos. Oliveira (2007) mostrou a viabilidade técnica da utilização como material de base de misturas de agregados reciclados de resíduos da construção civil com solos argilosos do município de Goiânia-GO. Na mesma linha, Amorim (2013) estudou em laboratório misturas de solos finos do município de Campo Verde - MT com resíduos da construção civil e demolição. O pesquisador construiu e monitorou uma pista experimental utilizando esses materiais em camada de base. Os resultados obtidos por esses experimentos também forma satisfatórios. Luz (2008) investigou as propriedades laboratoriais e de campo de misturas de argila laterítica de Goiânia - GO com fíler de pedreira do mesmo município. A pesquisadora concluiu que essa mistura mostrou-se adequada às condições estabelecidas pelas normas vigentes em pavimentação. No mesmo raciocínio, Cunha (2011) analisou em laboratório e campo, misturas de solo fino da região de metropolitana de Goiânia, com fíler e expurgo de pedreira. Dessa investigação, o pesquisador também concluiu sobre o desempenho positivo dos materiais estudos. Marques (2012) 
continuou o monitoramento dos trechos construídos por Luz (2008) e Cunha (2011) e, novamente, concluiu sobre viabilidade estrutural desses materiais em pavimentos de baixo custo. Metogo (2010), por sua vez, estudou em laboratório misturas de solo tropical com fosfogesso e cal e construiu uma pista experimental em Aparecida de Goiânia - GO com esses materiais. A pista passou por rigorosos controles tecnológicos durante sua construção. Todas as misturas analisadas apresentaram bom desempenho tanto em laboratório quanto em campo, com destaque para as misturas solo-cal e solo-fosfogesso-cal, podendo, inclusive, substituir o cascalho tradicionalmente utilizado.

\subsection{4- ESTABILIZÇÃO QUÍMICA DOS SOLOS COM CAL}

A estabilização química de um solo em vista sua aplicação em pavimentação é um procedimento antigo e refere-se às alterações produzidas na sua estrutura pela introdução de certa quantidade de aditivo, suficiente para melhorar as propriedades físicas e mecânicas do solo, possibilitando o seu emprego para fins de projeto (França, 2003). Na prática rodoviária assim como na literatura científica, o cimento, o betume e a cal ocupam lugares de destaque como estabilizantes químicos. A cal é um produto químico resultante da reação de calcinação de vários tipos de rochas calcarias (aragonitas, cálcicas, dolomitas, etc.) nas temperaturas da ordem de $1900^{\circ}$ a $2400^{\circ} \mathrm{C}$. Dois tipos de rochas são principalmente utilizados na produção industrial das cais: as rochas constituídas predominantemente por carbonato de cálcio (no mínimo 97\% de $\mathrm{CaO}_{3}$ ) e as rochas dolomíticas, possuindo um importante teor de carbonatos de magnésio (no mínimo $20 \%$ de $\mathrm{MgCaO}_{3}$ ). Da calcinação dessas duas rochas obtém-se respectivamente a cal cálcica virgem $(\mathrm{CaO})$ e a cal dolomítica virgem $\mathrm{CaO} . \mathrm{MgO}$. Genericamente, ambas as cais são denominadas de cales virgens ou vivas (Palmer, 1986). As reações químicas de calcinação são realizas segundo as Equações 2.7 e 2.8.

$$
\begin{aligned}
& \mathrm{CaCO}_{3}+\text { Calor } \rightarrow \mathrm{CaO}+\mathrm{CO}_{2} \\
& \mathrm{CaCO}_{3} \cdot \mathrm{MgCO}+\text { Calor } \rightarrow \mathrm{CaO} \cdot \mathrm{MgO}+\mathrm{CO}_{2}
\end{aligned}
$$

Depois da sua fabricação, as cais virgens podem ser submetidas a um processo de hidratação, dando assim origem às cais cálcicas e dolomitas hidratadas. As cais hidratadas, tanto cálcicas como dolomitas, são genericamente conhecidas como cais hidratadas. As reações envolvidas 
nesse processo são exotérmicas e ilustradas pelas Equações 2.9 a 2.11. Segundo Palmer (1986), as cales hidratadas são mais estáveis que as virgens. Elas possuem uma aparência branca quando originam das rochas calcárias puras e apresentam colorações creme, amarelada e levemente cinza quando provém de rochas impuras (Shirley, 2005).

$$
\begin{aligned}
& \mathrm{CaO}+\mathrm{H}_{2} \mathrm{O} \rightarrow \mathrm{CaO} \cdot(\mathrm{OH})_{2}+\text { Calor } \\
& \text { 2CaCO. } \mathrm{MgO}+3 \mathrm{H}_{2} \mathrm{O} \rightarrow 2 \mathrm{Ca}(\mathrm{OH})_{2} \mathrm{Mg}(\mathrm{OH})_{2}+\text { Calor } \\
& \text { CaCO. } \mathrm{MgO}+\mathrm{H}_{2} \mathrm{O}+\text { Pressão } \rightarrow \mathrm{Ca}(\mathrm{OH})_{2} \mathrm{MgO}+\text { Calor } \\
& \text { Onde: }
\end{aligned}
$$

$\mathrm{CaO} .(\mathrm{OH})_{2}$ : cal cálcica hidratada.

$\mathrm{Ca}(\mathrm{OH})_{2} \mathrm{Mg}(\mathrm{OH})_{2}$ : cal dolomítica dihidratada.

$\mathrm{Ca}(\mathrm{OH})_{2} \mathrm{MgO}$ : cal dolomítica monohidratada.

Em pavimentação, é comum utilizar tanto a cais virgens como as cais hidratadas, sendo que no Brasil, há uma predominância pelo emprego das cais hidratadas. Recorre se ao uso da cal para a modificação ou para estabilização dos solos. O termo modificação significa alterar apenas algumas propriedades do solo. Neste caso, utiliza-se uma pequena quantidade de cal. A estabilização, por sua parte, tem como objetivo principal o ganho de resistência e a diminuição da plasticidade. Neste caso, são necessárias maiores quantidades de cal. Segundo Bell (1996) e Little (1999) a cal atua em duas etapas na melhoria das propriedades físicoquímicas dos solos argilosos:

- Uma ação imediata, demora de horas a dias. Essa fase é caracterizada pela troca catiônica que se realiza entre os cátions $\mathrm{Ca}^{2+}$ trazidos pela cal e os íons metálicos presentes na superfície das partículas da argila. Estas ficam cercadas por uma difusão hídrica o que gera uma modificação da densidade das cargas elétricas ao redor das partículas e uma atração das partículas entre si. Esse processo é chamado de floculação e se acompanhado geralmente por uma diminuição da plasticidade.

- Uma ação ao longo prazo caracterizada pelas reações pozolânicas. Essas reações são responsáveis pelo contínuo aumento da resistência mecânica das misturas solo - cal. Esse aumento ocorre porque as fontes de sílica, alumina e ferro presentes no solo reagem com a cal e a água, formandos diversos produtos cimentícios. 
Contudo, a adição da cal no solo traz outras modificações nas suas propriedades físicas, químicas, estruturais e mecânicas. Afès \& Didier (2000) observaram uma diminuição contínua do valor do azul de metileno quando se adiciona a cal no solo, o que é traduzido por uma diminuição da superfície específica do solo. Diversos autores notaram que para uma mesma energia de compactação, as misturas solo-cal apresentam um menor peso especifico aparente máximo enquanto se percebe um aumento significativo do teor de umidade ótimo, em comparação ao solo natural (Afès \& Didier, 2000; Angelim, 2005). Também foi observado um acréscimo da massa especifica do material misturado (Angelim, 2005). Afès \& Didier (2000) realizaram a análise difratométrica aos raios-X de uma argila da Argélia misturada com cal e observaram uma mudança da estrutura da mistura traduzida pela formação de novos cristais e a desaparecimento de outros. Foi observado também que as misturas de solo+cal apresentam uma granulometria mais grosseira. O trabalho de Lima et al. (2000) mostrou que há um ganho significativo no valor da coesão nas misturas.

A melhoria das propriedades dos solos pela adição da cal depende de vários fatores. Pode ser citado o tipo de solo (expansivo ou não), os tipos de argilominerais, o tipo de cal empregada, o tempo de cura, o retardamento da compactação, o teor em matéria orgânica, o teor de cal utilizado, a temperatura de cura. Lovato (2004) estudou o comportamento mecânico de misturas de latossolos vermelhos de região de Cruz Alta (RS) com cal cálcica e dolomítica. Observou maiores resistências à compressão simples, tração por compressão diametral e, módulo resiliente com o uso da cal cálcica. Angelim (2005) investigou a influência do procedimento de mistura da cal no solo. Esse pesquisador observou melhores valores de índice de suporte para misturas realizadas por imersão da cal na água de compactação em comparação às misturas obtidas por adição da cal em pó, sendo essa forma a mais empregada na prática.

\section{3- AVALIAÇÃO DOS PAVIMENTOS ASFÁLTICOS}

A avaliação de um pavimento asfáltico tem como principal objetivo verificar com o tempo, o quanto o pavimento manteve-se capaz de atender às principais funções para as quais foi projetado. Basicamente, um pavimento é construído para resistir aos esforços oriundos do tráfego e do clima e proporcionar aos usuários conforto ao rolamento, economia no transporte 
e segurança. Desta forma, a avaliação dos pavimentos permite acompanhar o desempenho dos materiais constituintes do pavimento e a partir disso, desencadear ou não, ações de restauração desse pavimento. Para contemplar esse objetivo, a avaliação dos pavimentos divide-se dois eixos: a avaliação funcional e a avaliação estrutural, os quais são expostos a seguir.

\subsection{1- AVALIAÇÃO FUNCIONAL DOS PAVIMENTOS}

A avaliação funcional refere-se ao conjunto de métodos adotados para verificar as condições da superfície dos pavimentos, tendo em vista que sua qualidade interfere diretamente no conforto ao rolamento dos usuários. A avaliação funcional também pode ser entendida como a determinação da serventia do pavimento, conceito desenvolvido no início da década de sessenta a partir dos trabalhos realizados nas pistas experimentais da AASHO, e que se refere à capacidade de um determinado trecho de pavimento atender às condições de rolamento no estado em que se encontra, conforme reporta Huang (2004). A serventia é intimamente relacionada aos defeitos e as irregularidades longitudinais dos pavimentos, visto que são esses fatores os responsáveis por imporem dinâmicas indesejadas aos veículos e, consequentemente afetarem o conforto dos usuários e acarretarem danos nas peças desses veículos. A determinação da serventia dos pavimentos é uma antiga preocupação dos pesquisadores rodoviários, da qual surgiram procedimentos de avaliação subjetiva e objetiva do desempenho funcional dos pavimentos.

\subsubsection{1- AVALIAÇÃO SUBJETIVA}

Inicialmente idealizada pela AASHTO, esta é mais antiga forma de avaliação funcional do pavimento e, fundamenta-se sobre a percepção de conforto e suavidade ao rolamento que tem um grupo composto por no mínimo cinco avaliadores sobre o trecho de pavimento estudado. Cada membro do grupo deve ser ciente do objetivo da avalição e atribuir ao trecho uma nota variando de 0 a 5 caracterizando respectivamente o nível de serventia do trecho analisado como "péssimo" ou "ótimo". A partir dessas notas, é determinado o Valor de Serventia Atual - VSA, denominação brasileira correspondente ao Present Serviceability Ratio - PSR norte americano, pelo cálculo da média das avaliações individuais. A determinação da VSA é normatizada pela DNIT-009/2003 - PRO (DNIT, 2003) a qual traz maiores detalhes sobre o procedimento e indica os níveis de serventia conforme apresentado na Tabela 2.5. 
Tabela 2.5.Níveis de serventia (DNIT, 2003).

\begin{tabular}{|c|c|}
\hline Padrão de conforto ao rolamento & Avaliação (faixa de notas) \\
\hline Excelente & 4 a 5 \\
\hline Bom & 3 a 4 \\
\hline Regular & 2 a 3 \\
\hline Ruim & 1 a 2 \\
\hline Péssimo & 0 a 1 \\
\hline
\end{tabular}

Em geral, o VSA é elevado logo após a construção do pavimento, quando bem executado, pois exibe uma superfície suave, praticamente sem irregularidades sendo, no entanto, difícil de obter atingir a condição de perfeição, VSA=5 como ressaltado por Bernucci et al. (2008). Seu valor vai diminuindo com o passar do tempo pelos fatores tráfego e intemperismo conforme ilustrado pela Figura 2.13.

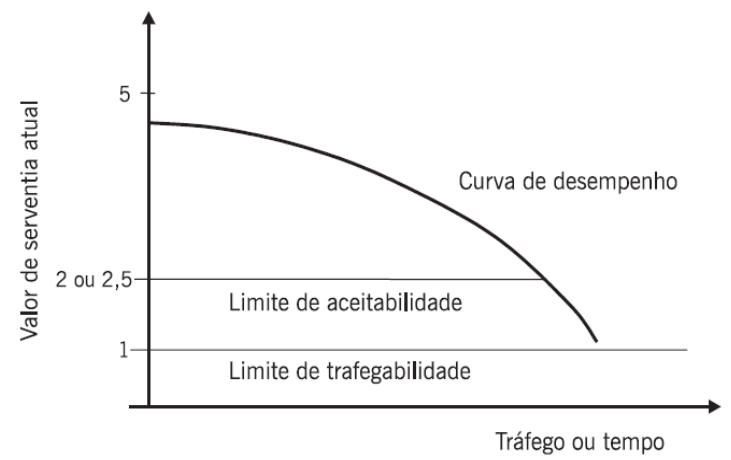

Figura 2.13. Variação da serventia com o tráfego ou com o tempo decorrido da utilização da via (Bernucci, 2008).

É por ser baseado na sensibilidade dos avaliadores e não em medidas direitas ou indiretas que esse procedimento é convenientemente qualificado de subjetivo. Tendo em vista a necessidade de padronizar cada vez mais os métodos de avalição funcional dos pavimentos e reduzir os vícios e interferências da percepção humana, foram propostos diversos outros procedimentos para esta finalidade. Esses procedimentos compõem o conjunto dos métodos de avaliação funcional mais objetiva dos pavimentos, os quais são descritos nas próximas linhas.

\subsubsection{2- AVALIAÇÃO OBJETIVA}

A avalição funcional objetiva dos pavimentos visa à apreciação das condições da superfície dos pavimentos a partir de medidas de campo e determinação matemática de dois principais índices: o International Roughness Index - IRI ou Índice Internacional de Irregularidade em tradução livre e o Índice de Gravidade Global - IGG dos pavimentos. Esses índices são 
intimamente relacionados às irregularidades longitudinais e aos defeitos de superfície dos pavimentos, respectivamente.

\section{- Irregularidade longitudinal - International Rougthness Index - IRI}

A irregularidade longitudinal é definida como o somatório dos desvios da superfície de um pavimento em relação a um plano de referência ideal do projeto geométrico que afeta a dinâmica do veículo, o efeito dinâmico das cargas, a qualidade ao rolamento e a drenagem superficial da via (Bernucci et al., 2008). No intuito de medir e quantificar essas irregularidades, diversos equipamentos foram desenvolvidos a partir da década sessenta. Entretanto, conforme relata Sayers et al., (1986), observou-se ainda uma grande dificuldade para correlacionar e transferir as medições obtidas entre esses equipamentos assim como a calibração desses aparelhos na base de uma escala comum. Para dirimir esse problema e fornecer à comunidade técnica mundial uma base comum para a quantificação das medidas de irregularidades longitudinais, o Banco Mundial promoveu, um encontro científico denominado International Road Roughness Experiment - IRRE aqui no Brasil em 1982, no qual foi adotado o International Roughness Index - IRI para esta finalidade (Sayer et al., 1986; Huang, 2004). Portanto, o IRI é nos dias atuais o índice estatístico, expresso em m/km, de maior aceitação internacional que quantifica os desvios da superfície do pavimento nas trilhas de rodas internas e externas em relação à linha de projeto. O processamento matemático do IRI encontra-se na norma ASTM E1926-2008 (ASTM, 2008). Conforme mostra a Figura 2.14, a faixa de variação da IRI depende do tipo de pavimento considerado assim como da velocidade de percurso do equipamento utilizado para medição.

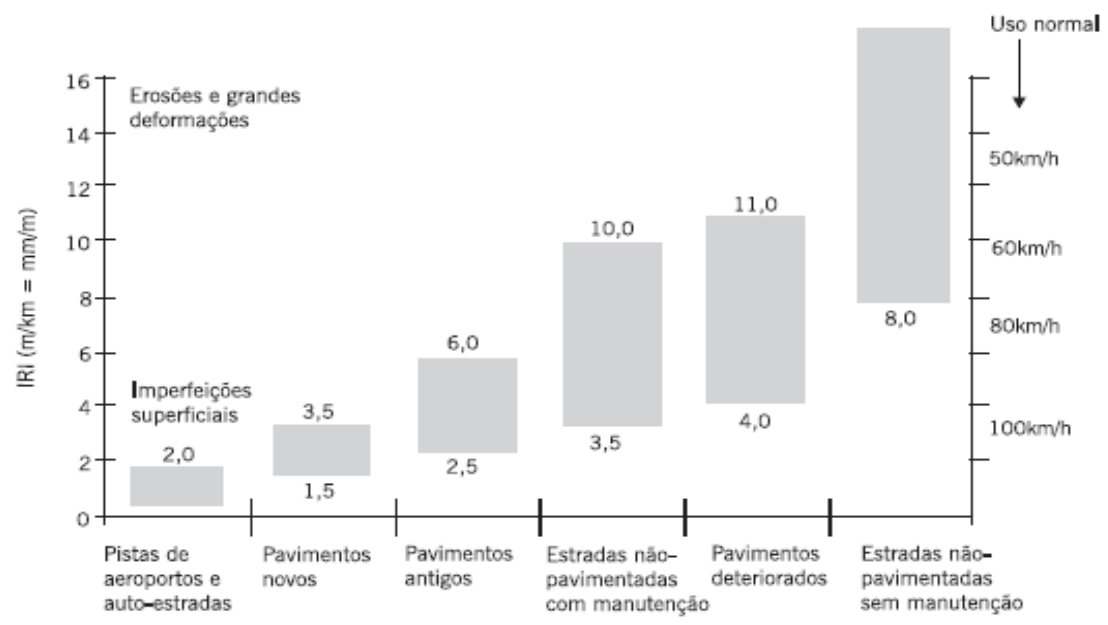

Figura. 2.14 - Faixas de variação do IRI dependendo do caso e situação considerados (Sayers \& Karamilhas, 1998 modificado por Bernucci, et al. 2008) 
De acordo com Perrera \& Kohn (2002), os equipamentos de medição das irregularidades longitudinais podem ser classificados em equipamentos de tipo:

- Manual, dos quais se destacam a mira e o nível para o levantamento topográfico das irregularidades e geralmente utilizado para a calibração de outros equipamentos e, o disptick que é um aparelho dotado de um inclinômetro que fornece a leitura de desníveis entre dois pontos. Na Figura 2.15 está apresentado o princípio de funcionamento do disptick. Os equipamentos deste tipo caracterizam-se pelo levantamento relativamente lento, trabalhoso e consequentemente de baixo rendimento.
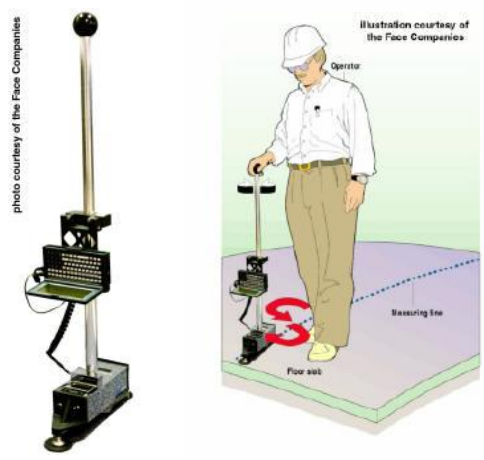

Figura 2.15 - Exemplo de funcionamento do disptick para levantamento das irregularidades do pavimento (Pavement-Interactive, 2007)

- Resposta, que fornecem um somatório de desvios do eixo de um veículo em relação à suspensão. De acordo com Bernucci et al.,(2008), esses equipamentos são chamados assim pois medem mais o efeito da irregularidade nos veículos do que a própria irregularidade. A Figura 2.16 apresenta o princípio de funcionamento de equipamento tipo resposta. Neste grupo encontram-se equipamentos como o Maysmeter. No início da década oitenta, foi desenvolvido no Brasil, o integrador IPR/USP, equipamento inspirado no Maysmeter, com o qual é possível caracterizar a irregularidade longitudinal do pavimento pelo Quociente de Irregularidade QI. Existe uma boa correlação entre o QI e o IRI dada pela relação QI=13 IRI (Medina \& Motta, 2015).

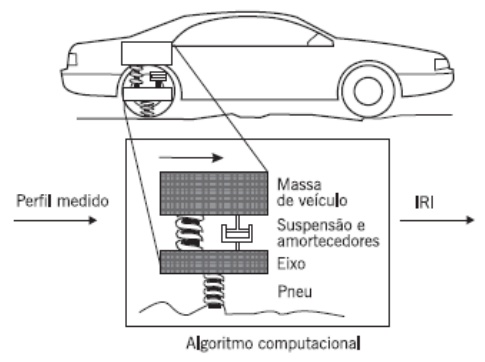

Figura 2.16 Princípio de funcionamento de um equipamento tipo-resposta (Bernucci, et al., 2008) 
- Perfilômetros dentro os quais tem-se, o Merlin, o perfilómetro de rodas, o perfilômetro leve, e os perfilômetros de alta velocidade caracterizados pelo alto rendimento nas medições dos quais destacam-se o Analyseur de Profil em Long $A P L$, Analisador de perfil longitudinal, desenvolvido pelo LCPC na França e o Pavement Scanner da Dynatest, veículo munido de sensores a laser, câmara filmadoras digitais. Esses dois equipamentos são apresentados na Figura 2.17.
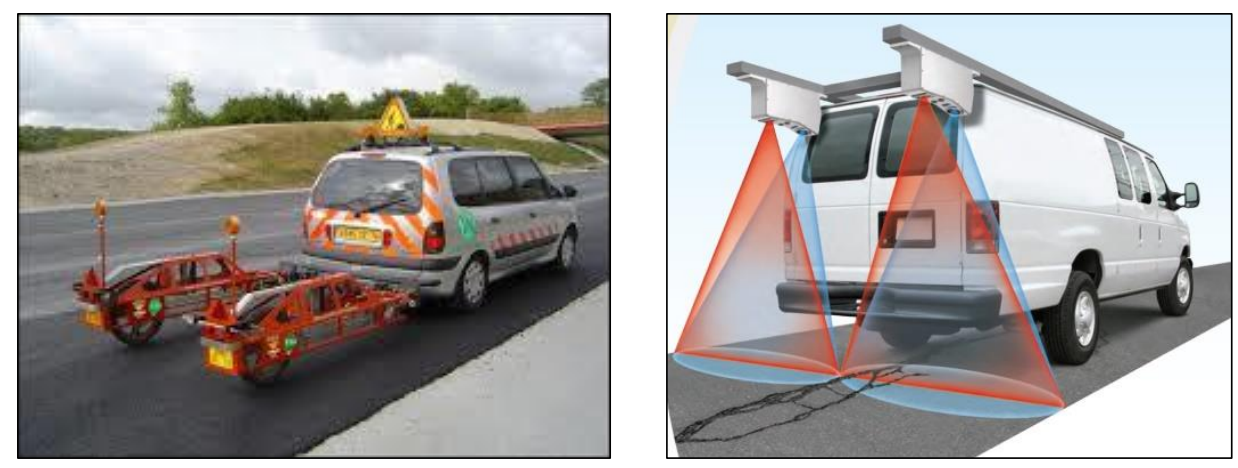

Figura 2.17. Perfilometros de alta velocidade. (a) APL (Technologies nouvelles, 2012). (b) Pavement Scanner. Fonte: Dynatest.

\section{- Identificação de defeitos - Índice de Gravidade Global - IGG}

Os defeitos de superfícies são danos ou deteriorações da superfície dos pavimentos asfálticos que podem ser identificadas ao olho nu. Seu levantamento tem por finalidade avaliar o estado de conservação dos pavimentos asfálticos e embasar o diagnóstico da situação funcional para subsidiar a definição de uma solução tecnicamente adequada, e em caso de necessidade, indicar a melhor ou melhores alternativas de restauração do pavimento (Bernucci et al., 2008). No intuito de padronizar a linguagem adotada na elaboração das normas, manuais, projetos e textos relativos aos pavimentos flexíveis, os termos técnicos empregados em defeitos foram claramente definidos pela norma DNIT-005/2003-TER (DNIT, 2003). Esta norma cataloga os defeitos em categorias e codificação em função das suas ocorrências em pesquisas de campo realizadas nesta pesquisa, sendo relacionados a seguir.

- As Fendas $(\boldsymbol{F})$ são entendidas como quaisquer descontinuidades na superfície do pavimento que conduza a abertura de menor ou maior porte. As fendas podem ser classificadas em como: 
- Fissuras, quando a abertura posicionada longitudinal, transversal ou obliquamente ao eixo da via é perceptível a olho nu apenas a distância inferior a 1,5m. São fendas que não causam problemas funcionais ao revestimento.

- Trincas, quando a abertura é maior a da fissura representando uns dos defeitos mais significativos dos pavimentos asfálticos. As trincas são divididas em:

- Trincas isoladas transversais quando se direcionem ortogonalmente ao eixo da via e consideradas curtas (TTC) se forem de comprimento inferior a $100 \mathrm{~cm}$ e longas (TTL) caso contrário.

- Trincas isoladas longitudinais quando predominantemente paralelas ao eixo e também consideradas curtas (TLC) se forem de comprimento inferior a $100 \mathrm{~cm}$ e longas (TLL) caso contrário.

- Trincas isoladas de retração quando não atribuídas a fenômenos de fadiga, mas sim a fenômenos de retração da camada de revestimento asfáltico ou da base do pavimento.

- Trinca tipo “couro de jacaré” quando são conjuntos de trincas interligadas sem direções preferenciais, assemelhando-se desta forma ao aspecto de couro de jacaré.

- Trincas tipo "bloco" quando constituídas por trincas interligadas caracterizadas pela configuração de blocos formados por lados bem definidos, podem apresentar ou não erosão acentuadas nas bordas.

- Os Afundamentos são as deformações permanentes do pavimento, seja do revestimento asfáltico, ou de suas camadas subjacentes incluindo o subleito, acompanhadas ou não de solevamento. Os afundamentos podem ser classificados como:

- Afundamento plástico (AP), quando as depressões são decorrentes principalmente da fluência do revestimento asfáltico, podendo ser localizado $(A L P)$ quando sua extensão não excede $6 \mathrm{~m}$ de comprimento ou longitudinal nas trilhas de roda (ATP) caso contrário.

- Afundamento de consolidação (AC), quando as depressões ocorrem por densificação diferencial e pode também ser localizado (ALC) quando não excede $6 \mathrm{~m}$ de comprimento ou longitudinal nas trilhas de rodas (ATC) caso contrário. 
- As Corrugações $(\boldsymbol{O})$ que são deformações transversais ao eixo da pista, em geral compensatórias, com depressões intercaladas de elevações, com comprimento de onda entre duas cristas de alguns centímetros ou dezenas de centímetros. As ondulações (O) são também deformações transversais ao eixo da pista, em geral decorrentes da consolidação diferencial do subleito, diferenciadas da corrugação pelo comprimento de onda entre duas cristas da ordem de metros. Ambas são classificadas pela letra "O" na norma brasileira, embora sejam decorrentes de fenômenos diferentes, observam Bernucci et al. (2008).

- O Escorregamento $(\boldsymbol{E})$ caracterizado pelo deslocamento do revestimento em relação à camada subjacente do pavimento, com o aparecimento de fendas em forma de meialua em decorrência da fluência do revestimento asfáltico.

- A Exsudação (EX) que é um defeito caracterizado pelo surgimento de ligante em abundância na superfície do revestimento decorrente em geral do excesso de ligante na massa asfáltica. As manchas resultantes desse fenômeno podem comprometer seriamente a aderência do revestimento aos pneumáticos, principalmente sob tempo de chuvoso, caracterizando grave problema funcional (DNIT, 2006).

- O Desgaste $(\boldsymbol{D})$ que é definido como o efeito do arrancamento progressivo do agregado do pavimento ou a perda progressiva de mástique juntos aos agregados caracterizados pela aspereza superficial do revestimento e geralmente provocados por esforços tangenciais causados pelo tráfego.

- A Panela $(\boldsymbol{P})$ ou buraco é uma cavidade que se forma no revestimento podendo ou não atingir as camadas subjacentes e é provocada por diversos fatores, inclusive a falta de aderência entre o as camadas superpostas.

- O Remendo $(\boldsymbol{R})$ que é uma panela ou qualquer outro orifício preenchido com uma ou mais camada de pavimento na operação comumente denominada "tapa-buraco". Embora possa ser considerada como uma ação corretiva, a presença de remendo em si sinaliza a ocorrência anterior de uma deterioração superficial.

Bernucci et al.(2008) alertam também sobre a ocorrência de outros tipos de defeitos que, embora não constaram na norma DNIT-005/2003 (DNIT, 2003), são também importantes e devem ser considerados para a análise das soluções de restauração como o polimento de agregados, bombeamento de finos, trincas distintas daquelas suscitadas como as trincas de bordos de acostamentos e parabólicas, falhas do bico espargidor, desnível entre pista e 
Universidade de Brasília

acostamento, marcas impressas na superfície - marcas de pneus, empolamento ou elevação por expansão ou raízes de árvores, entre outros. Na Figura 2.18 estão esquematizados alguns tipos de defeitos observáveis em superfície de pavimento. Já a Tabela 2.6 resume os defeitos assim como suas codificações e classificações.
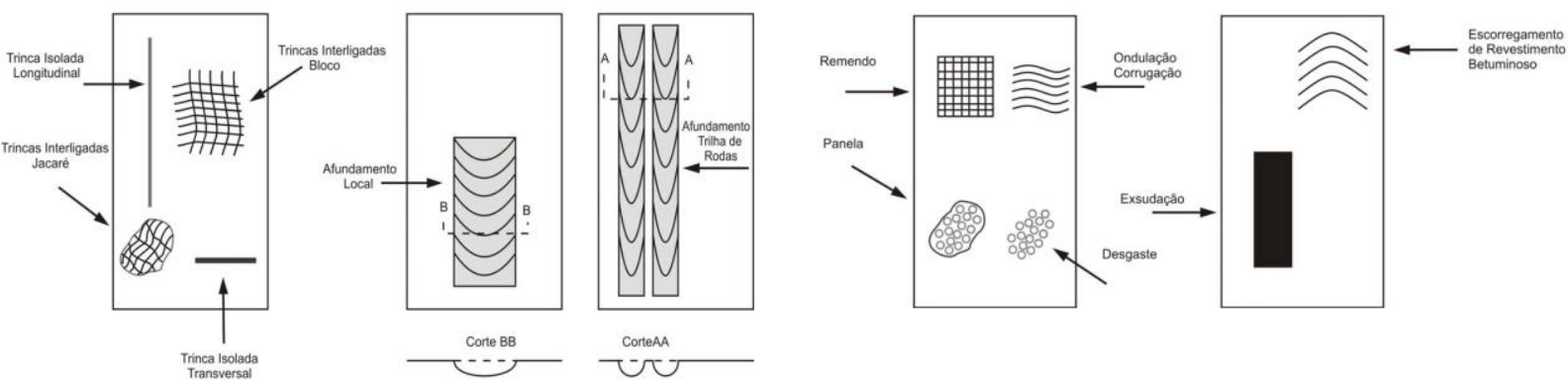

Figura 2.18. Representação esquemática dos defeitos ocorrentes na superfície dos pavimentos flexíveis e semirrígidos (modificado de DNIT, 2003).

Tabela 2.6. Resumo dos defeitos - Codificação e Classificação de acordo com a norma DNIT 005/2003- TER (DNIT, 2003. Modificado).

\begin{tabular}{|c|c|c|c|c|c|c|c|}
\hline & & FENDAS & & CODIFICAÇÃO & CLA & E DE & NDAS \\
\hline & & Fissuras & & FI & - & - & - \\
\hline Trincas no & & & Curtas & TTC & FC-1 & FC-2 & FC-3 \\
\hline revestimento & & Iransversais & Longas & TTL & FC-1 & FC-2 & FC-3 \\
\hline geradas por & Trincas Isoladas & & Curtas & TLC & FC-1 & FC-2 & FC-3 \\
\hline deformação & & Longitudinais & Longas & TLL & FC-1 & FC-2 & FC-3 \\
\hline $\begin{array}{l}\text { permanente } \\
\text { excessiva e/ou }\end{array}$ & Trincas & & $\begin{array}{l}\text { Sem erosão acentuada nas } \\
\text { bordas das trincas }\end{array}$ & $\mathrm{J}$ & - & FC-2 & - \\
\hline $\begin{array}{c}\text { decorrentes do } \\
\text { fenômeno de } \\
\text { fadiga }\end{array}$ & Interligadas & "Jacare" & $\begin{array}{l}\text { Com erosão acentuada nas } \\
\text { bordas das trincas }\end{array}$ & JE & - & - & FC-3 \\
\hline Trincas no & Trincas Isoladas & $\begin{array}{l}\begin{array}{l}\text { Devido à retra } \\
\text { (solo-cimento) }\end{array} \\
\end{array}$ & $\begin{array}{l}\text { mica ou dissecação da base } \\
\text { revestimento }\end{array}$ & TRR & FC-1 & FC-2 & FC-3 \\
\hline $\begin{array}{l}\text { revestimento nao } \\
\text { atribuídas ao }\end{array}$ & Trincas & "Rloc & $\begin{array}{l}\text { Sem erosão acentuada nas } \\
\text { bordas das trincas }\end{array}$ & TB & - & FC-2 & - \\
\hline fadiga & Interligadas & Б1000 & $\begin{array}{l}\text { Com erosão acentuada nas } \\
\text { bordas das trincas }\end{array}$ & TBE & - & & FC-3 \\
\hline
\end{tabular}

\begin{tabular}{|c|c|c|c|c|}
\hline \multicolumn{4}{|c|}{ OUTROS DEFEITOS } & CODIFICAÇÃO \\
\hline \multirow{4}{*}{ Afundamento } & \multirow[b]{2}{*}{ Plástico } & Local & $\begin{array}{l}\text { Devido à fluência plástica de uma ou mais } \\
\text { camadas do pavimento ou do subleito }\end{array}$ & ALP \\
\hline & & Da trilha & $\begin{array}{l}\text { Devido à fluência plástica de uma ou mais } \\
\text { camadas do pavimento ou do subleito }\end{array}$ & ATP \\
\hline & \multirow{2}{*}{ De consolidação } & Local & $\begin{array}{l}\text { Devido à consolidação diferencial ocorrente em } \\
\text { camadas do pavimento ou do subleito }\end{array}$ & ALC \\
\hline & & Da trilha & $\begin{array}{l}\text { Devido à consolidação diferencial ocorrente em } \\
\text { camadas do pavimento ou do subleito }\end{array}$ & ALC \\
\hline \multicolumn{4}{|c|}{$\begin{array}{l}\text { Ondulação/Corrugação - Ondulações transversais causadas por instabilidade de mistura betuminosa } \\
\text { constituinte do revestimento ou da base. }\end{array}$} & $\mathrm{O}$ \\
\hline \multicolumn{4}{|c|}{ Escorregamento (do revestimento betuminoso) } & $\mathrm{E}$ \\
\hline \multicolumn{4}{|c|}{ Exsudação do ligante betuminoso no revestimento } & EX \\
\hline \multicolumn{4}{|c|}{ Desgaste acentuado na superfície do revestimento } & $\mathrm{D}$ \\
\hline \multicolumn{4}{|c|}{ "Panelas" ou buracos decorrentes da desagregação do revestimento e às vezes de camadas inferiores } & $\mathrm{P}$ \\
\hline \multirow{2}{*}{\multicolumn{3}{|c|}{ Remendos }} & Remendo superficial & $\mathrm{RS}$ \\
\hline & & & Remendo profundo & $\mathrm{RP}$ \\
\hline \multicolumn{5}{|c|}{$\begin{array}{l}\text { NOTA 1: Classe das trincas isoladas } \\
\text { FC-1: Trincas com abertura superior à das fissuras e menores que } 1,0 \mathrm{~mm} \text {. } \\
\text { FC-2: Trincas com abertura superior a } 1,0 \mathrm{~mm} \text { e sem erosão nas bordas. } \\
\text { FC-3: Trincas com abertura superior a } 1,0 \mathrm{~mm} \text { e com erosão nas bordas. } \\
\text { NOTA 2: Classe das trincas interligadas }\end{array}$} \\
\hline
\end{tabular}


Feito o levantamento das condições da superfície baseando-se na norma DNIT-005/2003-TER (DNIT, 2003a), deve-se proceder à análise desses defeitos e das suas causas e atribuir indicadores numéricos que classifiquem o estado geral do pavimento. Para esse propósito, pode-se utilizar a norma DNIT-006/2003 (DNIT, 2003b) que estabelece uma sistemática de cálculo de um índice combinado de falhas denominado Índice de Gravidade Global (IGG), derivado do "Severity Index" utilizado no Canadá pela "Saskatchewan Department of Highways and Transportation" e adaptado pelo Engenheiro Armando Martins Pereira, para as condições de pavimentos brasileiros. O cálculo do IGG inclui também a medida das profundidades dos afundamentos de nas trilhas de rodas, avaliadas a partir das medidas das flechas com treliça de base igual a 1,20m. O IGG permite classificar o estado geral de um determinado trecho homogêneo de pavimento, em função da incidência de defeitos de superfície. Ele é um indicador das condições do pavimento, muito útil para a tomada de decisões quanto às intervenções de restauração necessárias, atribuindo-lhe conceitos variáveis segundo a Tabela 2.7 (DNIT, 2006).

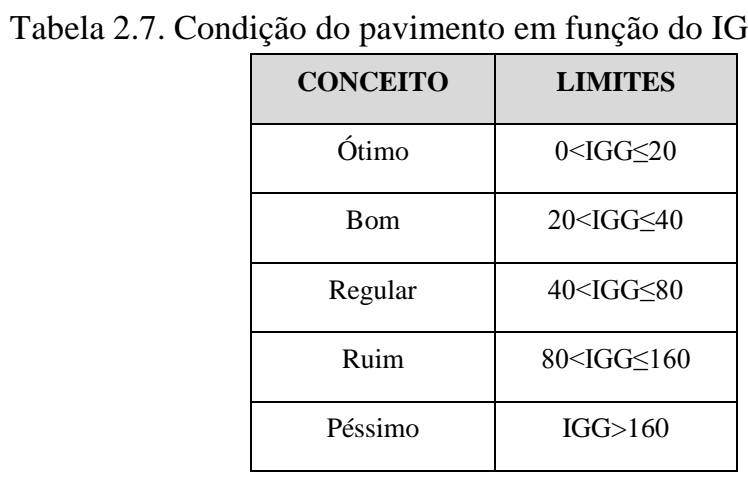

A sistemática de cálculo do IGG é baseada na atribuição de pesos ou fatores de ponderação aplicáveis a cada evento mensurado (frequência relativa de estações com ocorrência de cada tipo de defeito e parâmetros ligados à análise estatística das flechas nas trilhas de roda), pesos esses que buscam caracterizar sua influência sobre a serventia. No método descrito pela norma DNIT-006/2003 - PRO (DNIT, 2003b), deve-se implantar estações de ensaios afastadas de $20 \mathrm{~m}$, alternando as faixas de tráfego direita e esquerda, para o caso de pista simples. Para o caso de pista dupla, as estações devem estar afastadas de 20m, na mesma faixa de tráfego, que geralmente é a externa por ser a mais crítica. A superfície de avaliação é delimitada por uma secção transversal situada $3 \mathrm{~m}$ à ré da pista da estação, por outra situada $3 \mathrm{~m}$ avante, pelo eixo da pista de rolamento, para a pista simples, ou eixo de separação de faixa 
para a pista dupla. Com isso, cada estação corresponde a uma área de $21 \mathrm{~m}^{2}(6,0 \mathrm{~m}$ x 3,5m). Portanto, é fácil depreender que o processo implica em analisar aproximadamente $15 \%$ da área total do pavimento analisado. Em cada estação são anotados numa ficha de campo, os diferentes defeitos assim como a configuração de terraplenagem e a presença ou não de cada um dos tipos de falha. Adicionalmente, com a utilização de uma treliça como base de 1,2m, munida de uma régua graduada na sua região central, mede-se a flecha na roda externa e interna, expressa em mm (DNIT, 2006).

Os dados coletados no inventário são processados em escritório, seguindo as recomendações da norma DNIT-006/2005 (DNIT, 2005), devendo-se inicialmente separar os segmentos com características homogêneas, como por exemplo, aqueles que apresentam o mesmo tipo de constituição de estrutura (mesmo tipo de revestimentos, base, sub-base e subleito), o mesmo tipo de materiais constituintes as camadas e espessuras, a mesma incidência de tráfego e a mesma situação climática. Em seguida, deve-se determinar a frequência absoluta e relativa das falhas anotadas, bem como a média aritmética e a variância das flechas nas trilhas de roda. Para os eventos detectados, é atribuído um peso ou fator de ponderação que exprima sua maior ou menor importância no que diz respeito à serventia. Por exemplo, as trincas de classe 1 possuem pequena influência na serventia, recebendo por exemplo um fator de ponderação de 0,2 , enquanto para panelas e corrugações, as quais exercem forte influência na serventia, atribui-se um fator de ponderação maior igual a 1,0. O produto da frequência relativa de cada defeito pelo seu fator de ponderação resulta no índice de gravidade individual (IGI) correspondente ao evento, ou seja: a fração de IGG afetada pelo o evento. A somatória de todos os valores de IGI representa, finalmente, o valor do IGG a ser atribuído ao segmento homogêneo. A sistemática do DNIT 006/2003-PRO (DNIT, 2003b) propõe planilhas tanto para o levantamento dos defeitos e medidas das trilhas como para o cálculo dos IGG e consequentemente do IGG (DNIT, 2006).

Ressalta-se que além dos procedimentos de avaliação suscitados, existe dentro das normas brasileiras outro de método de levantamento das condições de superfície de pavimentos asfálticos, entretanto para fins de gerencia e estudos de pavimentos. Esse método encontra-se detalhado na norma DNIT-007/2003 - PRO (DNIT, 2003b), a qual escapa o escopo desta tese. No mesmo sentido, deve-se consultar a norma DNIT 008/2003 - PRO (DNIT, 2003c) caso deseja-se realizar o um levantamento visual contínuo para a avaliação da superfície dos 
pavimentos asfálticos, a qual leva à determinação de parâmetros como o Índice da Condição do Pavimento Flexível - ICPF e o Índice de Gravidade Global Expedito - IGGE.

\subsection{2- AVALIAÇÃO ESTRUTURAL DOS PAVIMENTOS}

A partir da sua abertura ao tráfego, o pavimento está sujeito a ciclos de carregamentos provenientes da passagem dos veículos e ações climáticas. Em decorrência desses carregamentos, a estrutura passa a sofrer deformações que podem ser separadas em elásticas ou recuperáveis e plásticas ou permanentes. A repetição das deformações elásticas durante a vida útil do pavimento, assim como o acúmulo das deformações permanentes são respectivamente, os principais responsáveis pelo surgimento de trincas por fatiga e afundamentos no pavimento. A ocorrência e o nível de gravidade dessas deformações são intimamente ligados às características estruturais do pavimento, em outros termos, às espessuras das suas camadas e aos tipos e propriedades mecânicas dos seus materiais. A avaliação estrutural dos pavimentos consiste em uma série de atividades desenvolvidas para verificar a capacidade de um pavimento a resistir mecanicamente aos efeitos dos carregamentos com o tempo, de forma a planejar ou não atividades de reparos. A avaliação estrutural dos pavimentos, portanto, tem como principais objetivos identificar os tipos de materiais que compõem uma estrutura de pavimento, determinar suas espessuras e suas propriedades mecânicas. Entre essas, as mais relevantes para análises mecanistícas e retroanálise, são os módulos de elasticidade e no melhor dos casos, os módulos resilientes. Para atingir esses objetivos, a avaliação estrutural procede por métodos destrutivos, semidestrutivos e não destrutivos.

\subsubsection{1- MÉTODOS DESTRUTIVOS}

Os métodos destrutivos são aqueles que procuram determinar as características físicas e mecânicas dos materiais nas condições em que se encontrem em campo. Para tanto, esses métodos lançam mão de abertura de poços e trincheiras na própria estrutura do pavimento avaliado. Destes, são retiradas amostras indeformadas ou deformadas de materiais que em seguida, são levados para ensaios de caraterização em laboratório. Nessas prospecções também é possível determinar as espessuras das camadas de materiais, sendo esse um dado fundamental para uma posterior retroanálise do pavimento. Na Figura 2.19 estão ilustrados um ensaio de determinação in-situ da massa específica aparente seca de uma camada de base 
de pavimento com uso do frasco areia após abertura de trincheira e a extração de um corpo de prova em pavimento com uma sonda rotativa.
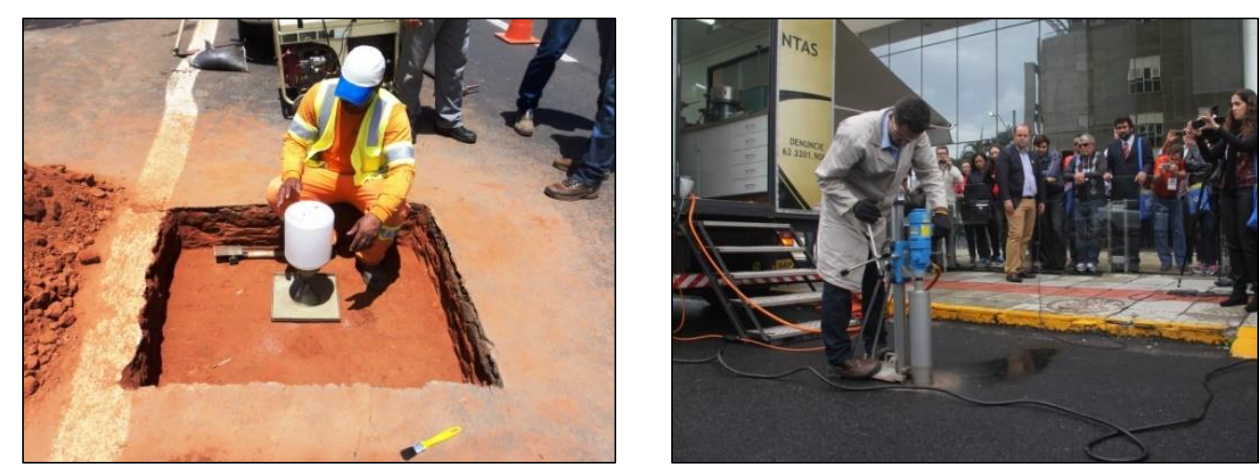

Figura 2.19. Métodos destrutivos para avaliação estrutural de pavimentos. a) Frasco de areia após abertura de trincheira. Fonte: Dynatest. b) Extração de corpo de prova em estrutura de pavimento com sonda rotativa Fonte TCE-SC.

Esses métodos têm como principal vantagem retratar melhor em laboratório as condições dos materiais em campo. Em contrapartida, apresentam desvantagens que muitas vezes os tornam inviáveis. Entre essas, tem-se a necessidade de parar em parte o trânsito, o que acarreta muito desconforto aos usuários, as preocupações com a segurança dos próprios operários dos equipamentos, o fato desses ensaios interferirem na própria estrutura do pavimento, podendo assim ser responsáveis por danos adicionais, o custo elevado das operações de extração das amostras, a demora dos ensaios e o número limitado de amostras. Além disso, nem sempre é possível reproduzir as condições de tensões e umidade dos materiais em campo no laboratório. Essas limitações têm levado cada vez mais à adoção de métodos de semidestrutivos e não destrutivos para a avaliação estrutural dos pavimentos.

\subsubsection{2- MÉTODOS SEMIDESTRUTIVOS}

Os métodos semidestrutivos são aqueles que procuram caracterizar tanto a estrutura como os materiais do pavimento pela realização de furos de menor abertura na estrutura do pavimento com uso de equipamentos de pequeno porte e portáteis. A partir desses ensaios, é possível obter algumas correlações com parâmetros tradicionais como o CBR. Alguns dos principais ensaios encontrados nessa categoria são apresentados a seguir.

\section{- Penetrômetro Dinâmico de Cone - DCP}


O DCP consiste em uma barra de aço de $16 \mathrm{~mm}$ de diâmetro tendo um cone de aço de $20 \mathrm{~mm}$ de diâmetro, com ângulo de $60^{\circ}$ em geratriz extremas, fixado na extremidade. O diâmetro da ponta cônica é superior ao diâmetro da haste. O conjunto cone - haste é posicionado na superfície da camada a ser avaliada e a penetração é realizada pela ação dinâmica de uma massa de aço, com $8 \mathrm{~kg}$ de peso, deslizando por uma haste cursora de $25 \mathrm{~mm}$ de diâmetro, com altura de queda livre de $57,5 \mathrm{~cm}$. Na lateral da barra de $16 \mathrm{~mm}$, é ajustada uma régua de aço graduada na qual são realizadas das leituras da profundidade de penetração do cone para cada série aplicada de golpes (Abitante et al., 2009). Antes do início das leituras, no entanto, devese aplicar pequenos golpes e verificar que o cone penetrou na camada até seu diâmetro maior. Na Figura 2.20 está ilustrado o equipamento desmontado e em uso.
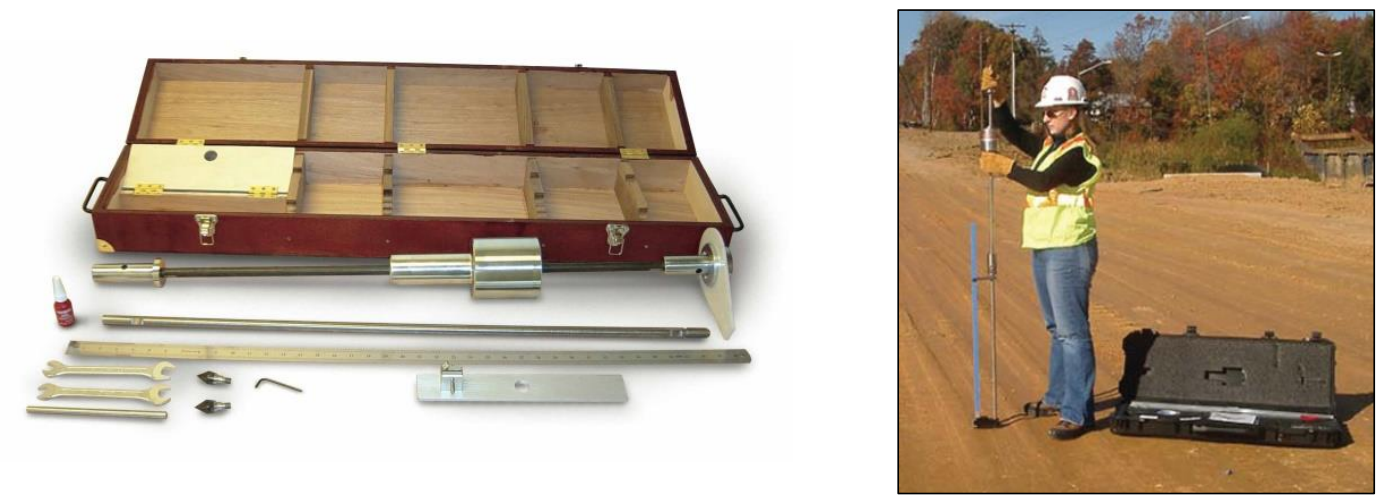

Figura 2.20. Equipamento DCP. (a) Desmontado. Fonte: Jet- Materials. (b) Em uso. Fonte: Hoskin-Scientific.

O DCP apresenta a vantagem de ser um equipamento leve e de fácil utilização. São geralmente necessários dois operadores para a realização do ensaio, sendo um para levantar o martelo e aplicar os golpes e o outro fazer as leituras da penetração do cone na régua verificando sempre a verticalidade do equipamento. Os resultados obtidos no ensaio são anotados em planilha onde é indicado para cada série de golpes, a penetração do cone. A partir desses resultados, obtém-se a curva DCP que é a representação do número de golpes acumulados no eixo das abcissas pela profundidade de penetração da haste correspondente, no eixo das ordenadas. A inclinação da curva DCP representa o DN, DCP Number ou Índice de penetração. A Figura 2.21 (a) apresenta um gráfico típico de um ensaio DCP. Nessa figura, a mudança de inclinação mostra a diferença de resistência no perfil, seja, pela variação de umidade, condições de compactação ou tipo de material. Tendo identificado a variação de resistência no perfil do solo, é possível elaborar o diagrama estrutural representando nas abscissas o índice de penetração DN e nas ordenadas, a profundidade de penetração do cone, 
conforme ilustrado na Figura 2.21(b). Algumas correlações existentes na literatura entre o CBR e o do DCP foram levantados por Silva Jr (2005) e estão resumidos na Tabela 2.8.
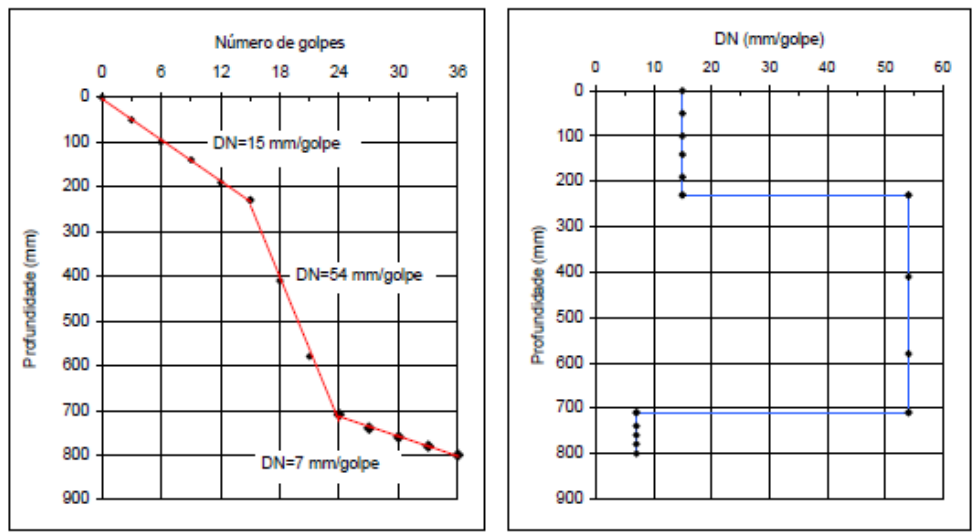

Figura 2.21. Exemplos de gráficos obtidos do ensaio DCP. (a) Curva DCP. (b) Diagrama estrutural. (Alves, 2002).

Tabela 2.8 - Correlações existentes na literatura técnica entre o CBR e o DCP (Silva Jr., 2005).

\begin{tabular}{|c|c|}
\hline Autores & Correlaçẫo \\
\hline $\begin{array}{c}\text { Rohn e Nogueira } \\
(1990)\end{array}$ & $\log (\operatorname{ISC})=2,034-1,1147 \log (\mathrm{DCP})$ \\
\hline $\begin{array}{c}\text { Livneh et al. } \\
(1992)\end{array}$ & $\log (\mathrm{ISC})=2,45-1,12 \log (\mathrm{DCP})$ \\
\hline $\begin{array}{c}\text { Webster et al. } \\
(1992)\end{array}$ & $\log (\operatorname{ISC})=2,46-1,12 \log (\mathrm{DCP})$ \\
\hline $\begin{array}{c}\text { Ese } \\
(1995)\end{array}$ & $\log (\operatorname{ISC})=2,44-1,07 \log (\mathrm{DCP})$ \\
\hline $\begin{array}{l}\text { Thounds } \\
\text { (1997) }\end{array}$ & ISC $=292 / \mathrm{DCP}^{1,12}$ \\
\hline $\begin{array}{l}\text { NCDOT - North Carolina } \\
\text { Departwent of Tranportation } \\
\text { (1998) }\end{array}$ & $\log (\operatorname{ISC})=2,60-1,07 \log (\mathrm{DCP})$ \\
\hline $\begin{array}{l}\text { Coonse } \\
(1999)\end{array}$ & $\log (\mathrm{ISC})=2,53-1,14 \log (\mathrm{DCP})$ \\
\hline $\begin{array}{l}\text { Paiva e Berti } \\
\text { (2004) }\end{array}$ & $\begin{array}{c}\log (\operatorname{ISC})=2,61-1,02 \log (\mathrm{DCP}) . \\
\text { in situ } \\
\begin{array}{c}\log (\mathrm{ISC})=2,59-1,01 \log (\mathrm{DCP}), \mathrm{em} \\
\text { laboratorio }\end{array}\end{array}$ \\
\hline
\end{tabular}

\section{- Panda}

Gouvés \& Barjot (1995) descrevem o Panda como um penetrômetro dinâmico ultraleve desenvolvido pelo Centre Universitaire des Sciences de Techniques de Clermont-Ferrant na França no início da década de noventa. O equipamento atualmente distribuído pela empresa Sol Solution, é composto por um martelo que serve para aplicar golpes sucessivos sobre um cabeçote acoplado a um trilho de hastes de 50 ou $100 \mathrm{~cm}$ de comprimento, munido na sua extremidade penetrante por uma ponteira cônica de 2,4 ou $10 \mathrm{~cm}^{2}$ de área. A execução dos ensaios de penetração com o Panda apresenta algumas vantagens particularmente no que diz respeito à extração do equipamento do solo no término da sondagem. Como suas ponteiras são descartadas no próprio solo, os atritos entre o trilho de hastes e o solo na extração são 
significativamente reduzidos, o que não acontece, por exemplo, com o DCP. Ainda, o Panda é munido de um sistema de aquisição de dados para transferi-los para um computador para análises posteriores. A Figura 2.22 mostra o equipamento desmontado, sendo utilizado em campo e um exemplo de perfil típico obtido com o Panda. Nesse perfil, o eixo vertical representa a profundidade de penetração da ponteira cônica e no horizontal, os dados de resistência do solo obtidos a partir da fórmula holandesa descrita na Equação 2.12.

$$
q_{d}=\frac{M V^{2}}{2 A e\left(1+\frac{P}{M}\right)}
$$

Onde:

$\mathrm{e}=$ Penetração provocada pelo golpe;

$\mathrm{A}=$ Área da ponteira;

$\mathrm{M}=$ Massa do martelo;

$\mathrm{P}=$ Massa do conjunto do equipamento;

$\mathrm{V}=$ Velocidade de impacto.
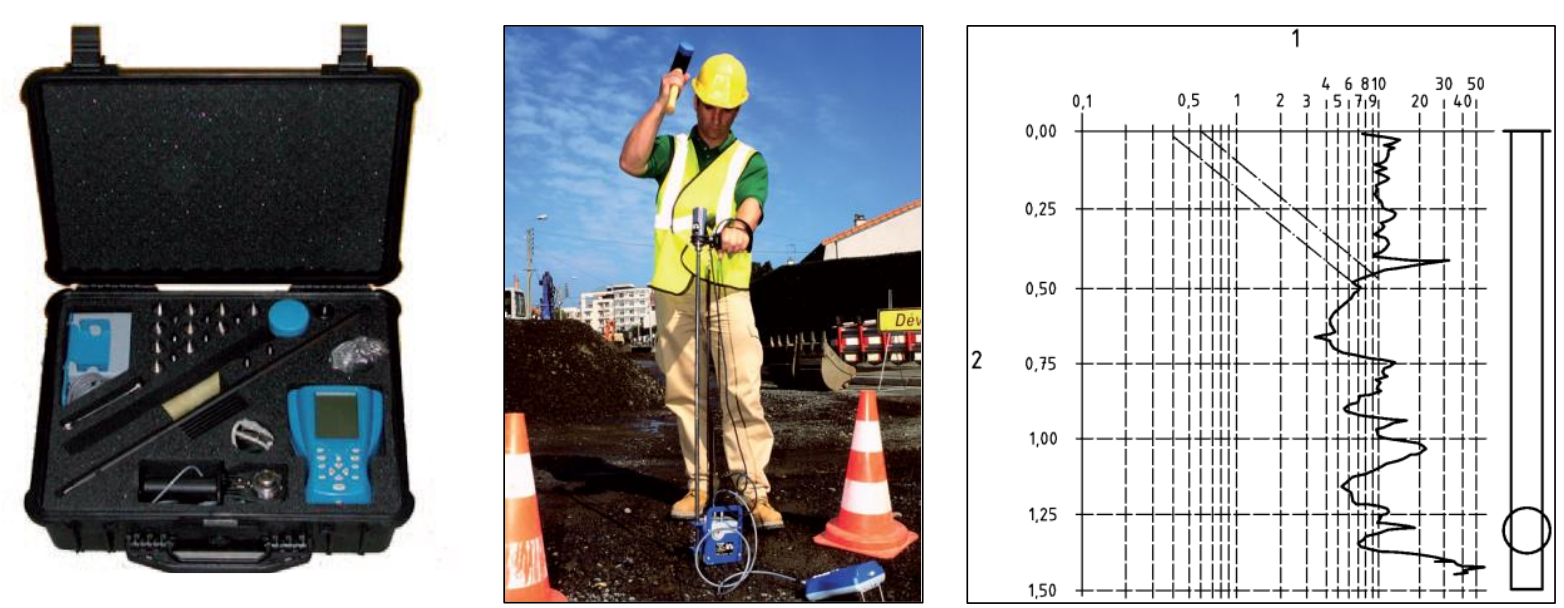

Figura 2.22 Equipamento PANDA. (a) Desmontado e dentro da sua mala. (b) Utilizado em campo. Fonte: SolSolution. (c) Exemplo de perfil obtido com o Panda. (AFNOR, 2000).

\subsubsection{3- MÉTODOS NÃO DESTRUTIVOS}

Os métodos não destrutivos, também conhecidos como NDT, NonDestructive Testing são aqueles que procurem inferir sobre as características estruturais do pavimento e as propriedades mecânicas e resilientes dos materiais que o compõem sem agredi-lo. Para tanto, esses métodos recorrem principalmente às medições e análises das deflexões elásticas da superfície dos pavimentos. Além de não danificar o pavimento, os ensaios não destrutivos apresentam como vantagens de serem rápidos e relativamente baratos. De acordo com Macedo (1996), essas vantagens popularizaram e promoveram o desenvolvimento de 
diferentes tipos de equipamentos para a medição dos deslocamentos. Entretanto, em função do tipo de carregamento aplicado, esses equipamentos ainda podem ser classificados em quase estático, por impacto e vibratório.

\section{- $\quad$ Equipamentos de carregamento quase estático.}

Com esses equipamentos, as deflexões são obtidas a partir a aplicação de estações de carregamentos estáticos em baixa velocidade. Entre estes, o mais comum são:

- Ensaio de prova de carga sobre placa. Esse ensaio tem como objetivo determinar as características mecânicas do pavimento a partir da medição das suas deformações elásticas e permanentes em diversos estágios de carregamento. Para sua execução, é utilizada uma placa metálica circular, um sistema de reação geralmente materializado por um caminhão com carregamento suficiente para não ocorrer basculamento, uma célula de carga acoplada a um macaco hidráulico para a aplicação dos estágios de carregamento e três extensômetros com resolução de $0,01 \mathrm{~mm}$ instalados sobre a placa de forma que suas posições formem um triângulo equilátero. A Figura 2.23 mostra o esquema de montagem de um ensaio de prova de carga. A norma DNIT 055/2004 - ME (DNIT, 2004) que regulamenta a realização desse ensaio para avaliação dos pavimentos, orienta para a determinação do coeficiente de recalque ou módulo de reação $K$ a partir da Equação 2.13. Conforme observam Medina \& Motta (2015), o ensaio de placa apresenta inconveniente de ser bastante penoso e de execução demorada. Rezende (2003) estima que é possível realizar cinco ensaios de placa por dia corrido de trabalho.

$$
K=\frac{\mathrm{P}}{\mathrm{W}}
$$

Onde:

$\mathrm{K}=$ Coeficiente de recalque em $\mathrm{MPa} / \mathrm{m}$.

$\mathrm{P}=$ Pressão aplicada em MPa.

$\mathrm{W}=$ Deslocamento vertical da área carregada em $\mathrm{m}$.

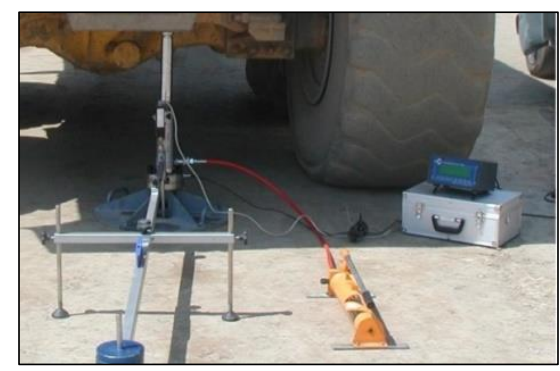

Figura 2.23. Esquema de montagem do ensaio de prova de carga sobre um pavimento. Fonte: Betoteste. 
- Ensaio de viga Benkelman. A viga Benkelman, segundo Ferreira (2007) e Balbo (2007), é de todos os equipamentos de medição deflectométrica, o mais conhecido em todos os países e, em particular no Brasil, onde a maioria das normas vigentes para projetos de avaliação estrutural e projetos de restauração de rodovias têm seus modelos de cálculos fundamentados nesse ensaio. Consiste de um equipamento muito simples e barato constituído de um conjunto de sustentação em que se articula uma alavanca interfixa, formando dois braços cujos comprimentos "a" e "b" obedecem às relações de 2/1, ou 3/1 ou ainda 4/1 conforme apresentado na Figura 2.24a. A extremidade do braço maior contém a ponta de prova da viga. A extremidade do braço menor aciona um extensômetro com resolução de $0,01 \mathrm{~mm}$ e possui um pequeno vibrador destinado a evitar eventuais inibições do ponteiro do extensômetro e dispõe de uma trava de proteção que deve ser utilizada por ocasião do transporte (DNER, 1994). O ensaio de viga é realizado com um caminhão carregado com $8,2 \mathrm{tf}(80 \mathrm{kN})$ no seu eixo traseiro simples com roda dupla com pneus calibrados na pressão de $5,6 \mathrm{kgf} / \mathrm{cm}^{3}(0,55 \mathrm{MPa})$. A ponta de prova da viga é inserida a meia distância das rodas de uma das trilhas, geralmente a externa conforme mostrado na Figura 2.24b. Nesse momento, é feita uma primeira leitura, a leitura inicial $\mathrm{L}_{0}$. Em seguida, o caminhão é afastado e posicionado a uma distância escolhida de forma que não se verifique mais a sua influência na deflexão do ponto de prova. A norma DNER 024/94 (DNER, 1994) que regulamenta o ensaio, recomenda uma distância mínima de 10 metros. Assim posicionado, é feito a leitura final $\mathrm{L}_{\mathrm{f}}$. A partir desses dados, determina-se a deflexão máxima do pavimento no ponto de prova $\mathrm{D}_{0}$ a partir da Equação 2.14 .

$$
D_{0}=\left(L_{o}-L_{f}\right) \cdot a / b
$$

Onde:

$\mathrm{D}_{0}=$ Deflexão máxima em $0,01 \mathrm{~mm}$.

$\mathrm{L}_{0}=$ Leitura inicial, em $0,01 \mathrm{~mm}$

$\mathrm{L}_{\mathrm{f}}=$ Leitura final, em $0,01 \mathrm{~mm}$

$\mathrm{a} / \mathrm{b}=$ Relação entre os braços maior e menor da viga.
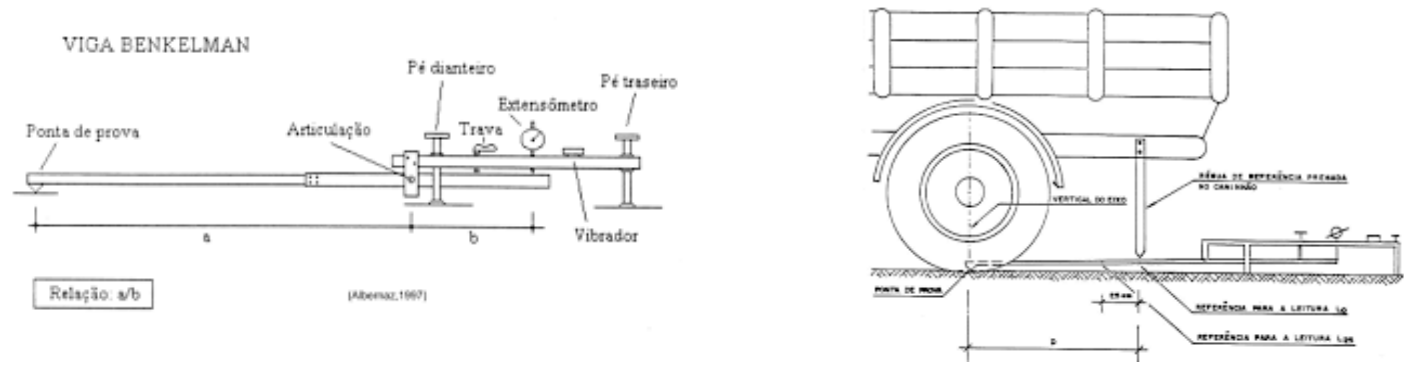

Figura 2.24. Ensaio de viga Benkelman. a) Esquema da viga Benkelman convencional. b) Posicionamento da viga para execução do ensaio. 
Durante a realização do ensaio, é também comum fazer leituras intermediárias entre a inicial e a final. Usualmente, essas leituras são realizadas com o ponto de carga localizado a 25, 50, 75, 100, 125, 150, 175 e 200 do ponto de prova da viga. A partir dessas medições, calculamse as deflexões correspondentes $\mathrm{D}_{25}, \mathrm{D}_{50}, \mathrm{D}_{75}, \mathrm{D}_{100}, \mathrm{D}_{125}, \mathrm{D}_{150}, \mathrm{D}_{175}$ e $\mathrm{D}_{200}$ e materializa-se a linha elástica de deflexão ou bacia deflectométrica do pavimento, importante para a realização da retroanálise dos pavimentos como comentado mais adiante. Atualmente são produzidas vigas Benkelman automatizadas de leitura eletrônica com LDVT e representação dessas deflexões em microcomputador. Para que não surjam trincas no revestimento do pavimento a norma DNER-PRO 011/79 (DNER, 1979) procedimento B, preconiza que a deflexão máxima do pavimento $\mathrm{D}_{0}$ não supera a deflexão admissível determinada pela Equação (2.15).

$$
D_{a d m}=10^{(3,01-0,176 \log N)}
$$

Onde:

$D_{\text {adm }}=$ Deflexão admissível, em $0,01 \mathrm{~mm}$

$\mathrm{N}=$ Número de solicitações do eixo padrão esperado.

Entretanto, a deflexão máxima, embora forneça uma boa ideia do estado do pavimento, não é suficiente para representar completamente o comportamento estrutural do pavimento. Observa-se que, por exemplo, pavimentos distintos podem apresentar o mesmo valor de deslocamento máximo, porém com bacias deflectométricas completamente diferentes. Por esse motivo, a cada deflexão máxima deve-se associar um raio de curvatura da linha elástica conforme calculado pela Equação (2.16).

$$
R=\frac{6250}{2\left(D_{0}-D_{25}\right)}
$$

Onde:

$\mathrm{R}=$ Raio de curvatura, em $\mathrm{m}$.

$\mathrm{D}_{0}=$ Deflexão máxima, em $0,01 \mathrm{~mm}$.

$\mathrm{D}_{25}=$ Deflexão medida a $25 \mathrm{~cm}$ do ponto de carga, em $0,01 \mathrm{~mm}$.

Considera-se que um pavimento asfáltico apresenta um comportamento satisfatório quando seu raio de curvatura é superior a 100m. Isso traduz uma melhor distribuição dos esforços entre as diferentes camadas do pavimento. A partir desses parâmetros, é possível avaliar melhor a estrutura do pavimento seguindo os critérios indicados pela norma DNER - PRO 011/79 (DNER, 1979) e ilustrados na Tabela 2.9. 
Tabela 2.9. Critério para avaliação estrutural de acordo com a norma DNER - PRO 011/79 (DNER, 1979).

\begin{tabular}{|c|c|c|c|c|c|}
\hline Hipótese & $\begin{array}{c}\text { Dados } \\
\text { deflectométricos } \\
\text { obtidos }\end{array}$ & Qualidade estrutural & $\begin{array}{l}\text { Necessidade de } \\
\text { estudos } \\
\text { complementares }\end{array}$ & $\begin{array}{c}\text { Critério para } \\
\text { cálculo de reforço }\end{array}$ & Medidas corretivas \\
\hline I & $\begin{aligned} \mathrm{D}_{0} & \leq \mathrm{D}_{\text {adm }} \\
\mathrm{R} & \geq 100\end{aligned}$ & BOA & NÂO & & $\begin{array}{l}\text { Apenas correções de } \\
\text { superfície }\end{array}$ \\
\hline \multirow{2}{*}{ II } & \multirow{2}{*}{$\begin{aligned} \mathrm{D}_{0} & >\mathrm{D}_{\text {adm }} \\
\mathrm{R} & \geq 100\end{aligned}$} & $\begin{array}{l}\mathrm{Se} \mathrm{D}_{0} \leq 3 \mathrm{D}_{\mathrm{adm}} \\
\text { REGULAR }\end{array}$ & NÃO & Deflectométrico & Reforço \\
\hline & & $\begin{array}{c}\mathrm{Se} \mathrm{D}_{0}>3 \mathrm{D}_{\mathrm{adm}} \\
\mathrm{MÁ}\end{array}$ & SIM & $\begin{array}{l}\text { Deflectométrico e } \\
\text { Resistência }\end{array}$ & $\begin{array}{l}\text { Reforço ou } \\
\text { reconstrução }\end{array}$ \\
\hline III & $\begin{aligned} \mathrm{D}_{0} & \leq \mathrm{D}_{\mathrm{adm}} \\
\mathrm{R} & <100\end{aligned}$ & REGULAR PARA MÁ & SIM & $\begin{array}{l}\text { Deflectométrico e } \\
\text { Resistência }\end{array}$ & $\begin{array}{l}\text { Reforço ou } \\
\text { reconstrução }\end{array}$ \\
\hline IV & $\begin{aligned} \mathrm{D}_{0} & \leq \mathrm{D}_{\mathrm{adm}} \\
\mathrm{R} & \geq 100\end{aligned}$ & MÁ & SIM & Resistência & $\begin{array}{l}\text { Reforço ou } \\
\text { reconstrução }\end{array}$ \\
\hline V & - & $\begin{array}{c}\text { MÁ } \\
\text { O pavimento apresenta } \\
\text { deformações } \\
\text { permanentes e rupturas } \\
\text { plásticas generalizadas } \\
\text { (IGG>180). }\end{array}$ & SIM & Resistência & Reconstrução \\
\hline
\end{tabular}

Alguns cuidados a serem tomados para o tratamento dos dados obtidos dos ensaios com a viga Benkelman. As deflexões do pavimento asfáltico sofrem variações de acordo com a temperatura do pavimento no momento da leitura. Dessa forma, para eliminar a influência da temperatura, se convertem as deflexões obtidas em diferentes temperaturas, D para uma temperatura equivalente padrão de $20^{\circ} \mathrm{C}$ utilizando a Equação 2.17. Além disso, as deflexões medidas devem ser corrigidas em função das variações sazonais conforme apresentado na Equação 2.18. Os valores sugeridos para o fator de correção sazonal $F_{s}$, de acordo com a norma DNER-PRO 11/79 (DNER, 1979) estão apresentados na Tabela 2.10.

$$
D_{20 o C}=\frac{D}{\left[10^{-3} \cdot e \cdot(t-20)\right]+1}
$$

Onde:

$\mathrm{D}_{20 \mathrm{oC}}=$ Deflexão corrigida para a temperatura de $20^{\circ} \mathrm{C}$, em $0,01 \mathrm{~mm}$.

$\mathrm{D}=$ Deflexão medida na temperatura " $\mathrm{t}$ ", em $0,01 \mathrm{~mm}$.

$\mathrm{t}=$ Temperatura do asfalto durante a medição, em ${ }^{\circ} \mathrm{C}$.

$\mathrm{e}=$ espessura da camada de asfalto, em $\mathrm{cm}$.

$$
D_{c}=D \times F_{S}
$$

Onde:

$\mathrm{D}=$ Deflexão característica do pavimento, em 0,01mm.

$\mathrm{D}_{\mathrm{c}}=$ Deflexão característica corrigida do pavimento, em $0,01 \mathrm{~mm}$.

$\mathrm{F}_{\mathrm{s}}=$ Fator de correção sazonal . 
Tabela 2.10. Valores de fatores de correção sazonal (DNER, 1979)

\begin{tabular}{|c|c|c|}
\hline \multirow{2}{*}{ Natureza do subleito } & \multicolumn{2}{|c|}{ Fator de correção sazonal - Fs } \\
\cline { 2 - 3 } & Estação seca & Estação Chuvosa \\
\hline Arenoso e permeável & $1,10-1,30$ & 1,00 \\
\hline Argiloso e sensível a umidade & $1,2-1,40$ & 1,00 \\
\hline
\end{tabular}

Feito o levantamento deflectométricos e as devidas correções, deve-se proceder a uma análise estatística dos dados. Para tanto, pode se recorrer a norma DNER-PRO 11/79 ou utilizar métodos de Análise de Variância - ANOVA como feito por Pessoa (2012). A partir desta, será possível delimitar segmento homogêneo no trecho de pavimento analisado. No mesmo intuito, Balbo (2007) indica que uma maneira prática de visualização dos segmentos homogêneos é inserir os dados obtidos em campo como espessuras de camadas, parâmetros geotécnicos, condições funcionais e estruturais entre outros, em planilha eletrônica, de forma a permitir uma visualização gráfica do trecho, das alterações existentes ao longo da via em estudo. Os segmentos homogêneos também podem ser definidos a partir do tipo de material utilizado na pista analisada.

- Equipamentos de carregamento vibratório. São equipamentos de medições deflectométrica nos quais as os carregamentos são aplicados por forças senoidais no pavimento. Entre esses pode-se destacar:

- Dynaflect que consiste em equipamento gerador de cargas cíclicas, acoplado a um pequeno reboque de rodas duplas, unidade de controle, sensores e um módulo de calibração dos sensores. A unidade de controle e o painel de leitura estão ligados ao reboque, o que permite que a operação seja feita da cabine do veículo (Borges, 2001).

- Road rater que é um equipamento vibratório capaz de variar tanto a magnitude do carregamento quanto a sua frequência. A magnitude do carregamento estático é variada através da transferência da carga do reboque para uma placa de carga. Para gerar o carregamento dinâmico, a massa é hidraulicamente aumentada ou reduzida. Quatro transdutores são utilizados para medição de deflexão no pavimento: um no centro da placa de carga e três localizados ao longo do sentido longitudinal da rodoviária, distantes de cerca de $30 \mathrm{~cm}$ um do outro (Borges, 2001).

\section{- Equipamentos de impacto.}

- Failling Weight Deflectometer - FWD. O FWD é atualmente o equipamento de medições deflectométricas o mais moderno e existe em dois modelos, Dynatest e Kuab sendo 
apresentados na Figura 2.25. Esse equipamento utiliza o carregamento dinâmico transiente em que um peso batente de queda choca-se contra a placa circular inteiriça ou segmentada e medem-se as deflexões máximas, segundo o alinhamento que passa pelo centro da placa (Medina \& Motta, 2015). O FWD apresenta como principais vantagens, a velocidade na execução do ensaio, o grande rendimento quando comparado com a viga, a eliminação dos eventuais erros de leituras do operador visto que elas são realizadas de forma automática por LVDTs. Entretanto, esse equipamento apresenta como inconvenientes seu custo de aquisição elevado e a necessidade de sempre ser calibrado num centro especializado. Além disso, os resultados fornecidos variam bastantes de um modelo para outro o que dificulta significativamente suas comparações. Por conta do imenso banco de dados existente para as deflexões obtidas com a viga Benkelman, encontra-se na literatura técnica tentativas de correlacionar os dados do FWD com os da viga. Vale ressaltar que embora, possam ser encontradas algumas relações coerentes entre essas duas medições, estas, no entanto não podem ser generalizadas para outras estruturas de pavimentos e condições de ensaios. A simples diferença no modo de aplicação das cargas e a localização dos pontos de leitura das deflexões nos dois ensaios por si só são fatores que dificultam consideravelmente o estabelecimento de correlações pertinentes entre as duas medidas. Na Figura 2.26 é ilustrada uma bacia deslocamento típica do ensaio com FWD. A norma DNER-PRO 273/96 (DNER, 1996) orienta sobre a determinação das deflexões com o Failling Weight Deflectometer.
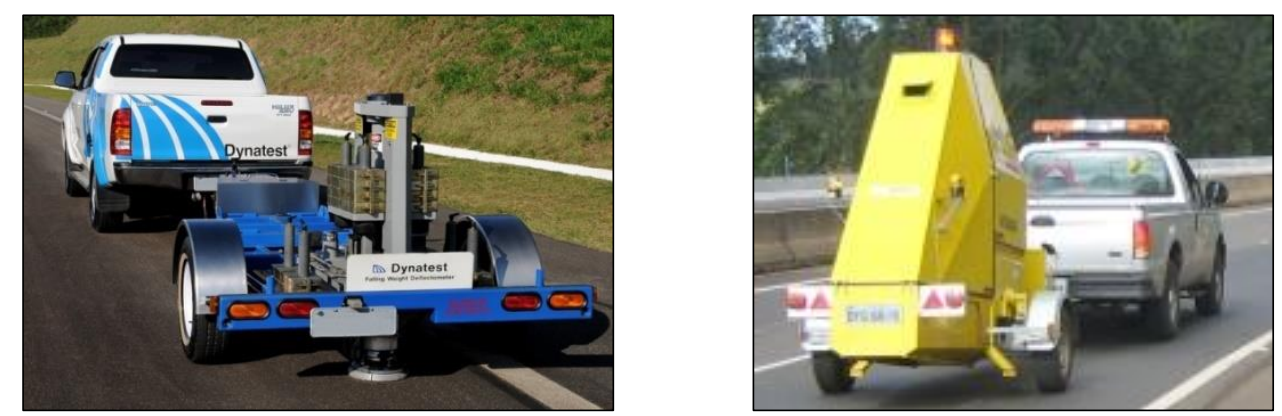

Figura 2.25. Modelos de Failling Weight Deflectometer. a) FWD Dynatest. Fonte Dynatest. b) Modelo Kuab. Fonte Kuab.

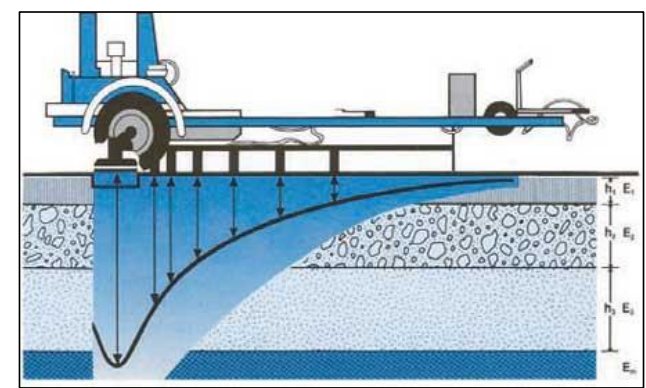

Figura 2.26. Bacia de deslocamento típica obtida com o FWD. Fonte: Dynatest 
- Light Weight Deflectometer - LWD. É um deflectômetro de impacto para as cargas baixas, que apresenta características para ser usado pontualmente em levantamentos durante a construção das camadas ou após. É uma versão simplificada do FWD, operada manualmente e tem uma placa de carga e três sensores para medir a deformabilidade das camadas, para determinar ín situ módulos de resiliência baixos, portanto em camadas não estabilizadas quimicamente, de até $1000 \mathrm{MPa}$. O equipamento é composto por uma célula de carga de alta precisão que mede o valor máximo da força de impacto da queda de peso de $15 \mathrm{~kg}$ acoplado a uma placa de carga com diâmetro de $300 \mathrm{~mm}$. O valor máximo da força de impacto realmente atuante é medido na célula de carga e os deslocamentos são medidos com três sensores, que ficam posicionados a diferentes distâncias em relação ao centro da placa. Esse equipamento é dotado de um sistema próprio de aquisição e armazenamento de dados (Medina \& Mota, 2015). A Figura 2.27 ilustra a execução do ensaio com o LWD.
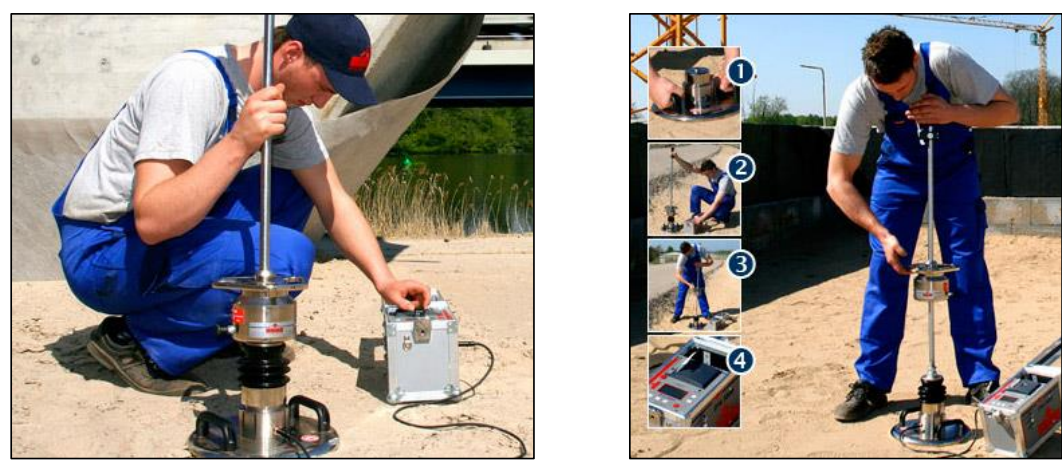

Figura 2.27. Execução do ensaio com o deflectômetro. Fonte: Geneq Inc.

\subsubsection{RETRONÁLISE DE PAVIMENTOS}

A retroanálise como definida pela norma ASTM D 5858-96 (ASTM, 2015), é uma técnica analítica utilizada para determinar o módulo equivalente das camadas de um pavimento correspondente a uma carga aplicada e as deflexões medidas, para o emprego em projeto de avaliação e restauração dos pavimentos. Diversos métodos podem ser utilizados para a realização da retroanálise: interativos, banco de dados, soluções fechadas da teoria da elasticidade, estas, restritas a sistemas de duas camadas e, sistemas de equações simultâneas (ASTM, 2015). De acordo com Macêdo (1995), a maioria dos procedimentos de retroanálises tem como roteiro as seguintes etapas

a) Estimativa dos módulos ou faixas de módulos iniciais a partir da experiência do engenheiro ou via bancos de dados; 
b) Cálculo da bacia de deflexões utilizando os módulos estimados na primeira etapa e aplicando conceitos da teoria da elasticidade e da mecânica dos pavimentos;

c) Comparação das deflexões medidas e calculadas;

d) Ajuste dos módulos através de técnicas que reduzem as diferenças entre as deflexões medidas e as calculadas;

e) Repetição das etapas "b" e "c" até que o erro verificado entre as bacias medidas e calculadas obedecem a um critério de tolerância preestabelecido, ou que o conjunto de módulos não varie mais do que um intervalo prefixado, ou ainda que programa atinja um certo número de iterações.

Tem grande influência na eficiência das análises, a espessura das camadas e a escolha dos módulos iniciais. O critério de convergência também vai ter influência relativa no procedimento. Vários critérios podem ser utilizados para limitar a diferença entre as deflexões medidas e calculadas no processo iterativo, para o ajusto das bacias, dentre esses: o erro relativo em cada sensor; a soma dos valores absolutos das diferenças entre deflexões medida e calculada em cada sensor; soma das diferenças ao quadrado e raiz média quadrática (Medina \& Mota, 2015). A iteração manual das deferências entre as curvas deflectométricas medidas e calculas é um processo bastante tedioso. Atualmente, existem programas computacionais que permitem a automatização da retroanálise dos pavimentos. Entre esses tem-se, o ELMOD desenvolvido e disponibilizado pela Dynatest para os equipamentos FWD da mesma marca, o EVERCALC, o BAKFAA da Federation Administration Administration e disponível gratuitamente na internet, entre outros. No Brasil, foi desenvolvido e está sendo aprimorado o programa de dimensionamento e verificação de pavimento asfálticos SISPAV por Franco (2007). Este através do seu módulo RETRONÁLISE permite realizar retroanálise de pavimentos. Vale ressaltar que, por inferir o módulo equivalente de um sistema de camadas, a boa interpretação dos resultados obtidos do processo de retroanálise depende muito da experiência do engenheiro visto que uma mesma bacia deflectométrica pode representar combinação de módulos de bem distintos. 


\section{CAPÍTULO 3}

\section{3 - METODOLOGIA}

Nesse capítulo são apresentados os materiais e as misturas utilizadas nesta pesquisa. Em seguida, são descritos todos os ensaios de laboratório e de campo realizados neste trabalho assim como o levantamento dos defeitos de pavimento observados na pista experimental.

\section{1 - MATERIAIS}

Os principais materiais utilizados neste trabalho foram o fosfogesso di-hidratado, o solo e cal. A partir desses materiais, foram realizadas e estudadas diversas misturas em laboratório. $\mathrm{O}$ fosfogesso foi fornecido pela empresa AngloAmerican Ldta, localizada na cidade de Catalão - GO. Trata-se de um fosfogesso de tipo dihidratado e seu aspecto depois da coleta pode ser visto na Figura 3.1.
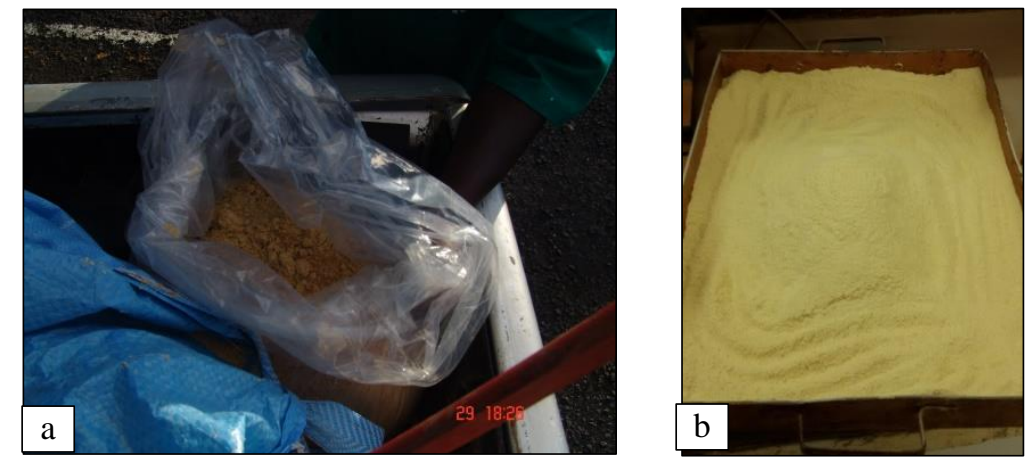

Figura 3.1. Aspetos do fosfogesso: (a) Logo após a coleta; (b) Após secagem em laboratório.

No intuito de melhor analisar o efeito do teor de fosfogesso nas propriedades geotécnicas das misturas com solo, num primeiro momento foram escolhidos cinco teores desse subproduto para a análise: 10, 15, 20, 25 e 30\%. Estimou-se que teores de fosfogesso menores que 10\% tornariam economicamente inviável o reaproveitamento desse resíduo, enquanto o máximo de $30 \%$ foi escolhido para melhor entender e avaliar o comportamento das misturas com teores um pouco acima dos $20 \%$ sugeridos por Mesquita (2007). Tendo em vista que a viabilidade 
econômica do uso de um resíduo só é justificada se o mesmo é reutilizado na região onde é gerado, resolveu-se desenvolver a pesquisa com o solo coletado na própria cidade de Catalão - GO. Com base no plano diretor de desenvolvimento urbano e ambientalmente sustentável da cidade de Catalão promulgado em 05.08.2004, foi escolhido um ponto de coleta de forma que o material selecionado para a pesquisa fosse o mesmo encontrado nas principais zonas de expansão futura da cidade. Conforme indicado na Figura 3.2, o ponto de coleta do solo utilizado neste estudo encontra-se na latitude: -18.1429760903 e longitude: -47.9518463742 , próximo à rodovia estadual GO-330. Nessa figura, também possível localizar área de geração do fosfogesso. As Figuras 3.3(a) e (b) ilustram a operação de coleta do solo.

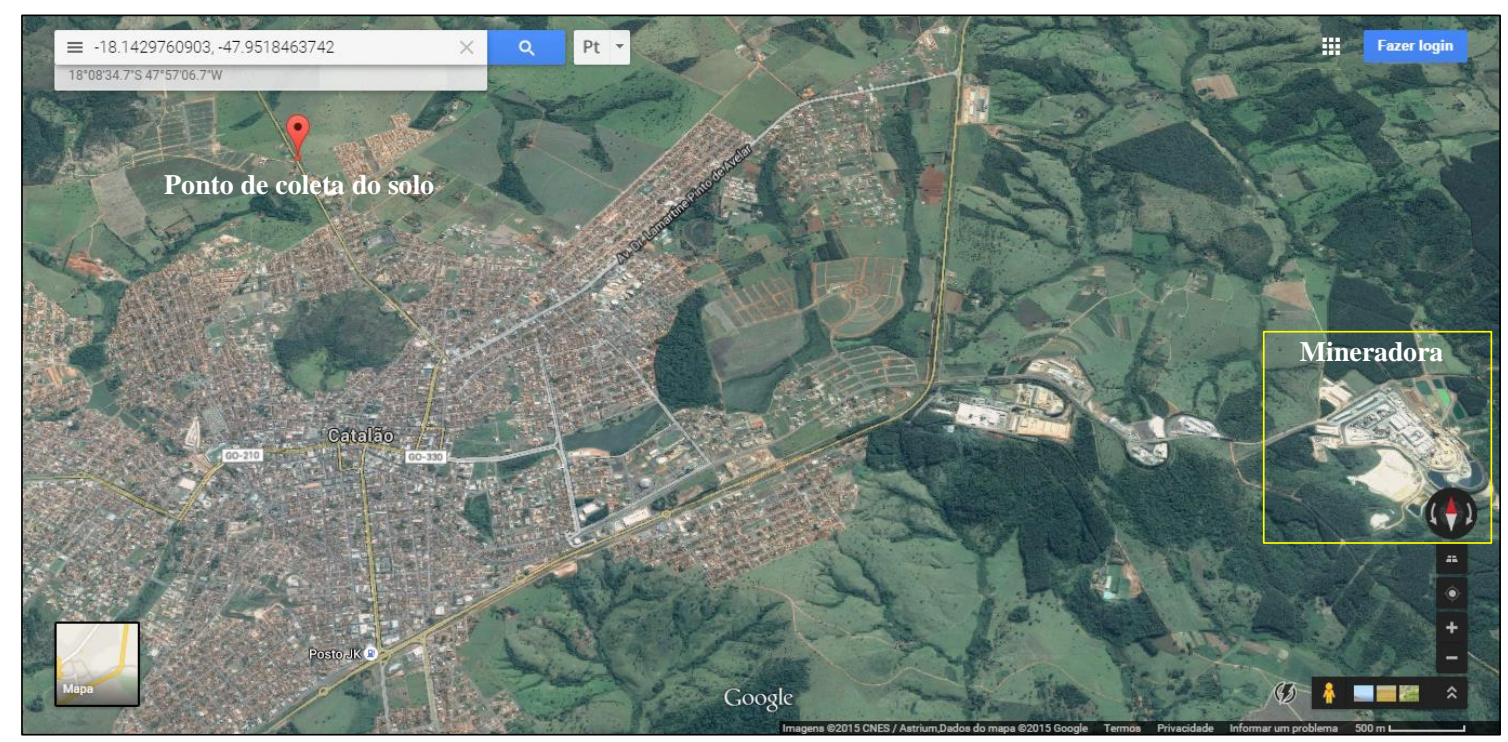

Figura 3.2. Localização do ponto de coleta dos solos e da área de geração do fosfogesso. (Google Maps, 2015).
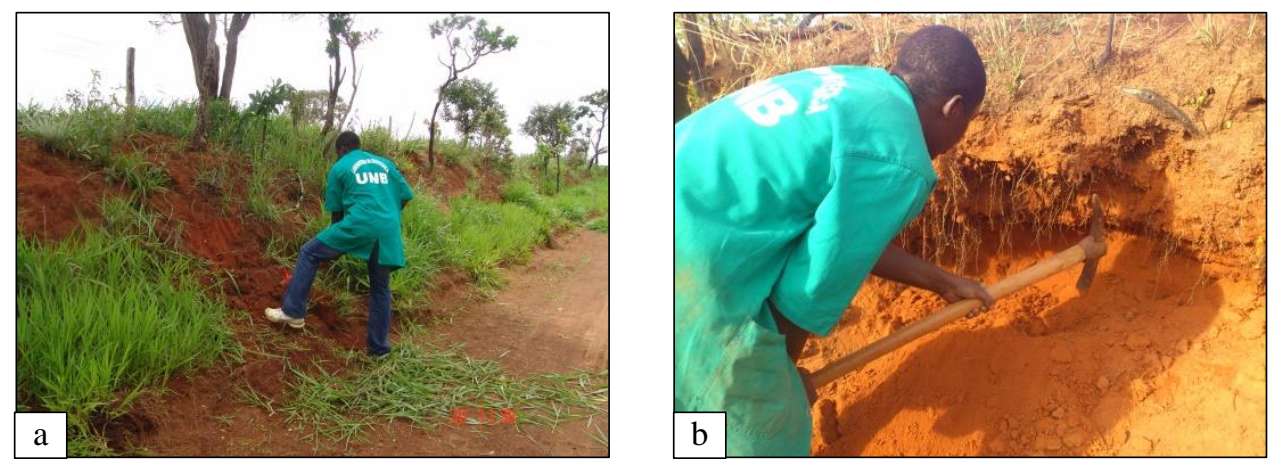

Figura 3.3. Processo de coleta das amostras de solo nas margens da rodovia GO-330 em Catalão. a) Retirada da camada vegetal. b)Coleta da amostra.

Como estabilizante químico, usou-se a cal hidratada do tipo CHIII, uma vez que a mesma já vem sendo utilizada em pesquisas anteriores e inclusive para a construção da pista experimental monitorada neste trabalho. Além disso, esse tipo de cal hidratada é a que apresenta maior disponibilidade no mercado local. Para melhor acompanhar a influência desse 
estabilizante nas misturas, foram adotados os teores de 2, 4, 6, 8 e $10 \%$. Com os materais selecionados, foram realizadas misturas que permitissem uma melhor avaliação da influência de cada componente. Essas misturas foram divididas em dois grupos denominados G-I e G-II, respectivamente. Na Tabela 3.1 estão apresentadas as diferentes dosagens estudadas. Observase que o grupo G-I permitiu avaliar melhor a influência do fosfogesso no solo, enquanto as misturas G-I-1, G-II-1, G-II-7, G-II-13, G-II-19, G-II-5 salientam mais o efeito da cal sozinha associada ao solo. O material com a denominação G-I-1 refere-se ao solo sem aditivo e serviu de referência nesta pesquisa. A Figura 3.4 mostra o solo, o fosfogesso, a cal e as misturas analisadas nesta pesquisa.

\begin{tabular}{|c|c|c|c|c|}
\hline \multirow{7}{*}{ GRUPO G-I } & Materiais & S (\%) & FG (\%) & $\mathrm{CH}(\%)$ \\
\hline & G-I-1 & 100 & 0 & 0 \\
\hline & G-I-2 & 90 & 10 & 0 \\
\hline & G-I-3 & 85 & 15 & 0 \\
\hline & G-I-4 & 80 & 20 & 0 \\
\hline & G-I-5 & 75 & 25 & 0 \\
\hline & G-I-6 & 70 & 30 & 0 \\
\hline \multirow{30}{*}{ GRUPO G-II } & G-II-1 & 98 & 0 & 2 \\
\hline & G-II-2 & 88 & 10 & 2 \\
\hline & G-II-3 & 83 & 15 & 2 \\
\hline & G-II-4 & 78 & 20 & 2 \\
\hline & G-II-5 & 73 & 25 & 2 \\
\hline & G-II-6 & 68 & 30 & 2 \\
\hline & G-II-7 & 96 & 0 & 4 \\
\hline & G-II-8 & 86 & 10 & 4 \\
\hline & G-II-9 & 81 & 15 & 4 \\
\hline & G-II-10 & 76 & 20 & 4 \\
\hline & G-II-11 & 71 & 25 & 4 \\
\hline & G-II-12 & 66 & 30 & 4 \\
\hline & G-II-13 & 94 & 0 & 6 \\
\hline & G-II-14 & 84 & 10 & 6 \\
\hline & G-II-15 & 79 & 15 & 6 \\
\hline & G-II-16 & 74 & 20 & 6 \\
\hline & G-II-17 & 69 & 25 & 6 \\
\hline & G-II-18 & 64 & 30 & 6 \\
\hline & G-II-19 & 92 & 0 & 8 \\
\hline & G-II-20 & 82 & 10 & 8 \\
\hline & G-II-21 & 77 & 15 & 8 \\
\hline & G-II-22 & 72 & 20 & 8 \\
\hline & G-II-23 & 67 & 25 & 8 \\
\hline & G-II-24 & 62 & 30 & 8 \\
\hline & G-II-25 & 90 & 0 & 10 \\
\hline & G-II-26 & 80 & 10 & 10 \\
\hline & G-II-27 & 75 & 15 & 10 \\
\hline & G-II-28 & 70 & 20 & 10 \\
\hline & G-II-29 & 65 & 25 & 10 \\
\hline & G-II-30 & 60 & 30 & 10 \\
\hline
\end{tabular}

Obs. $\mathrm{S}=$ Solo; $\mathrm{FG}=$ Fosfogesso; $\mathrm{CH}=\mathrm{Cal}$ hidratada. 


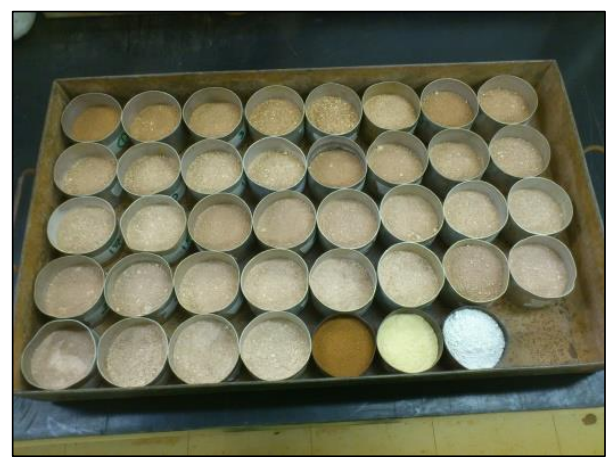

Figura 3.4. Solo, fofogesso, cal e misturas estudadas na primeira fase dos ensaios.

\section{2 - MÉTODOS}

Nesse parágrafo são apresentados e descritos todos os ensaios de laboratório e de campo realizados nesta pesquisa assim como o levantamento dos defeitos observados na pista experimental de Aparecida de Goiânia (GO).

\subsection{1 - ENSAIOS DE LABORATÓRIO}

Os ensaios de laboratório tiveram como objetivo principal caracterizar e avaliar as propriedades tecnológicas dos materiais estudados.

\subsubsection{1- ENSAIOS DE CARACTERIZAÇÃO}

Essa fase teve como principal finalidade o enquadramento do solo e das misturas de acordo com os sistemas convencionais de classificação do "Transportation Research Board" (TRB) e do Sistema Unificado de Classificação dos Solos (SUCS) e a determinação de algumas propriedades físicas dos materiais. Para tanto, foram realizados os ensaios de:

- Limites de consistência de acordo com as normas NBR 6459 (ABNT, 1984a) e NBR 7180 (ABNT, 1984b).

- Granulometria com e sem defloculante para o solo de acordo com a norma NBR 7181 (ABNT, 1984).

- Granulometria sem defloculante para o solo, o fosfogesso, a cal e as misturas com a utilização do granulômetro a laser MICROTRAC S3500 ilustrado na Figura 3.5(a). Esse equipamento pode ser utilizado para materiais de faixa granulométrica de 0,02 a $3000 \mu \mathrm{m}$ e as análises podem ser realizadas com ou sem a utilização do ultrassom para a desagregação física dos agregados. 
- Massa específica dos grãos de acordo com a norma ASTM-D5550-06 (ASTM, 2006) com o uso do PENTAPYC 5200e para o solo, o fosfogesso, a cal e as diferentes misturas. O PENTAPYC 5200e apresentado na Figura 3.5(b) é um equipamento adquirido pelo Laboratório de Geotecnia da Universidade de Brasília em 2011 que permite a determinação da massa específica dos grãos de cinco amostras de forma rápida e simultânea.

- Potencial hidrogeniônico pH para avaliar sua variação com o aumento dos teores de fosfogesso e cal no solo. A Figura 3.6 ilustra alguns passos desse ensaio.

- Difratometria de raios-X realizados no Instituto de Geociências da Universidade de Brasília no intuito de acompanhar o processo a formação de novos minerais, em misturas de solo, fosfogesso e cal. O mineral de maior interesse nessas investigações foi a etringita, principal responsável pela expansão das misturas. A Figura 3.7 mostra o equipamento de difratometria utilizado, da marca RIGAKU assim como uma vista da interface do software de tratamento dos dados.
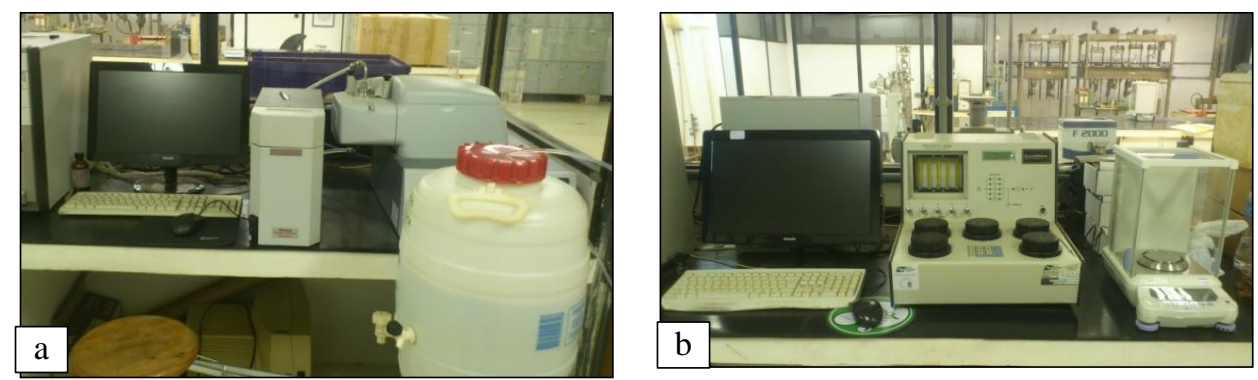

Figura 3.5. Equipamentos utilizados para os ensaios de caracterização (a) Granulômetro a laser MICROTRAC S3500; (b) PENTAPYC 5200e.
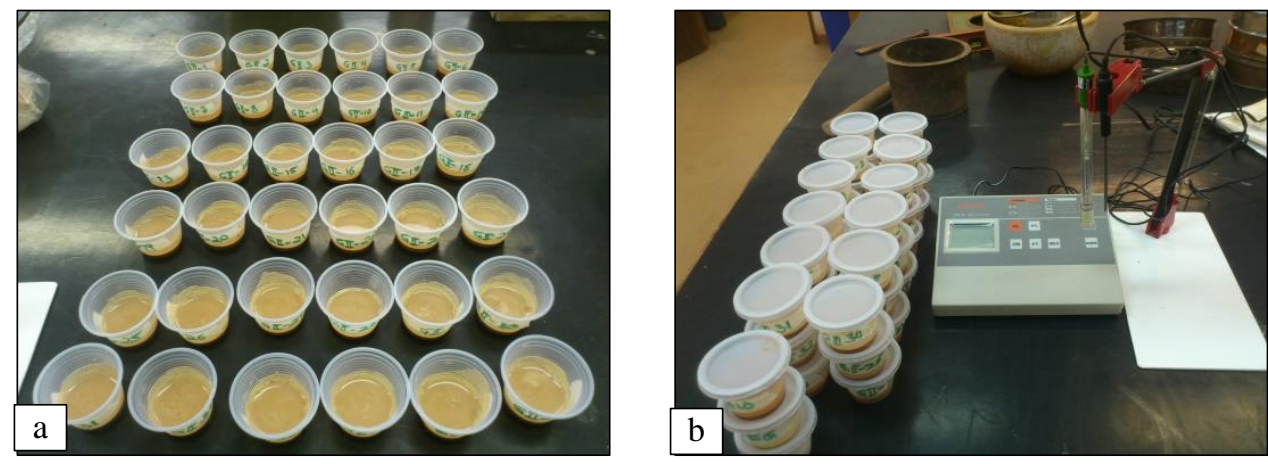

Figura 3.6. Execução dos ensaios de medição de pH: (a)Preparação das amostras; (b)pHmetro digital. 

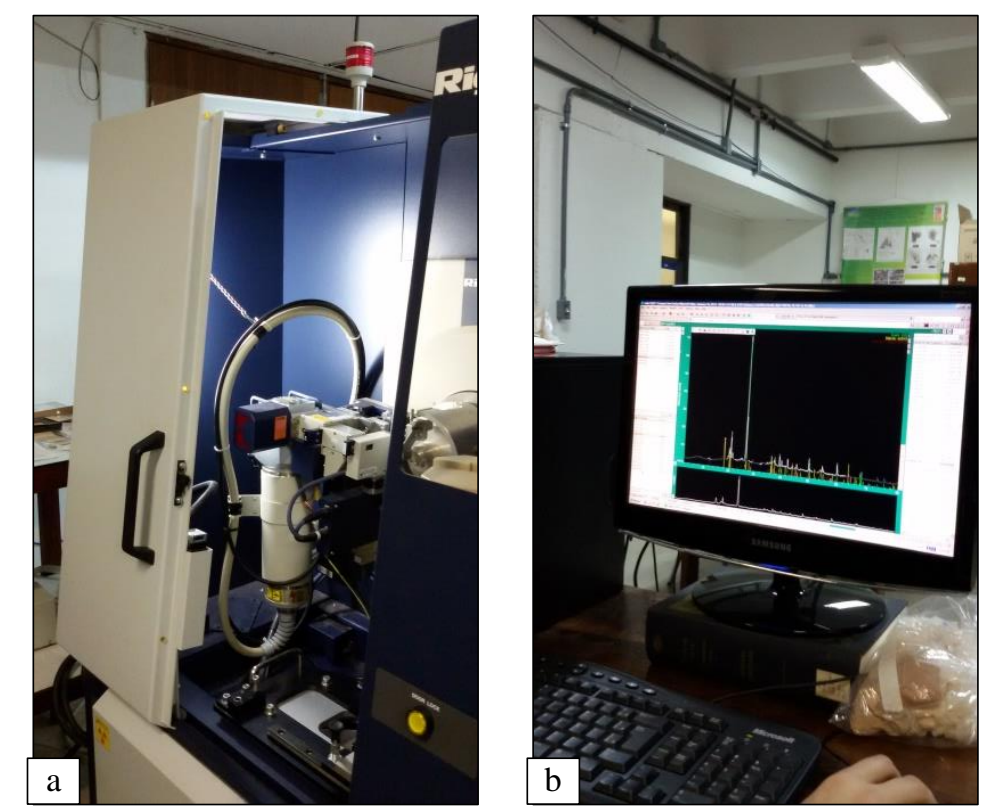

Figura 3.7. Execução dos ensaios de difratometria de raios-X: (a) Equipamento de difratometria de raio-X da marca RIGAKU; (b) Tratamento dos dados.

\subsubsection{2 - ENSAIOS DA METODOLOGIA MCT}

No intuito de classificar o solo da presente pesquisa de acordo com a metodologia MCT, foram realizados os ensaios de compactação Mini-MCV e perda de massa por imersão de acordo com as normas DNER-ME 258/94 e DNER-ME 256/94 (DNER, 1994). Salienta-se que a metodologia MCT apresenta-se atualmente como a mais indicada para a classificação dos solos tropicais para fins rodoviários. De acordo com seus idealizadores, essa metodologia permite classificar os materiais em função do seu desempenho tecnológico, diferentemente das classificações tradicionais que, por sua vez são baseadas na granulometria e nos limites de consistências dos materiais (Villibor \& Nogami, 2009). Na Figura 3.8 são ilustrados alguns detalhes dos ensaios da metodologia MCT para fins classificatórios.
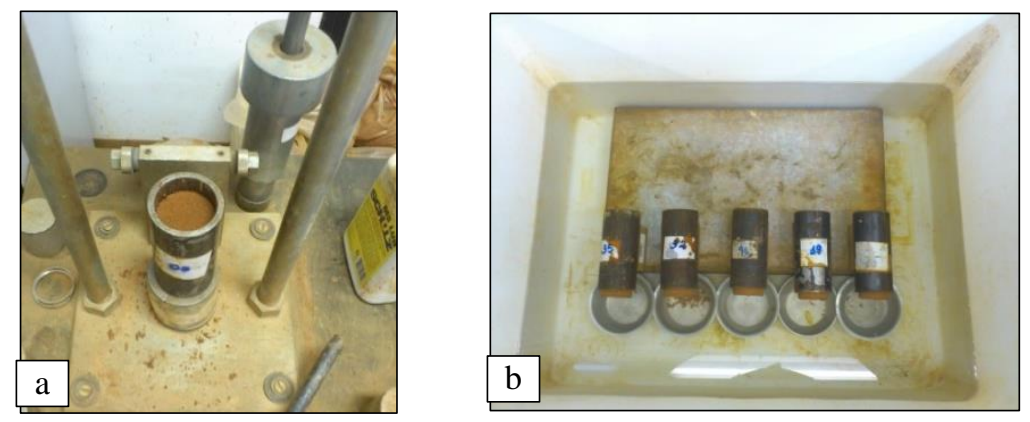

Figura 3.8. Ensaios da classificação MCT. (a) Compactação Mini-MCV; (b) Perda de massa por imersão. 


\subsubsection{3 - ENSAIOS DE COMPACTAÇÃO MINI-PROCTOR, EXPANSÃO E MINI-CBR}

Tendo em vista a quantidade significativa de amostras e o fato deste estudo envolver materiais finos tropicais, avaliou-se mais adequado recorrer aos ensaios mini-Proctor (ME 228 - DNER, 1994a) e expansão - mini-CBR (ME 254- DNER, 1997) para a determinação dos parâmetros de compactação, valores de expansão e índice de suporte dos materiais, em vez dos ensaios convencionais de compactação, expansão e CBR. Ainda, para verificar o efeito da imersão na perda da resistência das amostras, foram realizados ensaios adicionais de mini-CBR sem imersão. Como se pretende aplicar os materiais em camada de base optou-se por utilizar a energia de compactação intermediária. Sabe-se que as misturas solo+fosfogesso+cal possuem um potencial expansivo significativo em razão da formação da etringita após a imersão dos corpos de prova (Rufo, 2009; Metogo, 2010). Como tentativa de controlar essa expansão, foram compactados dois grupos de corpos de prova. Um primeiro grupo constituído por corpos de prova ensaiados conforme a norma DNER-ME 254 (DNER, 1997), ou seja, com imersão imediata, leitura da expansão após 24 horas e execução do ensaio mini-CBR. O segundo grupo foi constituído por corpos de provas compactados nas mesmas condições de umidade e energia, porém, deixados em cura de 7 dias na câmara úmida antes da imersão, expansão e mini-CBR. Como mostrado na Equação 3.1, a formação da etringita está intimamente relacionada ao acréscimo da água nas misturas.

$6 \mathrm{Ca}^{2+}+2 \mathrm{Al}\left(\mathrm{OH}_{4}\right)^{-}+4 \mathrm{OH}^{-}+3\left(\mathrm{SO}_{4}\right)^{2}-+26 \mathrm{H}_{2} \mathrm{O} \rightarrow \mathrm{Ca}_{6} \mathrm{Al}_{2}\left(\mathrm{SO}_{4}\right)_{3}(\mathrm{OH})_{12}, 26 \mathrm{H}_{2} \mathrm{O}$

De acordo com Ouhadi \& Yong (2008), a etringita atinge seu estágio final 48 horas após a hidratação dos materiais, e já com 24 horas esse mineral encontra-se a 83\% da sua formação. Trata-se, portanto de uma reação rápida e sendo assim, se torna uma concorrente significativa para as reações de floculação e pozolânicas proporcionadas pela presença da cal nas misturas. Observar um tempo de cura antes da imersão visou, portanto, favorecer o desenvolvimento das reações de floculação e as pozolânicas antes da saturação dos corpos de prova e, consequentemente, controlar a formação da etringita e a expansão excessiva das misturas. Uma vez que na prática de construção rodoviária é sempre recomendado executar as camadas de base durante a estação seca, acredita-se que nessa condição, o prazo de cura de 7 dias seria razoável para a pista não sofrer danos devidos à saturação provocada por forte chuva. Para os dois grupos de amostras, os ensaios de mini-CBR foram executados para verificar a 
ocorrências ou não das reações pozolânicas. A Figura 3.9 mostra a execução dos ensaios de expansão e mini-CBR.
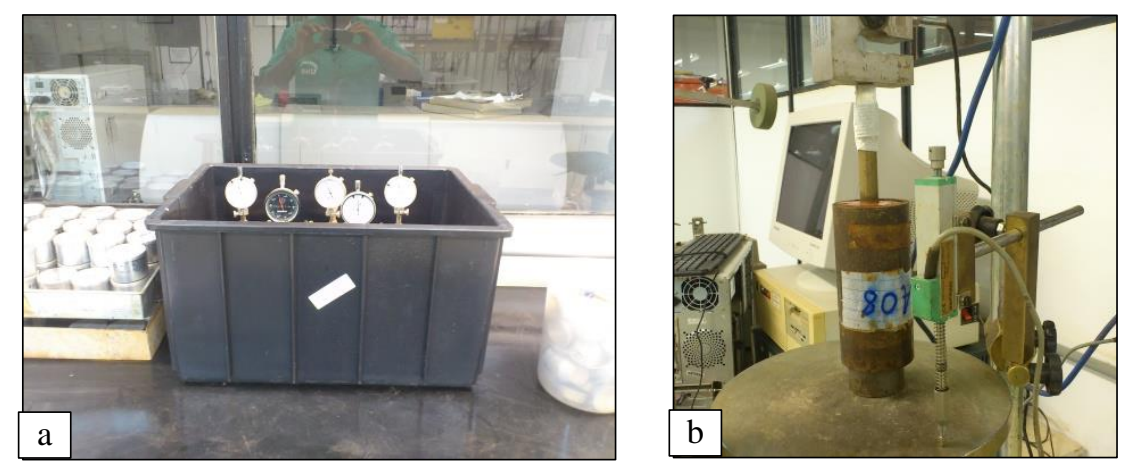

Figura 3.9. Ensaios a) Expansão. b) Mini-CBR com imersão.

\subsubsection{4 - ENSAIOS DE COMPRESSÃO SIMPLES}

Os ensaios de compressão simples foram realizados de acordo com a norma NBR 12770 (ABNT, 1992), com a velocidade de 1,25mm/min. Esses ensaios tiveram como objetivo obter as curvas tensão-deformação dos materiais e suas resistências de ruptura. Os ensaios para determinação da resistência à compressão simples são tradicionalmente utilizados para acompanhar os ganhos de resistência entre as misturas e com o tempo de cura. Nesse caso, apenas para as misturas que apresentaram bom desempenho nos ensaios de mini-CBR foram realizados esses ensaios e com períodos de curas diferentes para acompanhar a evolução da resistência ao longo do tempo. Os tempos de cura adotados foram de 7, 14, 28 e 60 dias. As amostras foram moldadas nas condições de compactação mini-Protor na energia intermediária. Para a cura, os corpos de provas foram envelopados com papel filme e mantidos em caixas de isopor fechadas para garantir que não ocorresse perda de umidade. Para tentar reproduzir as condições de compactação dinâmica do campo e manter a homogeneidade da massa específica absoluta, os corpos de prova foram todos compactados de acordo com o seguinte roteiro:

1. Separou-se aproximadamente $400 \mathrm{~g}$ de material seco próximo a sua umidade higroscópica. Essa umidade era constantemente avaliada para evitar eventuais erros na fase de umedecimento.

2. Determinou-se a quantidade de água necessária para atingir a umidade ótima da amostra. Esta água foi adicionada ao material seco, misturada e deixada em repouso por no mínimo 12 horas para garantir o total umedecimento da amostra. 
3. Calculou-se a massa de solo a ser compactada para obter um corpo de prova de $5 \mathrm{~cm}$ de diâmetro para $10 \mathrm{~cm}$ de altura, na umidade ótima e peso específico seco aparente máximo previamente determinados.

4. A massa calculada anteriormente foi dividida em cinco pacotes pequenos correspondendo a cada camada de material a ser compactada no molde.

5. Foram delimitadas as espessuras na circunferência do pistão que seria utilizado para a compressão das camadas e garantir a espessura requerida para cada camada.

6. Para uma melhor extração dos corpos de prova, utilizou-se um molde tripartido com base e colarinhos e cabeçote para a moldagem dos corpos de prova.

7. Uma fina camada vaselina também foi colocada nas faces internas das três partes do molde para facilitar a extração dos corpos de prova no fim da moldagem.

8. Essas faces foram montadas na base do molde e travadas com ajuda de colarinhos e chaves.

9. No fundo do molde foi colocado um papel filtro.

10. Despejou-se o material correspondente a confecção da primeira camada, um dos cinco pacotes, e o conjunto foi levado para a prensa eletromecânica de CBR.

11. Foi posicionado o pistão dentro do cilindro.

12. Verificou-se o dispositivo de reação.

13. Foi ligado o equipamento e este levantou a base móvel da prensa junto com o conjunto composto pelo molde tripartido e o pistão até encostar-se ao sistema de reação e realizar a compactação da camada.

14. Após a moldagem da primeira camada do corpo prova, o conjunto foi retirado da prensa e, com a ajuda de uma chave de fenda (ou estrela), a camada foi escarificada.

15. Despejou-se a segunda remessa de material e o processo de compactação foi repetido até a obtenção do corpo de prova final.

16. Em seguida, foi retirado o molde da prensa e em seguida os colarinhos.

17. Sem desfazer as três peças de molde, o conjunto composto pelo molde e o corpo de prova foi retirado da base.

18. Inverteu-se a posição do conjunto, sendo o topo do corpo de prova colocado em cima do pistão utilizado para a compactação.

19. Em seguida, retirou-se cuidadosamente cada uma das partes do molde tripartido aplicando leves golpes sobre a base das peças. 
20. Deste processo, obteve-se um corpo prova perfeitamente cilíndrico conforme apresentado na Figura 3.10.

21. Para fins de verificação, pesou-se e mediu-se as dimensões do corpo de prova deixando-o assim pronto para os demais ensaios.
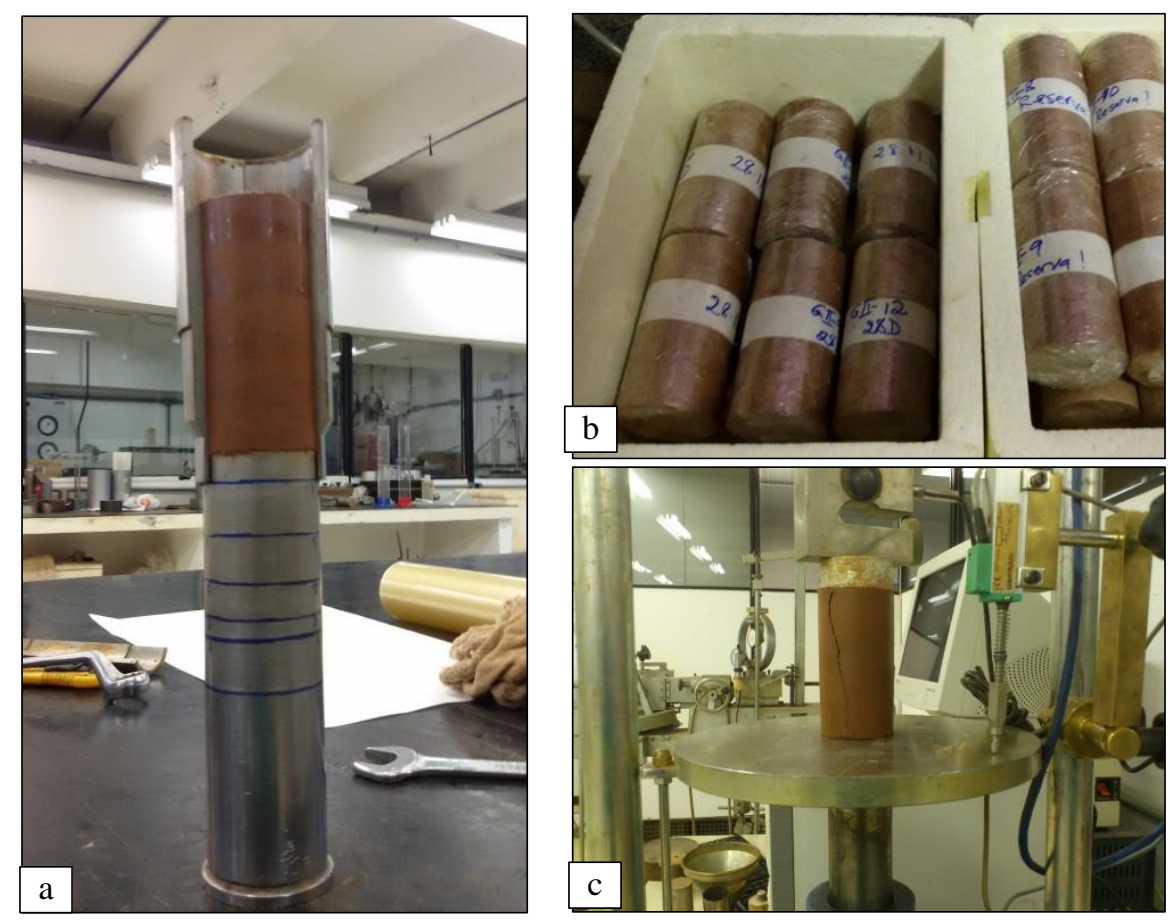

Figura 3.10. Ensaios de compressão simples: (a) Moldagem dos corpos de prova; (b) Armazeneamento dos corpos de prova para cura; (c) Realização do ensaio de compressão simples.

\subsubsection{5 - ENSAIOS PARA DETERMINAÇÃO DOS MÓDULOS DE RESILIÊNCIA}

Os ensaios triaxiais cíclicos foram executados no INFRALAB da Universidade de Brasília e de acordo com a norma T 307-99 (AASHTO, 2003) com o objetivo de determinar os módulos de resiliência dos materiais. O módulo de resiliência é definido pela Equação 3.2 e é importante tanto para dimensionamento de pavimento novo e quanto avaliação estrutural, por retroanálise por exemplo. $\mathrm{O}$ equipamento triaxial utilizado para a execução desse ensaio é constituído por pórticos de reação, câmara triaxial, sistema de válvulas para aplicação de cargas, LVDTs - Linear Variable Differential Transformers para a leitura dos deslocamentos do corpo de prova. O sistema de aquisição de dados utilizado é do próprio equipamento da marca ELE International Limited England. Para esse ensaio, foram utilizadas amostras com as melhores resistências obtidas nos ensaios de compressão simples. Os corpos de provas foram moldados e curados conforme descrito anteriormente para os ensaios de compressão simples. 


$$
M_{r}=\frac{\sigma_{d}}{\varepsilon}
$$

Onde:

$\mathrm{Mr}=$ Módulo de resiliência em MPa;

$\sigma_{d}=$ Tensão desvio;

$\varepsilon=$ Deformação específica recuperável.

Os procedimentos adotados neste ensaio foram realizado conforme os seguintes passos:

1. Os corpos de prova eram inicialmente pesados e suas medidas tomadas.

2. Colocava-se um papel a filtro sobre a base da célula triaxial;

3. Instalava-se o corpo de prova imediatamente em cima do papel filtro;

4. Coloca-se o segundo papel filtro e o cabeçote, no topo do corpo de prova;

5. Envolvia-se o corpo de prova com uma membrana de látex;

6. Colocava-se anéis de borracha na base e no cabeçote para fixação da membrana;

7. Instalava-se a câmara triaxial;

8. Ajustava-se a célula de carga no cabeçote em cima do corpo de prova.

9. Regulava-se a posição dos LVDT’s;

10. Iniciava-se a aplicação da tensão de confinamento;

11. O ensaio era iniciado por meio da aplicação dos ciclos de carregamento. Realizava-se o condicionamento da amostra pela aplicação de 500 carregamentos seguindo os carregamentos de referência do ensaio de acordo com a norma AASHTO T 307-99 (AASHTO, 2003).

12. Depois dos ciclos de carregamento, caso o corpo de prova não rompesse antes do término do ensaio, era possível finalizar com um ensaio de compressão convencional, ou seja, com a pressão de confinamento.

Na Figura 3.11 são apresentados alguns passos de execução do ensaio. Já a Figura 3.12 mostra a tela de saída dos dados do ensaio triaxial. 

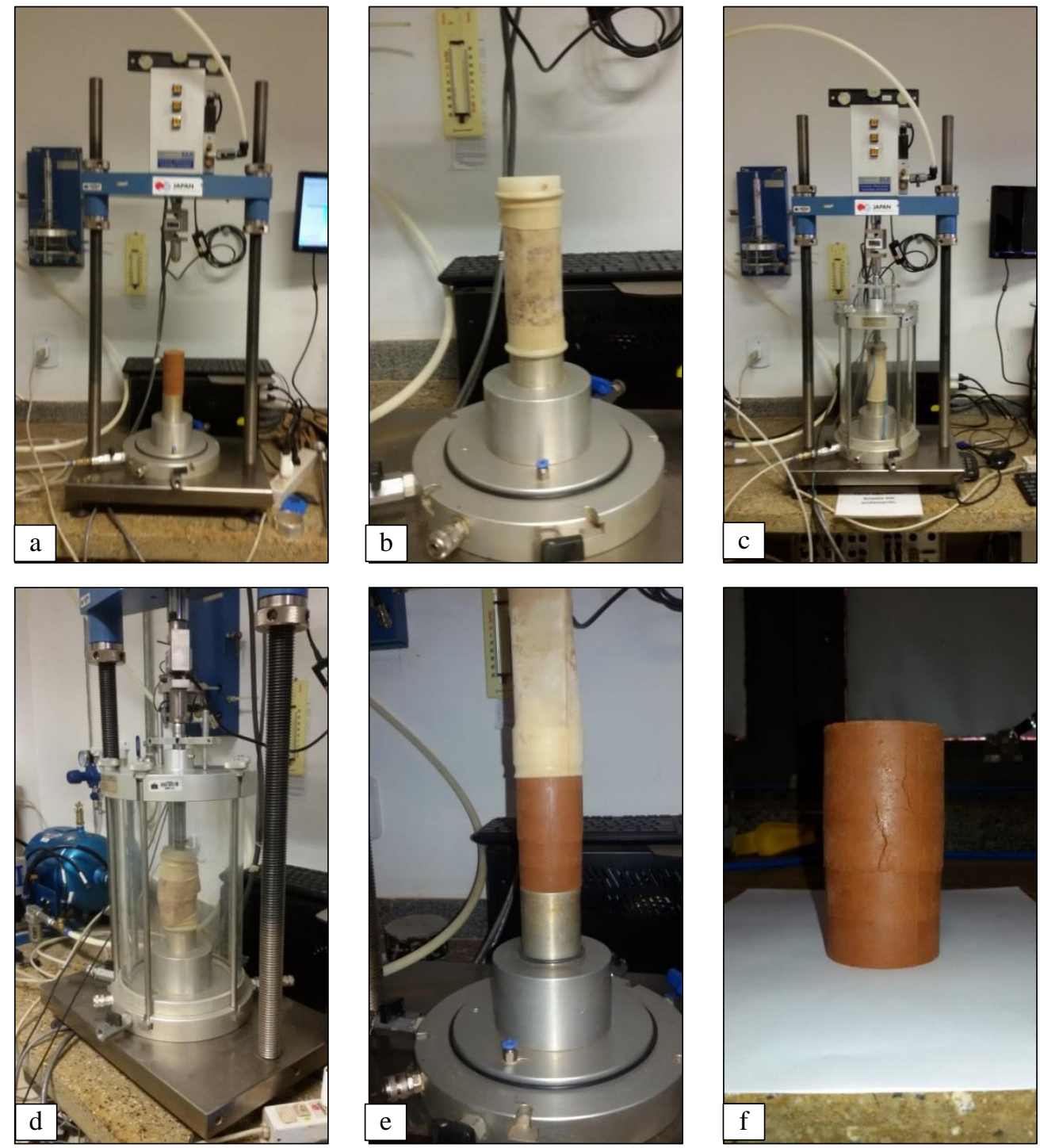

Figura 3.11. Etapas do ensaio triaxial dinâmico: (a) Instalação do corpo de prova na base do equipamento; (b) Instalação da membrana; (c) Corpo de prova montado e pronto para o ensaio; (d) Rompimento do corpo de prova; (e) Corpo de prova rompido (f) Corpo de prova rompido.

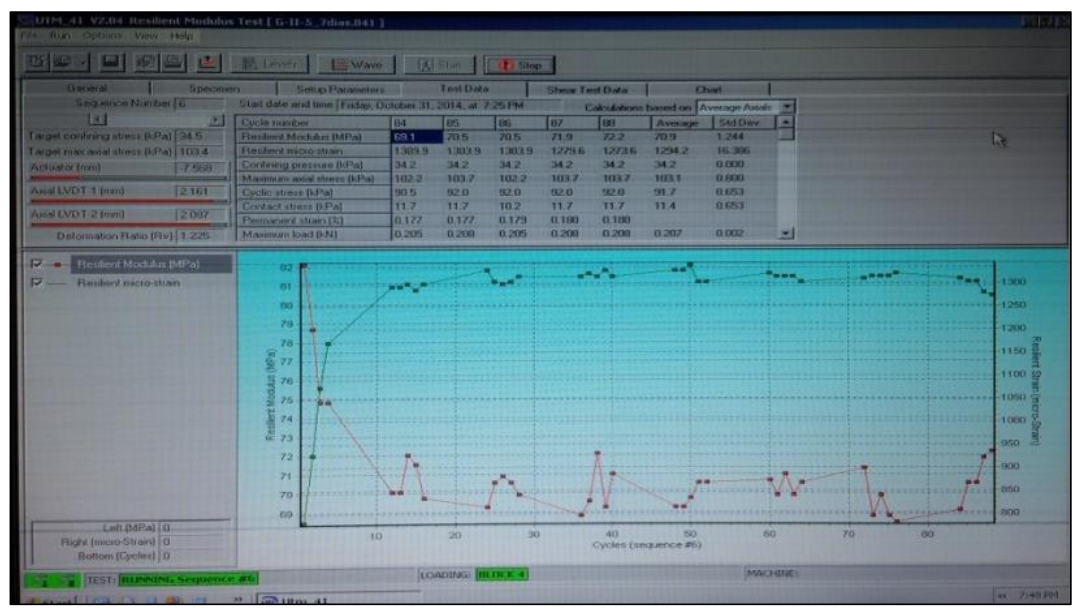

Figura 3.12. Tela de entrada e saída do equipamento do triaxial dinâmico ELE. 


\subsection{2 - ENSAIOS DE CAMPO}

Os ensaios de campo realizados nesta pesquisa tiveram como principal objetivo acompanhar o desempenho estrutural da pista experimental construída em outubro de 2009 no município de Aparecida de Goiânia-GO e acompanhada por Metogo (2010). Nas próximas linhas são descritos mais detalhadamente tanto a pista experimental e quanto esses ensaios. Os ensaios foram executados nas campanhas experimentais de Outubro 2010, Junho 2011, Novembro 2011, Novembro 2012 e Junho 2014.

\subsubsection{1 - PISTA EXPERIMENTAL}

A pista experimental objeto deste trabalho é fruto de uma parceria com a prefeitura de Aparecida de Goiânia e está localizada na Avenida Brasília, Setor Vila Brasília, conforme mostrado na Figura 3.13.

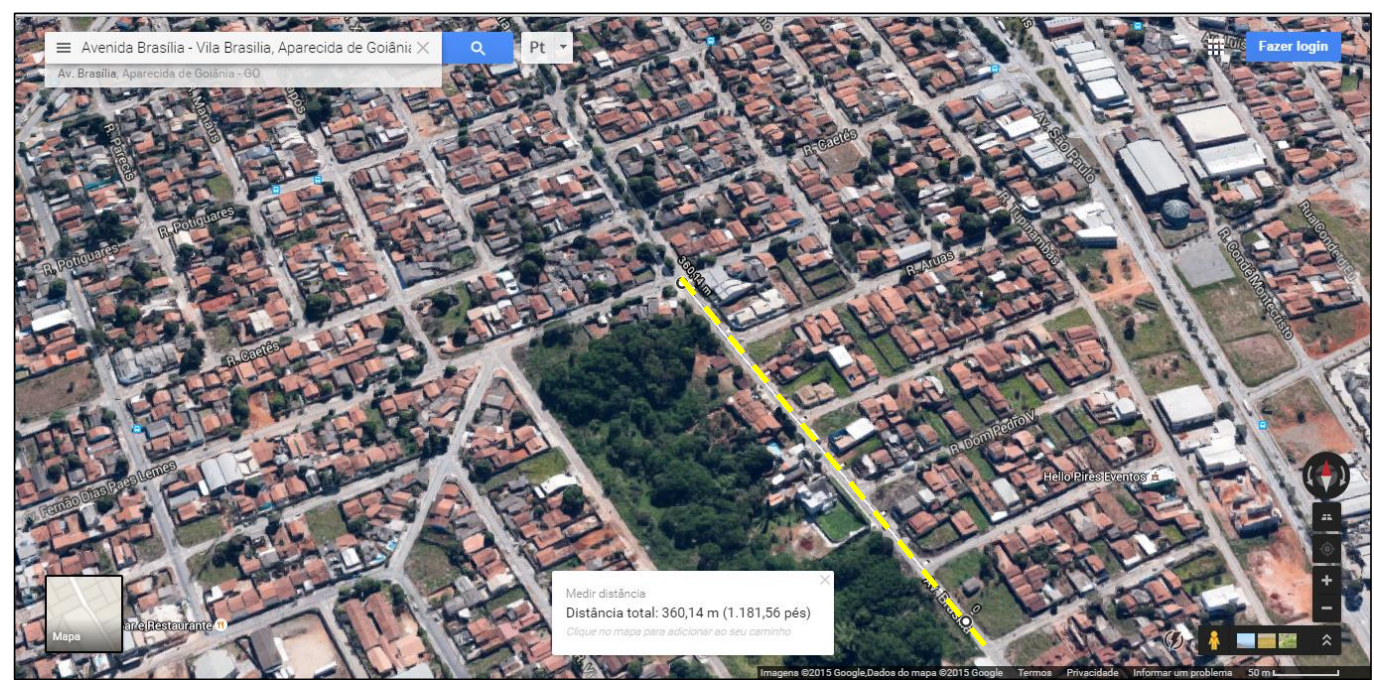

Figura 3.13. Localização da pista experimental, $16^{\circ} 44^{\prime} 45.21$ '’ $-49^{\circ} 15 ' 28.35$ 'W (Google Maps, 2015).

Conforme já descrito por Metogo (2010), essa pista possui uma extensão total de 360 metros e 9 metros de largura. No entanto, a parte referente a esta pesquisa tem 240 metros de comprimento, sendo a outra parte relacionada com as pesquisas desenvolvidas por Cunha (2011) e Marques (2012). Por ser uma via de baixo volume de tráfego, a seção projetada pela prefeitura para este trecho foi de uma camada de base com $15 \mathrm{~cm}$ de espessura e um revestimento em pré-misturado a frio de aproximadamente $3 \mathrm{~cm}$ de espessura como mostrado na Figura 3.14. Para fins de estudo, a pista foi subdividida em quatro subtrechos de 60 metros 
cada, sendo diferenciados apenas pelo tipo de material utilizado na base, conforme descrito a seguir:

- Estaca 0+00 a 3+00: solo local $(80 \%)+$ fosfogesso $(20 \%)$;

- Estaca 3+00 a 6+00: solo local $(80 \%)+$ fosfogesso $(11 \%)+$ cal calcítica CH-III (9\%);

- Estaca 6+00 a 9+00: solo local $(91 \%)+$ cal calcítica CH-III (9\%);

- Estaca $15+00$ a $18+00$ : cascalho $(100 \%)$.

A escolha desses materiais e das porcentagens das misturas foi definida a partir de resultados de ensaios de laboratório realizados por Mesquita (2007), sendo que os subtrechos executados com misturas do solo encontrado no próprio local da obra com fosfogesso e com cal podem ser considerados ambientalmente corretos. A seção em cascalho foi executada para servir de comparação com as misturas alternativas e já que esse foi o material utilizado para a composição da base de todas as vias pavimentadas desse bairro.

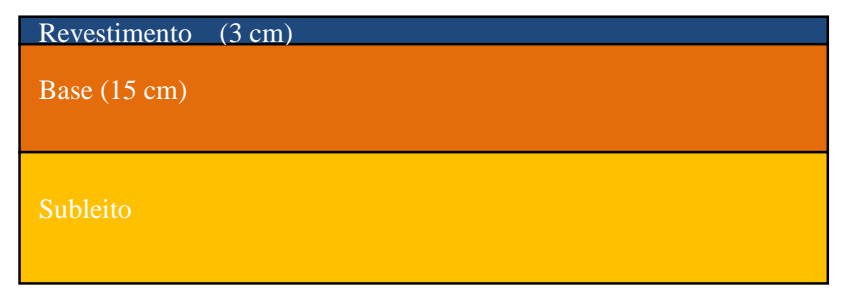

Figura 3.14. Croqui esquemático da estrutura do pavimento analisado (Metogo, 2010).

\subsubsection{2 - ENSAIOS DE VIGA BENKELMAN}

Para o ensaio de viga Benkelman, o equipamento foi inicialmente calibrado conforme recomendação da norma DNER-PRO 175/94 (DNER, 1994b) e em seguida, o ensaio foi realizado de acordo com as especificações da norma ME 24 (DNER, 1994c). Os ensaios foram executados em estacas distantes de $10 \mathrm{~m}$ entre si e locadas em cada bordo ao longo da pista experimental. Estacas pares foram utilizadas para nortear os ensaios no bordo esquerdo do pavimento enquanto as ímpares identificaram os ensaios realizados no bordo direito conforme apresentado na Figura 3.15. A partir desses ensaios, foi possível determinar as deflexões máximas, características e as bacias de deformação do pavimento quando submetido à ação de um caminhão carregado de 8,2t no seu eixo traseiro e com pneus calibrados com $560 \mathrm{kPa}$. A Figura 3.16 ilustra alguns passos da execução desse ensaio em campo. 


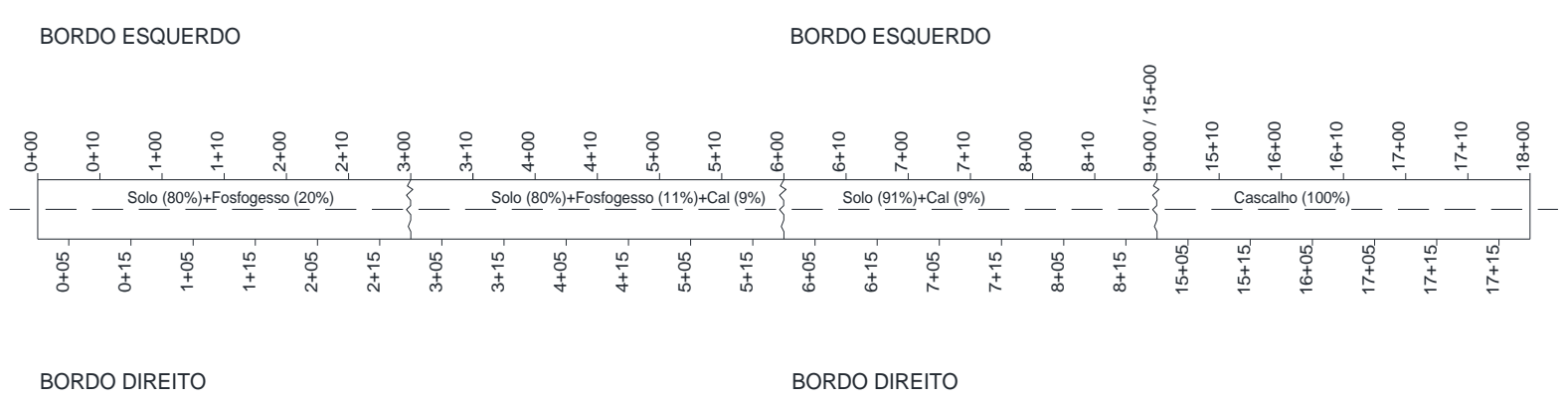

Figura 3.15. Localização das estacas para os ensaios de viga Benkelman.
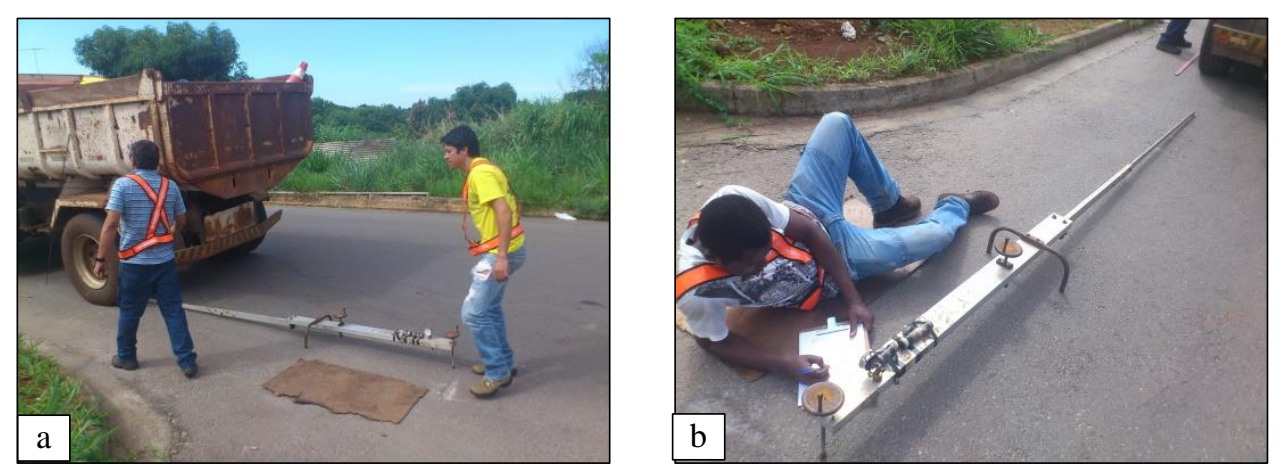

Figura 3.16 Execução dos ensaios de viga Benkelman:(a)Posicionamento da viga; (b) Leitura dos deslocamentos da ponta de ensaio da viga.

\subsubsection{3 - ENSAIOS DE PROVA DE CARGA ESTÁTICA}

Esse ensaio teve como objetivo medir as deformações verticais do pavimento quando submetido à ação de carregamento estático. Para tanto, foram utilizados, uma placa metálica de $30 \mathrm{~cm}$ de diâmetro, um sistema de reação constituído por um caminhão de 8,2t, uma célula de carga acoplada a um macaco hidráulico para medição e aplicação dos carregamentos e três extensômetros com precisão de $0,01 \mathrm{~mm}$ instalados sobre a placa de forma que suas posições formassem um triângulo equilateral. Os extensômetros eram fixados por meio de braços de aço, numa viga metálica horizontal instalada numa distância fora da área de interferência do ensaio. Os ensaios foram realizados com estágios de carregamentos manual de 5 minutos cada um. Após o último estágio de carregamento, procedeu-se o descarregamento com intervalos de tempo maiores, mas também com tempo de estabilização de 5 minutos. O ensaio de prova de carga sobre placa em pavimento é regulamentado pela norma DNIT 055-04 (DNIT, 2004). Para cada trecho estudado, foram realizados três ensaios localizados no bordo esquerdo, centro e no bordo direito da pista, como ilustrado na Figura 3.17. Para evitar qualquer interferência entre os ensaios, foi observada uma distância mínima de $50 \mathrm{~cm}$ entre pontos 
ensaiados em campanhas diferentes. A Figura 3.18 mostra alguns passos da execução do ensaio de prova de carga.

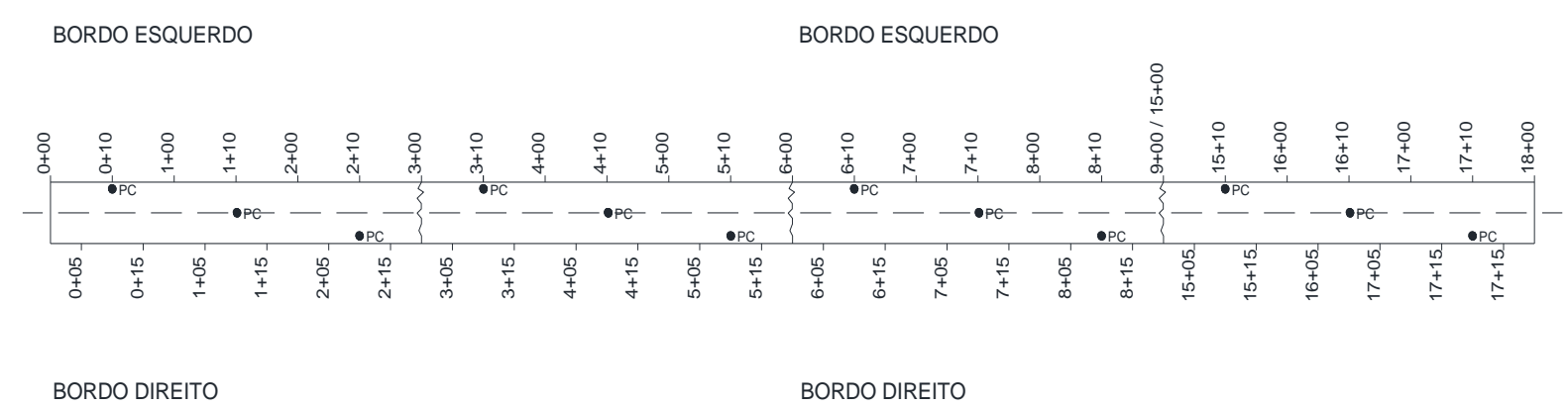

Figura 3.17 - Localização das estacas para os ensaios de prova de carga estática.
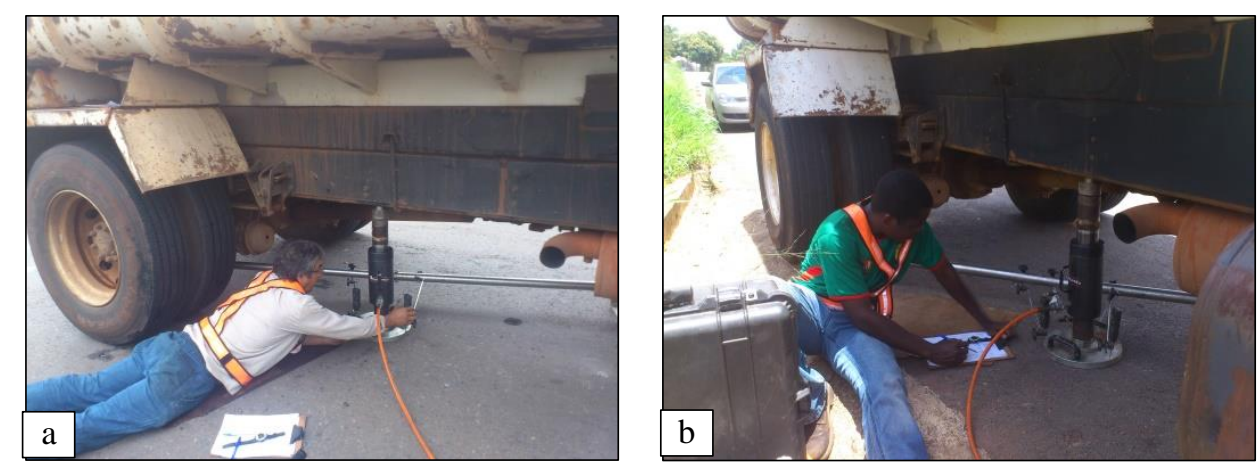

Figura 3.18. Execução dos ensaios de prova de carga estática: (a)Posicionamento do macaco; (b) Leitura dos deslocamentos.

\subsubsection{4 - ENSAIOS DE PENETROMETRO DINÂMICO DE CONE - DCP}

Os ensaios DCP foram realizados aplicando golpes sucessivos com um peso de $8 \mathrm{~kg}$ deixando-o cair em queda livre em uma altura constante de $57,5 \mathrm{~cm}$, sobre um suporte conectado a uma haste de $1 \mathrm{~m}$ de comprimento e munida de uma ponta cônica de $60^{\circ}$ de ângulo de abertura e $20 \mathrm{~mm}$ de diâmetro. A energia devida à queda do peso fazia penetrar essa ponta na camada. Em seguida, media-se a penetração no solo com uma régua metálica fixada ao equipamento. Para cada estaca as leituras iniciavam apenas depois de ter verificado visualmente que o cone tivesse penetrado até o seu diâmetro maior. Os ensaios foram executados nas mesmas estacas definidas para os ensaios de prova de carga e de acordo com a norma D6951-03 (ASTM, 2003). A Figura 3.18 mostra a execução desse ensaio. 


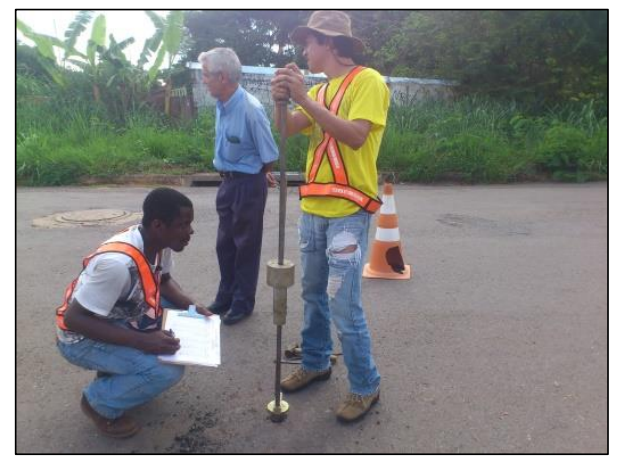

Figura 3.19 Execução do ensaio DCP.

\subsubsection{5 - LEVANTAMENTO DOS DEFEITOS SUPERFICIAIS DO PAVIMENTO}

$\mathrm{Na}$ última campanha de ensaios de campo, além das medições feitas para fins de avaliação estrutural do pavimento, foram realizados alguns levantamentos visuais de defeitos superficiais do pavimento de acordo com a norma DNIT-005/2003-TER (DNIT, 2003) para completar a avaliação do pavimento e auxiliar no melhor entendimento do seu desempenho e degradações. Na Figura 3.20 são ilustrados alguns dos defeitos observados em campo.
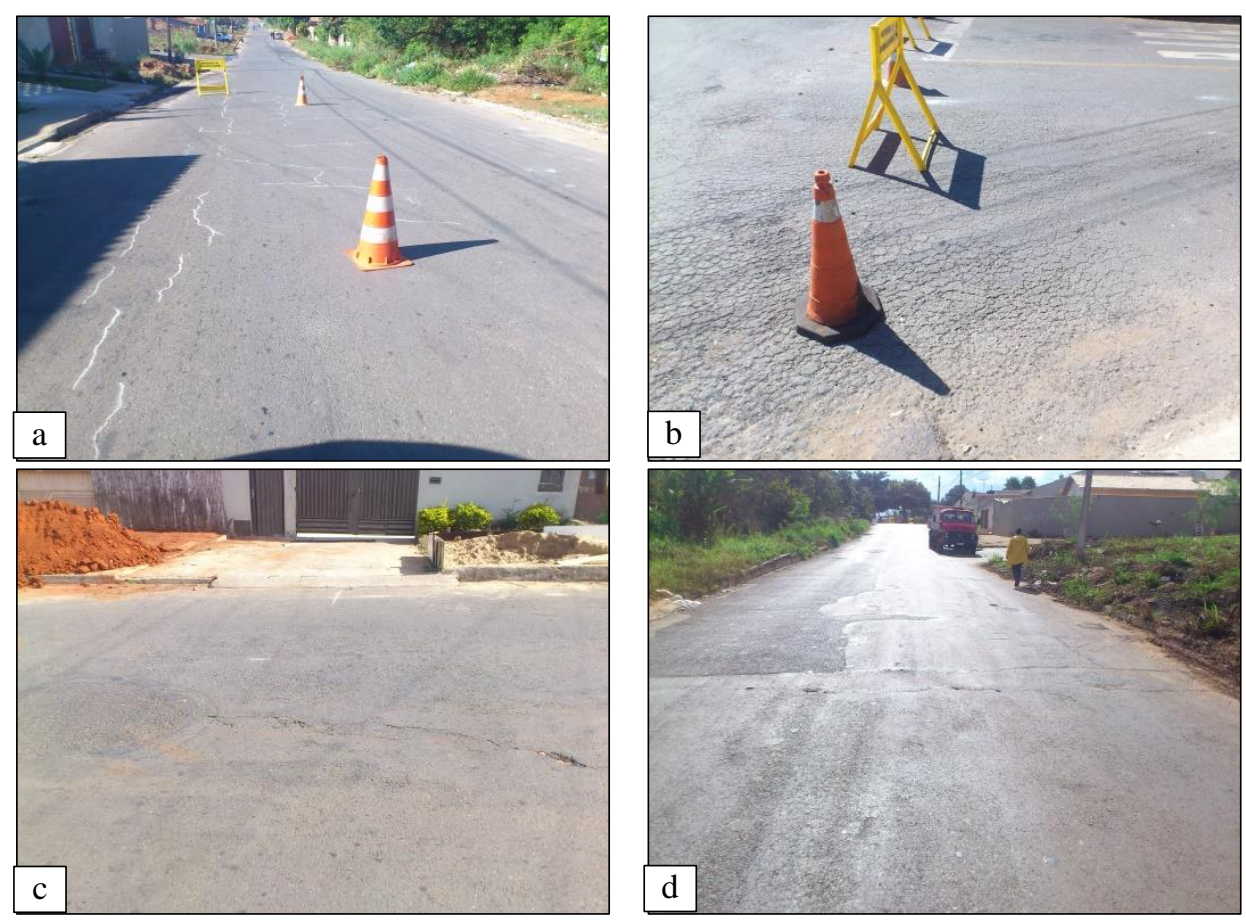

Figura 3.20. Defeitos superficiais levantados em campo em junho de 2014: (a) Trincas longitudinais em trilhas; (b)Trincas tipo couro de jacaré; (c)Trinca longitudinal; (d) Remendos; 


\section{Universidade de Brasília}

Departamento de Engenharia Civil / FT

Programa de Pós-Graduação em Geotecnia
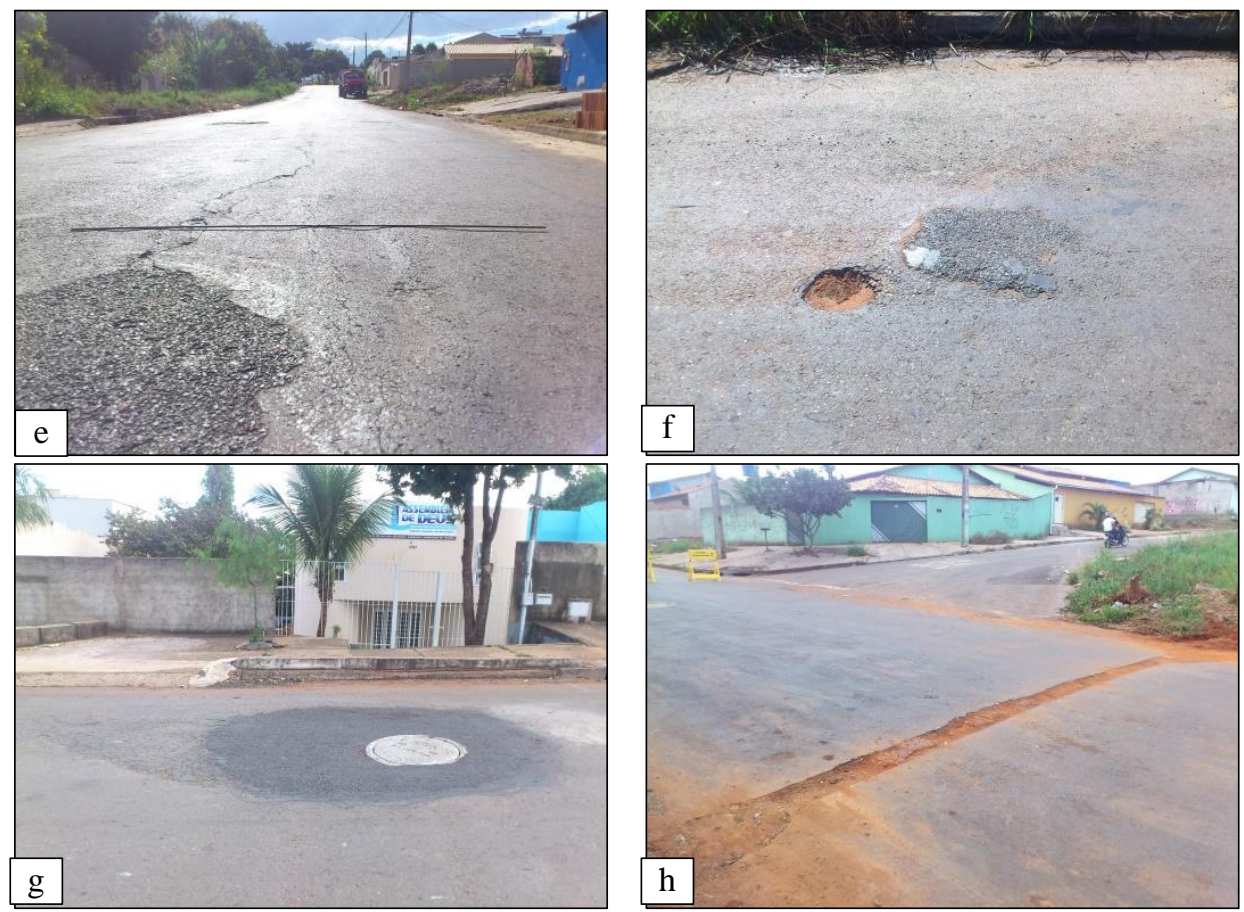

Figura 3.20(continuação). Defeitos superficiais levantados em campo em junho de 2014: (e) Afundamento na trilha de roda interna, trinca longitudinal, remendo; (f) Panela; (g) Instalação da rede de esgoto; (h) Escavação transversal para passagem de canalizações. 


\section{4 - RESULTADOS E ANÁLISES}

Neste capítulo estão apresentados e discutidos todos os resultados obtidos a partir dos ensaios de laboratório realizados com os materiais estudados e dos ensaios de campo executados na pista experimental durante os seis anos de monitoramento, desde sua construção em 2009 até 2014.

\section{1 - ENSAIOS DE LABORATÓRIO}

\subsection{1 - ENSAIOS DE CARACTERIZAÇÃO}

A seguir são apresentados os resultados dos ensaios de caracterização e a classificação dos materiais estudados de acordo com a Transportation Research Board - TRB e o Sistema de Classificação Unificado - SUCS, sendo estes os sistemas de classificação tradicionalmente utilizados na área de geotecnia.

\subsubsection{1 - ANÁLISES GRANULOMÉTRICAS}

A Tabela 4.1 apresenta os resultados obtidos nos ensaios de análise granulométrica sem e com uso de defloculante hexametafosfato de sódio na fase de sedimentação para o solo de acordo com a norma NBR 7181 (ABNT,1984). Dessa análise, o solo apresenta-se como uma areia siltosa quando ensaiado sem defloculante. Quando se utiliza o defloculante, são verificadas variações nos resultados obtidos. O uso do defloculante gera desagregação das partículas de solo, tornando este mais fino. Esse é um comportamento típico dos solos tropicais, cujas concreções são desfeitas pela ação do defloculante. A Figura 4.1 apresenta a distribuição granulométrica do solo com e sem defloculante.

\begin{tabular}{lcc}
\multicolumn{3}{c}{ Tabela 4.1. Frações e parâmetros granulométricos do solo. } \\
\hline Amostra & s/defloculante & c/defloculante \\
\hline Areia Grossa $(2-0,6 \mathrm{~mm})$ & 3,6 & 2,1 \\
\hline Areia Média $(0,6-0,2 \mathrm{~mm})$ & 44,8 & 40,8 \\
\hline Areia Fina $(0,2-0,06 \mathrm{~mm})$ & 35,6 & 21,2 \\
\hline Silte $(0,06-0,002 \mathrm{~mm})$ & 16,0 & 10,1 \\
\hline Argila $(<0,002 \mathrm{~mm})$ & 0,0 & 25,9
\end{tabular}




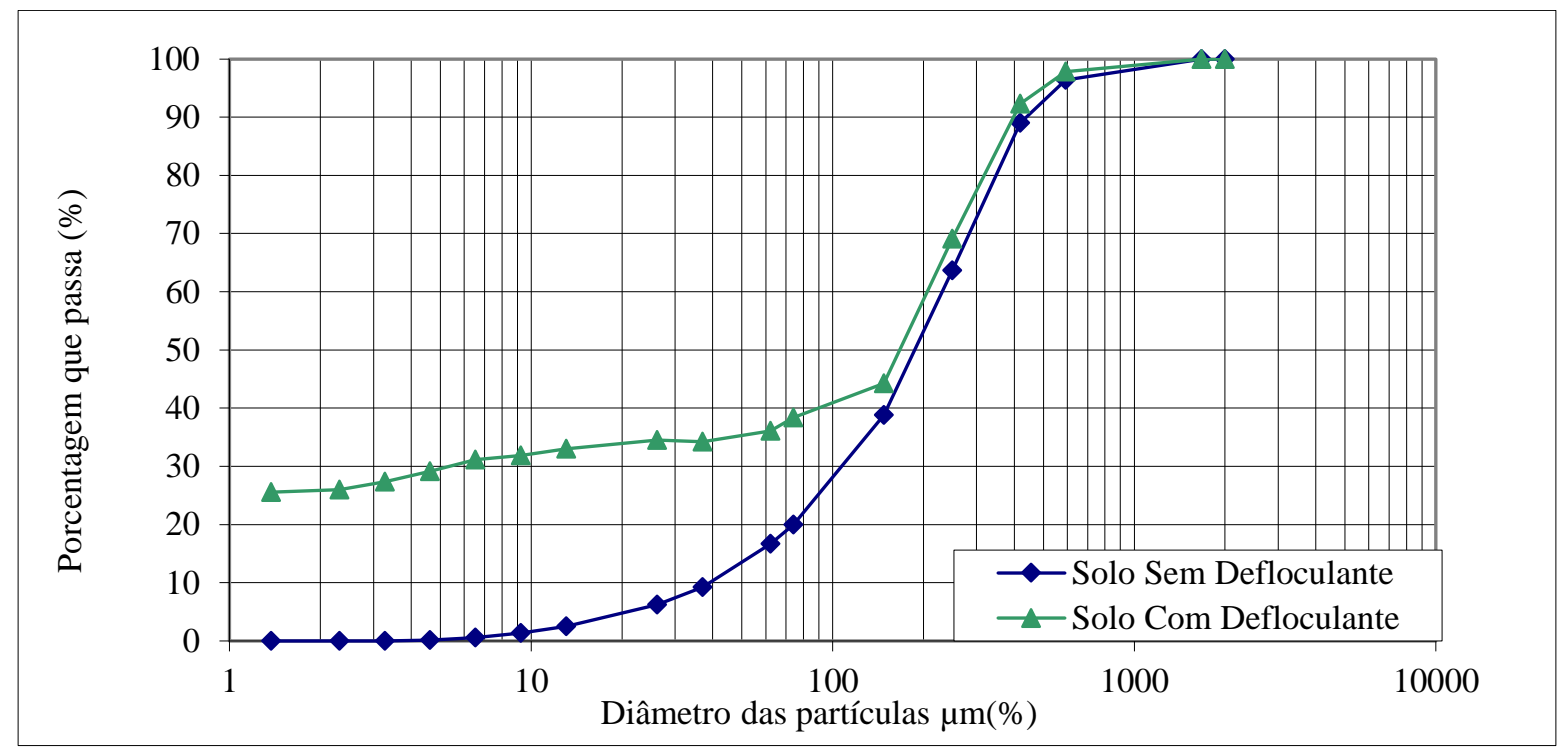

Figura 4.1. Distribuição granulométrica do solo com e sem defloculante.

Na Tabela 4.2 estão apresentadas as frações e os parâmetros granulométricos do solo, do fosfogesso e da cal, obtidos a partir do granulômetro a laser MICROTRAC S3500 sem uso do defloculante e do ultrassom. Para as misturas, esses mesmos dados estão apresentados nas Tabelas 4.3 e 4.4. Tanto para o solo como para o fosfogesso observa-se uma predominância da fração arenosa. No que se refere especificamente ao fosfogesso, esperava-se obter uma porcentagem maior da fração silte como tem sido observado na grande maioria dos estudos reportados na literatura. No entanto, acredita-se que essa variação foi devida à diferença entres as metodologias de análises granulométricas utilizadas, uma vez que a tradicional apresentada na NBR 7181 (ABNT, 1984c) tem uma abordagem gravimétrica (peneiramento e sedimentação), enquanto a da MICROTRAC S3500 é baseada na obtenção dos diâmetros a partir da difração de 3 lasers nas partículas como mostrado na Figura 4.2. De uma forma geral, observa-se uma diminuição da fração de areia média e um aumento da fração silte nas misturas com o aumento da quantidade de fosfogesso. O teor de cal utilizado não alterou significativamente a granulometria das misturas. Todos os materiais analisados apresentam coeficientes de uniformidade $(\mathrm{Cu})$ superiores a 4 e coeficientes de curvatura $(\mathrm{Cc})$ variando entre 1 e 3. Com isso, conclui-se que esses materiais são bem graduados. As Figuras 4.3 e 4.4 ilustram essas considerações. 
Universidade de Brasília

Departamento de Engenharia Civil / FT

Programa de Pós-Graduação em Geotecnia

Tabela 4.2. Frações e parâmetros granulométricos do solo, fosfogesso e cal.

\begin{tabular}{lccc}
\hline Amostra & S & FG & CH \\
\hline Areia Grossa $(2-0,6 \mathrm{~mm})$ & 3,5 & 0,3 & 0,0 \\
\hline Areia Média $(0,6-0,2 \mathrm{~mm})$ & 44,6 & 23,0 & 2,6 \\
\hline Areia Fina $(0,2-0,06 \mathrm{~mm})$ & 35,9 & 50,2 & 28,2 \\
\hline Silte $(0,06-0,002 \mathrm{~mm})$ & 16,0 & 26,4 & 57,3 \\
\hline Argila $(<0,002 \mathrm{~mm})$ & 0,0 & 0,0 & 11,9 \\
\hline $\mathrm{D}_{10}(\mathrm{~mm})$ & 0,040 & 0,025 & 0,002 \\
\hline $\mathrm{D}_{30}(\mathrm{~mm})$ & 0,113 & 0,067 & 0,011 \\
\hline $\mathrm{D}_{60}(\mathrm{~mm})$ & 0,233 & 0,139 & 0,045 \\
\hline $\mathrm{Cu}$ & 5,90 & 5,47 & 29,38 \\
\hline $\mathrm{Cc}$ & 1,38 & 1,25 & 1,64
\end{tabular}

Obs. $\mathrm{S}=\mathrm{Solo} ; \mathrm{FG}=$ fosfogesso; $\mathrm{CH}=\mathrm{Cal} ; \mathrm{Cu}=$ Coeficiente de Uniformidade; $\mathrm{Cc}=$ Coeficiente de curvatura.

Tabela 4.3. Frações granulométricas das misturas.

\begin{tabular}{|c|c|c|c|c|c|c|}
\hline Amostra & G II-1 & G II-2 & G II-3 & G II-4 & G II-5 & G II-6 \\
\hline Areia Grossa $(2-0,6 \mathrm{~mm})$ & 2,6 & 3,3 & 2,2 & 2,5 & 2,1 & 0,1 \\
\hline Areia Média $(0,6-0,2 \mathrm{~mm})$ & 43,6 & 40,6 & 40,1 & 37,7 & 36,4 & 33,3 \\
\hline Areia Fina $(0,2-0,06 \mathrm{~mm})$ & 36,9 & 37,4 & 38,0 & 40,0 & 40,1 & 42,8 \\
\hline Silte $(0,06-0,002 \mathrm{~mm})$ & 16,8 & 18,7 & 19,8 & 19,8 & 21,5 & 23,8 \\
\hline Argila $(<0,002 \mathrm{~mm})$ & 0,0 & 0,0 & 0,0 & 0,0 & 0,0 & 0,0 \\
\hline Amostra & G II-7 C & G II-8 & G II-9 & G II-10 & G II-11 & G II-12 \\
\hline Areia Grossa $(2-0,6 \mathrm{~mm})$ & 1,3 & 2,8 & 2,4 & 2,0 & 2,0 & 0,4 \\
\hline Areia Média $(0,6-0,2 \mathrm{~mm})$ & 35,5 & 43,1 & 40,4 & 37,6 & 40,3 & 36,3 \\
\hline Areia Fina $(0,2-0,06 \mathrm{~mm})$ & 41,5 & 36,1 & 37,3 & 39,5 & 35,5 & 38,7 \\
\hline Silte $(0,06-0,002 \mathrm{~mm})$ & 21,5 & 18,0 & 19,9 & 21,0 & 22,2 & 24,5 \\
\hline $\operatorname{Argila}(<0,002 \mathrm{~mm})$ & 0,2 & 0,0 & 0,0 & 0,0 & 0,0 & 0,0 \\
\hline Amostra & G II-13 & G II-14 & G II-15 & G II-16 & G II-17 & G II-18 \\
\hline Areia Grossa $(2-0,6 \mathrm{~mm})$ & 0,7 & 0,2 & 1,0 & 0,3 & 0,2 & 0,0 \\
\hline Areia Média $(0,6-0,2 \mathrm{~mm})$ & 41,7 & 38,8 & 39,4 & 36,1 & 35,7 & 32,8 \\
\hline Areia Fina $(0,2-0,06 \mathrm{~mm})$ & 37,1 & 36,1 & 37,0 & 38,0 & 38,3 & 39,9 \\
\hline Silte $(0,06-0,002 \mathrm{~mm})$ & 20,1 & 24,5 & 22,4 & 25,3 & 25,8 & 27,1 \\
\hline Argila $(<0,002 \mathrm{~mm})$ & 0,4 & 0,5 & 0,2 & 0,2 & 0,1 & 0,1 \\
\hline Amostra & G II-19 & G II-20 & G II-21 & G II-22 & G II-23 & G II-24 \\
\hline Areia Grossa $(2-0,6 \mathrm{~mm})$ & 0,4 & 1,2 & 1,2 & 0,6 & 0,0 & 0,0 \\
\hline Areia Média $(0,6-0,2 \mathrm{~mm})$ & 39,7 & 38,2 & 38,4 & 35,1 & 34,0 & 33,5 \\
\hline Areia Fina $(0,2-0,06 \mathrm{~mm})$ & 37,2 & 37,3 & 36,1 & 37,0 & 39,1 & 39,8 \\
\hline Silte $(0,06-0,002 \mathrm{~mm})$ & 22,3 & 23,0 & 23,8 & 26,7 & 26,8 & 26,5 \\
\hline Argila $(<0,002 \mathrm{~mm})$ & 0,5 & 0,3 & 0,4 & 0,5 & 0,1 & 0,1 \\
\hline Amostra & G II-25 & G II-26 & G II-27 & G II-28 & G II-29 & G II-30 \\
\hline Areia Grossa $(2-0,6 \mathrm{~mm})$ & 1,0 & 0,3 & 0,3 & 1,7 & 3,3 & 0,1 \\
\hline Areia Média $(0,6-0,2 \mathrm{~mm})$ & 42,4 & 38,7 & 37,5 & 38,1 & 35,4 & 32,8 \\
\hline Areia Fina $(0,2-0,06 \mathrm{~mm})$ & 33,2 & 36,4 & 35,7 & 38,1 & 36,6 & 40,2 \\
\hline Silte $(0,06-0,002 \mathrm{~mm})$ & 22,9 & 24,2 & 26,2 & 22,2 & 24,7 & 27,0 \\
\hline Argila $(<0,002 \mathrm{~mm})$ & 0,5 & 0,4 & 0,4 & 0,0 & 0,0 & 0,0 \\
\hline
\end{tabular}

Obs. GII-I a GII-30 = Misturas de solo com fosfogesso e cal. 
Universidade de Brasília

Departamento de Engenharia Civil / FT

Programa de Pós-Graduação em Geotecnia

Tabela 4.4. Parâmetros granulométricos das misturas.

\begin{tabular}{|c|c|c|c|c|c|c|}
\hline Amostra & G II-1 & G II-2 & G II-3 & G II-4 & G II-5 & G II-6 \\
\hline $\mathrm{D}_{10}(\mathrm{~mm})$ & 0,036 & 0,032 & 0,031 & 0,032 & 0,029 & 0,026 \\
\hline $\mathrm{D}_{30}(\mathrm{~mm})$ & 0,109 & 0,099 & 0,094 & 0,091 & 0,084 & 0,075 \\
\hline $\mathrm{D}_{60}(\mathrm{~mm})$ & 0,226 & 0,217 & 0,209 & 0,201 & 0,194 & 0,176 \\
\hline$\overline{\mathrm{Cu}}$ & 6,30 & 6,68 & 6,78 & 6,26 & 6,68 & 6,78 \\
\hline$\overline{\mathrm{Cc}}$ & 1,45 & 1,39 & 1,38 & 1,27 & 1,26 & 1,24 \\
\hline Amostra & G II-7 & G II-8 & G II-9 & G II-10 & G II-11 & G II-12 \\
\hline $\mathrm{D}_{10}(\mathrm{~mm})$ & 0,025 & 0,033 & 0,030 & 0,030 & 0,024 & 0,022 \\
\hline $\mathrm{D}_{30}(\mathrm{~mm})$ & 0,085 & 0,105 & 0,093 & 0,087 & 0,085 & 0,077 \\
\hline $\mathrm{D}_{60}(\mathrm{~mm})$ & 0,189 & 0,226 & 0,212 & 0,198 & 0,210 & 0,181 \\
\hline$\overline{\mathrm{Cu}}$ & 7,65 & 6,80 & 7,09 & 6,66 & 8,586 & 8,32 \\
\hline $\mathrm{Cc}$ & 1,55 & 1,48 & 1,37 & 1,27 & 1,417 & 1,50 \\
\hline Amostra & G II-13 & G II-14 & G II-15 & G II-16 & G II-17 & G II-18 \\
\hline $\mathrm{D}_{10}(\mathrm{~mm})$ & 0,023 & 0,019 & 0,022 & 0,018 & 0,018 & 0,020 \\
\hline $\mathrm{D}_{30}(\mathrm{~mm})$ & 0,097 & 0,077 & 0,086 & 0,074 & 0,072 & 0,067 \\
\hline $\mathrm{D}_{60}(\mathrm{~mm})$ & 0,209 & 0,195 & 0,202 & 0,181 & 0,175 & 0,156 \\
\hline $\mathrm{Cu}$ & 9,06 & 10,28 & 9,23 & 9,84 & 9,52 & 7,94 \\
\hline$\overline{\mathrm{Cc}}$ & 1,96 & 1,61 & 1,68 & 1,64 & 1,62 & 1,47 \\
\hline Amostra & G II-19 & G II-20 & G II-21 & G II-22 & G II-23 & G II-24 \\
\hline $\mathrm{D}_{10}(\mathrm{~mm})$ & 0,018 & 0,020 & 0,019 & 0,015 & 0,017 & 0,018 \\
\hline $\mathrm{D}_{30}(\mathrm{~mm})$ & 0,087 & 0,084 & 0,078 & 0,068 & 0,068 & 0,069 \\
\hline $\mathrm{D}_{60}(\mathrm{~mm})$ & 0,200 & 0,197 & 0,198 & 0,176 & 0,162 & 0,163 \\
\hline $\mathrm{Cu}$ & 11,16 & 9,94 & 10,61 & 11,46 & 9,72 & 9,13 \\
\hline$\overline{\mathrm{Cc}}$ & 2,11 & 1,79 & 1,64 & 1,74 & 1,72 & 1,65 \\
\hline Amostra & G II-25 & G II-26 & G II-27 & G II-28 & G II-29 & G II-30 \\
\hline $\mathrm{D}_{10}(\mathrm{~mm})$ & 0,017 & 0,017 & 0,015 & 0,025 & 0,021 & 0,019 \\
\hline $\mathrm{D}_{30}(\mathrm{~mm})$ & 0,087 & 0,079 & 0,072 & 0,084 & 0,076 & 0,068 \\
\hline $\mathrm{D}_{60}(\mathrm{~mm})$ & 0,216 & 0,195 & 0,187 & 0,199 & 0,194 & 0,174 \\
\hline $\mathrm{Cu}$ & 12,92 & 11,45 & 12,57 & 7,93 & 9,37 & 9,12 \\
\hline$\overline{\mathrm{Cc}}$ & 2,09 & 1,90 & 1,84 & 1,43 & 1,42 & 1,38 \\
\hline
\end{tabular}

$\mathrm{Cu}=$ Coeficiente de Uniformidade; $\mathrm{Cc}=$ Coeficiente de curvatura .

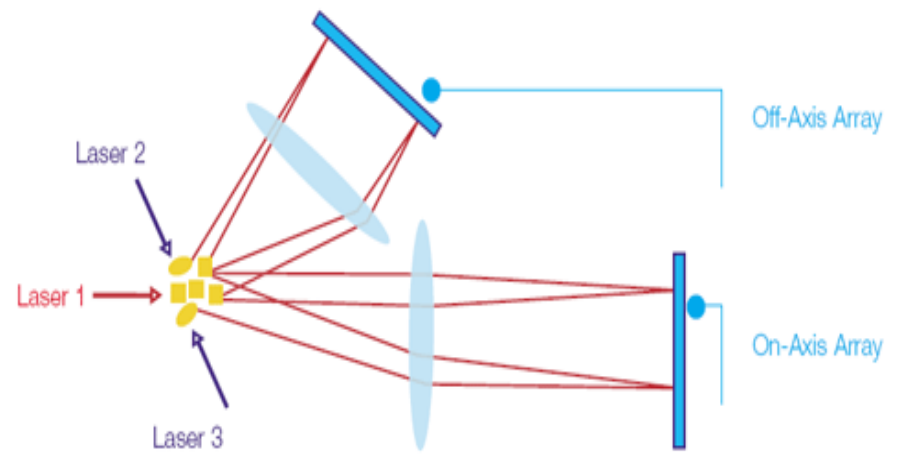

Figura 4.2. Sistema de 3 laser utilizado pelo MICROTRAC S3500. 
Universidade de Brasília

Departamento de Engenharia Civil / FT

Programa de Pós-Graduação em Geotecnia

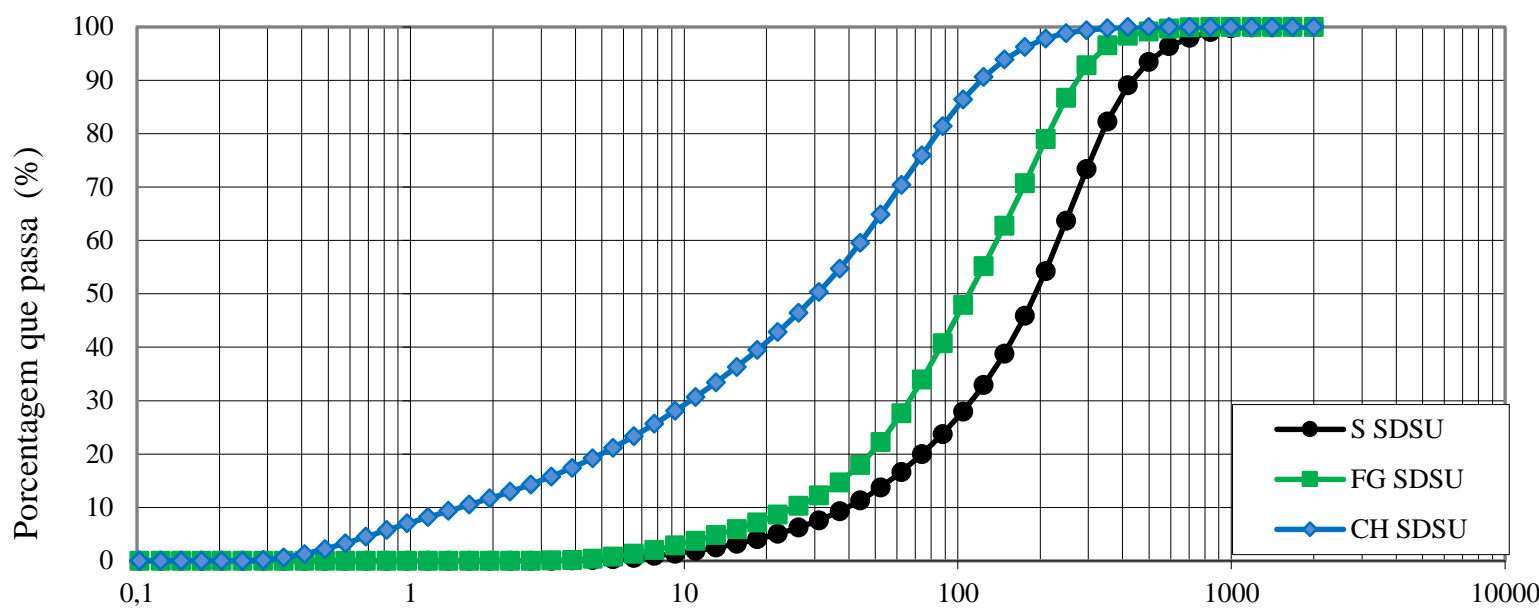

(a)

Diamêtros das partículas $(\mu \mathrm{m})$

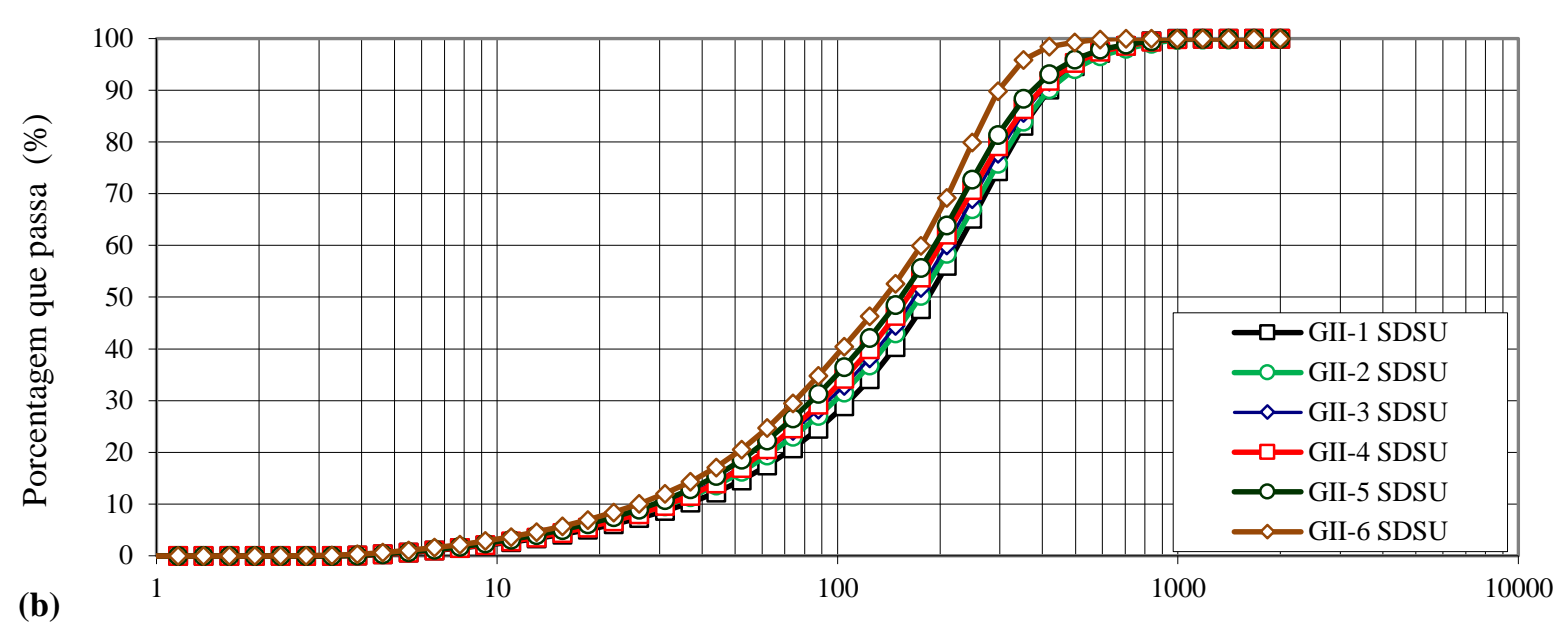

Diamêtros das partículas $(\mu \mathrm{m})$

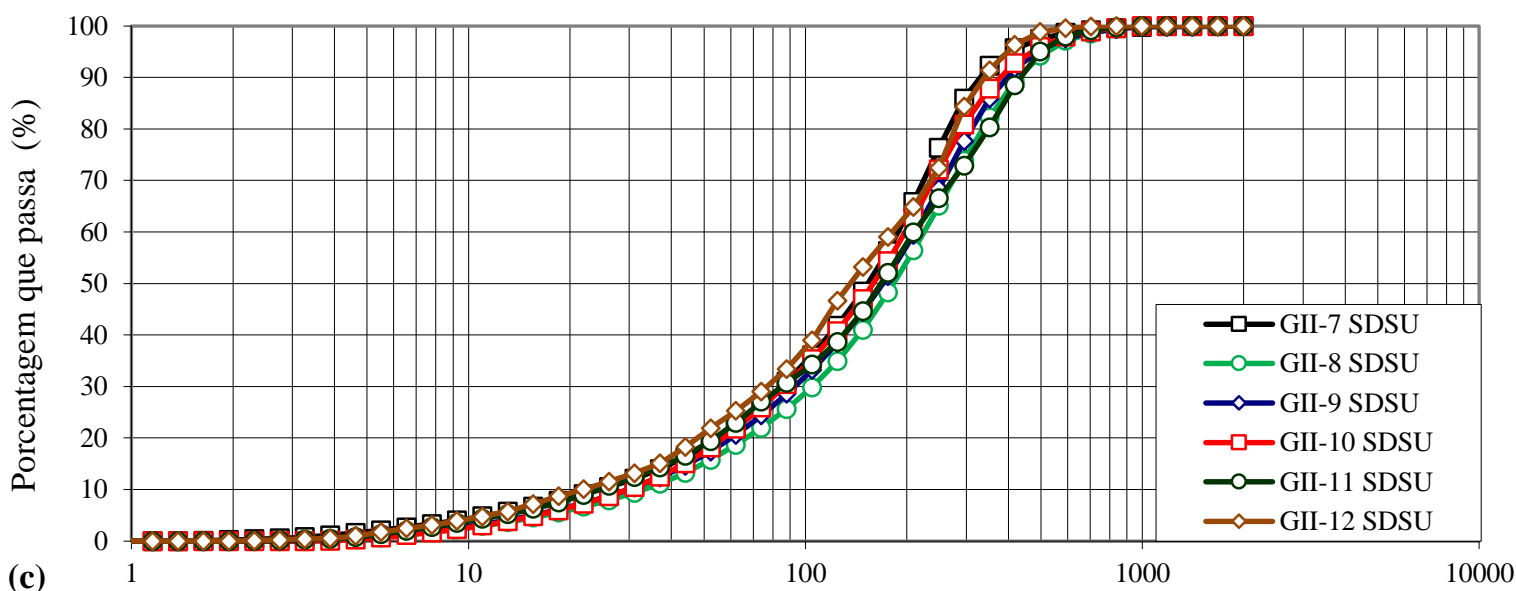

Diamêtros das partículas $(\mu \mathrm{m})$

Figura 4.3. Curvas granulométricas sem defloculante e sem ultrassom dos materiais (a) $\mathrm{S}=$ Solo, $\mathrm{FG}=$ fosfogesso e $\mathrm{CH}=\mathrm{Cal}$, (b) GII-1, 2, 3, 4, 5 e 6, (c) GII-7, 8, 9, 10, 11 e 12. Obs.: SDSU = Sem Defloculante e Sem Ultrassom. 
Universidade de Brasília

Departamento de Engenharia Civil / FT

Programa de Pós-Graduação em Geotecnia

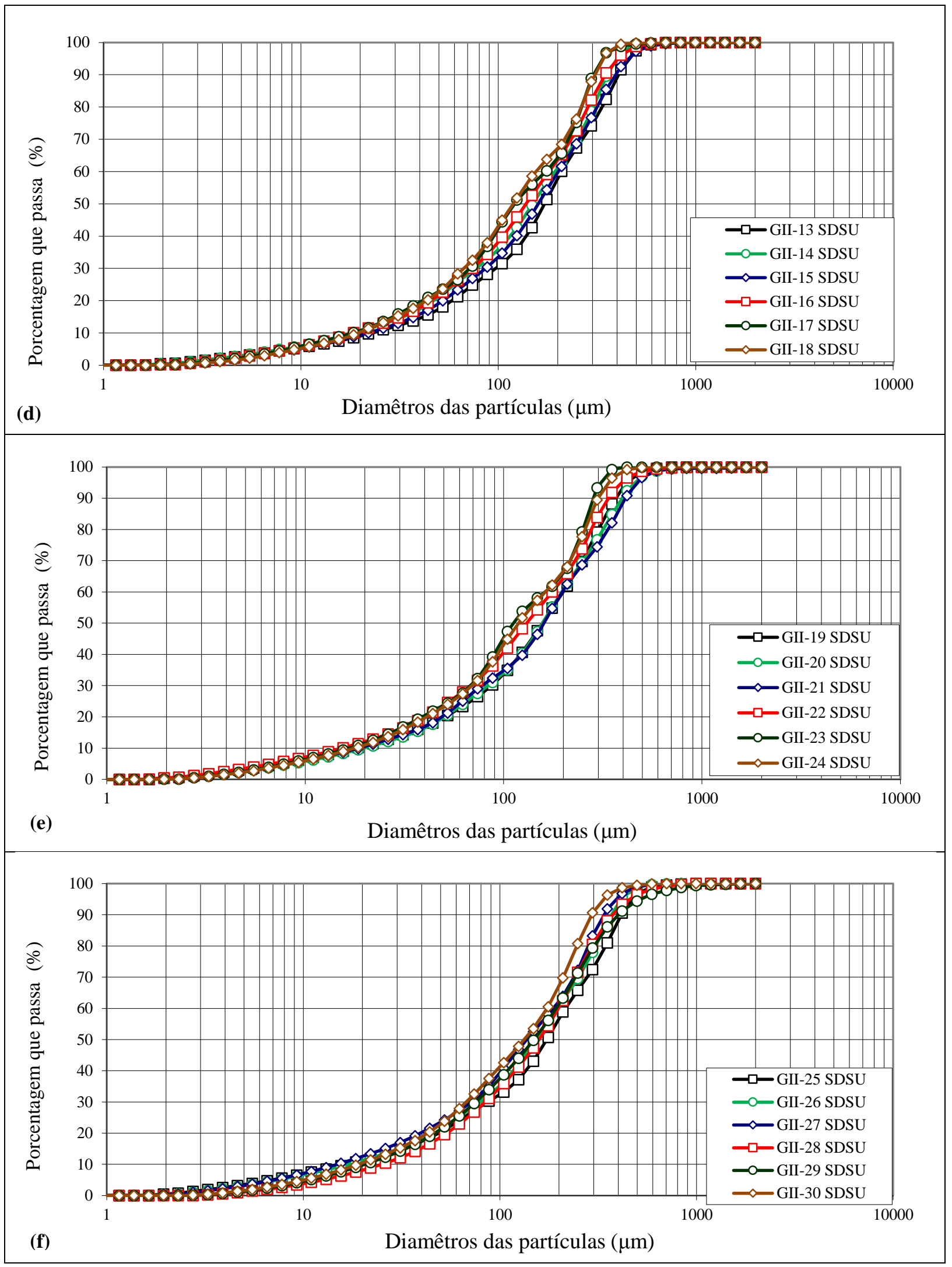

Figura 4.4. Curvas granulométricas sem defloculante e sem ultrassom dos materiais (d) GII-13, 14, 15, 16, 17 e 18 (e) GII-19, 20, 21, 22, 23 e 24 (f) GII-25, 26, 27, 28, 29 e 30. Obs.: SDSU = Sem Defloculante e Sem Ultrassom. 


\subsubsection{2 - LIMITES DE CONSISTÊNCIA}

Os valores obtidos para os limites de liquidez $\left(\mathrm{W}_{\mathrm{L}}\right)$, plasticidade $\left(\mathrm{WP}_{\mathrm{P}}\right)$ e índice de plasticidade (IP) dos materiais estudados estão apresentados na Tabela 4.5. Como discutido em pesquisas anteriores (Mesquita, 2007; Rufo, 2009; Metogo, 2010), o fosfogesso não apresenta a trabalhabilidade necessária para a execução dos ensaios de limite de consistência. Por esse motivo, é considerado não plástico (NP). Tanto o solo como as misturas apresentaram limites de liquidez variando 31 e 40\%, podendo ser considerados como materiais com valores médios de limites de liquidez. Entretanto, conforme apresentados nas Figuras 4.5 (a) e (b), esse parâmetro aumenta significativamente com o teor de fosfogesso enquanto que com a cal, não se observa variação. Essa tendência também é observada com os limites de plasticidade como ilustrado nas Figuras 4.5 (c) e (d). Quanto aos índices de plasticidade, o solo (GI-1) com IP=6 $\%$ é de baixa plasticidade. Já para misturas, esse parâmetro varia de 7 a $12 \%$ fazendo dessas misturas, materiais de plasticidade média. Com as Figuras 4.5 (e) e (f) verifica-se que tanto aumento do teor de cal como de fosfogesso não alteram significativamente os índices de plasticidade.

Tabela 4.5. Valores obtidos dos ensaios de limites de consistência para os materiais estudados.

\begin{tabular}{|c|c|c|c|c|c|c|}
\hline Amostra & G I-1 & G I-2 & G I-3 & G I-4 & G I-5 & G I-6 \\
\hline $\mathrm{W}_{\mathrm{L}}$ & 32 & 34 & 37 & 36 & 36 & 36 \\
\hline $\mathrm{W}_{\mathrm{P}}$ & 26 & 27 & 27 & 27 & 27 & 29 \\
\hline IP & 6 & 7 & 10 & 9 & 10 & 7 \\
\hline Amostra & G II-1 & G II-2 & G II-3 & G II-4 & G II-5 & G II-6 \\
\hline $\mathrm{W}_{\mathrm{L}}$ & 32 & 36 & 37 & 37 & 38 & 42 \\
\hline $\mathrm{WP}_{\mathrm{P}}$ & 23 & 28 & 31 & 25 & 28 & 30 \\
\hline IP & 9 & 8 & 6 & 12 & 10 & 12 \\
\hline Amostra & G II-7 & G II-8 & G II-9 & G II-10 & G II-11 & G II-12 \\
\hline $\mathrm{W}_{\mathrm{L}}$ & 35 & 36 & 37 & 37 & 40 & 39 \\
\hline $\mathrm{W}_{\mathrm{P}}$ & 24 & 28 & 26 & 28 & 25 & 28 \\
\hline IP & 10 & 8 & 11 & 10 & 15 & 11 \\
\hline Amostra & G II-13 & G II-14 & G II-15 & G II-16 & G II-17 & G II-18 \\
\hline $\mathrm{w}_{\mathrm{L}}$ & 34 & 35 & 36 & 38 & 37 & 40 \\
\hline$W_{P}$ & 25 & 25 & 27 & 27 & 27 & 32 \\
\hline IP & 9 & 9 & 10 & 11 & 9 & 8 \\
\hline Amostra & G II-19 & G II-20 & G II-21 & G II-22 & G II-23 & G II-24 \\
\hline $\mathrm{W}_{\mathrm{L}}$ & 33 & 35 & 37 & 38 & 39 & 40 \\
\hline $\mathrm{W}_{\mathrm{P}}$ & 26 & 27 & 27 & 28 & 27 & 28 \\
\hline IP & 8 & 8 & 10 & 10 & 12 & 12 \\
\hline Amostra & G II-25 & G II-26 & G II-27 & G II-28 & G II-29 & G II-30 \\
\hline $\mathrm{W}_{\mathrm{L}}$ & 31 & 34 & 34 & 36 & 38 & 40 \\
\hline $\mathrm{W}_{\mathrm{P}}$ & 23 & 25 & 26 & 27 & 28 & 30 \\
\hline IP & 9 & 10 & 8 & 10 & 10 & 11 \\
\hline
\end{tabular}

Obs. $\mathrm{w}_{\mathrm{L}}=$ Limite de liquidez; $\mathrm{w}_{\mathrm{P}}=$ Limites de Plasticidade; $\mathrm{IP}=$ Índice de plasticidade. 
Universidade de Brasília

Departamento de Engenharia Civil / FT

Programa de Pós-Graduação em Geotecnia
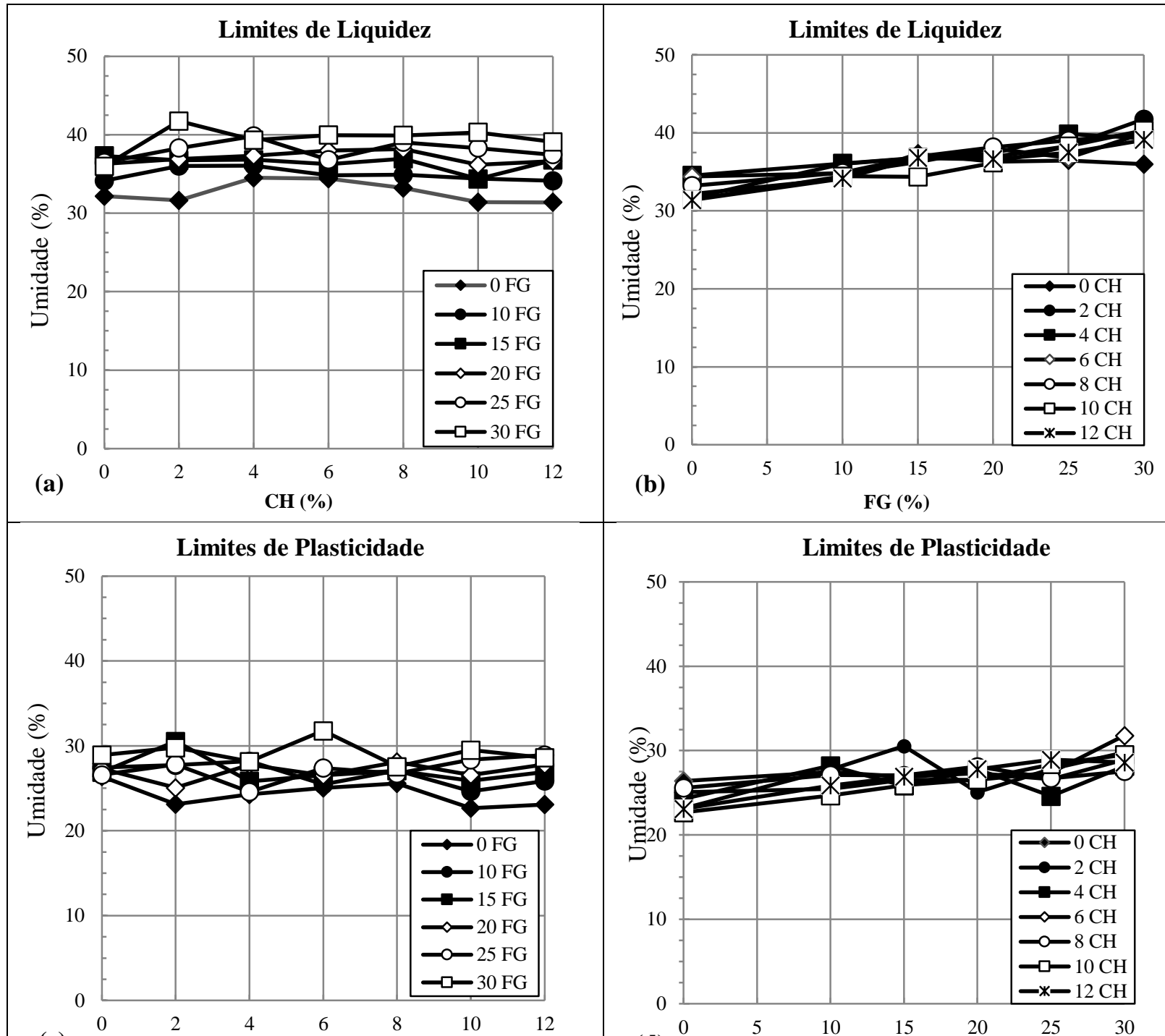

(c)

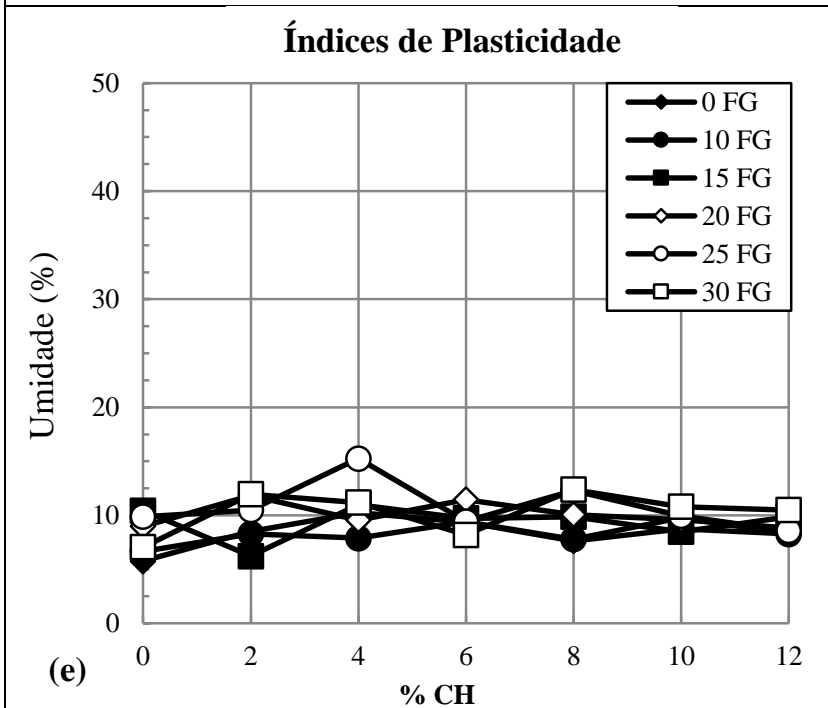

Limites de Plasticidade

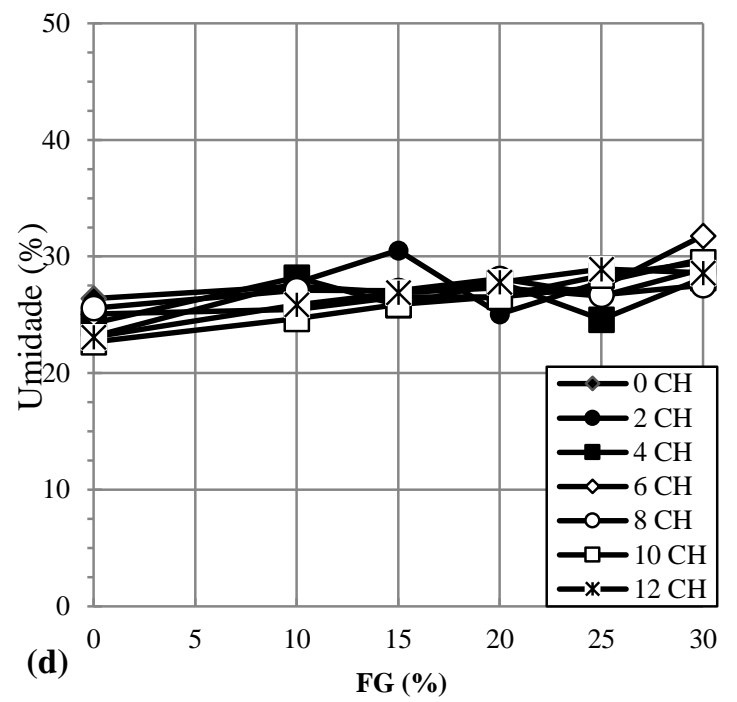

Índices de Plasticidade

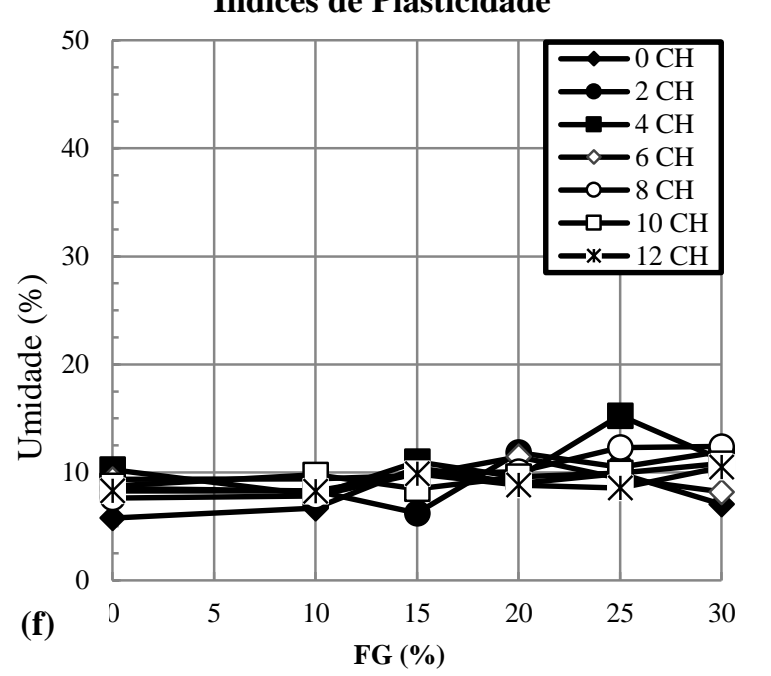

Figura 4.5. Variação dos limites de consistência. (a) Variação dos limites de liquidez com o teor de cal. (b) Variação dos limites de liquidez com o teor de fosfogesso. (c) Variação dos limites de plasticidade com o teor de cal. (d) Variação dos limites de plasticidade com o teor de fosfogesso. (e) Variação dos índices de plasticidade com o teor de cal. (f) Variação dos índices de plasticidade com o teor de fosfogesso. 


\subsubsection{3 - CLASSIFICAÇÕES SUCS E TRB}

A partir dos dados obtidos da análise granulométrica sem defloculante e dos ensaios de limites de consistência, foi possível classificar os materiais de acordo com a Transportation Research Board - TRB e o Sistema Unificado de Classificação dos Solos - SUCS. Todas as amostras apresentaram índices de grupo nulos. Na Tabela 4.6 estão apresentados os grupos classificatórios dos materiais. Observa-se que existe pouca variação dentre os subgrupos e que as amostras pertencem ao grupo A-2 da TRB correspondendo aos solos arenosos siltosos. Nesse grupo se encaixa também o fosfogesso. Nota-se, entretanto, predominância do grupo A-2-4. Por essa classificação, esses materiais seriam bons se constituírem materiais de subleito. Já de acordo com o sistema SUCS, todos os materiais são classificados no grupo CL das argilas inorgânicas de baixa a média plasticidade ou argilas pedregulhosas, arenosas e siltosas. O fosfogesso por sua vez é classificado areia fina siltosa (ML) nesse sistema devido à sua característica não plástica.

Tabela 4.6. Classificação dos materiais de acordo com a TRB e o SUCS.

\begin{tabular}{ccccccc}
\hline Amostra & G I-1 & G I-2 & G I-3 & G I-4 & G I-5 & G I-6 \\
\hline TBR & A-2-4 & - & - & - & - & - \\
\hline SUCS & CL-ML & - & - & - & - & - \\
\hline Amostra & G II-1 & G II-2 & G II-3 & G II-4 & G II-5 & G II-6 \\
\hline TBR & A-2-4 & A-2-4 & A-2-4 & A-2-6 & A-2-4 & A-2-7 \\
\hline SUCS & CL & CL & CL-ML & CL & CL & CL \\
\hline Amostra & G II-7 & G II-8 & G II-9 & G II-10 & G II-11 & G II-12 \\
\hline TBR & A-2-4 & A-2-4 & A-2-6 & A-2-4 & A-2-6 & A-2-6 \\
\hline SUCS & CL & CL & CL & CL & CL & CL \\
\hline Amostra & G II-13 & G II-14 & G II-15 & G II-16 & G II-17 & G II-18 \\
\hline TBR & A-2-4 & A-2-4 & A-2-4 & A-2-6 & A-2-4 & A-2-4 \\
\hline SUCS & CL & CL & CL & CL & CL & CL \\
\hline Amostra & G II-19 & G II-20 & G II-21 & G II-22 & G II-23 & G II-24 \\
\hline TBR & A-2-4 & A-2-4 & A-2-4 & A-2-4 & A-2-6 & A-2-6 \\
\hline SUCS & CL & CL & CL & CL & CL & CL \\
\hline Amostra & G II-25 & G II-26 & G II-27 & G II-28 & G II-29 & G II-30 \\
\hline TBR & A-2-4 & A-2-4 & A-2-4 & A-2-4 & A-2-4 & A-2-6 \\
\hline SUCS & CL & CL & CL & CL & CL & CL \\
\hline
\end{tabular}

\subsubsection{MASSA ESPECÍFICA DOS GRÃOS}

Os valores de massa específica do solo (GI-1), do fosfogesso e da cal obtidos pelo PENTAPYC 5200e foram respectivamente de $2,71 \mathrm{~g} / \mathrm{cm}^{3}, 2,67 \mathrm{~g} / \mathrm{cm}^{3}$ e $2,54 \mathrm{~g} / \mathrm{cm}^{3}$. O solo apresentou um valor que o enquadra na faixa geralmente observada para solos da região (entre 2,60 e 2,80 g/ $\left.\mathrm{cm}^{3}\right)$, onde costuma-se encontrar minerais como a caulinita $\left(2,61-2,68 \mathrm{~g} / \mathrm{cm}^{3}\right)$, o quartzo $\left(2,59-2,63 \mathrm{~g} / \mathrm{cm}^{3}\right)$ e a gibbsita $\left(2,40 \mathrm{~g} / \mathrm{cm}^{3}\right)$. O valor da massa específica dos grãos obtido para o fosfogesso foi significativamente inferior ao encontrado nos trabalhos de

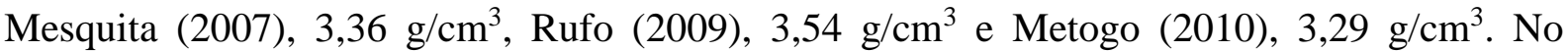


entanto, esse valor foi ligeiramente superior ao encontrado por Matos (2011), 2,60 g/ $\mathrm{cm}^{3}$. Essas variações podem ser devidas às diferenças de temperaturas de secagem nas estufas utilizadas entre as pesquisas, uma vez que para Mesquita (2007), Rufo (2009), Metogo (2010) essa temperatura foi de $105^{\circ} \mathrm{C}$ enquanto para Matos (2011) foi utilizada a temperatura de $70^{\circ} \mathrm{C}$. Para temperaturas acima de $70^{\circ} \mathrm{C}$, o fosfogesso di-hidratado tente a perder suas moléculas de água e dessa forma, se torna progressivamente hemi-hidratado e finalmente anidro. Essa transformação pode ser responsável pela variação de massa específica absoluta do fosfogesso para as temperaturas de $70^{\circ} \mathrm{C}$ e $105^{\circ} \mathrm{C}$. A cal apresentou a menor massa específica dos grãos. Sendo assim, observou-se uma diminuição dos valores desse parâmetro para as misturas, à medida que aumentava-se a quantidade de fosfogesso e de cal. Na Tabela 4.7 estão apresentados os valores de massa especifica dos grãos para as misturas.

Tabela 4.7.Valores de massa específica dos grãos para as diferentes misturas.

\begin{tabular}{|c|c|c|c|c|c|c|}
\hline Amostra & G I-1 & G I-2 & G I-3 & G I-4 & G I-5 & G I-6 \\
\hline$\gamma_{\mathrm{s}}\left(\mathrm{g} / \mathrm{cm}^{3}\right)$ & 2,714 & 2,710 & 2,708 & 2,706 & 2,704 & 2,702 \\
\hline Amostra & G II-1 & G II-2 & G II-3 & G II-4 & G II-5 & G II-6 \\
\hline$\gamma_{\mathrm{s}}\left(\mathrm{g} / \mathrm{cm}^{3}\right)$ & 2,696 & 2,694 & 2,690 & 2,687 & 2,684 & 2,680 \\
\hline Amostra & G II-7 & G II-8 & G II-9 & G II-10 & G II-11 & G II-12 \\
\hline$\gamma_{\mathrm{s}}\left(\mathrm{g} / \mathrm{cm}^{3}\right)$ & 2,688 & 2,683 & 2,678 & 2,675 & 2,671 & 2,669 \\
\hline Amostra & G II-13 & G II-14 & G II-15 & G II-16 & G II-17 & G II-18 \\
\hline$\gamma_{\mathrm{s}}\left(\mathrm{g} / \mathrm{cm}^{3}\right)$ & 2,689 & 2,683 & 2,677 & 2,675 & 2,670 & 2,666 \\
\hline Amostra & G II-19 & G II-20 & G II-21 & G II-22 & G II-23 & G II-24 \\
\hline$\gamma_{\mathrm{s}}\left(\mathrm{g} / \mathrm{cm}^{3}\right)$ & 2,675 & 2,670 & 2,670 & 2,669 & 2,666 & 2,663 \\
\hline Amostra & G II-25 & G II-26 & G II-27 & G II-28 & G II-29 & G II-30 \\
\hline$\gamma_{\mathrm{s}}\left(\mathrm{g} / \mathrm{cm}^{3}\right)$ & 2,670 & 2,666 & 2,664 & 2,661 & 2,657 & 2,653 \\
\hline
\end{tabular}

Obs. $\gamma_{\mathrm{s}}=$ Massa específica dos grãos.

\subsection{3 - METODOLOGIA MCT}

\subsubsection{1 - CLASSIFICAÇÃO MCT}

Com os ensaios de compactação Mini-MCV e perda de massa por imersão da metodologia MCT, foi possível obter as de curvas de deformabilidade do solo, sua família de curvas de compactação assim como a curva de perda de massa por imersão, por mini-MCV. Essas curvas estão apresentadas nas Figuras 4.6 (a), (b) e (c), respectivamente. Com base nessas figuras foi possível determinar os parâmetros necessários para a classificação MCT, coeficientes c', d', a perda de massa por imersão Pi(\%) e o índice de laterização e'. Na Tabela 4.8 estão apresentados os valores obtidos. A partir desses resultados foi possível classificar o solo de acordo com a metodologia MCT. Conforme ilustrado na Figura 4.6(d), o solo estudado apresenta um comportamento tecnológico de solos lateríticos arenosos (LA'). 
Tabela 4.8. Parâmetros de obtidos da metodologia MCT para a classificação do solo.

\begin{tabular}{cccc}
\hline $\mathbf{c}^{\prime}$ & $\mathbf{d}^{\prime}$ & $\mathbf{P i}(\%)$ & e' $^{\prime}$ \\
\hline 1,02 & 85 & 13,4 & 0,72
\end{tabular}

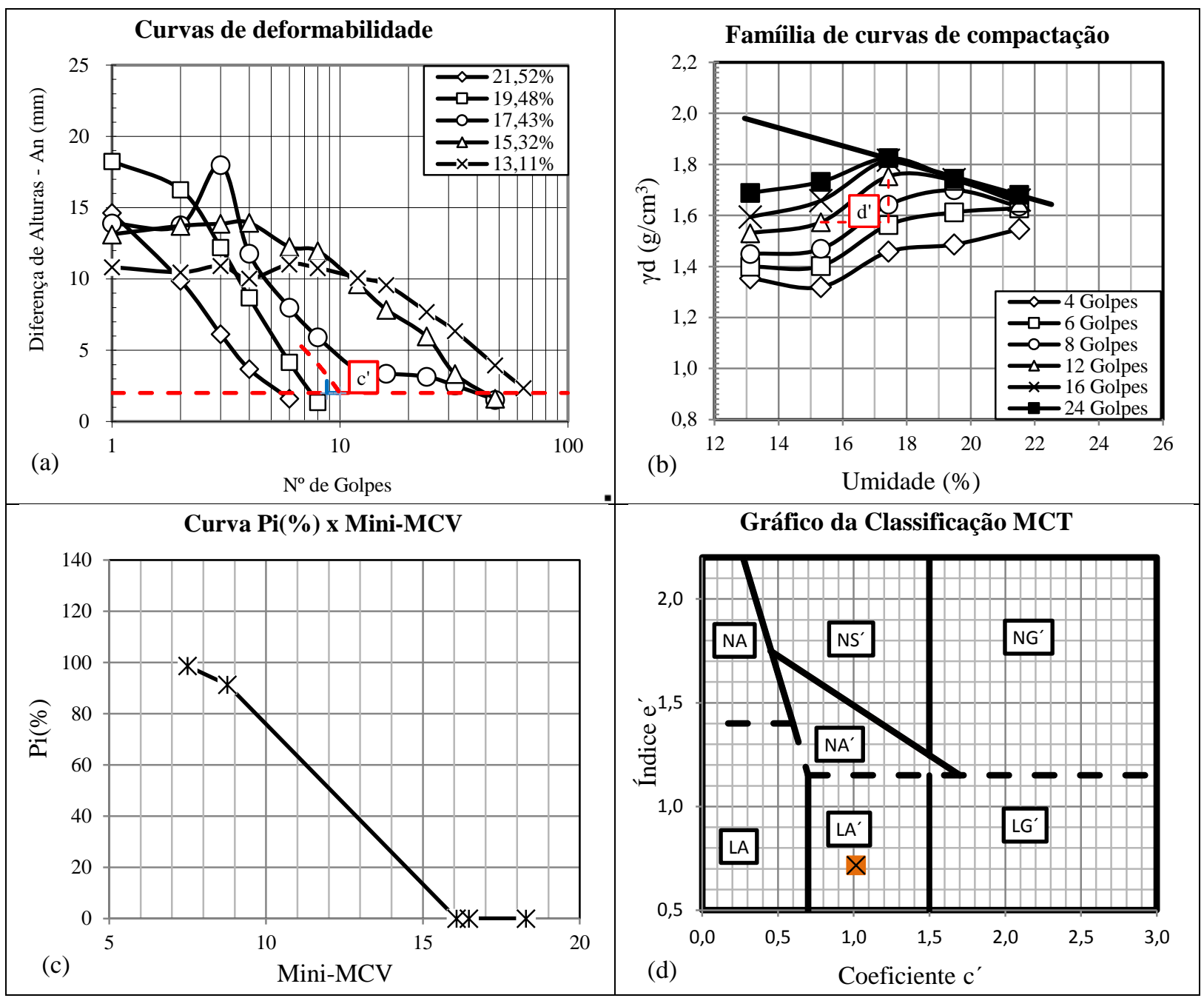

Figura 4.6. Classificação MCT.(a) Curvas de deformabilidade (b) Família de curvas de compactação (c) Curva de perda de massa por imersão (d) Gráfico da classificação MCT para o solo estudado.

\subsubsection{2 - MINI-PROCTOR}

Os resultados obtidos dos ensaios de compactação mini-Proctor estão apresentados na Tabela 4.9. Nas Figuras 4.7 (a) e (c) verifica-se que o aumento do teor de fosfogesso gera aumento da umidade ótima e diminuição do peso específico aparente seco máximo. Quanto à cal, observase um comportamento parabólico tanto para umidade ótima como para o peso específico aparente seco máximo. Como pode se verificar na Figura 4.10 (b), a partir de 2\% de cal, as misturas com teor de fosfogesso de 0 e $10 \%$ apresentam uma variação côncava da umidade ótima, enquanto para as misturas com 20, 25 e $30 \%$ de fosfogesso, tem-se uma variação 
Universidade de Brasília

Departamento de Engenharia Civil / FT

Programa de Pós-Graduação em Geotecnia

convexa. Nota-se também, um ponto comum de mudança de comportamento das curvas correspondendo à mistura com $6 \%$ de cal e $15 \%$ de fosfogesso, o que sugere um ponto ótimo de estabilização. Observa-se a partir da Figura 4.7 (d) que para os pesos específicos aparentes secos, as concavidades são apenas invertidas. As curvas de compactação dos materiais em função dos teores de fosfogesso e de cal estão ilustradas pelas Figuras 4.8 e 4.9, respectivamente.

Tabela 4.9. Parâmetros obtidos dos ensaios de compactação mini-Proctor.

\begin{tabular}{|c|c|c|c|c|c|c|}
\hline Amostra & G I-1 & G I-2 & G I-3 & G I-4 & G I-5 & G I-6 \\
\hline $\mathrm{w}_{\mathrm{ot}} \cdot(\%)$ & 17,2 & 17,5 & 18,8 & 19,6 & 20,0 & 22,2 \\
\hline$\gamma_{\mathrm{dmax}}\left(\mathrm{kN} / \mathrm{m}^{3}\right)$ & 18,1 & 17,5 & 17,4 & 17,2 & 16,8 & 16,4 \\
\hline Amostra & G II-1 & G II-2 & G II-3 & G II-4 & G II-5 & G II-6 \\
\hline$\gamma_{\mathrm{dmax}}\left(\mathrm{kN} / \mathrm{m}^{3}\right)$ & 18,2 & 16,8 & 16,8 & 16,1 & 16,1 & 15,4 \\
\hline Amostra & G II-7 & G II-8 & G II-9 & G II-10 & G II-11 & G II-12 \\
\hline Amostra & G II-13 & G II-14 & G II-15 & G II-16 & G II-17 & G II-18 \\
\hline $\mathrm{w}_{\mathrm{ot}} \cdot(\%)$ & 18,8 & 20,3 & 21,7 & 21,9 & 20,8 & 21,9 \\
\hline$\gamma_{\mathrm{dmax}}\left(\mathrm{kN} / \mathrm{m}^{3}\right)$ & 16,9 & 16,7 & 16,6 & 15,9 & 16,0 & 15,6 \\
\hline Amostra & G II-19 & G II-20 & G II-21 & G II-22 & G II-23 & G II-24 \\
\hline $\mathrm{w}_{\mathrm{ot}} \cdot(\%)$ & 18,0 & 20,7 & 21,4 & 22,3 & 23,4 & 23,2 \\
\hline$\gamma_{\mathrm{dmax}}\left(\mathrm{kN} / \mathrm{m}^{3}\right)$ & 17,3 & 16,7 & 16,4 & 16,1 & 15,6 & 15,5 \\
\hline
\end{tabular}

Obs.: $\mathrm{w}_{\mathrm{ot}}=$ umidade ótima; $\gamma_{\mathrm{dmax}}=$ Peso específico aparente seco máximo.

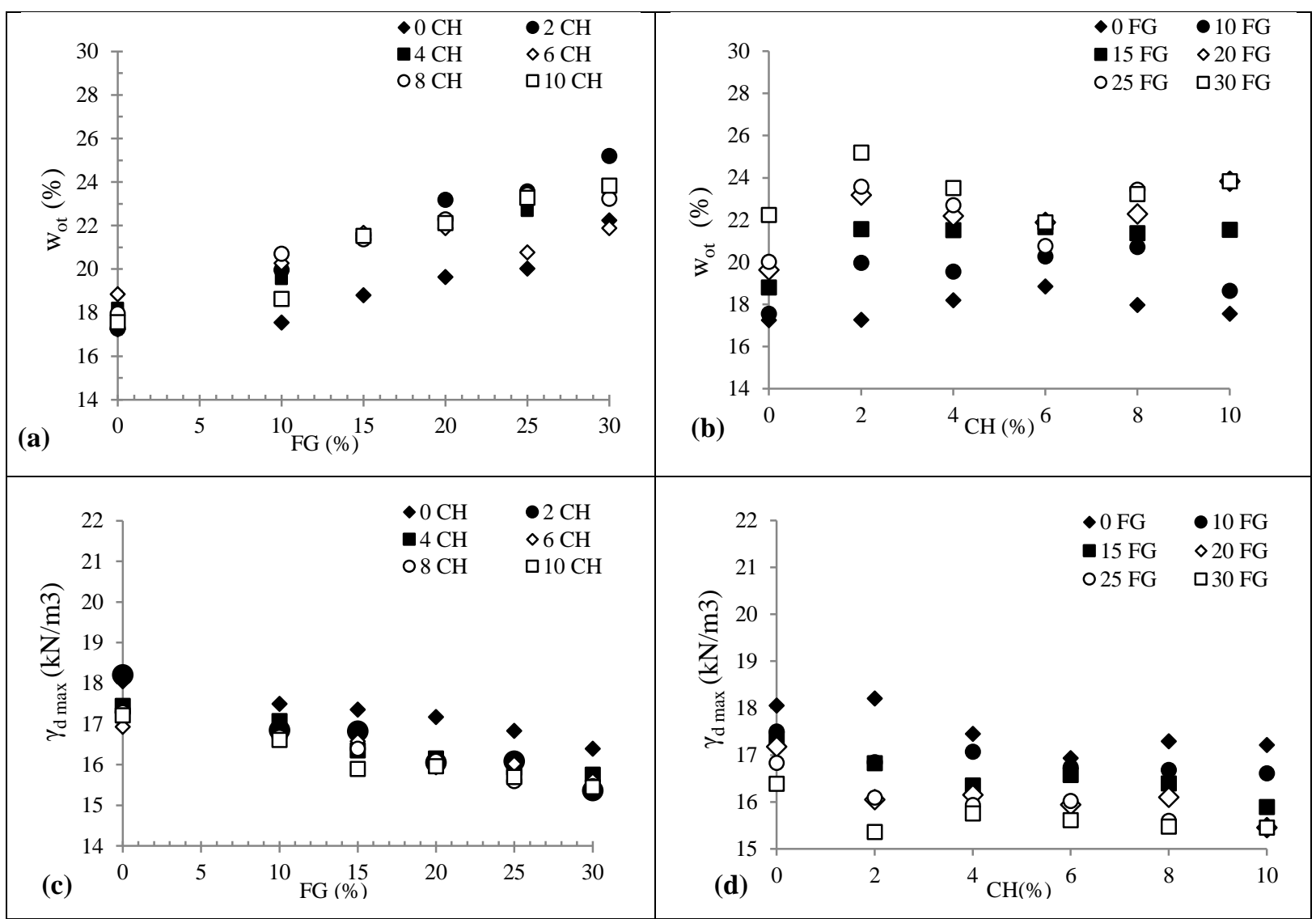

Figura 4.7. Variação das umidades ótimas e $\gamma_{\mathrm{dmax}}$ :(a) e (c) com $\%$ de fosfogesso (b) e (d) com \% de Cal. 
Universidade de Brasília

Departamento de Engenharia Civil / FT

Programa de Pós-Graduação em Geotecnia

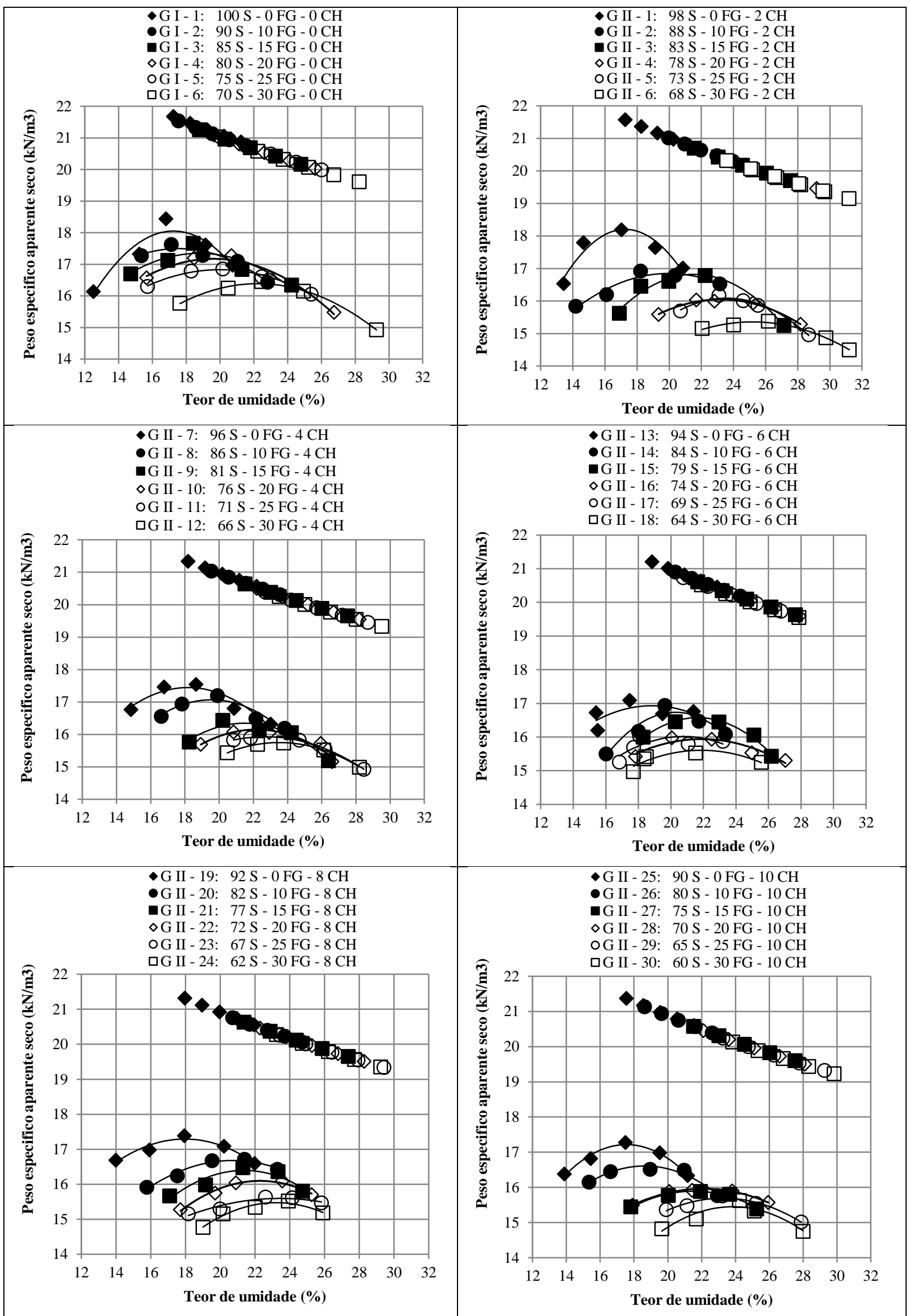

Figura 4.8. Curvas de compactação Mini-Proctor e de saturação dos materiais em função dos teores de fosfogesso. 
Universidade de Brasília

Departamento de Engenharia Civil / FT

Programa de Pós-Graduação em Geotecnia

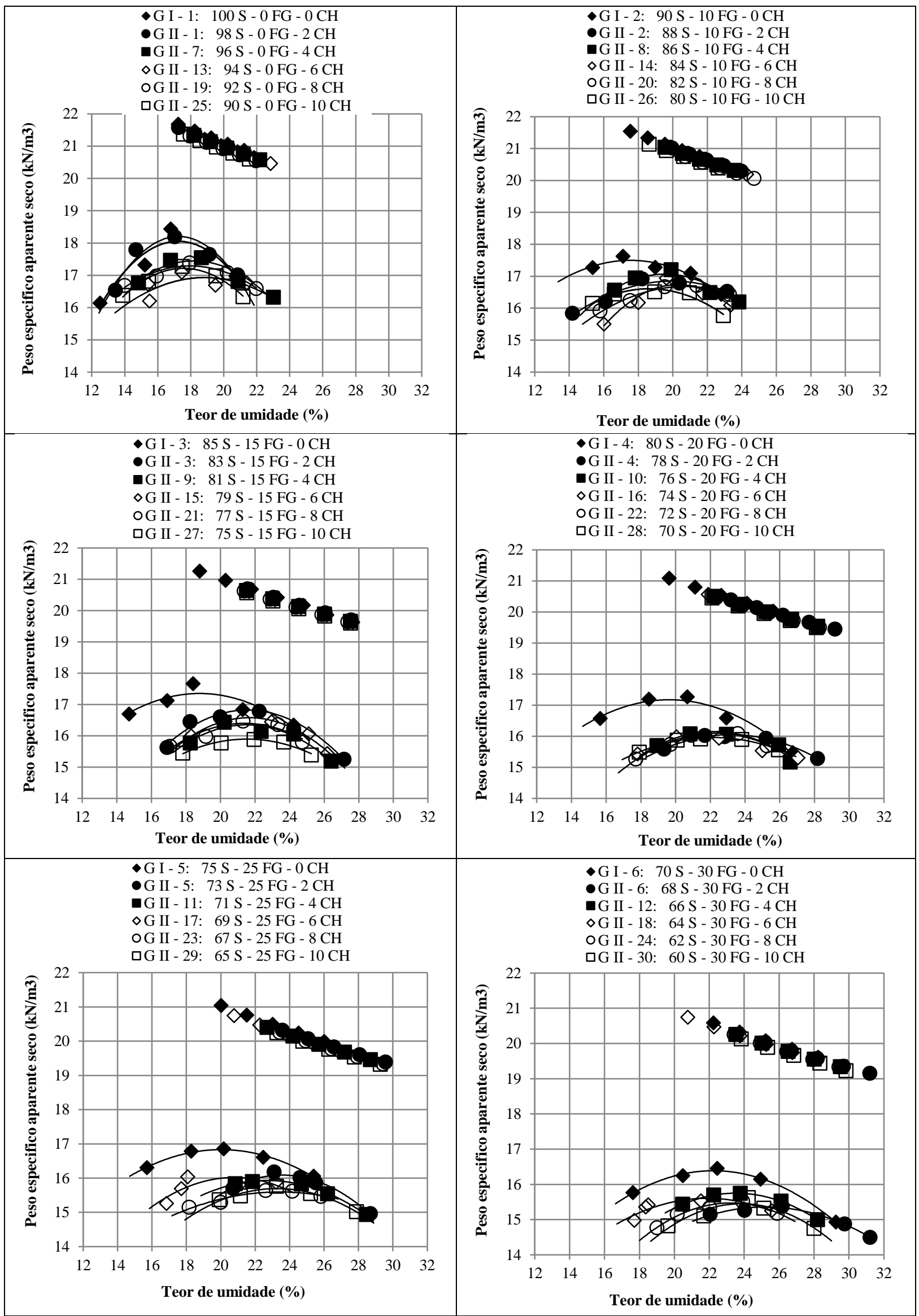

Figura 4.9. Curvas de compactação Mini-Proctor e de saturação dos materiais em função dos teores da cal. 


\subsubsection{3 - MINI - CBR E EXPANSÃO}

A Tabela 4.10 apresenta os resultados obtidos dos ensaios de mini-CBR sem imersão, com imersão e com cura de 7 dias e imersão. Nas Figuras 4.13 a 4.30 estão ilustradas as curvas obtidas a partir desses ensaios assim como as variações das expansões para as misturas estudadas. Uma vez que não eram esperadas expansões excessivas nem reações pozolânicas nas misturas constituídas apenas com o solo e o fosfogesso (GI-1, 2, 3, 4, 5,6), julgou-se desnecessário moldar corpos de prova para cura. A partir dos dados apresentados na Tabela 4.10, foi possível observar que o aumento do teor de fosfogesso aumenta os valores de miniCBR com imersão em relação aos valores obtidos para o solo puro, de $9,3 \%$ a $27,7 \%$. A presença do fosfogesso nas misturas GI-1, 2, 3, 4, 5, e 6 melhorou também perda de suporte mini-CBR por imersão (PSI), passando de um valor considerado médio de $57 \%$ a um valor baixo de $21 \%$ para a mistura com $20 \%$ de fosfogesso.

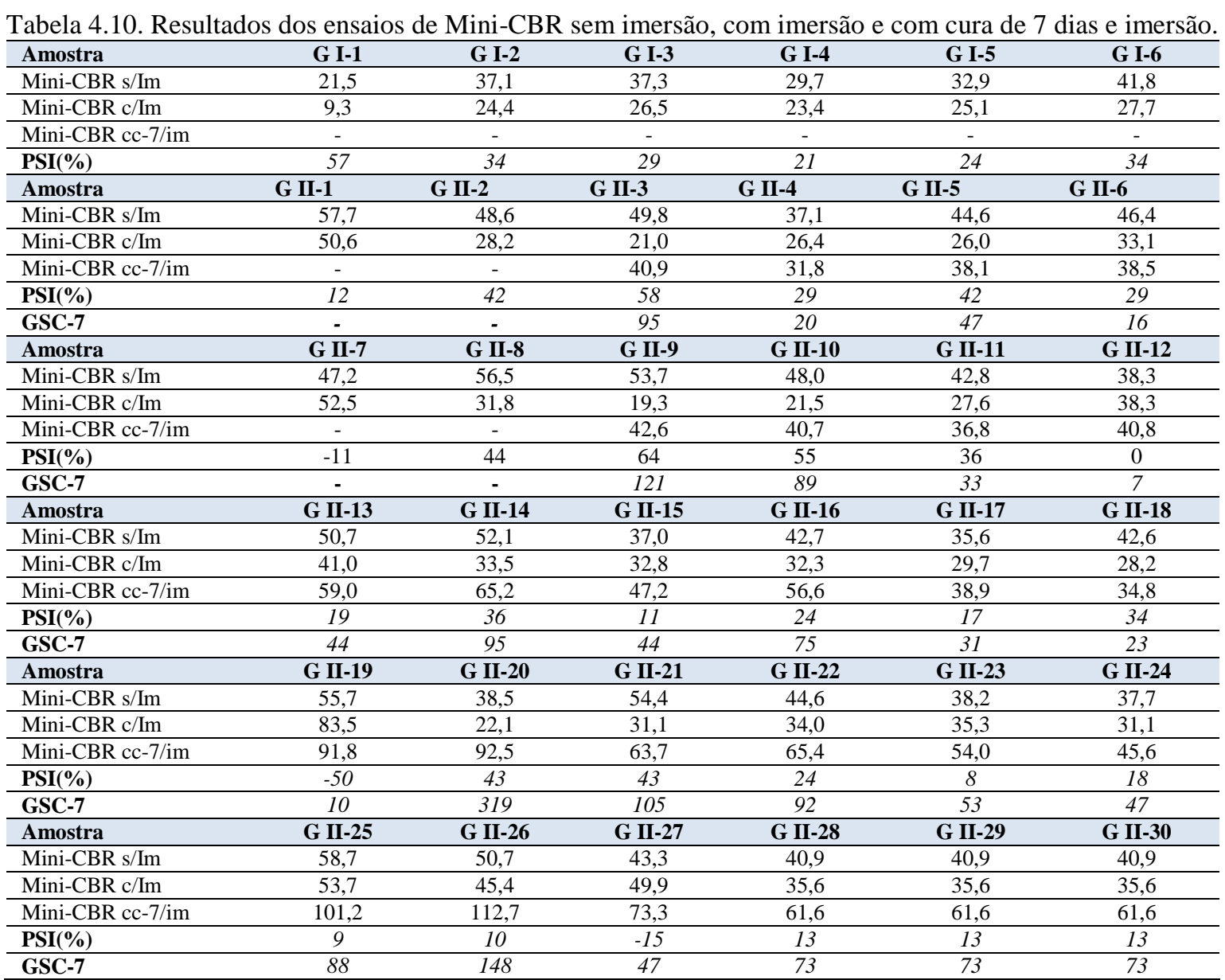

Nota: PSI =Perda de suporte mini-CBR por imersão; GSI=Ganho de suporte por tempo de cura de 7 dias.

De forma geral, os valores de perda de suporte mini-CBR por imersão variam de baixas $(<40 \%)$ a médias (40 a 70\%). Valores negativos de PIS sugerem a ocorrência de aumento de 
suporte com a imersão. A cura de 7 dias dos materiais proporcionou ganhos de suporte. Isto pode ser verificado com valores de GSC (ganhos de suporte por tempo de cura de 7 dias) variando entre $7 \%$ para a mistura GII-12 e 319\% para a mistura GII-20. Isso comprova que nesse tempo, já se observam os efeitos das reações pozolânicas. Na metodologia MCT, valores de mini-CBR superiores a 30\% são considerados muito elevados (Nogami \& Vilibor, 2009) e conforme apresentado nas Figuras 4.10 a 4.27, apenas as misturas GI-1 a 6, GII- 2, 3, 4, 5, 9,10, 11 e 20 apresentaram mini-CBR inferiores a esse limite. Essas misturas, no entanto, apresentam mini-CBR considerados elevados pelo método porque se enquadram na faixa de 12 a 30\%, exceto a amostra de solo GI-1, com 9,3\% de mini-CBR. Já com cura de 7 dias, nenhuma mistura apresentou resistência inferior a 30\%. Sendo assim, pelo critério de resistência, o uso dessas misturas pode ser considerado adequado em camadas de pavimentos de baixos custos. No entanto, ainda é necessário avaliar o comportamento expansivo desses materiais. Nas curvas de expansão também apresentadas nas Figuras 4.10 a 4.27 é possível observar que, como esperado, para as umidades próximas da condição ótima, as misturas GI-1 a 6 apresentam expansões que não excedem 0,3\%. Esse é o limite preconizado pela norma ME 192 (DNER, 1988) para os materiais serem usados em camadas de base. As misturas constituídas apenas por solo e cal (GII - 1, 7, 13, 19 e 25) apresentam também expansões nessa faixa. Para as misturas com solo, fosfogesso e cal, notou-se em todos os casos, valores de expansões superiores a $0,5 \%$, no entanto inferiores a $3 \%$, valor considerado elevado pela Metodologia MCT (Nogami \& Vilibor, 2009). Entretanto, quando essas mesmas misturas foram submetidas à cura, observou-se uma forte redução desse parâmetro para as misturas GII-3, 4, 5, 6, 8, 9, 10, 11, 12, 14, 15, 16, 17, 21, 22, 23 e 24 com valores próximos da ótima, sendo todos inferiores a $0,3 \%$. Isso mostra que para essas misturas, a cura de 7 dias gerou um efeito positivo na minimização da expansão. Para as misturas GII-18 e 20, embora tenha sido observada diminuição da expansão, as mesmas permaneceram superiores a 0,5\%. Já nas misturas GII-26, 27, 28, 29 e 30 não foi observada a diminuição da expansão com a cura utilizada. Acredita-se que para essas misturas, mais ricas em cal e fosfogesso, seja preciso maior tempo de cura para se possibilitar maior consumo desses componentes nas reações pozolânicas antes da ocorrência da expansão devida à formação da etringita. As Figuras 4.28 e 4.29 mostram a variação dos valores de mini-CBR em função do teor de fosfogesso e de cal, respectivamente. Observa-se que o aumento de resistência das misturas com a cura é devido mais à presença da cal do que à do fosfogesso. 


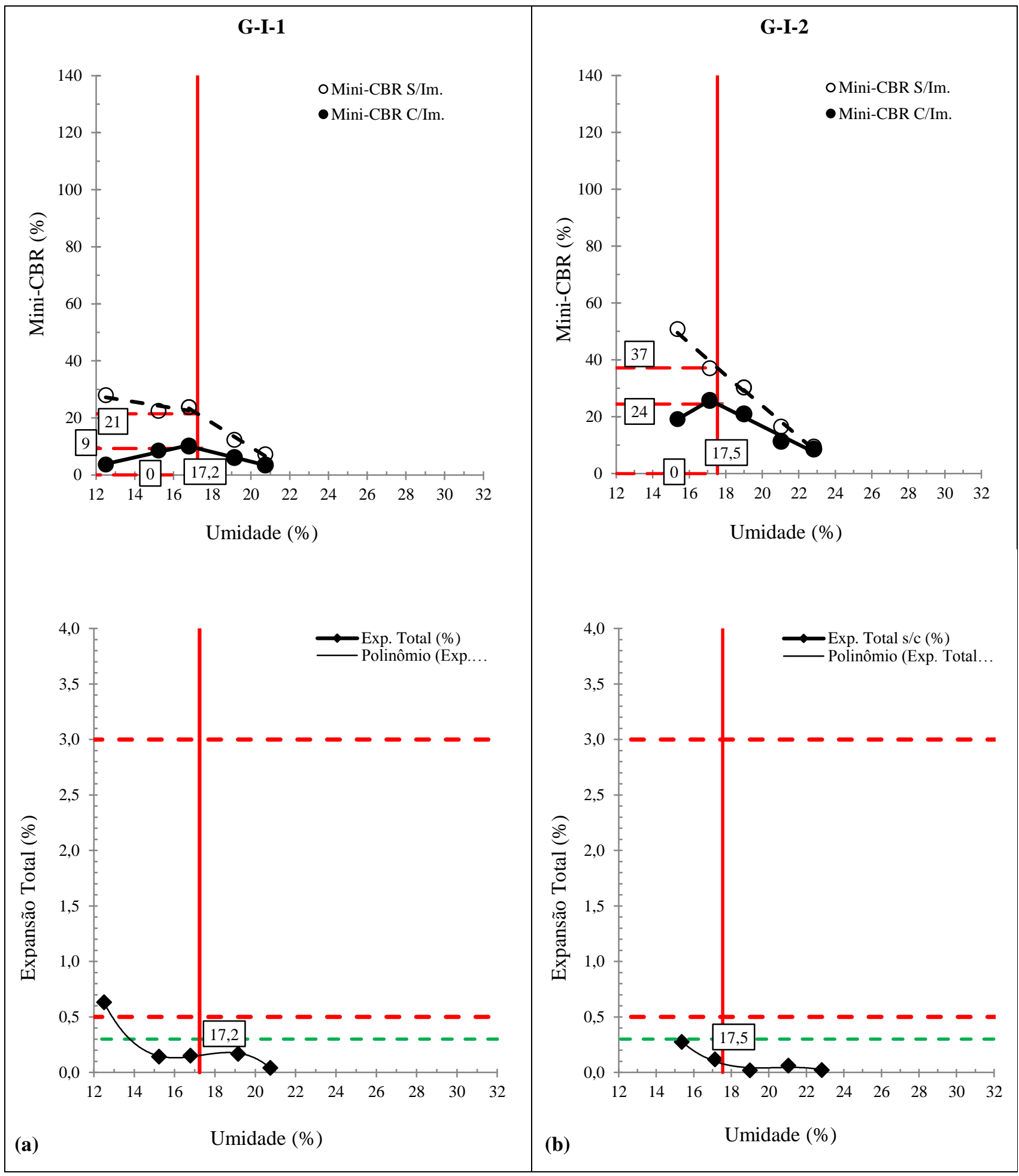

Figura 4.10. Curvas obtidas dos ensaios de Mini-CBR com e sem imersão, Expansão com imersão imediata e com imersão após 7 dias de cura (a) GI-1 (b) GI-2.

Obs. S/Im= Sem imersão, C/Im=Com imersão imediata; Exp.Total s/c=Expansão total sem cura e após imersão. 


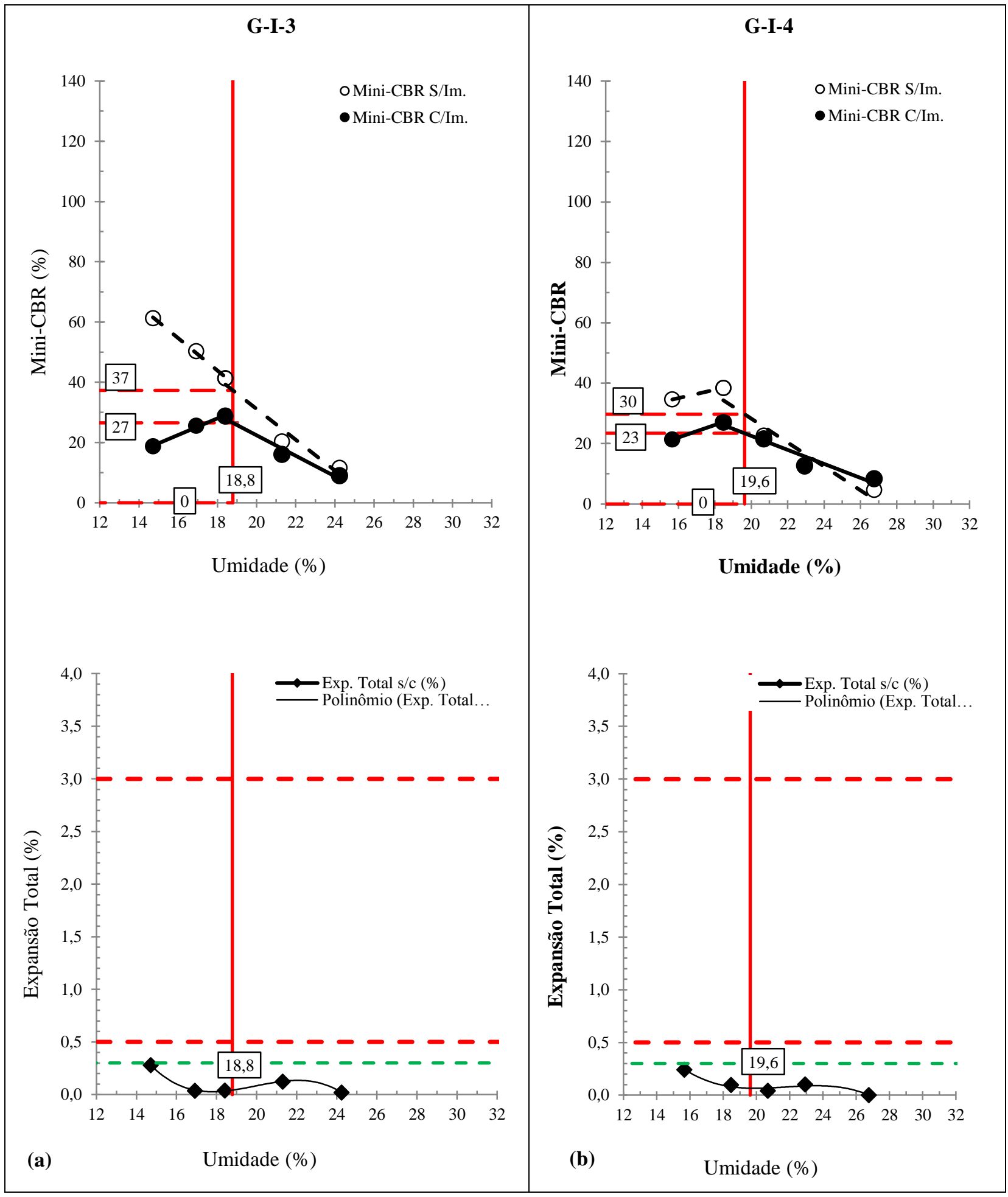

Figura 4.11. Curvas obtidas dos ensaios de Mini-CBR com e sem imersão, Expansão com imersão imediata e com imersão após 7 dias de cura (a) GI-3 (b) GI-4.

Obs. S/Im= Sem imersão, C/Im=Com imersão imediata; Exp.Total s/c=Expansão total sem cura e após imersão. 


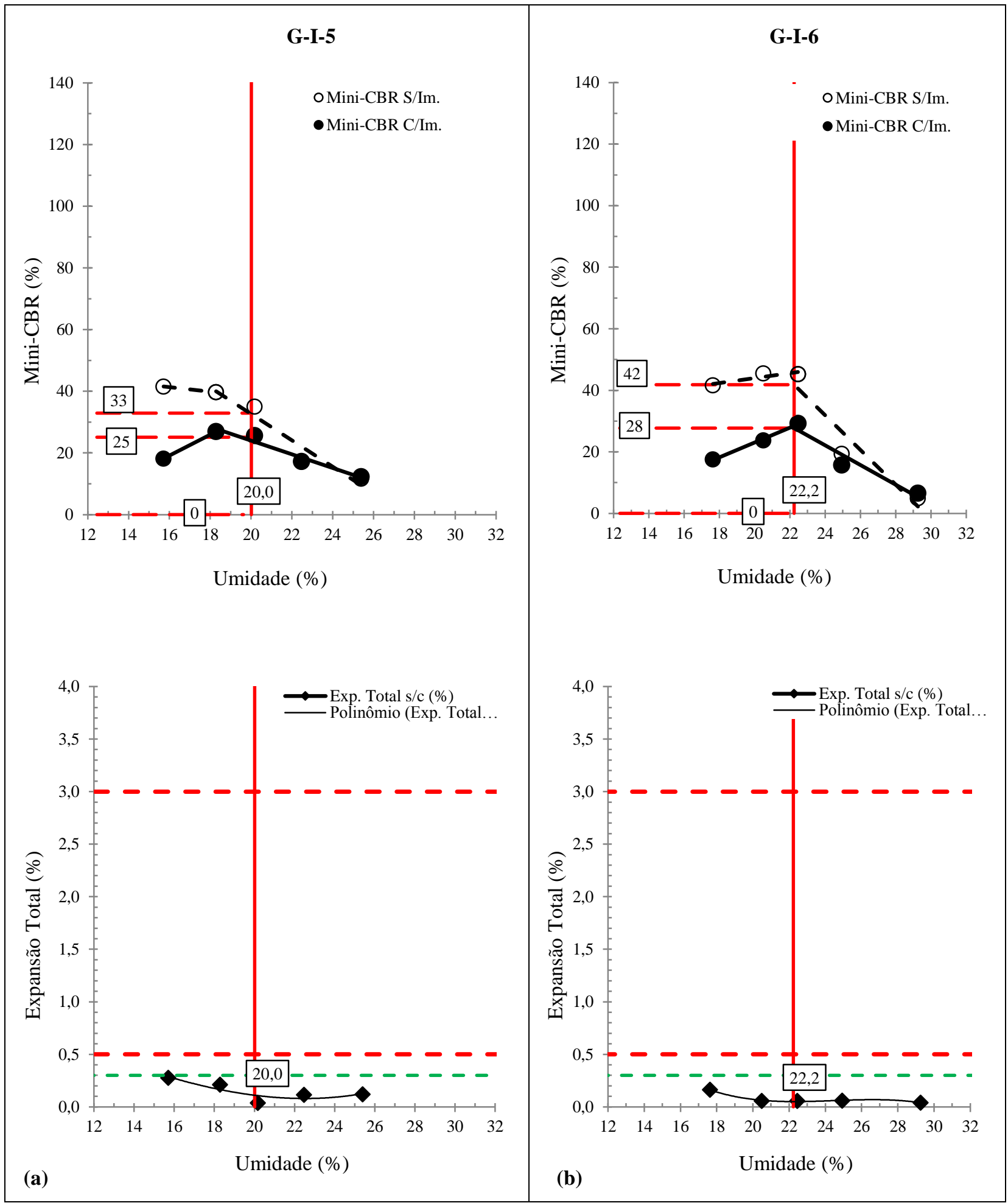

Figura 4.12. Curvas obtidas dos ensaios de Mini-CBR com e sem imersão, Expansão com imersão imediata e com imersão após 7 dias de cura (a) GI-5 (b) GI-6.

Obs. S/Im= Sem imersão, C/Im=Com imersão imediata; Exp.Total s/c=Expansão total sem cura e após imersão. 


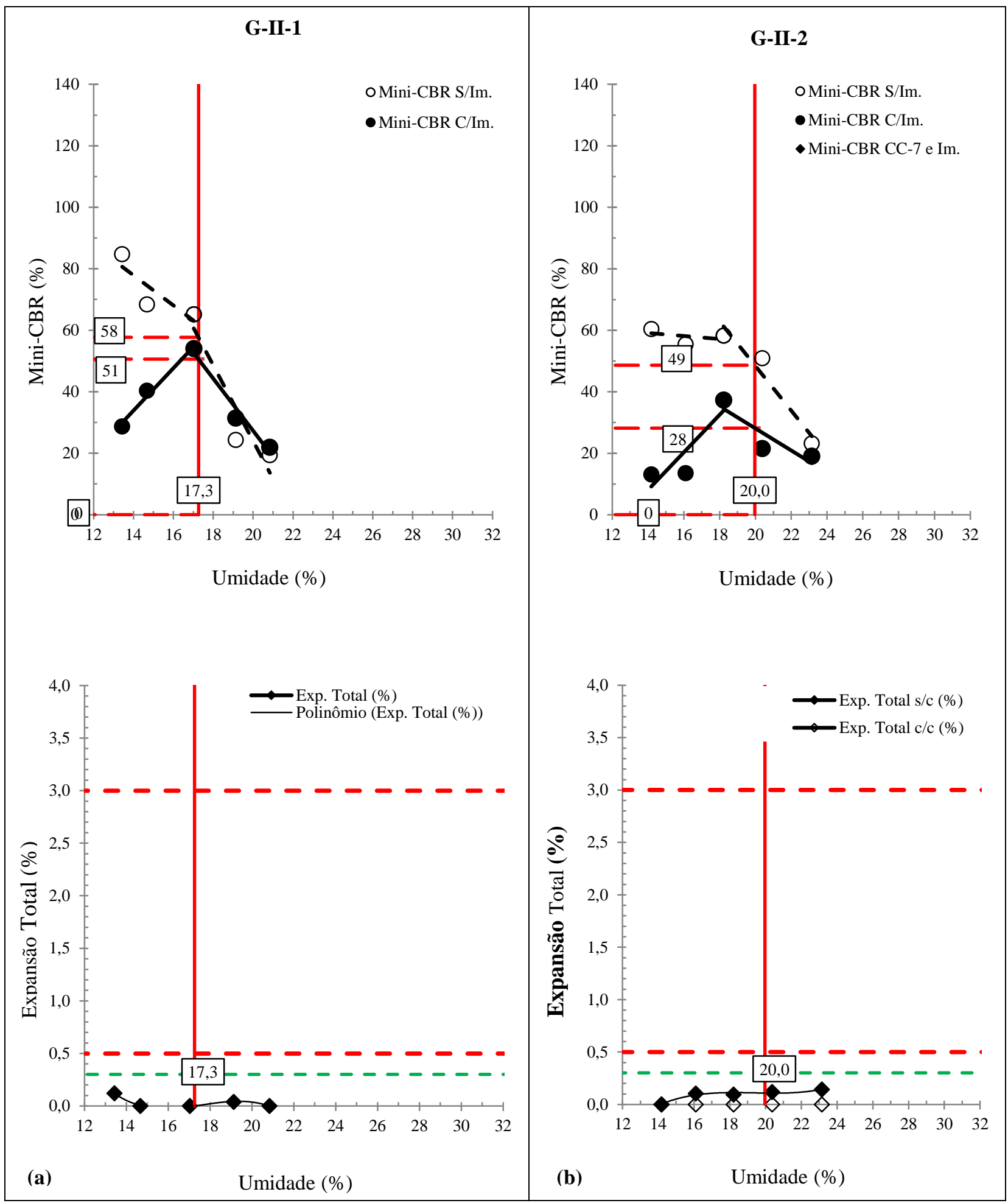

Figura 4.13. Curvas obtidas dos ensaios de Mini-CBR com e sem imersão e com imersão após 7 dias de cura; Expansão com imersão imediata e com imersão após 7 dias de cura (a) GII-1 (b) GII-2.

Obs. S/Im= Sem imersão, C/Im=Com imersão imediata; Exp.Total s/c=Expansão total sem cura e após imersão, Exp.Total c/c=Expansão total com cura e após imersão. 


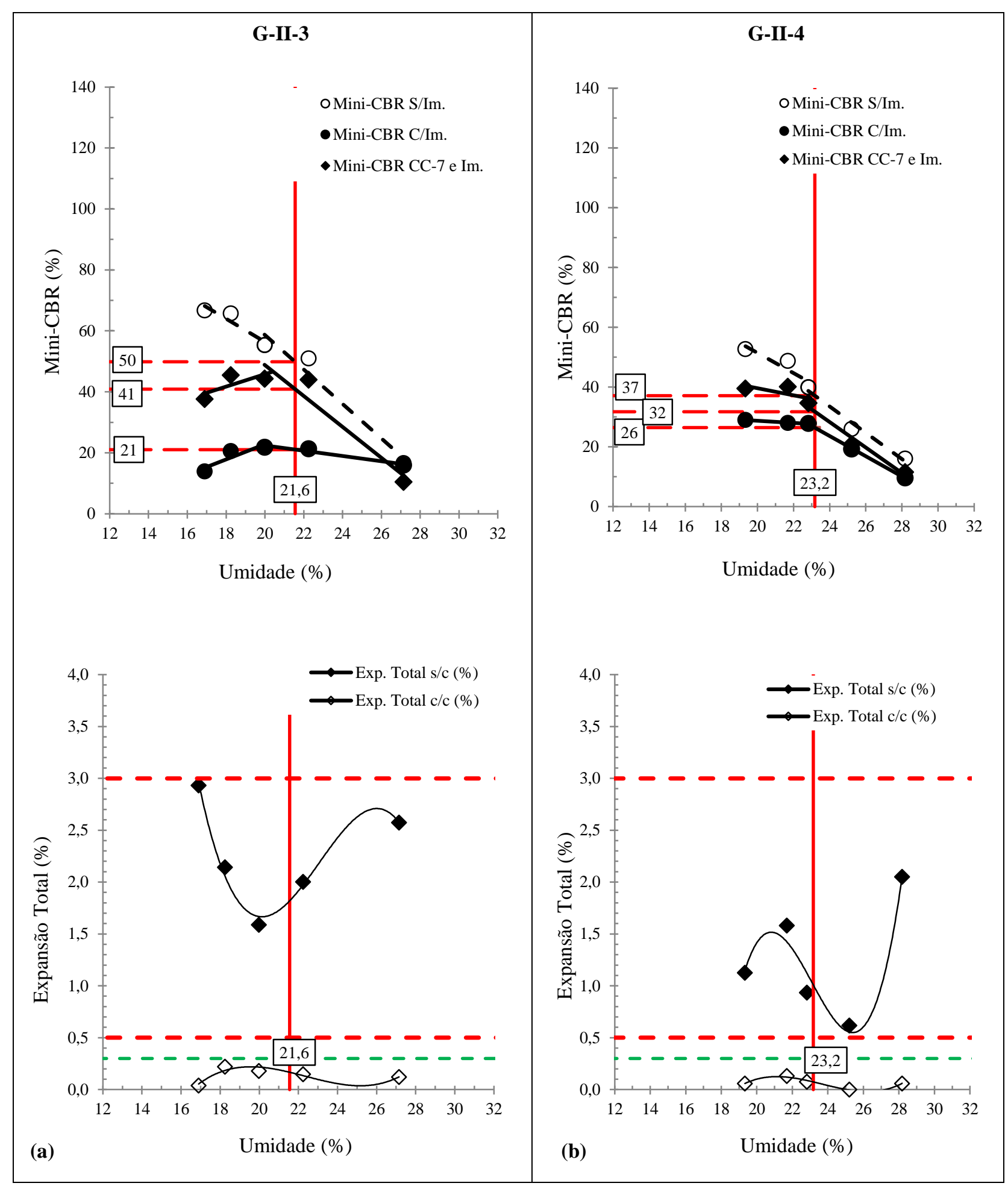

Figura 4.14. Curvas obtidas dos ensaios de Mini-CBR com e sem imersão e com imersão após 7 dias de cura; Expansão com imersão imediata e com imersão após 7 dias de cura (a) GII-3 (b) GII-4.

Obs. S/Im= Sem imersão, C/Im=Com imersão imediata; Exp.Total s/c=Expansão total sem cura e após imersão, Exp.Total c/c=Expansão total com cura e após imersão. 


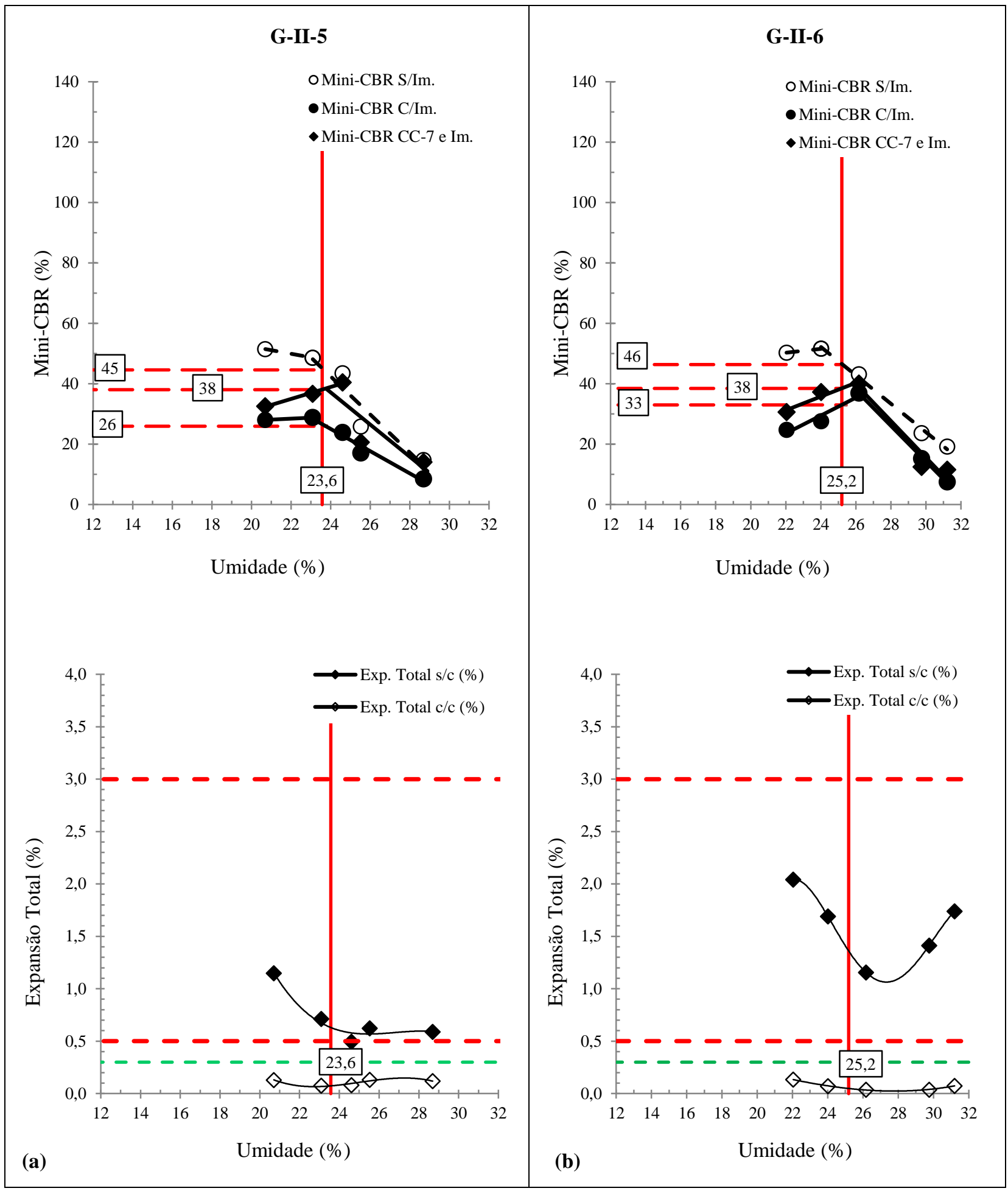

Figura 4.15. Curvas obtidas dos ensaios de Mini-CBR com e sem imersão e com imersão após 7 dias de cura; Expansão com imersão imediata e com imersão após 7 dias de cura (a) GII-5 (b) GII-6.

Obs. S/Im= Sem imersão, C/Im=Com imersão imediata; Exp.Total s/c=Expansão total sem cura e após imersão, Exp.Total c/c=Expansão total com cura e após imersão. 


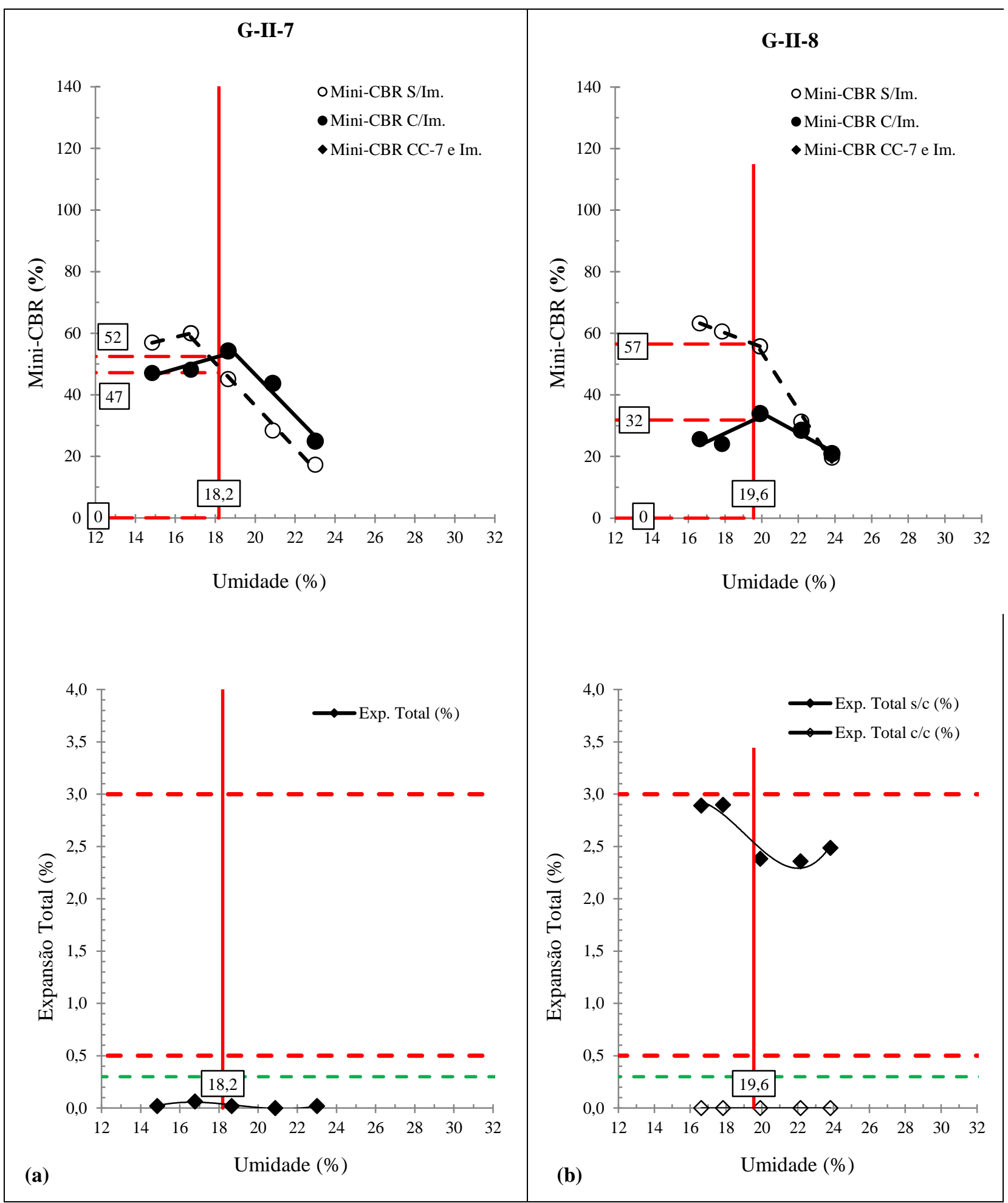

Figura 4.16. Curvas obtidas dos ensaios de Mini-CBR com e sem imersão e com imersão após 7 dias de cura; Expansão com imersão imediata e com imersão após 7 dias de cura (a) GII-7 (b) GII-8.

Obs. S/Im= Sem imersão, C/Im=Com imersão imediata; Exp.Total s/c=Expansão total sem cura e após imersão, Exp.Total c/c=Expansão total com cura e após imersão. 


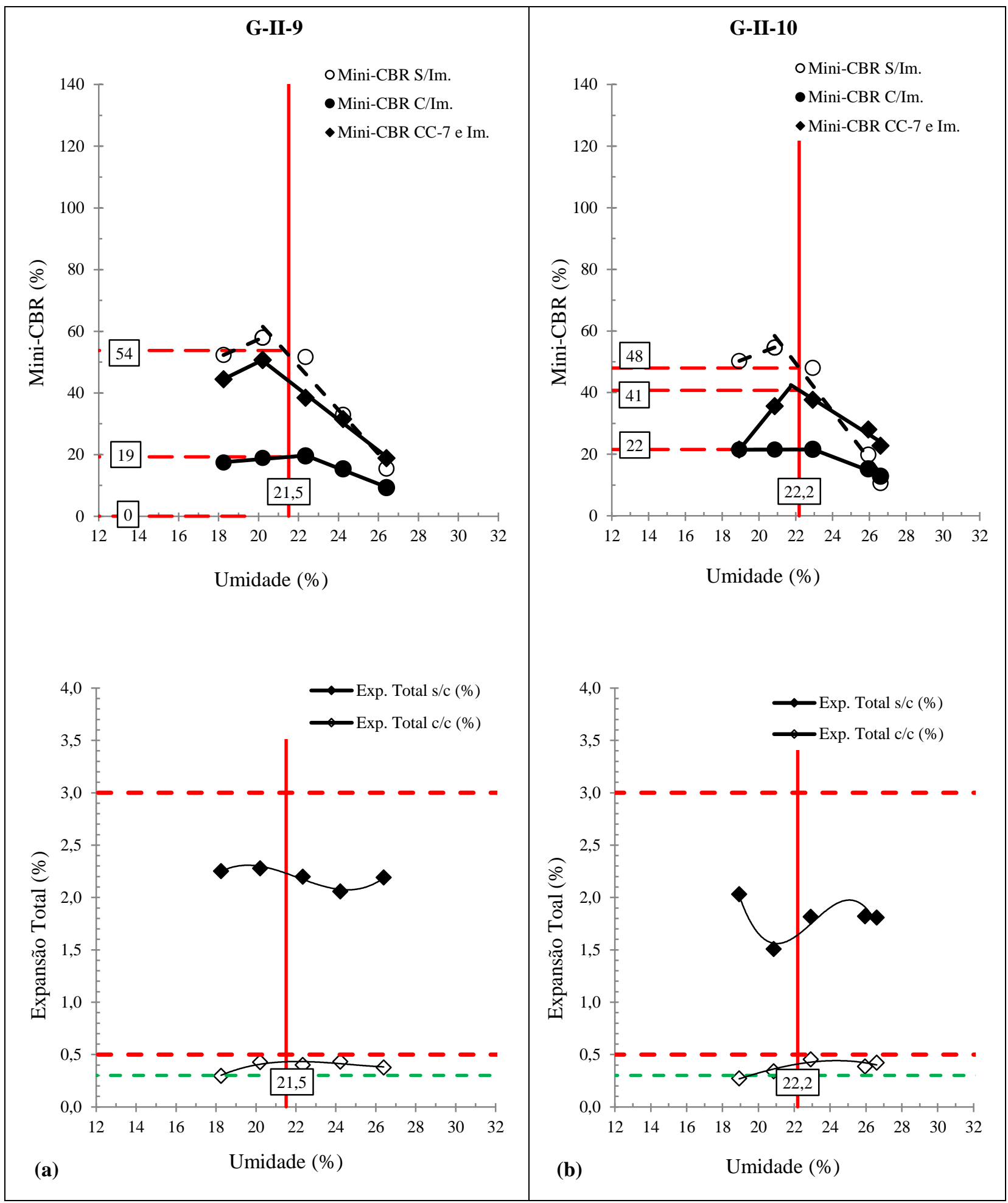

Figura 4.17. Curvas obtidas dos ensaios de Mini-CBR com e sem imersão e com imersão após 7 dias de cura; Expansão com imersão imediata e com imersão após 7 dias de cura (a) GII-9 (b) GII-10.

Obs. S/I= Sem imersão, C/Im=Com imersão imediata; Exp.Total s/c=Expansão total sem cura e após imersão, Exp.Total c/c=Expansão total com cura e após imersão. 


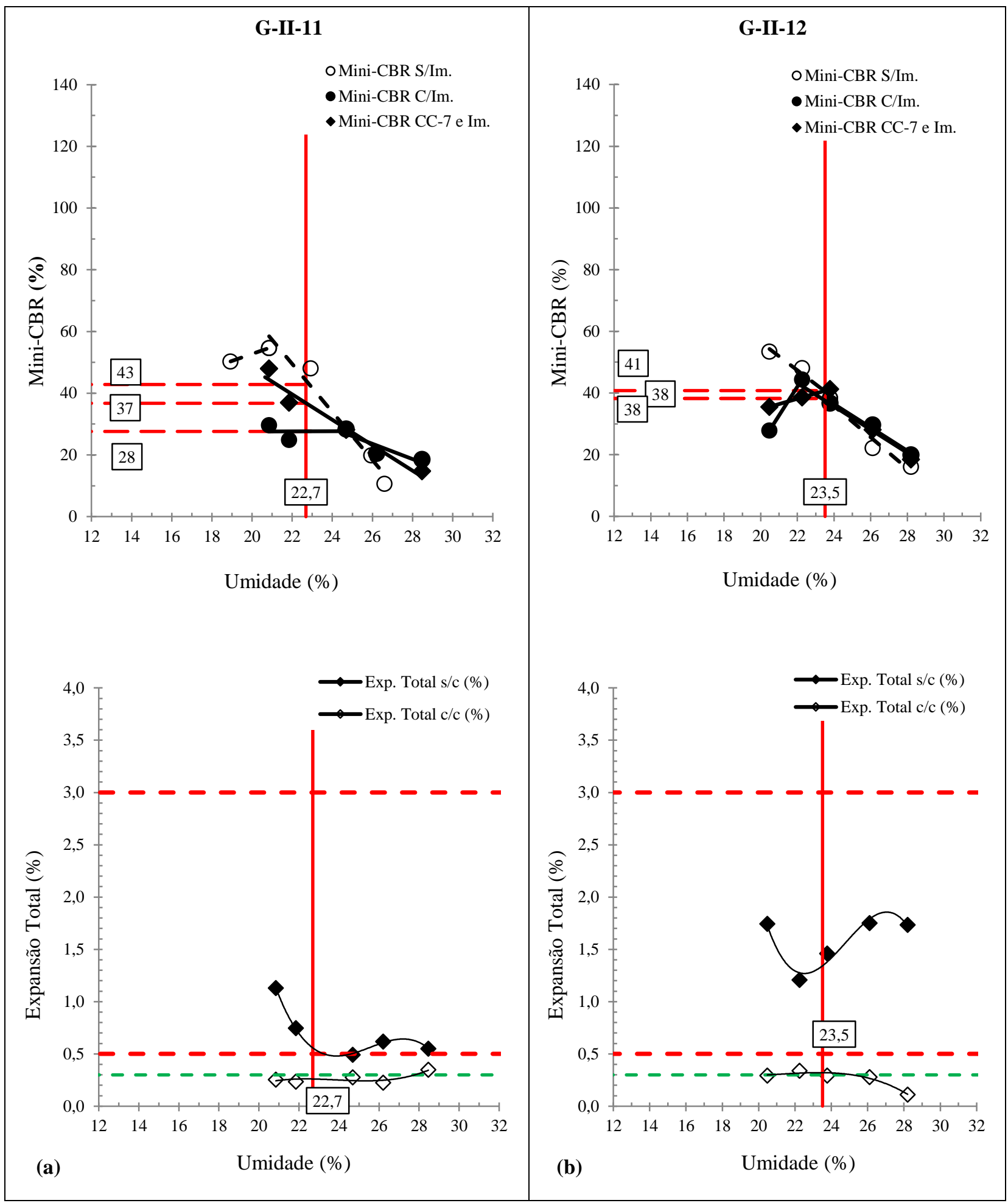

Figura 4.18. Curvas obtidas dos ensaios de Mini-CBR com e sem imersão e com imersão após 7 dias de cura; Expansão com imersão imediata e com imersão após 7 dias de cura (a) GII-11 (b) GII-12.

Obs. S/Im= Sem imersão, C/Im=Com imersão imediata; Exp.Total s/c=Expansão total sem cura e após imersão, Exp.Total c/c=Expansão total com cura e após imersão. 


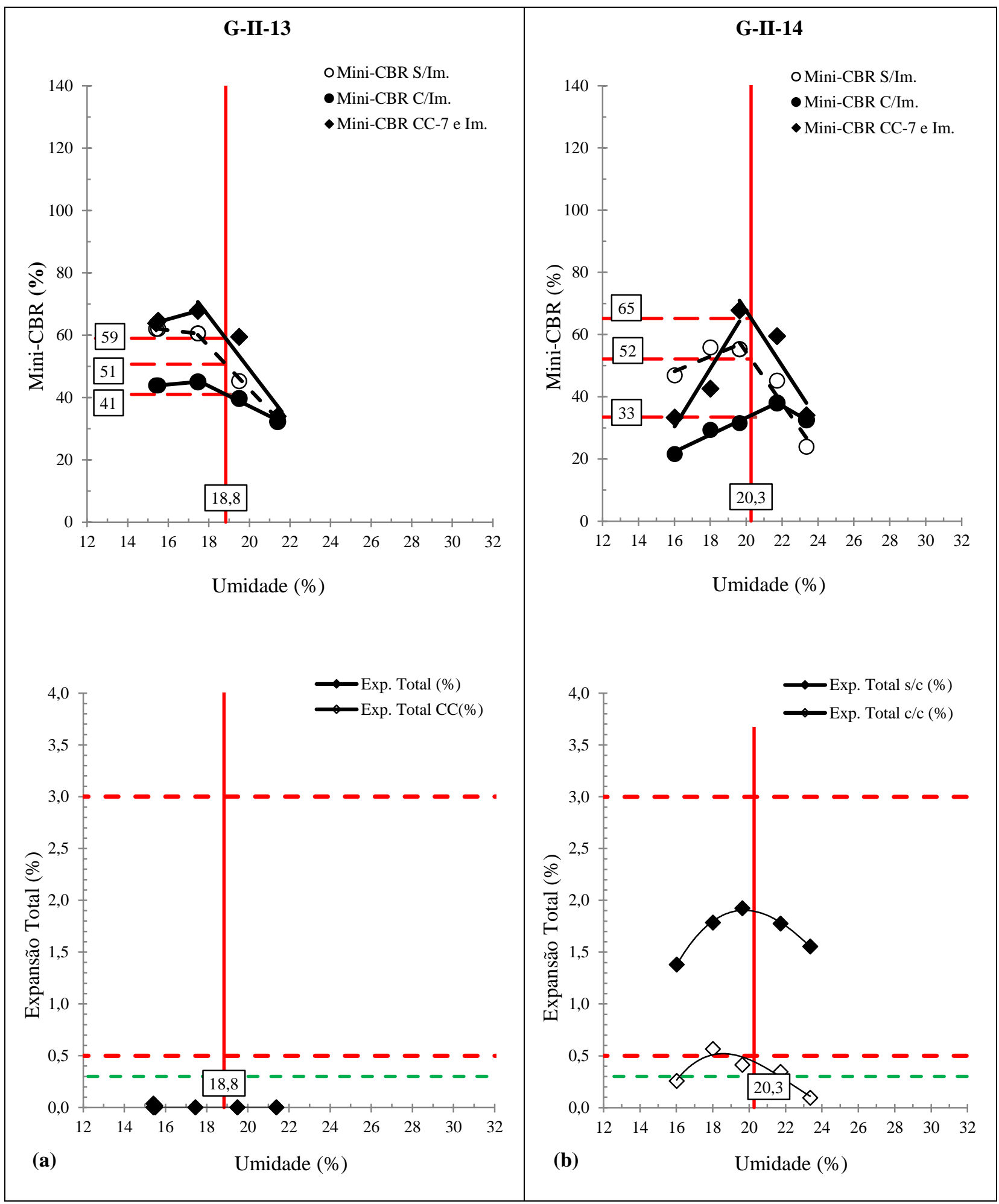

Figura 4.19. Curvas obtidas dos ensaios de Mini-CBR com e sem imersão e com imersão após 7 dias de cura; Expansão com imersão imediata e com imersão após 7 dias de cura (a) GII-13 (b) GII-14.

Obs. S/Im= Sem imersão, C/Im=Com imersão imediata; Exp.Total s/c=Expansão total sem cura e após imersão, Exp.Total c/c=Expansão total com cura e após imersão. 


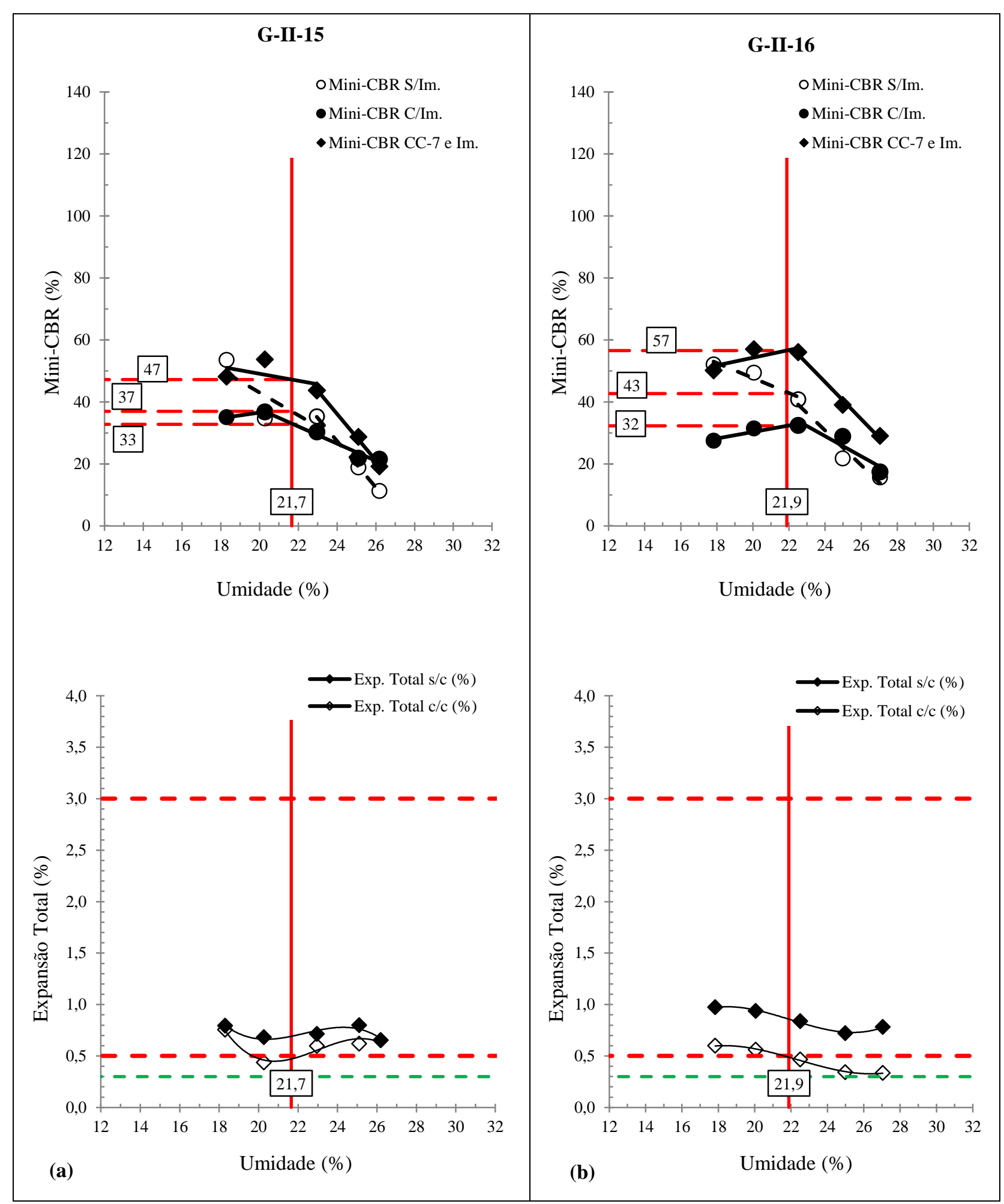

Figura 4.20. Curvas obtidas dos ensaios de Mini-CBR com e sem imersão e com imersão após 7 dias de cura; Expansão com imersão imediata e com imersão após 7 dias de cura (a) GII-15 (b) GII-16.

Obs. S/Im= Sem imersão, C/Im=Com imersão imediata; Exp.Total s/c=Expansão total sem cura e após imersão, Exp.Total c/c=Expansão total com cura e após imersão. 


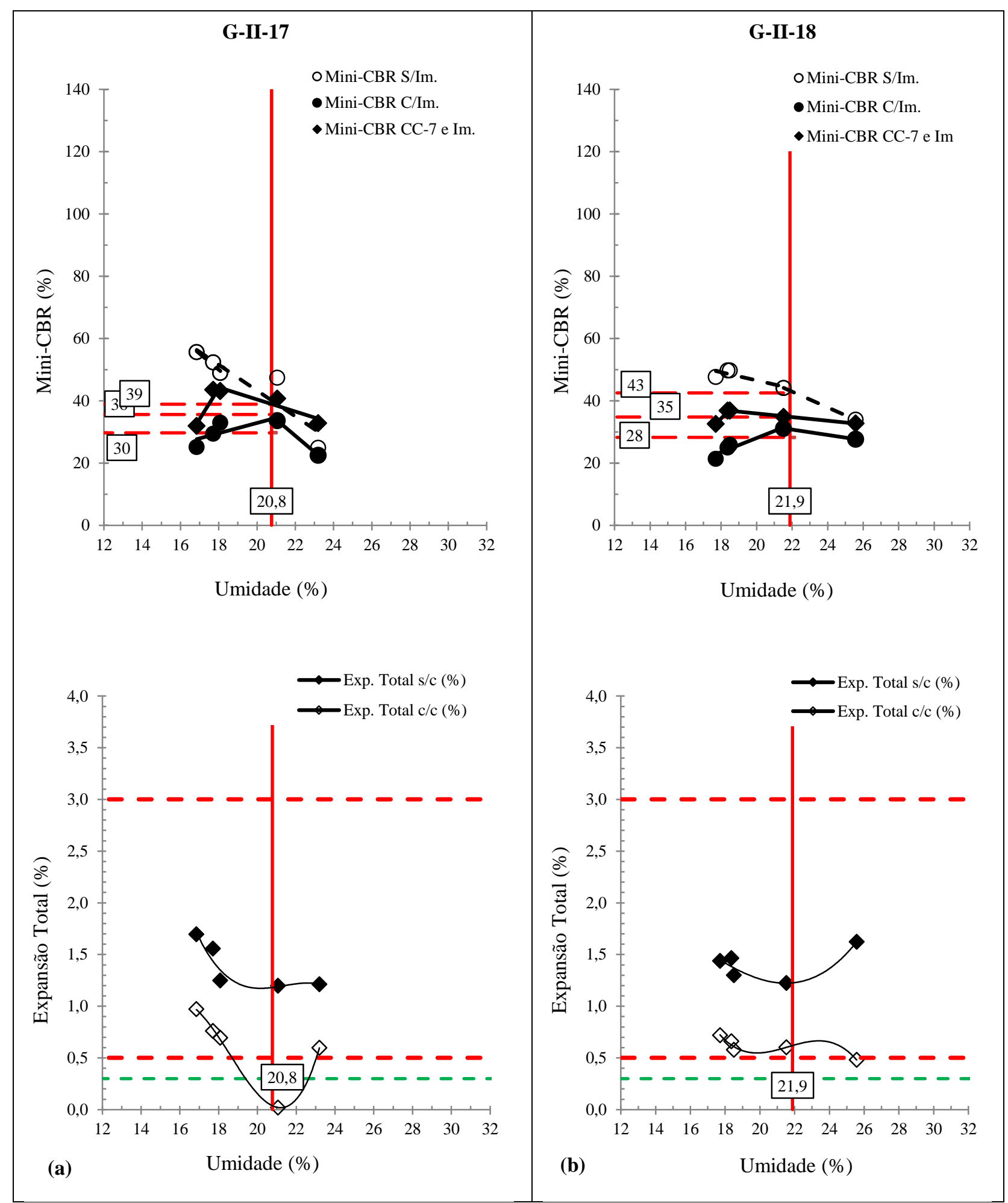

Figura 4.21 Curvas obtidas dos ensaios de Mini-CBR com e sem imersão e com imersão após 7 dias de cura; Expansão com imersão imediata e com imersão após 7 dias de cura (a) GII-17 (b) GII-18.

Obs. S/Im= Sem imersão, C/Im=Com imersão imediata; Exp.Total s/c=Expansão total sem cura e após imersão, Exp.Total c/c=Expansão total com cura e após imersão. 


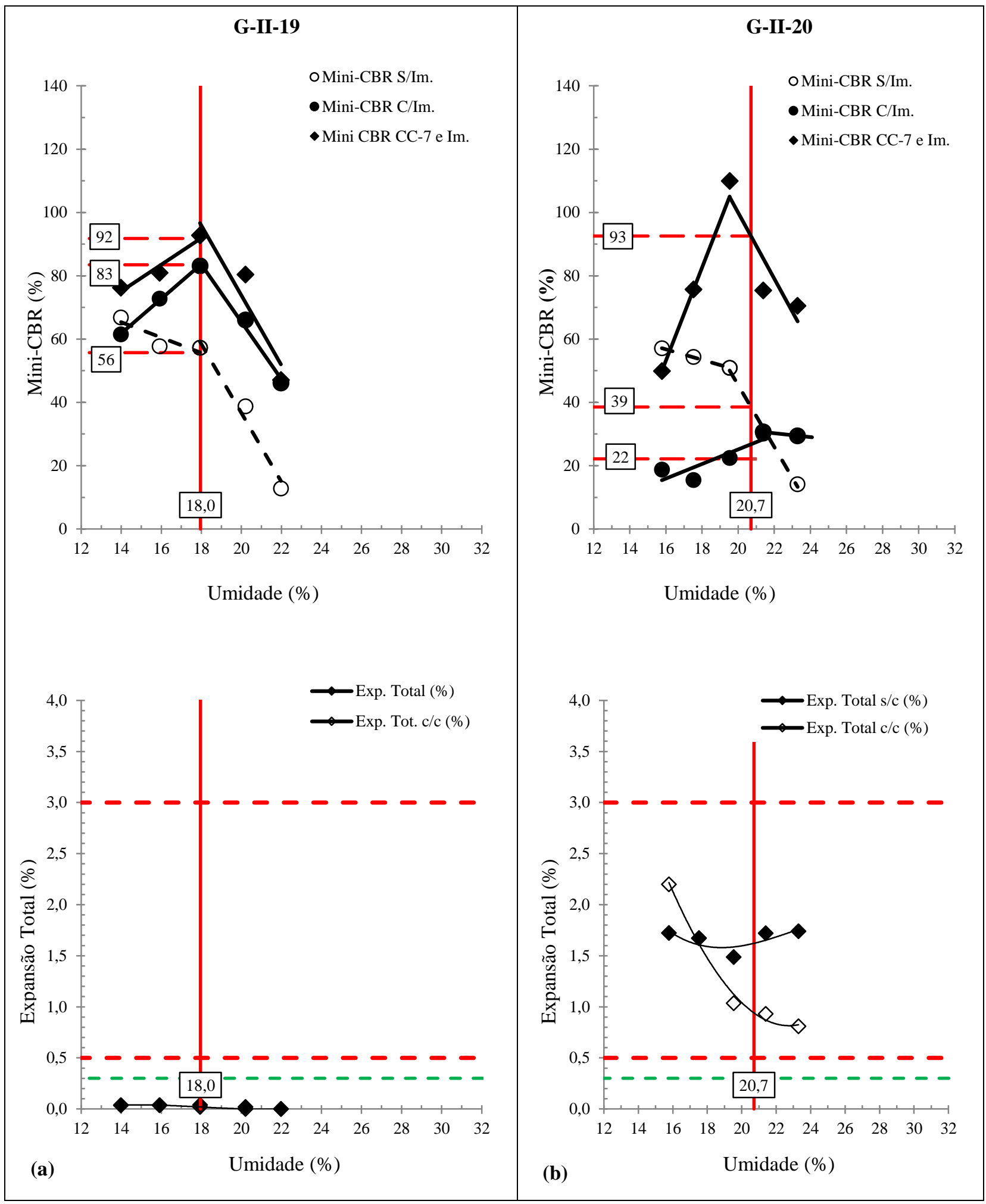

Figura 4.22. Curvas obtidas dos ensaios de Mini-CBR com e sem imersão e com imersão após 7 dias de cura; Expansão com imersão imediata e com imersão após 7 dias de cura (a) GII-19 (b) GII-20.

Obs. S/Im= Sem imersão, C/Im=Com imersão imediata; Exp.Total s/c=Expansão total sem cura e após imersão, Exp.Total c/c=Expansão total com cura e após imersão. 


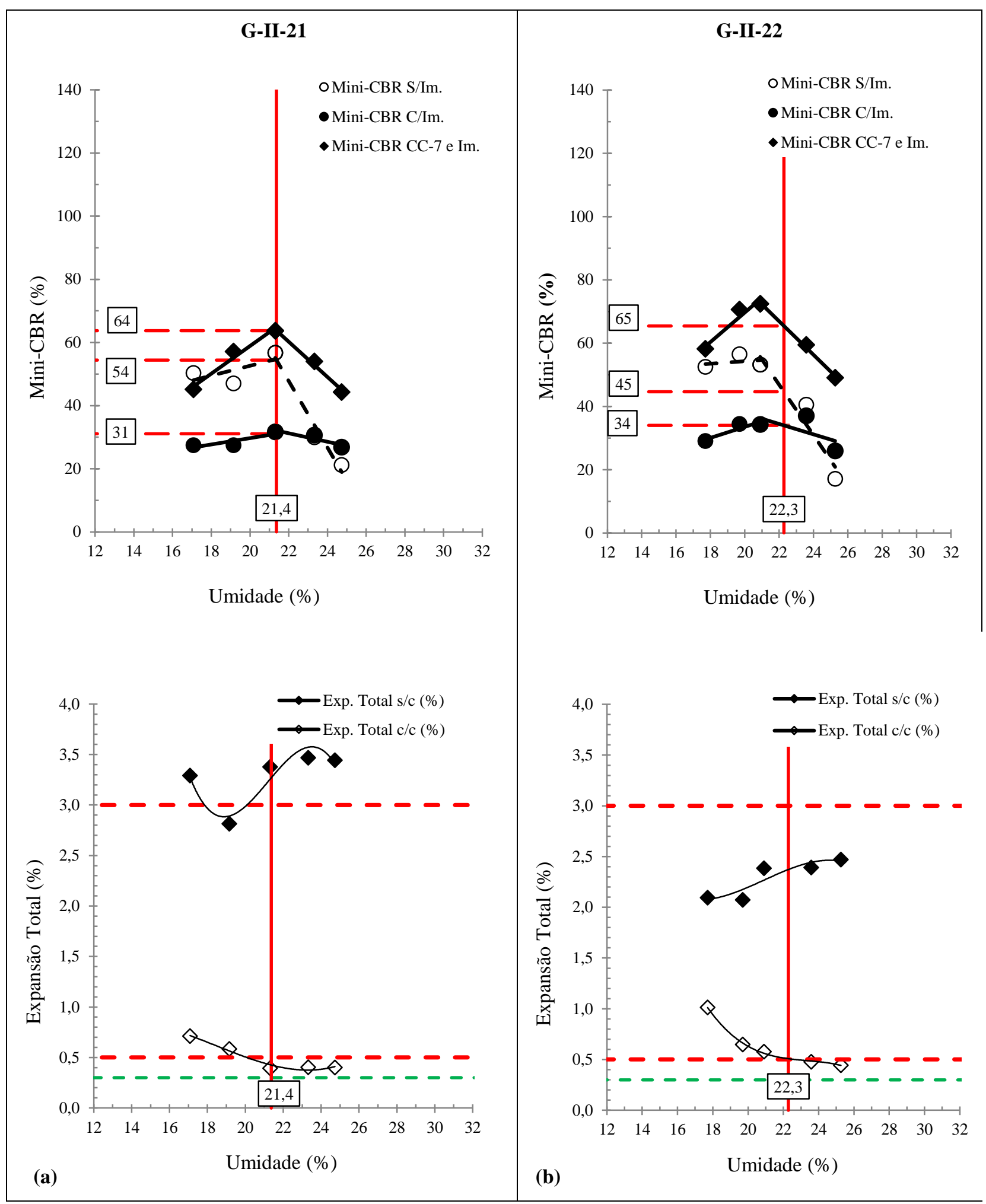

Figura 4.23. Curvas obtidas dos ensaios de Mini-CBR com e sem imersão e com imersão após 7 dias de cura; Expansão com imersão imediata e com imersão após 7 dias de cura (a) GII-21 (b) GII-22.

Obs. S/Im= Sem imersão, C/Im=Com imersão imediata; Exp.Total s/c=Expansão total sem cura e após imersão, Exp.Total c/c=Expansão total com cura e após imersão. 


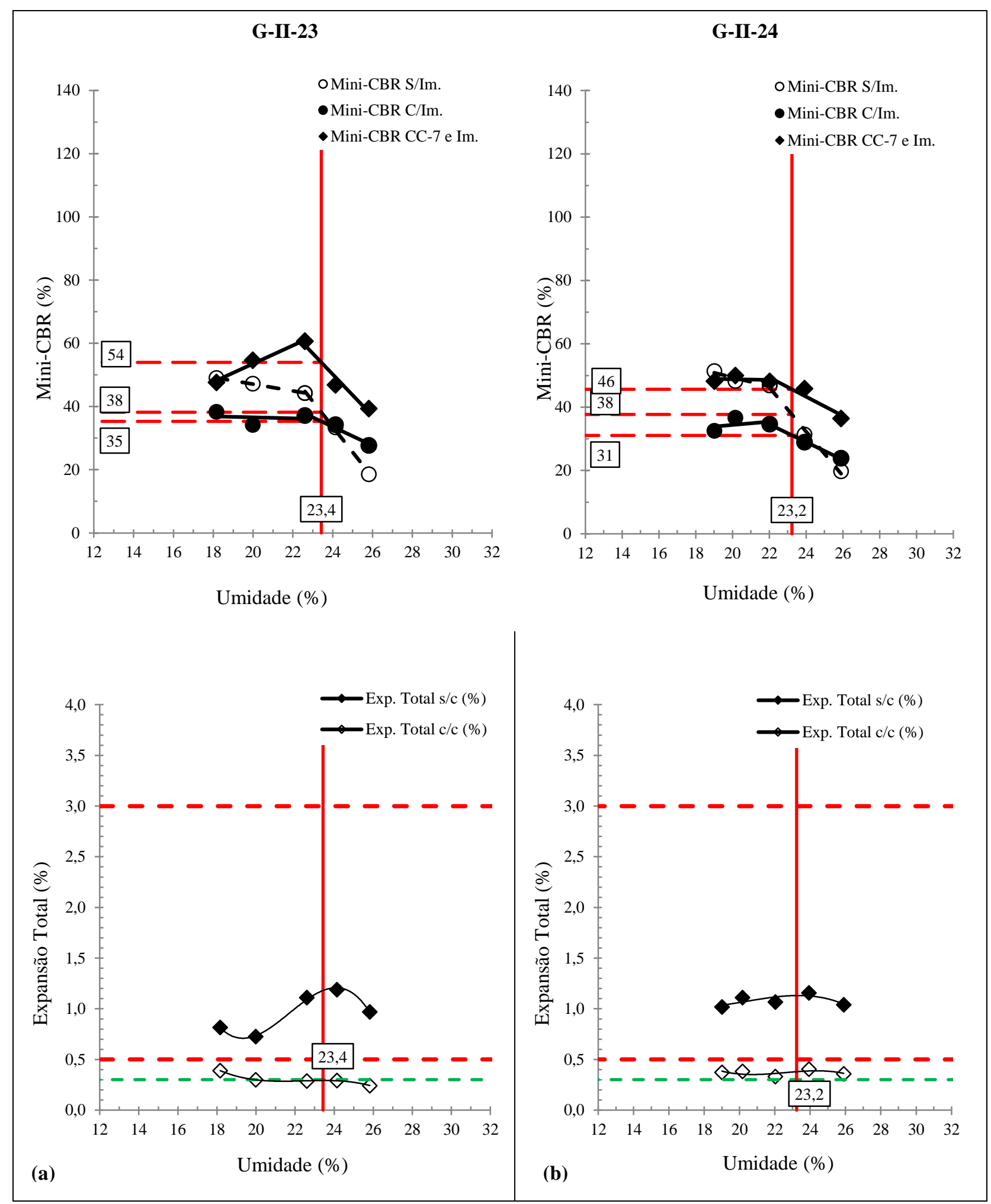

Figura 4.24. Curvas obtidas dos ensaios de Mini-CBR com e sem imersão e com imersão após 7 dias de cura; Expansão com imersão imediata e com imersão após 7 dias de cura (a) GII-23 (b) GII-24.

Obs. S/Im= Sem imersão, C/Im=Com imersão imediata; Exp.Total s/c=Expansão total sem cura e após imersão, Exp.Total c/c=Expansão total com cura e após imersão. 


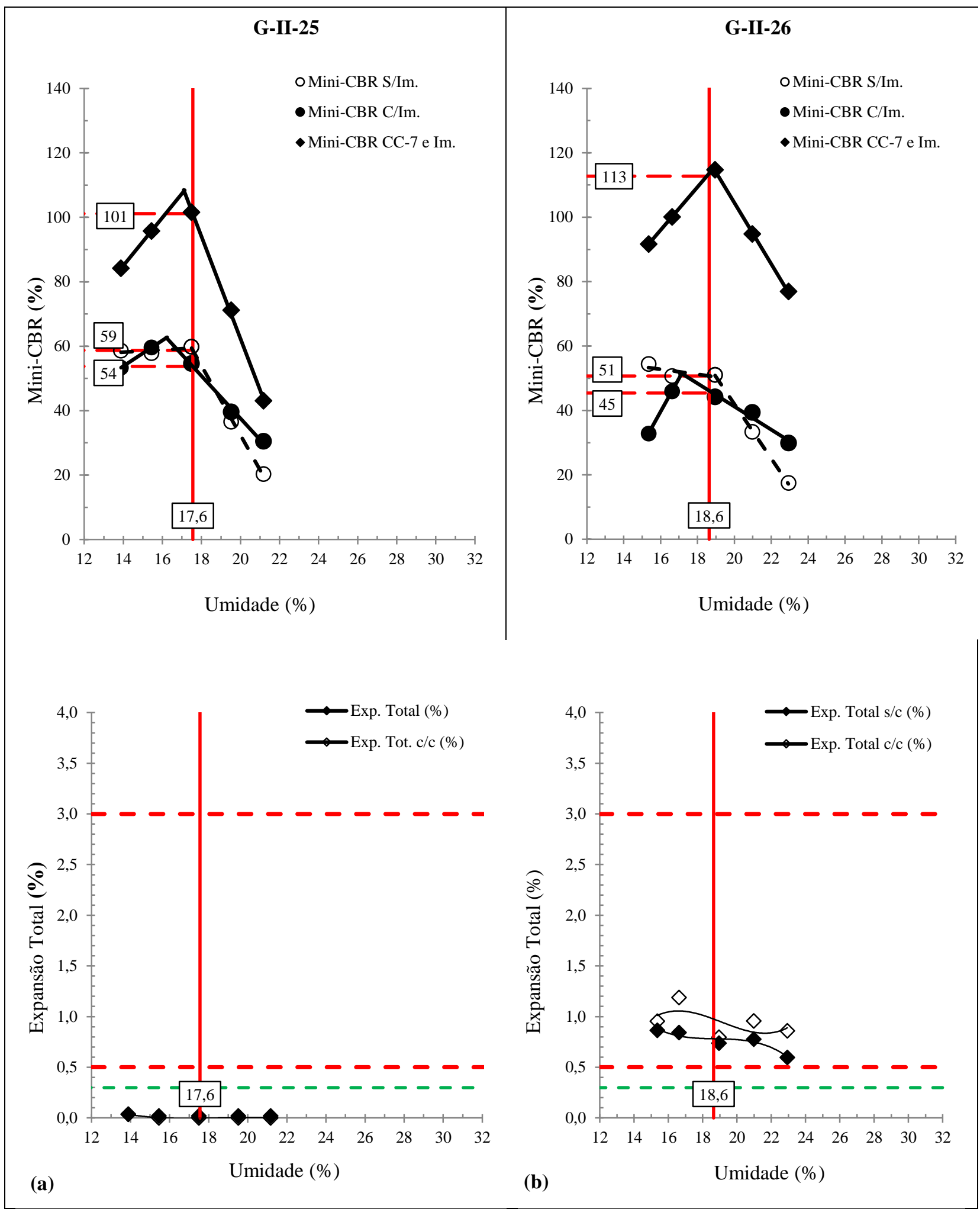

Figura 4.25. Curvas obtidas dos ensaios de Mini-CBR com e sem imersão e com imersão após 7 dias de cura; Expansão com imersão imediata e com imersão após 7 dias de cura (a) GII-25 (b) GII-26.

Obs. S/Im= Sem imersão, C/Im=Com imersão imediata; Exp.Total s/c=Expansão total sem cura e após imersão, Exp.Total c/c=Expansão total com cura e após imersão. 


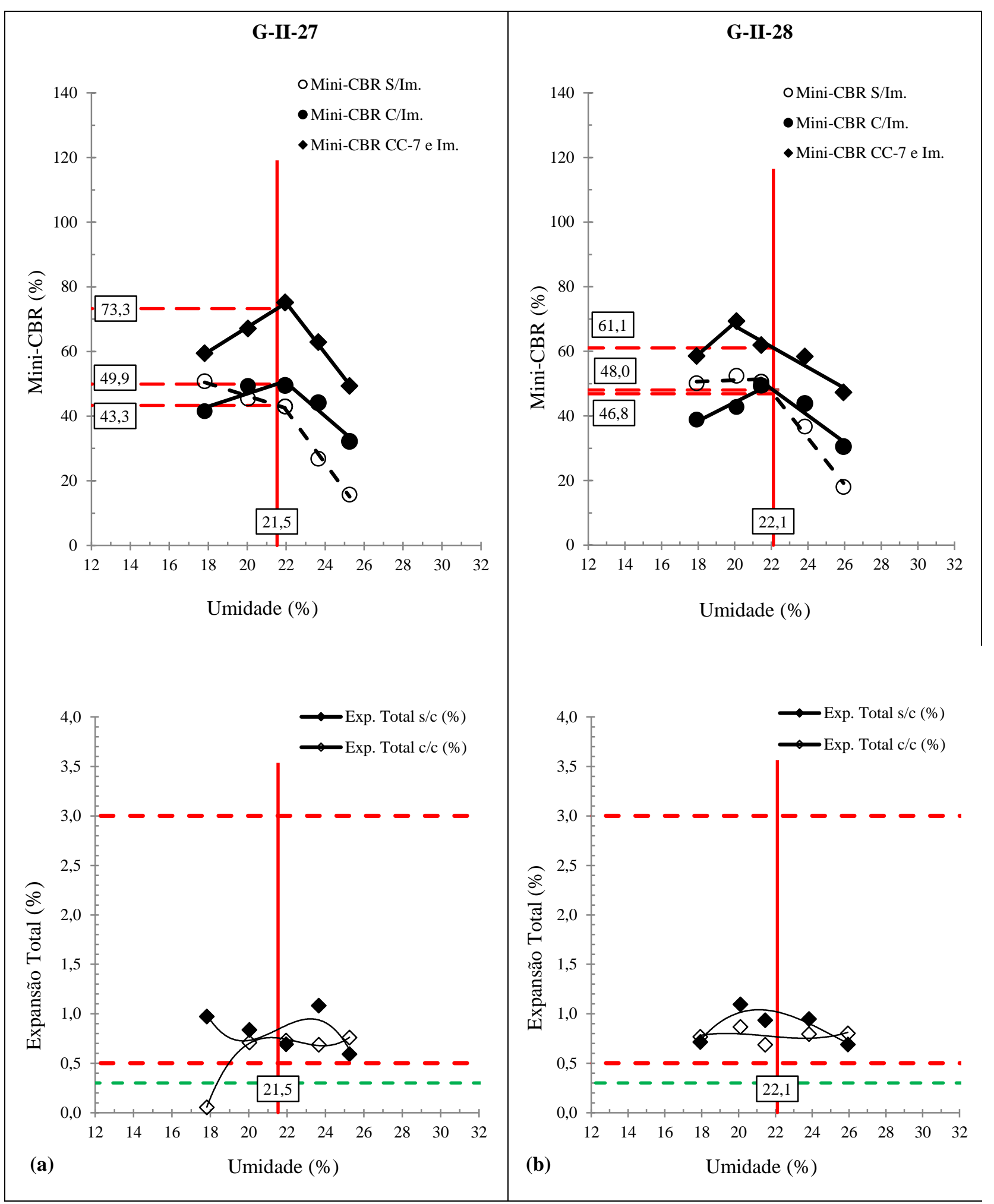

Figura 4.26. Curvas obtidas dos ensaios de Mini-CBR com e sem imersão e com imersão após 7 dias de cura; Expansão com imersão imediata e com imersão após 7 dias de cura (a) GII-27 (b) GII-28.

Obs. S/Im= Sem imersão, C/Im=Com imersão imediata; Exp.Total s/c=Expansão total sem cura e após imersão, Exp.Total c/c=Expansão total com cura e após imersão. 


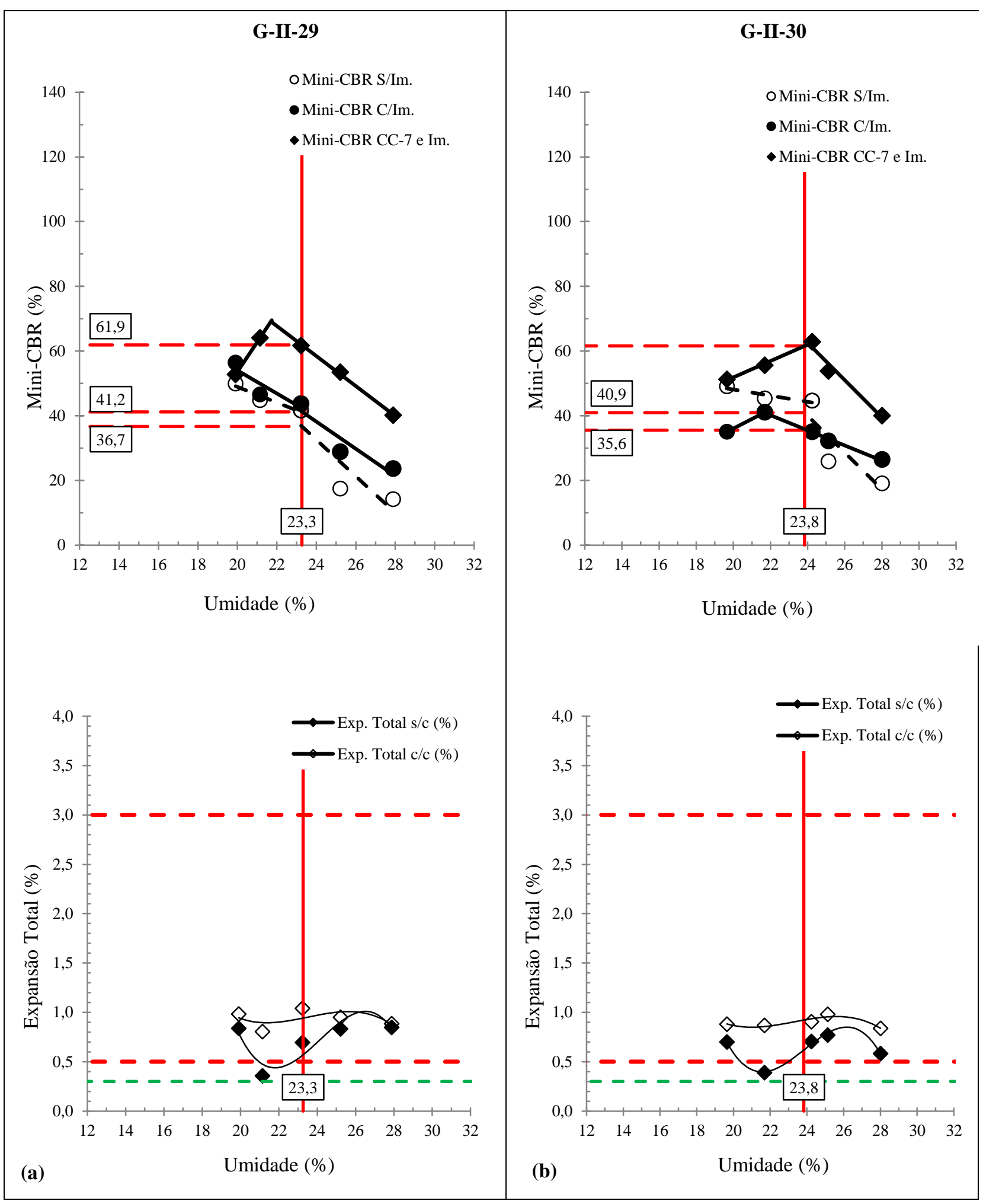

Figura 4.27. Curvas obtidas dos ensaios de Mini-CBR com e sem imersão e com imersão após 7 dias de cura; Expansão com imersão imediata e com imersão após 7 dias de cura (a) GII-29 (b) GII-30.

Obs. S/Im= Sem imersão, C/Im=Com imersão imediata; Exp.Total s/c=Expansão total sem cura e após imersão, Exp.Total c/c=Expansão total com cura e após imersão. 


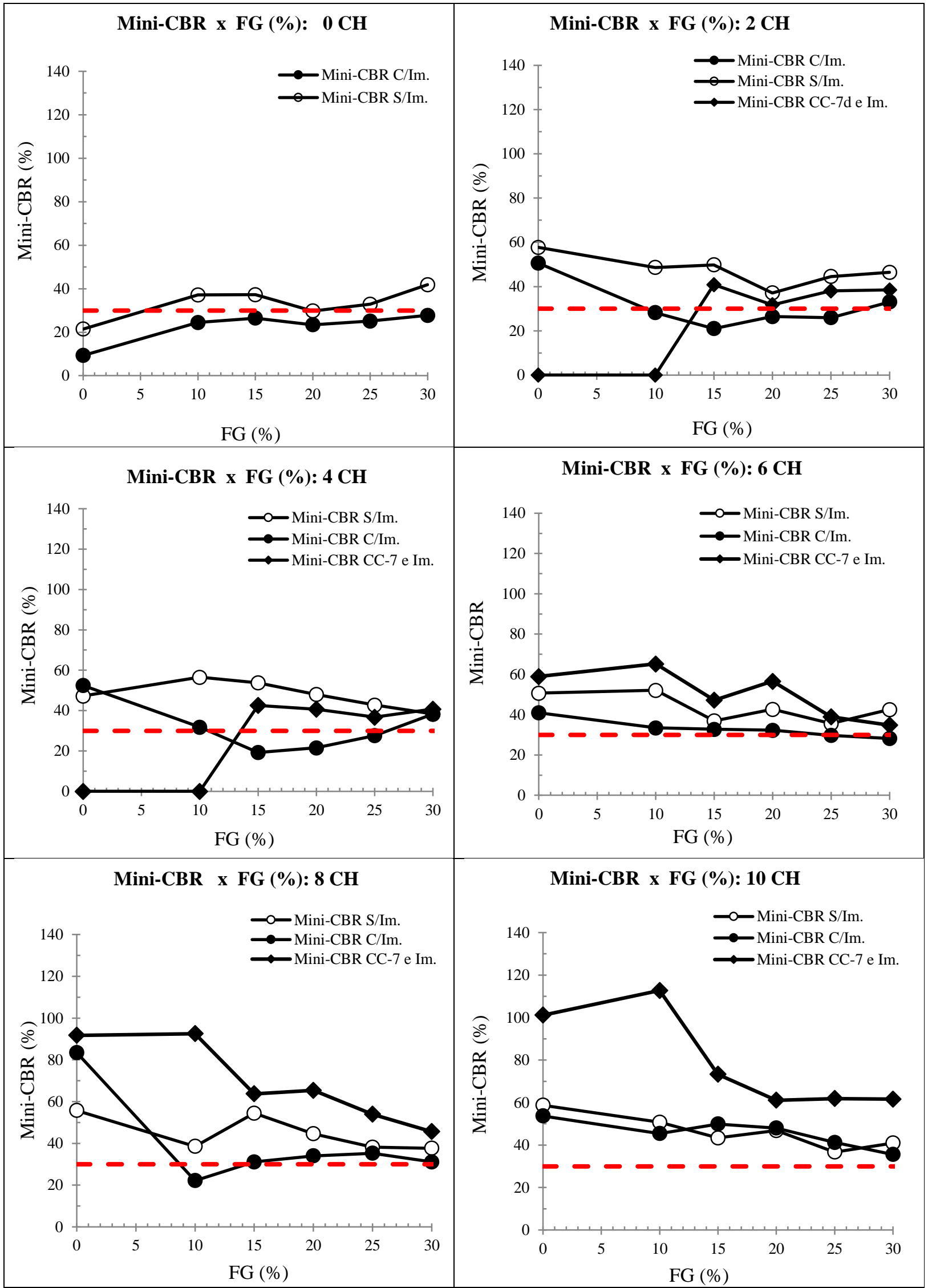

Figura 4.28. Variação dos valores de Mini-CBR com e sem imersão e com imersão após 7 dias de cura em função do teor de fosfogesso. 


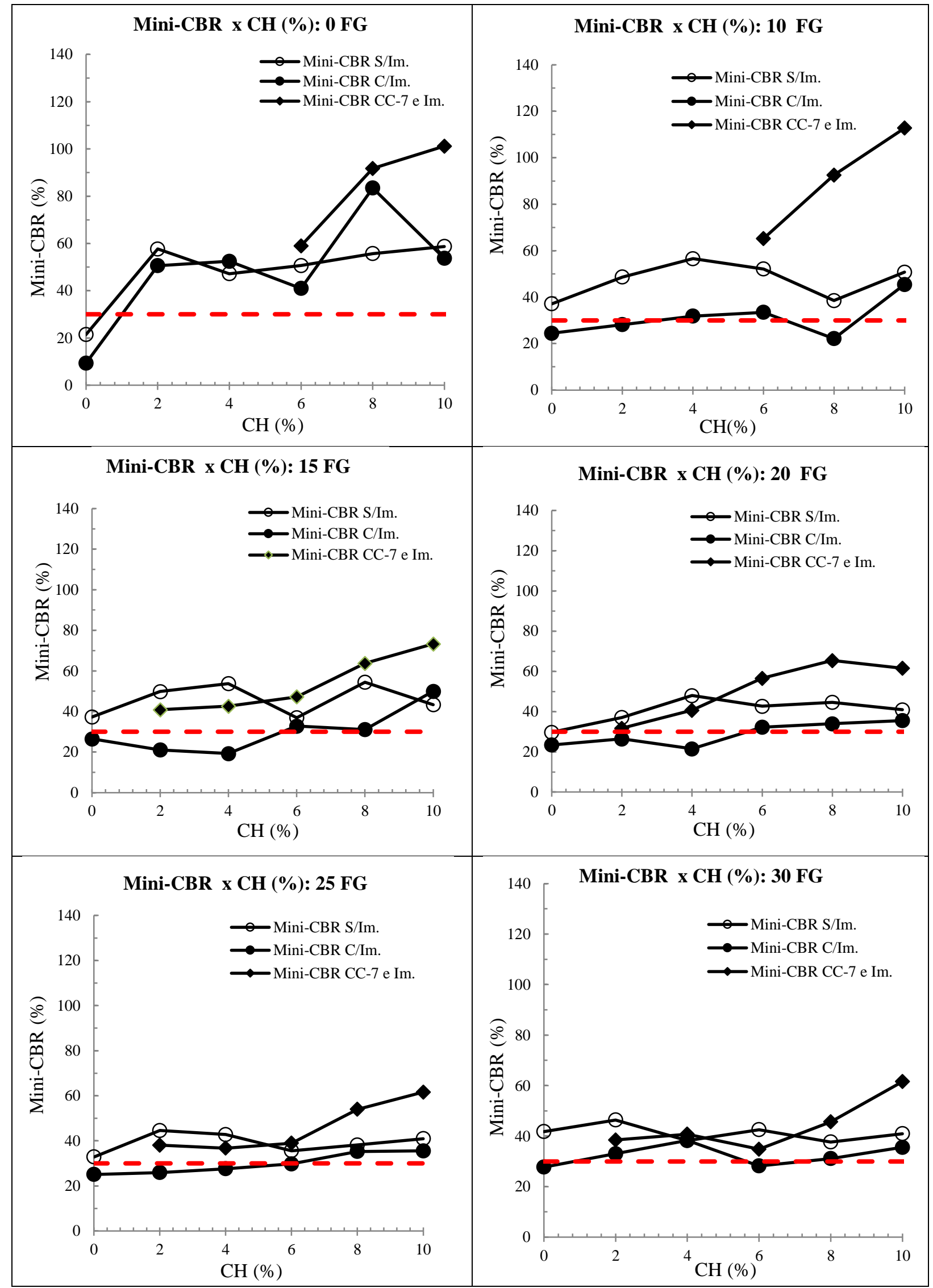

Figura 4.29. Variação dos valores de Mini-CBR com e sem imersão e com imersão após 7 dias de cura em função do teor de cal. 


\subsection{3 - POTENCIAL HIDROGENIÔNICO}

Nas Figuras 4.30 a-d, estão apresentados os resultados obtidos dos ensaios de pH com água e com cloreto de potássio. Observa-se que tanto com água quanto com o $\mathrm{KCl}$, há um aumento desse parâmetro com a adição da cal quando comparado com a adição de fosfogesso. Isso mostra uma maior influência do teor de cal na regulação da acidez das misturas, na capacidade de troca catiônica e sugere uma maior participação desse material nos ganhos de resistências iniciais das misturas em relação ao fosfogesso.

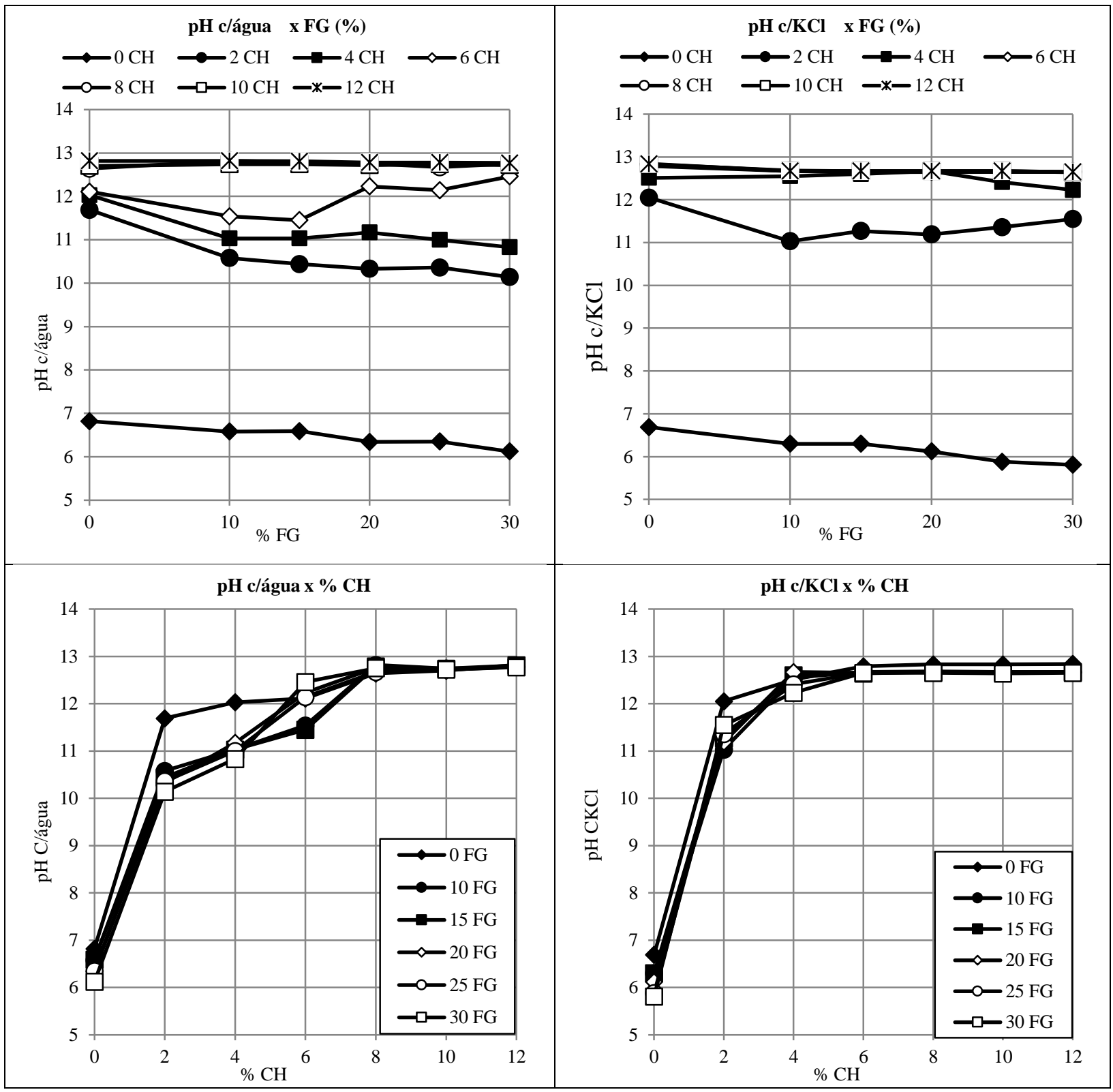

Figura 4.30. Variação dos valores de pH com água e $\mathrm{KCl}$. a) e b) em função do teor de fosfogesso. c) e d) em função do teor de cal. 


\subsection{4 - DIFRATOMETRIA DE RAIOS-X}

Os difratogramas apresentados na Figura 4.31a mostram que os principais argilominerais que compõem o solo em estudo são o quartzo $\left(\mathrm{SiO}_{2}\right)$, caulinita $\left(\mathrm{Al}_{2} \mathrm{Si}_{2} \mathrm{O}_{2}(\mathrm{OH})_{4}\right)$, ilita $\left(\left(\mathrm{K}, \mathrm{H}_{3} \mathrm{O}\right) \mathrm{Al}_{2} \mathrm{Si}_{3} \mathrm{AlO}_{10}(\mathrm{OH})_{2}\right)$ e a gibbsita $\left(\mathrm{Al}(\mathrm{OH})_{3}\right)$. Esses são os argilominerais comumente encontrados em solos lateríticos. Já o fosfogesso apresenta na sua composição, o sulfato de cálcio hidratado $\left(\mathrm{CaSO}_{4} .2 \mathrm{H}_{2} \mathrm{O}\right)$ e o quartzo conforme pode ser visualizado na Figura $4.31 \mathrm{~b}$. Os ensaios de difratometria de raio-x realizados nas misturas GII-1 a 30 mostraram que nessas misturas, a partir de teores de fosfogesso e cal de $20 \%$ e $6 \%$, respectivamente, ocorre a formação da etringita. Esse fato é ilustrado pelas Figuras 4.32, onde estão apresentados os difratogramas das misturas GII-1, GII-2, GII-3, GII-4, GII-12, GII-16, GII-22 e GII-30. Dessa observação, recomenda-se ter cuidados redobrados quando recorrer a esses tipos de misturas, pois, em função da possibilidade de ocorrer a formação da etringita, podem apresentar um caráter bastante expansivo quando aplicadas em campo.

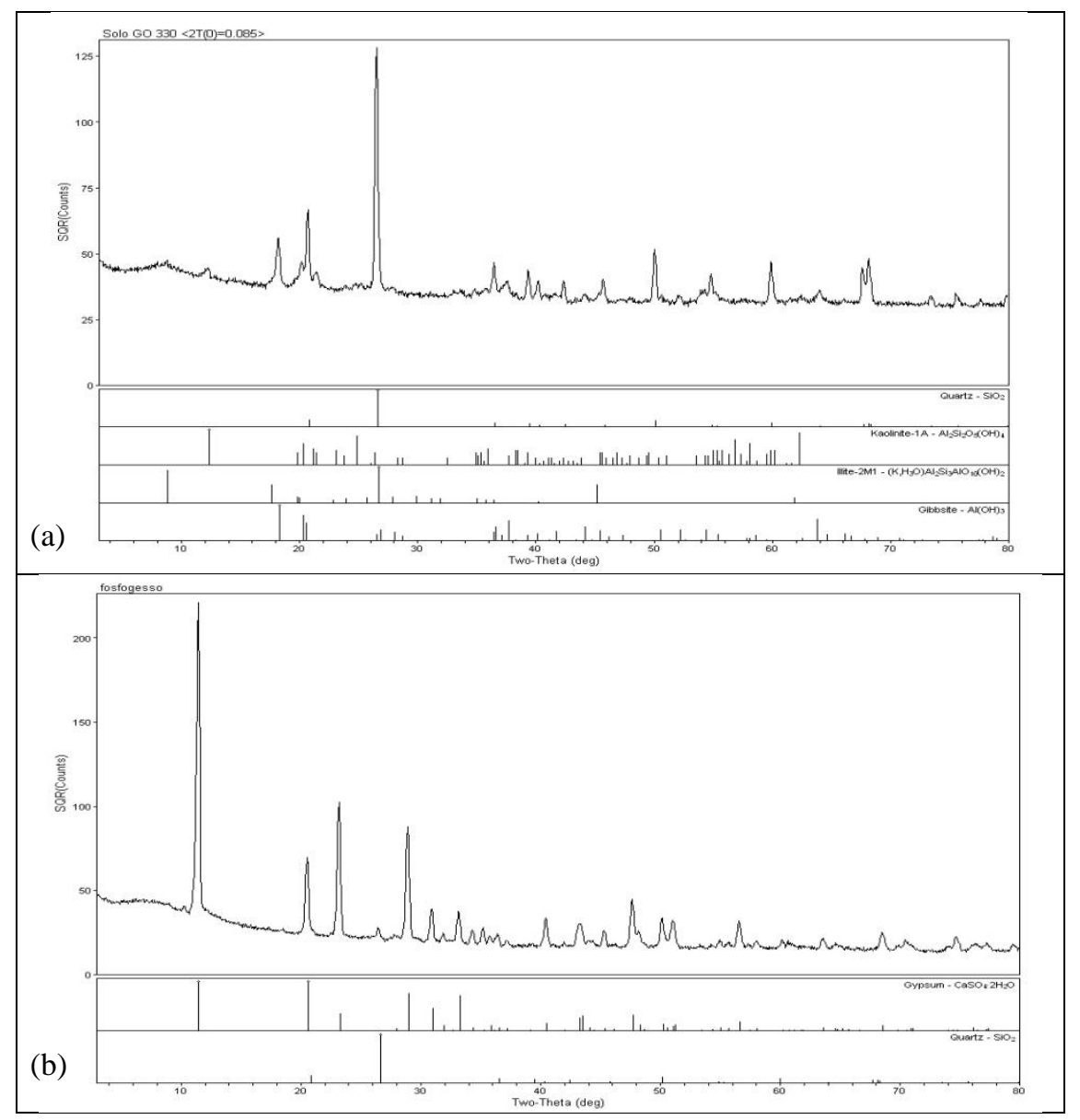

Figura 4.31. Difratogramas obtidos dos ensaios de difratometria de raio-x. a) Amostra de solo. b) Fosfogesso. 


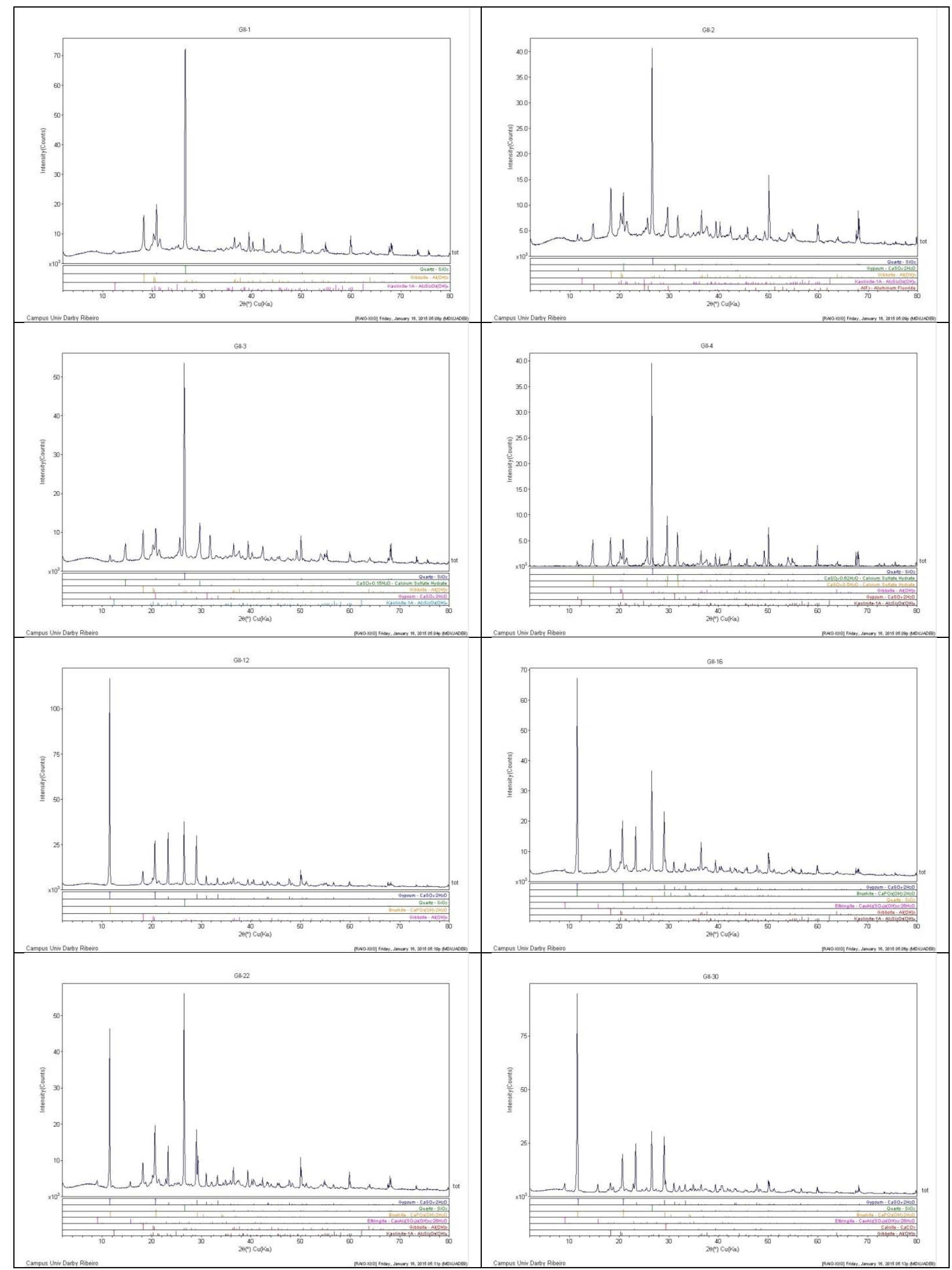

Figura 4.32. Difratogramas obtidos dos ensaios de difratometria de raio-x: GII-1, GII-2. GII-3, GII-4, GII-12, GII-16, GII-22 e GII-30. 


\subsection{5 - RESISTÊNCIAS À COMPRESSÃO SIMPLES}

Com base os resultados obtidos nos ensaios de mini-CBR, expansão e difratometria de raiosX, verificou-se que o teor de $20 \%$ de fosfogesso é o que apresentou melhor trabalhabilidade dentre as misturas em estudo. Por esse motivo, foi adotado para a realização dos ensaios de compressão simples esse teor de fosfogesso, verificando apenas a evolução da resistência das misturas com o aumento do teor de cal e do tempo de cura. Os resultados obtidos desses ensaios para a amostra de solo (GI-1) e as misturas com GI-4, GII-4, 10, 16 e 22 para tempos de cura de 0, 7, 14, 28 e 60 dias estão apresentados na Tabela 4.11. As Figuras 4.33 a e b, ilustram a evolução de resistência da compressão simples das misturas em função do teor de cal e do tempo de cura, respectivamente.

Tabela 4.11. Resistências à compressão simples do solo e das misturas com $20 \%$ fosfogesso em kPa.

\begin{tabular}{lccccccc}
\hline Amostra & & GI-1 (Solo) & GI-4 & GII-4 & GII-10 & GII-16 & GII-22 \\
\hline \%Solo & 100 & 80 & 78 & 76 & 74 & 72 \\
\hline \% FG & & 0 & 20 & 20 & 20 & 20 & 20 \\
\hline \% Cal & & 0 & 0 & 2 & 4 & 6 & 8 \\
\hline \multirow{4}{*}{ Idade } & 0dia & 431 & 453 & 520 & 822 & 960 & 1078 \\
\cline { 2 - 7 } & 7 dias & - & 461 & 553 & 1006 & 1103 & 1220 \\
\cline { 2 - 7 } & 14 dias & - & 474 & 598 & 1175 & 1436 & 1509 \\
\cline { 2 - 7 } & 28 dias & - & 478 & 630 & 1276 & 1483 & 1617 \\
\cline { 2 - 7 } & 60 dias & - & 486 & 681 & 1382 & 1493 & 1694 \\
\hline
\end{tabular}

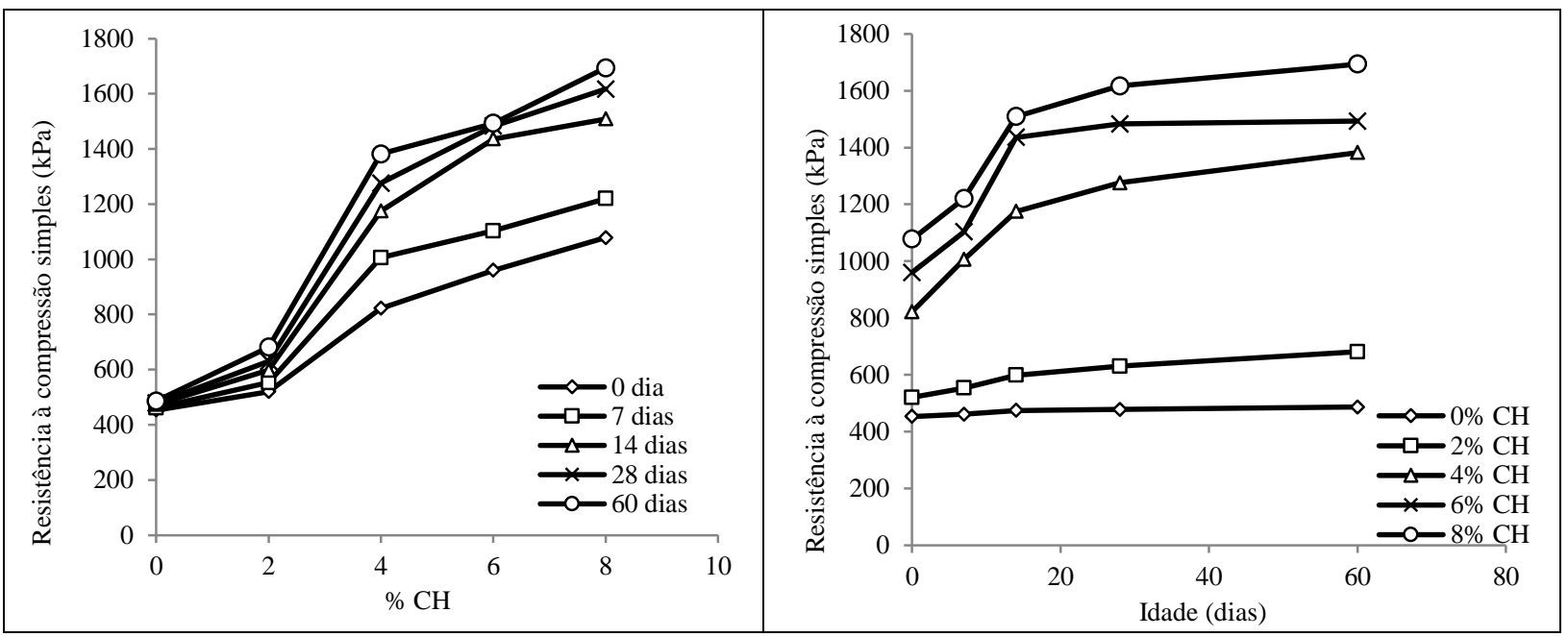

Figura 4.33. Evolução da resistência à compressão das misturas. a) Com o teor de cal. b) Com o tempo de cura.

Observa-se que a adição de $20 \%$ de fosfogesso gera uma variação pouco significativa na resistência à compressão do solo. Como esperado também, não se verificou ganho significativo de resistência com o tempo de cura para as misturas com fosfogesso e sem cal. 
Isso mostra que o fosfogesso por si só não desenvolve reações pozolânicas importantes quando misturado somente com solo em estudo. Entretanto, observa-se um constante ganho de resistência com a adição da cal. Nas primeiras idades esse ganho está relacionado às reações de floculações provocadas pela cal. Já nas idades mais avançadas, o ganho de resistência é a devido ao desenvolvimento das reações pozolânicas. Para as misturas com teores de cal de 4, 6 e 8\%, verifica-se que com a cura, a resistência à compressão simples se atinge e supera o valor mínimo de $1200 \mathrm{kPa}$ adotado para as misturas solo cimento com sete dias de cura para fins de pavimentação, conforme consta na especificação de serviço Departamento de Estradas e Rodagem do Paraná ES-P 11/05 (DER-PR, 2005).

\subsection{6 -MÓDULOS DE RESILIÊNCIA}

Para os ensaios triaxiais dinâmicos, foram utilizados, pelos motivos expostos anteriormente, as mesmas dosagens utilizadas para os ensaios de compressão simples. Teve-se inicialmente a intenção de realizar esses ensaios para diferentes tempos de cura, ou seja, para 1, 7, 14, 28 e 60 dias. Entretanto, durante a realização dos ensaios foram encontrados diversas inconsistências nos resultados e dificuldades para encontrar correlações coerentes entre os materiais ensaiados a partir dos modelos tradicionalmente utilizados para os ensaios de módulo de resiliência: sigma 3, sigma D, universal e composto. Essa situação levou a várias repetições dos ensaios e perdas de corpos de prova. Sendo, assim limitou-se à realização dos ensaios para as amostras suscitadas, no entanto, apenas para um dia de cura. Entre os modelos de calibração, o composto, apresentado na Equação 4.1, é que melhor caracterizou o comportamento resiliente dos materiais estudados. Na Tabela 4.12 estão apresentados os parâmetros obtidos em laboratório para as amostras ensaiadas.

$$
M_{R}=k_{1} \sigma_{3}^{k_{2}} \sigma_{D}^{k_{3}}
$$

Onde:

$M_{R}=$ Módulo de resiliência.

$\sigma_{3}=$ Tensão confinante.

$\sigma_{D}=$ Tensão desvio.

$k_{1}, k_{2}$ e $k_{3}=$ Parâmetros de calibração do modelo obtido dos resultados dos ensaios. 
Tabela 4.12. Parâmetros obtidos dos ensaios de módulo de resiliência calibrados para o modelo composto (MPa)

\begin{tabular}{lcccc}
\hline Amostra & $\mathbf{k}$ 1 & $\mathbf{k}_{2}$ & $\mathbf{k} \mathbf{3}$ & $\mathbf{R}^{\mathbf{2}}$ \\
\hline GI-1 & 188,133 & 0,208 & $-0,287$ & 0,64 \\
\hline GI-4 & 126,295 & $-0,023$ & $-0,083$ & 0,42 \\
\hline GII-4 & 220,261 & $-0,134$ & $-0,123$ & 0,52 \\
\hline GII-10 & 467,141 & $-0,112$ & $-0,191$ & 0,83 \\
\hline GII-16 & 179,24 & 0,338 & $-0,346$ & 0,52 \\
\hline GII-22 & 127,886 & 0,058 & $-0,155$ & 0,42 \\
\hline
\end{tabular}

A partir desses resultados, procurou-se avaliar o comportamento de cada mistura quando aplicada na camada de base de um pavimento flexível cuja estrutura está apresentada na Tabela 4.13.

Tabela 4.13. Estrutura do pavimento considerado para as simulações.

\begin{tabular}{lccc}
\hline Estrutura & Espessura $(\mathbf{c m})$ & E (MPa) & Poisson \\
\hline Revestimento & 5 & 3000 & 0,4 \\
\hline Base & 15 & MR & 0,35 \\
\hline Subleito & Semi-infinita & 100 & 0,35 \\
\hline
\end{tabular}

Como parâmetros de avaliação, adotou-se a deflexão elástica no topo da camada de revestimento do ponto localizado entre as rodas de um eixo simples de rodas duplas com o carregamento padrão de 8,2t e a deformação vertical no topo do subleito correspondente. Para tanto, recorreu-se ao programa de análise de tensões e deformações AEMC do pacote SisPav desenvolvido pela Universidade Federal do Rio de Janeiro. Na Figura 4.34 está apresentada uma tela de entrada e saída dos resultados do programa.

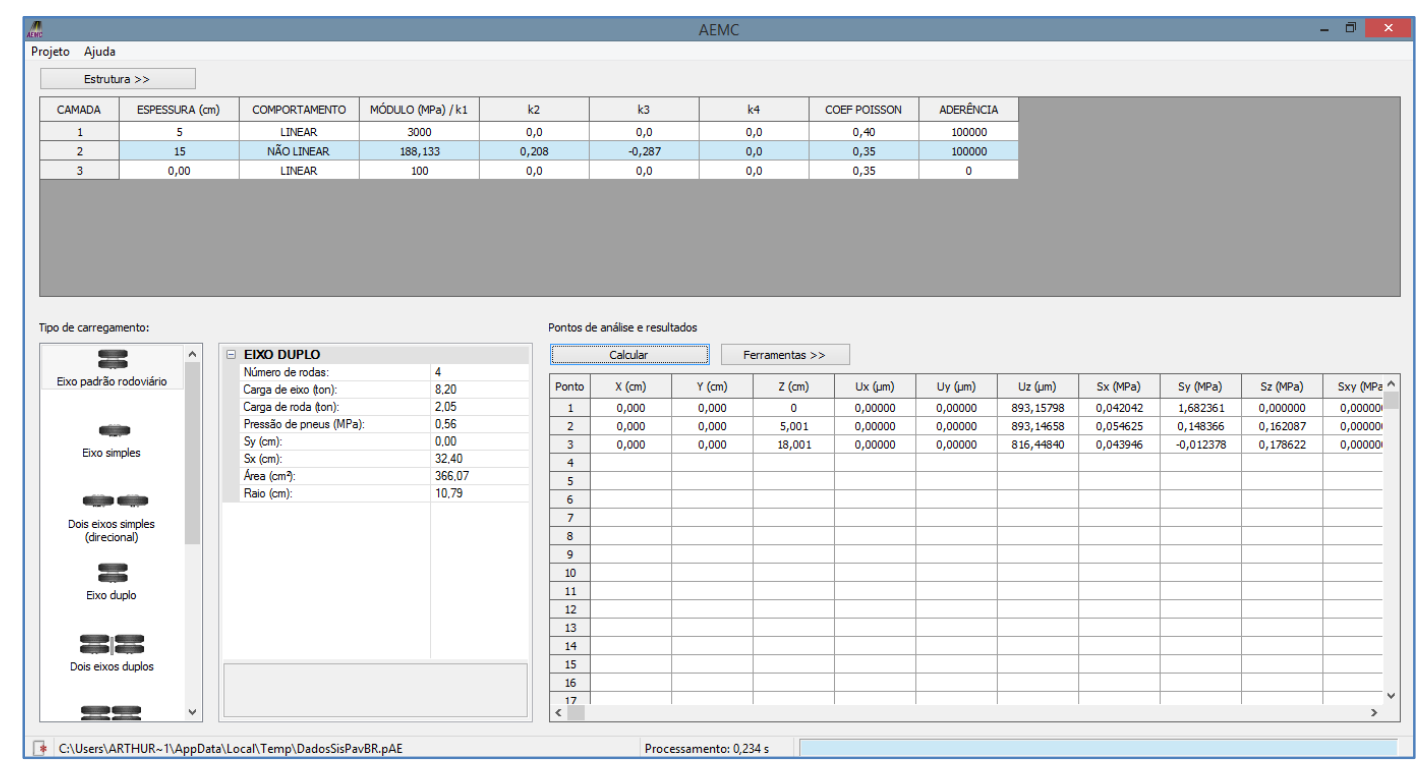

Figura 4.34. Tela de entradas de dados e saídas de resultados do programa AEMC. 
A partir dessas simulações, da Equação 4.1 e da Tabela 4.12, determinou-se os módulos de resiliência correspondentes ao estado de tensões do topo da camada de base. Em seguida, foram estimados os números de eixo padrão $\mathrm{N}$ correspondente às deflexões elásticas do topo do revestimento e à deformação vertical do topo do subleito utilizando os modelos da DNERPRO 11/79 (DNER, 1979) e de Dormon \& Metcalf - 1965, respectivamente, conforme recomenda o Departamento de Estradas e Rodagem de São Paulo (DER-SP, 2006). As Equações 4.2. e 4.3 apresentam esses modelos. Na Tabela 4.14 estão apresentados os resultados obtidos dessas simulações e nas Figuras 4.35 e 4.36 seus gráficos comparativos.

$$
\begin{aligned}
& N_{D}=10^{\left(\frac{3,01-\log D}{0,176}\right)} \\
& N_{\text {Sub }}=6,069 \cdot 10^{-10} \varepsilon_{v}^{-4,762}
\end{aligned}
$$

Onde:

$\mathrm{N}_{\mathrm{D}}=$ Número de eixos padrão de $80 \mathrm{kN}$ para a deflexão elástica recuperável.

$\mathrm{N}_{\text {Sub }}=$ Número de eixos padrão de $80 \mathrm{kN}$ para a deformação elástica no topo do subleito.

Tabela 4.14. Resultados obtidos das simulações.

\begin{tabular}{lccccccc}
\hline Amostra & $\boldsymbol{\sigma}_{\mathbf{1}}(\mathbf{M P a})$ & $\boldsymbol{\sigma}_{\mathbf{3}}(\mathbf{M P a})$ & $\mathbf{U z}\left(\mathbf{1 0}^{-2} \mathbf{m m}\right)$ & $\mathbf{E z}(\mathbf{m} / \mathbf{m})$ & $\mathbf{M}_{\mathbf{R}}(\mathbf{M P a})$ & $\mathbf{N}_{\mathbf{D}}$ & $\mathbf{N S u b}$ \\
\hline G-I-1 & 0,162 & 0,148 & 89 & $6,89 \mathrm{E}-04$ & 436 & $1,04 \mathrm{E}+06$ & $6,93 \mathrm{E}+05$ \\
\hline G-I-4 & 0,167 & 0,148 & 92 & $8,84 \mathrm{E}-04$ & 184 & $8,64 \mathrm{E}+05$ & $2,11 \mathrm{E}+05$ \\
\hline G-II-4 & 0,281 & 0,121 & 82 & $3,01 \mathrm{E}-04$ & 366 & $1,64 \mathrm{E}+06$ & $3,58 \mathrm{E}+07$ \\
\hline G-II-10 & 0,583 & 0,148 & 76 & $1,33 \mathrm{E}-04$ & 678 & $2,55 \mathrm{E}+06$ & $1,72 \mathrm{E}+09$ \\
\hline G-II-16 & 0,167 & 0,117 & 93 & $9,49 \mathrm{E}-04$ & 244 & $8,22 \mathrm{E}+05$ & $1,50 \mathrm{E}+05$ \\
\hline G-II-22 & 0,167 & 0,119 & 93 & $9,14 \mathrm{E}-04$ & 181 & $8,43 \mathrm{E}+05$ & $1,80 \mathrm{E}+05$ \\
\hline \multicolumn{7}{c}{ Obs. Uz = Deflexão elástica no topo do revestimento. Ez = Deformação vertical no topo do subleito. }
\end{tabular}

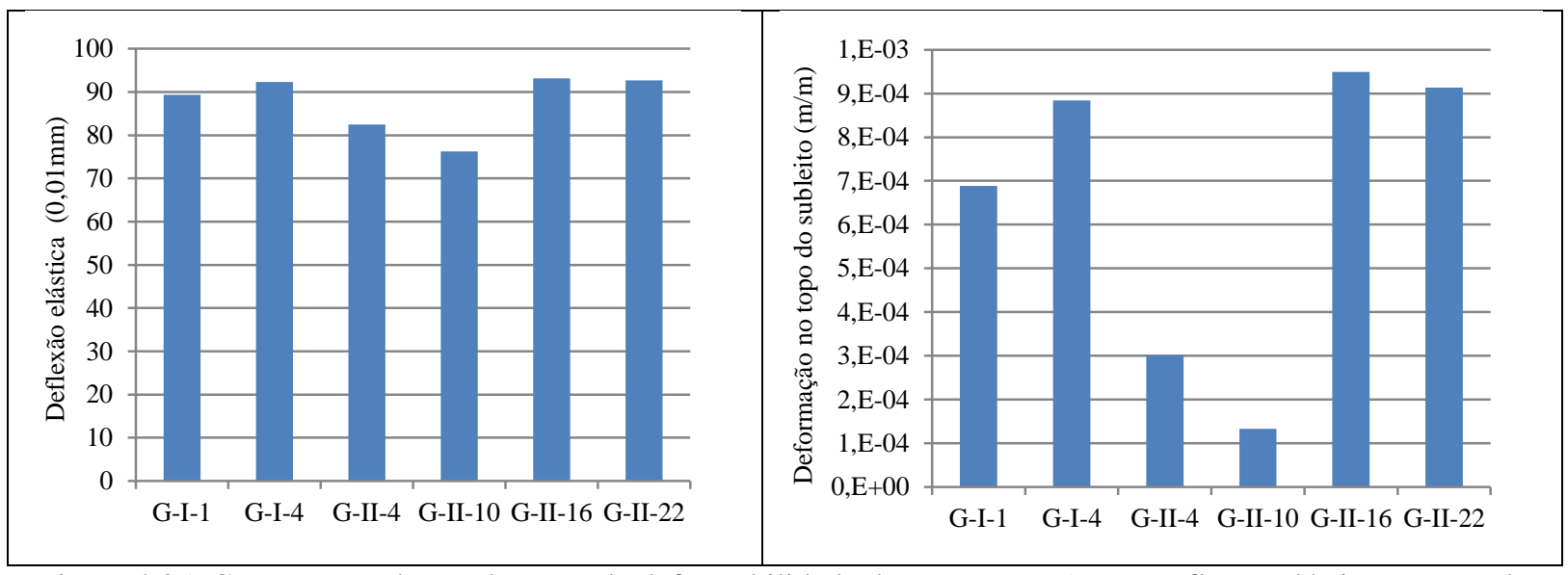

Figura 4.35. Comparação dos parâmetros de deformabilidade das amostras. a) Uz: Deflexão elástica no topo do revestimento. B)Ez: Deformação vertical no topo do subleito. 


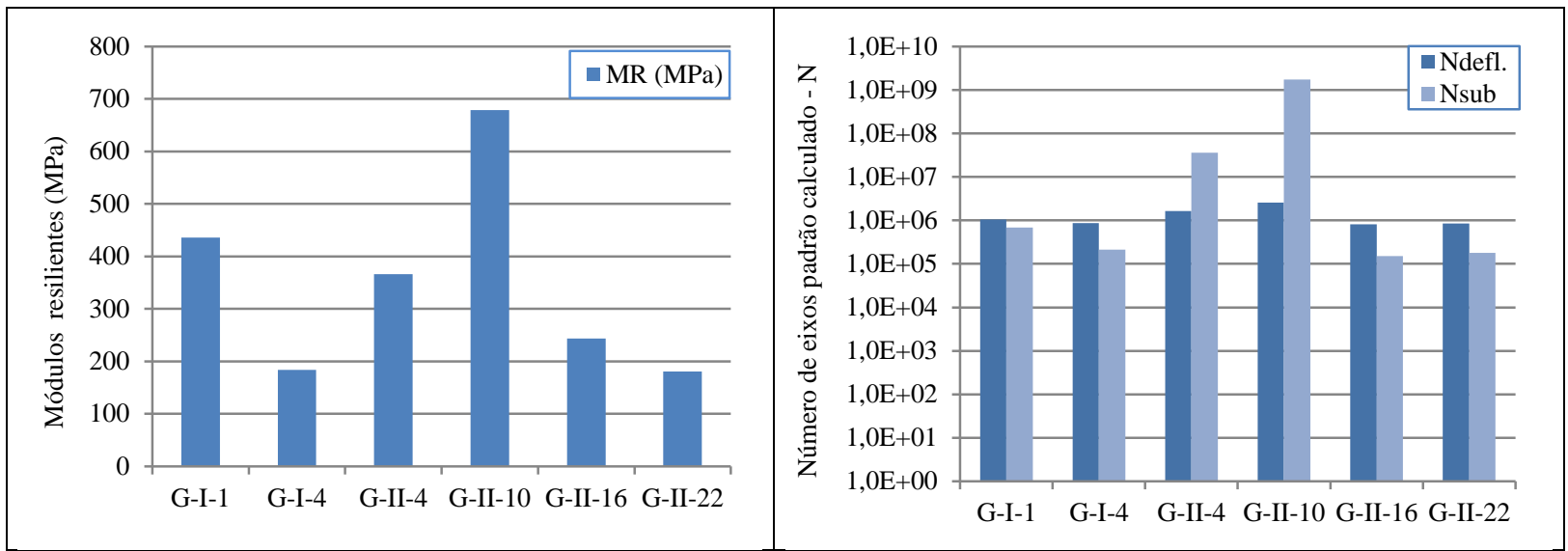

Figura 4.36. Comparação do desempenho dos materiais. a) Módulos resilientes das simulações. b) Números de eixos padrão - N obtidos dos modelos DNER-PRO 11/79 e Dormon \& Metcaff-1965.

Dessas simulações, observa-se que todas as misturas apresentaram deflexões elásticas do topo do revestimento inferiores a $100.10^{-2} \mathrm{~mm}$ o que pode ser considerado bom para um pavimento de baixo custo novo tendo em vista que esse ainda passará por uma fase de consolidação em função do tráfego até atingir uma fase elástica caracterizada pela diminuição desse parâmetro. A partir desses valores obteve-se números de solicitações do eixo padrão semelhantes e na ordem de $10^{6}$. Nota-se que as misturas GII-4 (78\%solo+20\%fosfogesso+2\%cal) e GII-10 (76\%solo+20\%fosfogesso+4\%cal) são que melhor absorvem os esforços verticais produzidos pelo carregamento e protegem melhor o subleito. Nota-se também que são essas misturas que apresentam os maiores módulos de resiliência com valores de 366 e $678 \mathrm{MPa}$ respetivamente. Conforme ilustra a Figura 4.36, essas condições aumentam significativamente o número de eixo padrão necessário para se verificar os danos por acumulação de deformação permanente no subleito.

\section{2 - ENSAIOS DE CAMPO}

A seguir são apresentados os resultados e gráficos dos ensaios de campo realizados na pista experimental de Aparecida de Goiânia, desde a época da sua construção em outubro de 2009 até junho de 2014, data do último monitoramento dessa pista. Mais especificamente, as etapas de ensaio foram executadas em outubro 2009, maio 2010, outubro 2010, junho 2011, novembro 2011, novembro 2012 e junho 2014. No entanto, tendo em vista a influência das condições climáticas nos parâmetros obtidos dos ensaios de campo, serão inicialmente apresentados os dados pluviométricos pertinentes às diferentes épocas de avaliação do pavimento. 


\subsection{1 - DADOS PLUVIOMÉTRICOS}

Para analisar melhor os resultados obtidos em campo, foram pesquisados os gráficos de precipitação disponíveis no site internet do Instituto Nacional de Meteorologia (INMET). Esses gráficos foram obtidos a partir da estação mais próxima da pista experimental (cerca de $8,8 \mathrm{~km}$ ), localizada na latitude $16^{\circ} 40^{\prime} 00^{\prime \prime} \mathrm{S}$ longitude $049^{\circ} 15^{\prime} 00^{\prime \prime} \mathrm{W}$ a $741,48 \mathrm{~m}$ de altura, na cidade de Goiânia e para os períodos de outubro 2009, maio 2010, outubro 2010, junho 2011, novembro 2011, novembro 2012 e junho 2014 e são ilustrados na Figura 4.37. Com base nesses dados, observa-se que quatro etapas de ensaios foram realizadas em estação chuvosa, mais especificamente, outubro 2009 e 2010 e, novembro 2011 e 2012. Esses fatos levam a considerar fatores sazonais definidos pela norma DNER-PRO 11/79 (DNER, 1979), particularmente nas análises das deflexões do pavimento com a viga Benkelman.

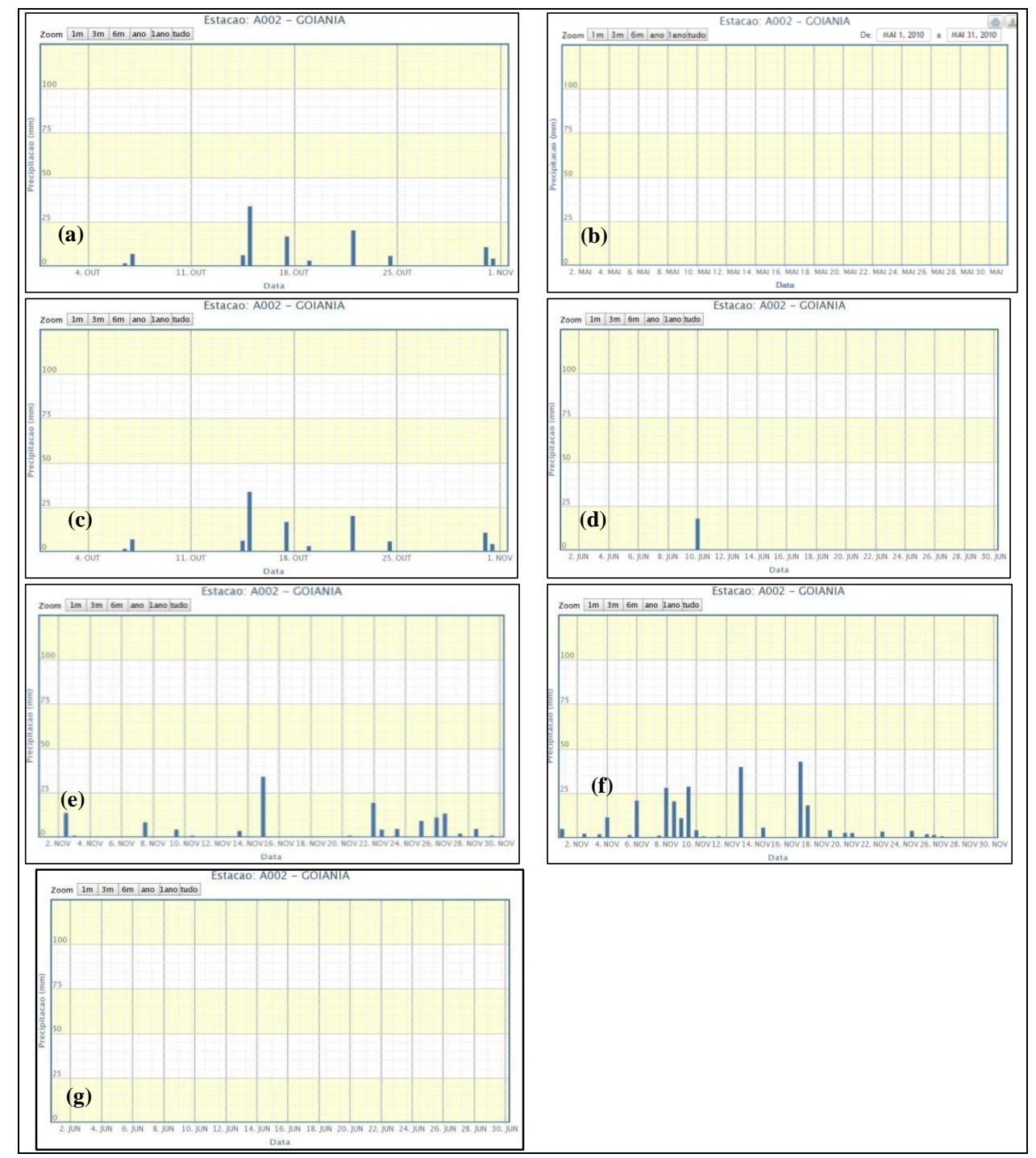

Figura 4.37. Gráficos de precipitação referentes ao local da pista experimental. a) Outubro 2009. b) Maio 2010. c) Outubro 2010. d) Junho 2011. e) Novembro 2011. f) Novembro 2012. g) Junho 2014. 


\subsection{2 - ENSAIOS DE VIGA BENKELMAN}

Inicialmente, todas das medições realizadas em campo com a viga Benkelman foram corrigidas em função da temperatura do pavimento durante a realização dos ensaios e da espessura da camada de revestimento asfáltico de acordo com o gráfico de correção de deflexão de pavimento do Departamento de Estradas e Rodagem de São Paulo (DER-SP, 2006) ilustrado na Figura 4.38.

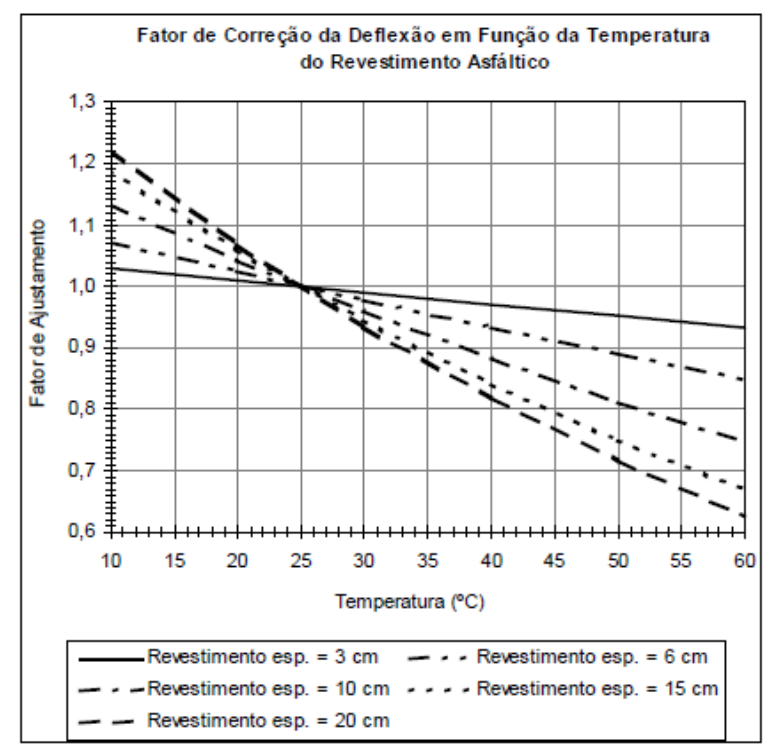

Figura 4.38. Gráfico de fator de correção da deflexão em função da temperatura do revestimento asfáltico (DERSP, 2006).

Em seguida, as medições deflectométricas corrigidas foram utilizadas para representar graficamente as bacias de deslocamentos de todos os pontos levantados nas sete campanhas de coleta de dados em campo. Nas Figuras 4.39 a 4.45 estão apresentadas as bacias deflectométricas obtidas dessas campanhas para cada estaca dos trechos experimentais, nos bordos direito e esquerdo. Nessas figuras, também constam as curvas de limites de aceitação superior e inferior das deflexões. Conforme orienta a norma DNER-PRO 11/79 (DNER, 1979), todos os valores individuais situados fora desses limites foram eliminados das amostras e os parâmetros estatísticos recalculados. Nas Figuras 4.46 a 4.52 estão apresentados os deflectogramas obtidos a partir das deflexões máximas no perfil da pista experimental e os raios de curvatura correspondentes. 
Universidade de Brasília

Departamento de Engenharia Civil / FT

Programa de Pós-Graduação em Geotecnia

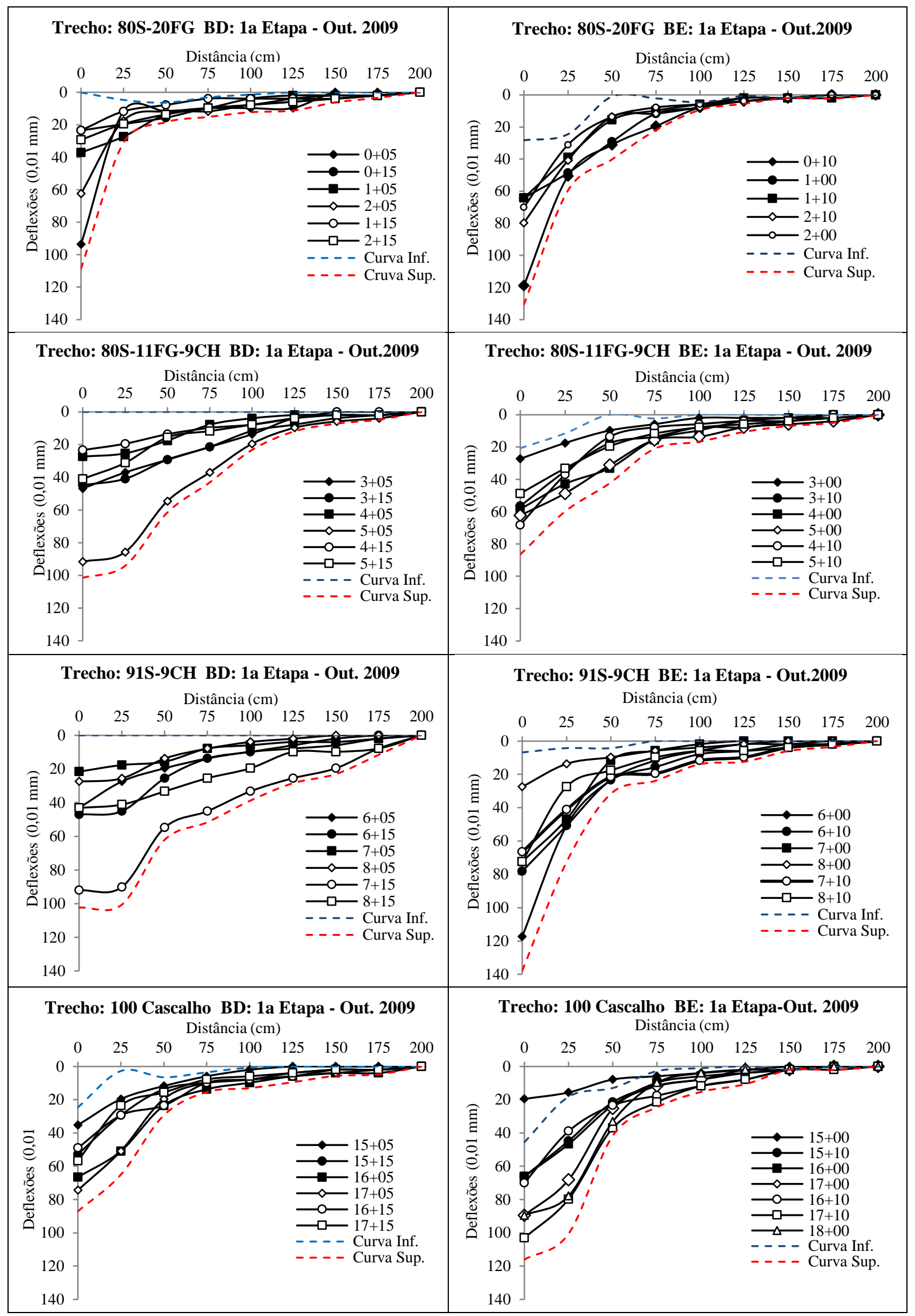

Figura 4.39. Bacias de deslocamentos obtidas na $1^{\mathrm{a}}$ Etapa. Nota: BE=Bordo Esquerdo; BD=Bordo Direito. 
Universidade de Brasília

Departamento de Engenharia Civil / FT

Programa de Pós-Graduação em Geotecnia

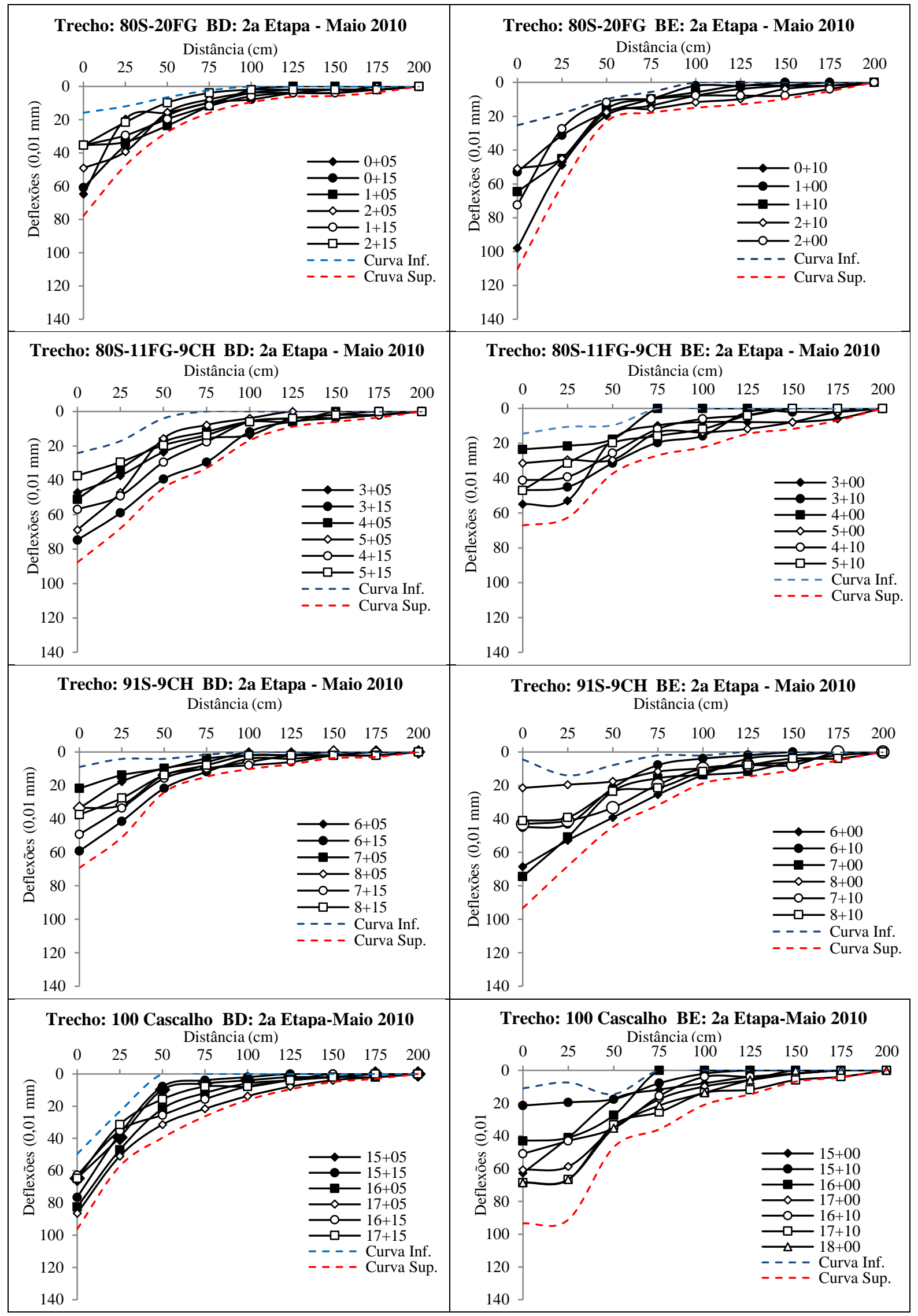

Figura 4.40. Bacias de deslocamentos obtidas na $2^{\text {a }}$ Etapa. Nota: BE=Bordo Esquerdo; BD=Bordo Direito. 
Universidade de Brasília

Departamento de Engenharia Civil / FT

Programa de Pós-Graduação em Geotecnia

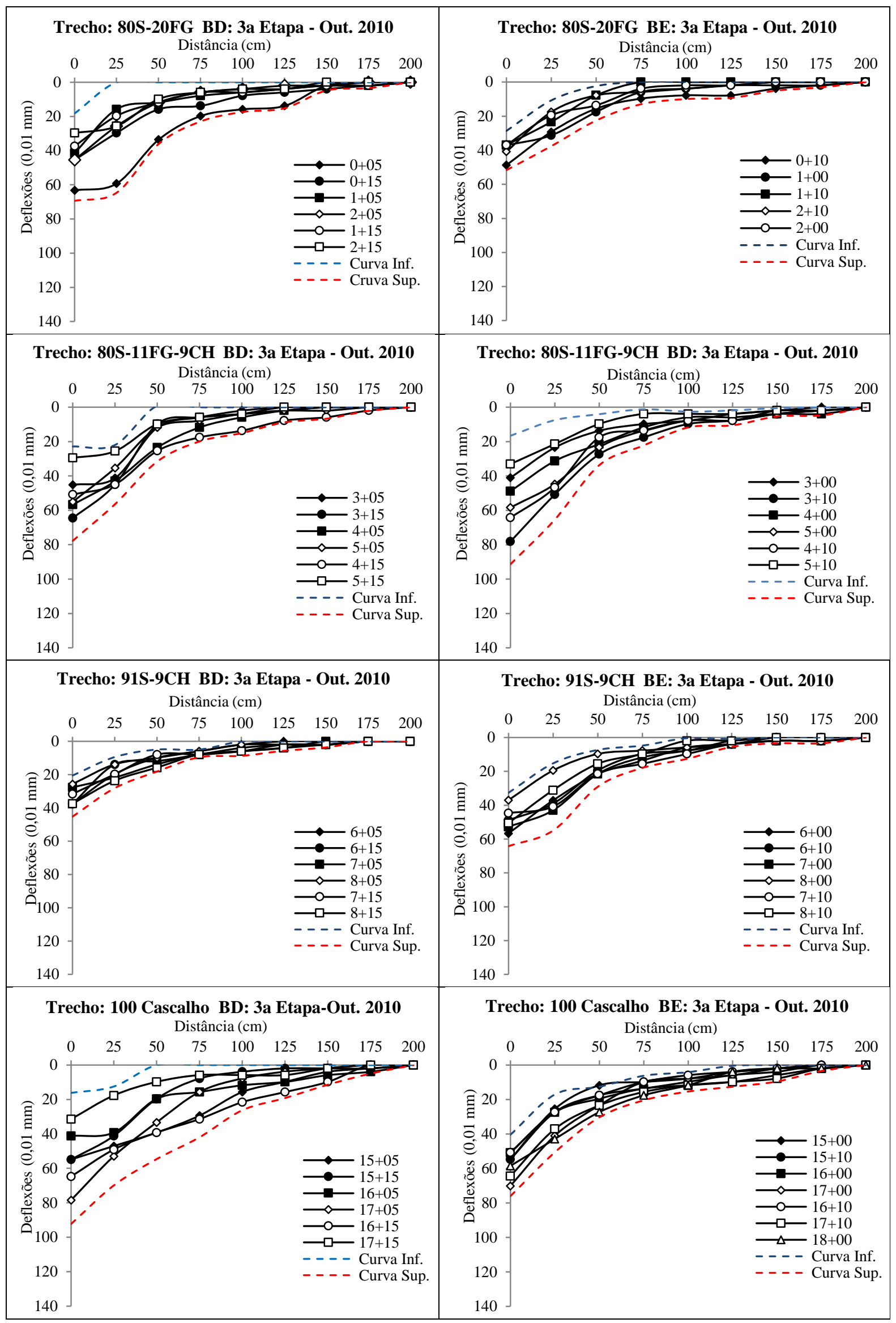

Figura 4.41. Bacias de deslocamentos obtidas na $3^{\mathrm{a}}$ Etapa. Nota: BE=Bordo Esquerdo; BD=Bordo Direito. 
Universidade de Brasília

Departamento de Engenharia Civil / FT

Programa de Pós-Graduação em Geotecnia

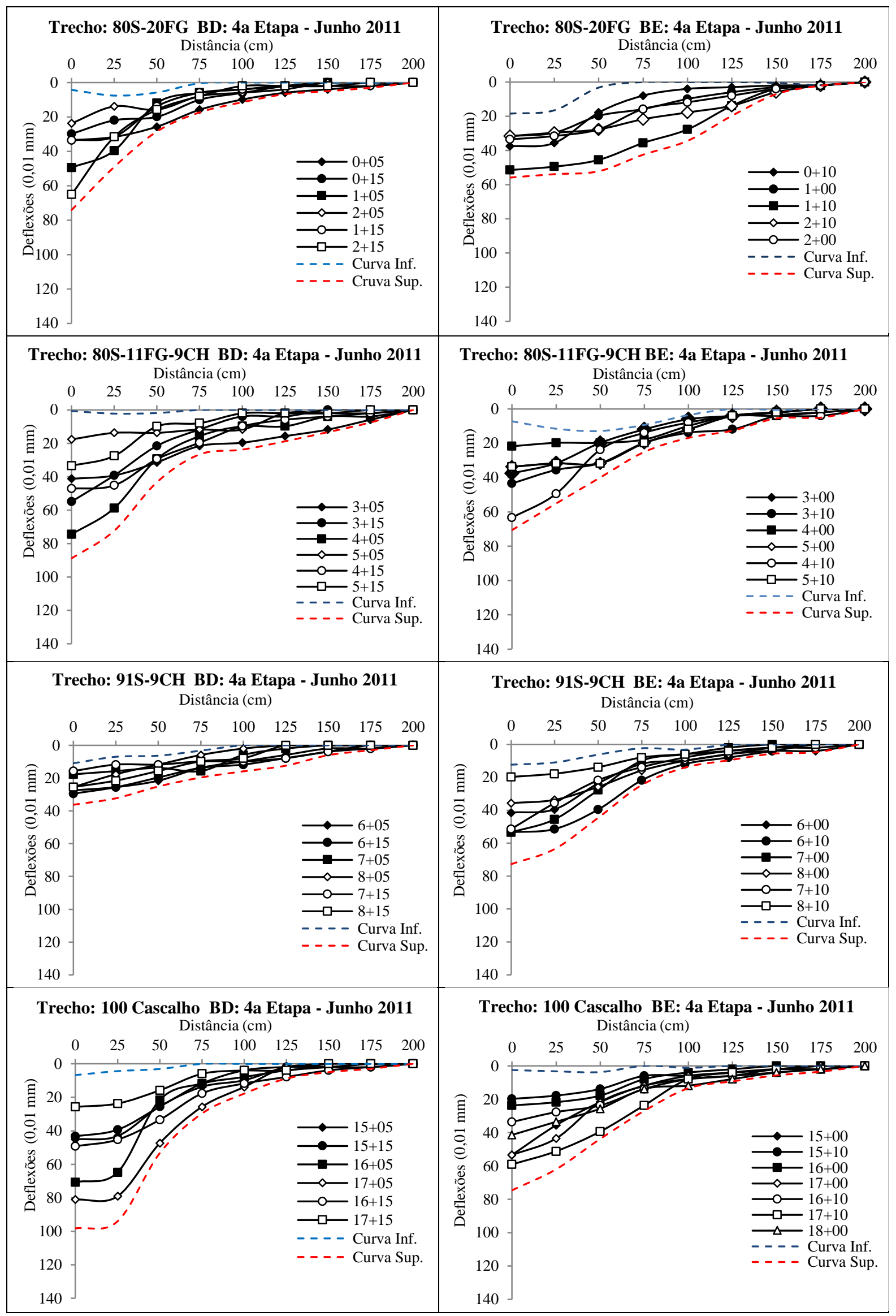

Figura 4.42. Bacias de deslocamentos obtidas na $4^{\mathrm{a}}$ Etapa. Nota: BE=Bordo Esquerdo; BD=Bordo Direito. 
Universidade de Brasília

Departamento de Engenharia Civil / FT

Programa de Pós-Graduação em Geotecnia

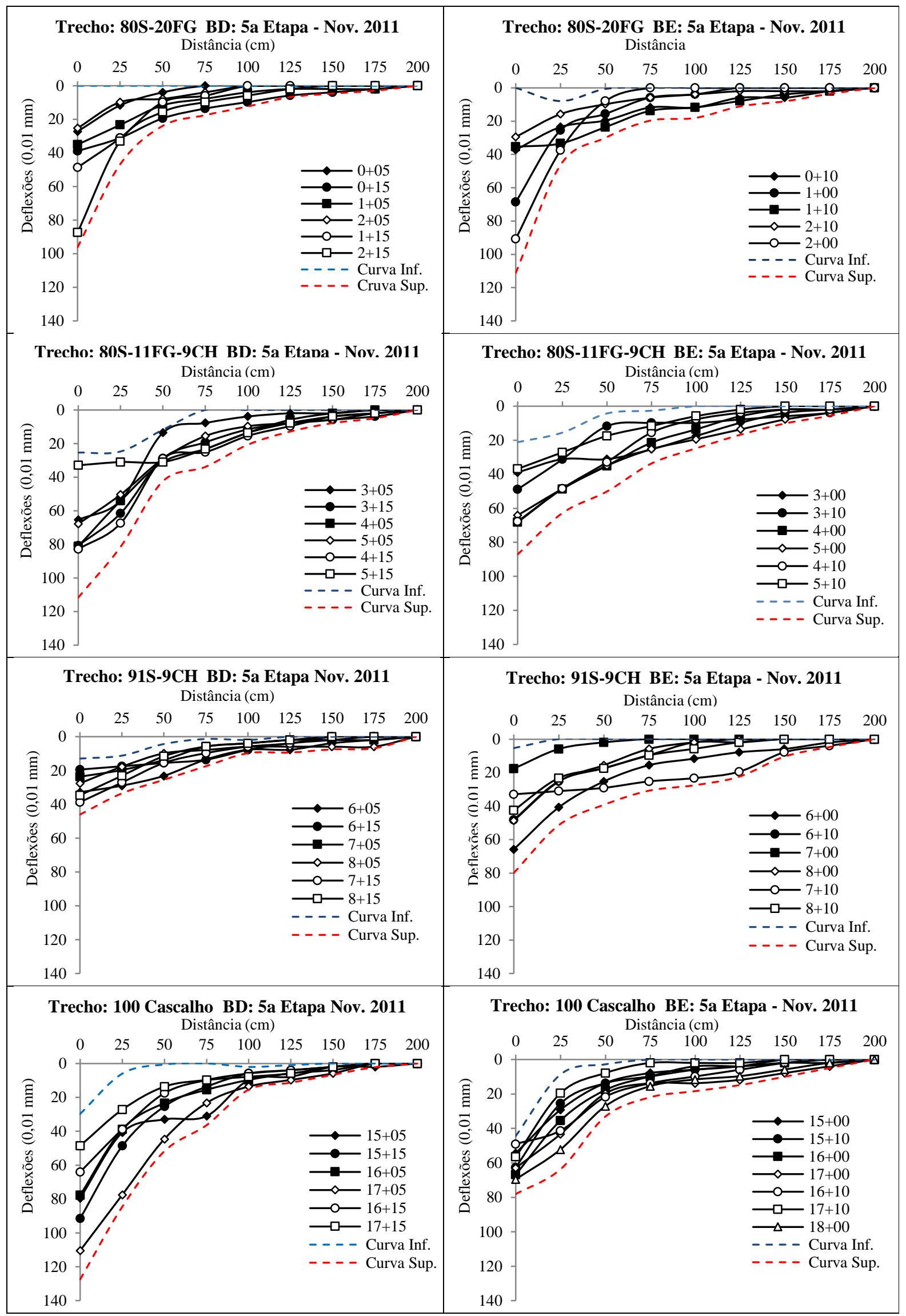

Figura 4.43. Bacias de deslocamentos obtidas na $5^{\text {a }}$ Etapa. Nota: BE=Bordo Esquerdo; BD=Bordo Direito. 
Universidade de Brasília

Departamento de Engenharia Civil / FT

Programa de Pós-Graduação em Geotecnia

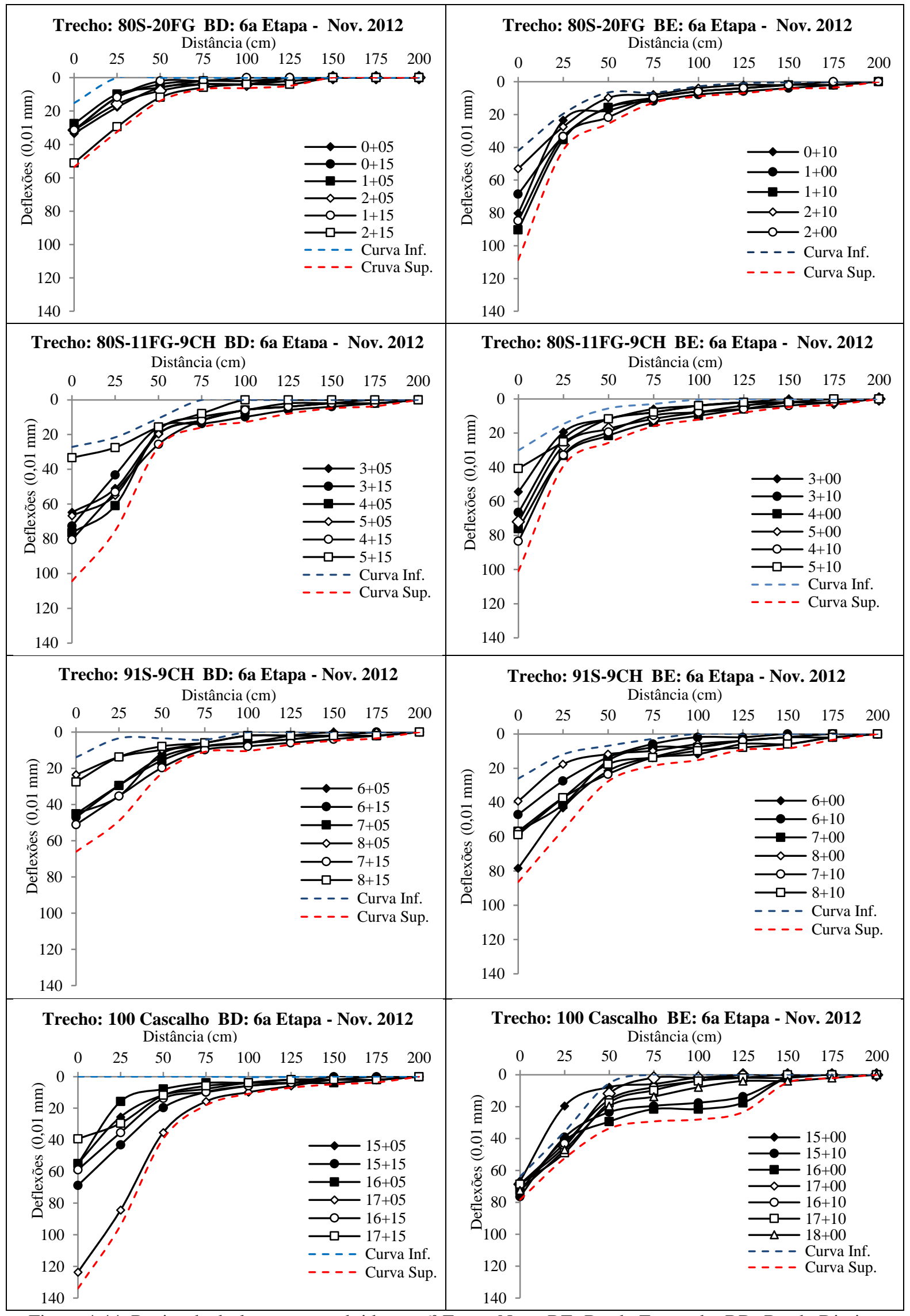

Figura 4.44. Bacias de deslocamentos obtidas na $6^{\mathrm{a}}$ Etapa. Nota: BE=Bordo Esquerdo; BD=Bordo Direito. 
Universidade de Brasília

Departamento de Engenharia Civil / FT

Programa de Pós-Graduação em Geotecnia

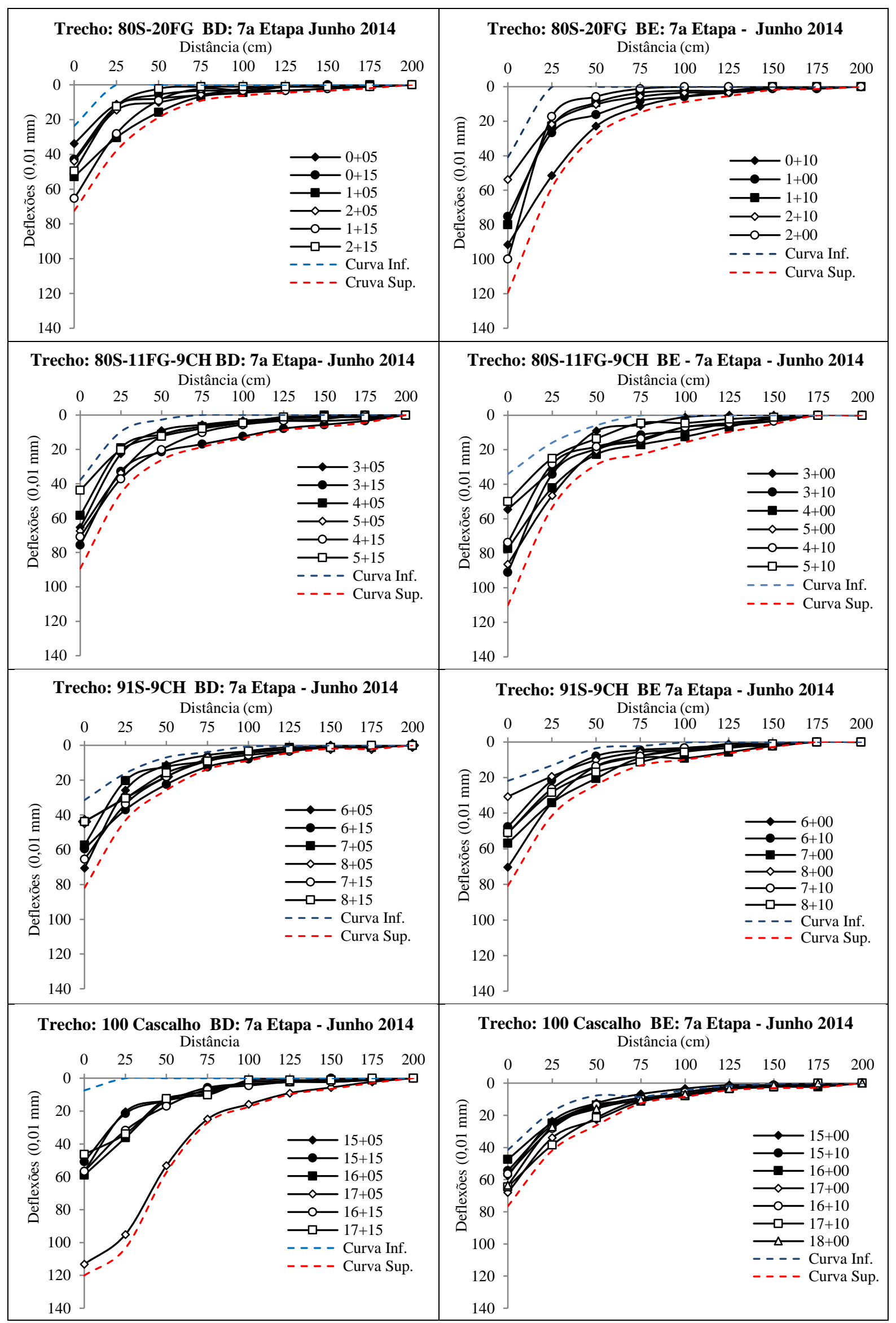

Figura 4.45. Bacias de deslocamentos obtidas na $7^{\text {a }}$ Etapa. Nota: BE=Bordo Esquerdo; BD=Bordo Direito. 


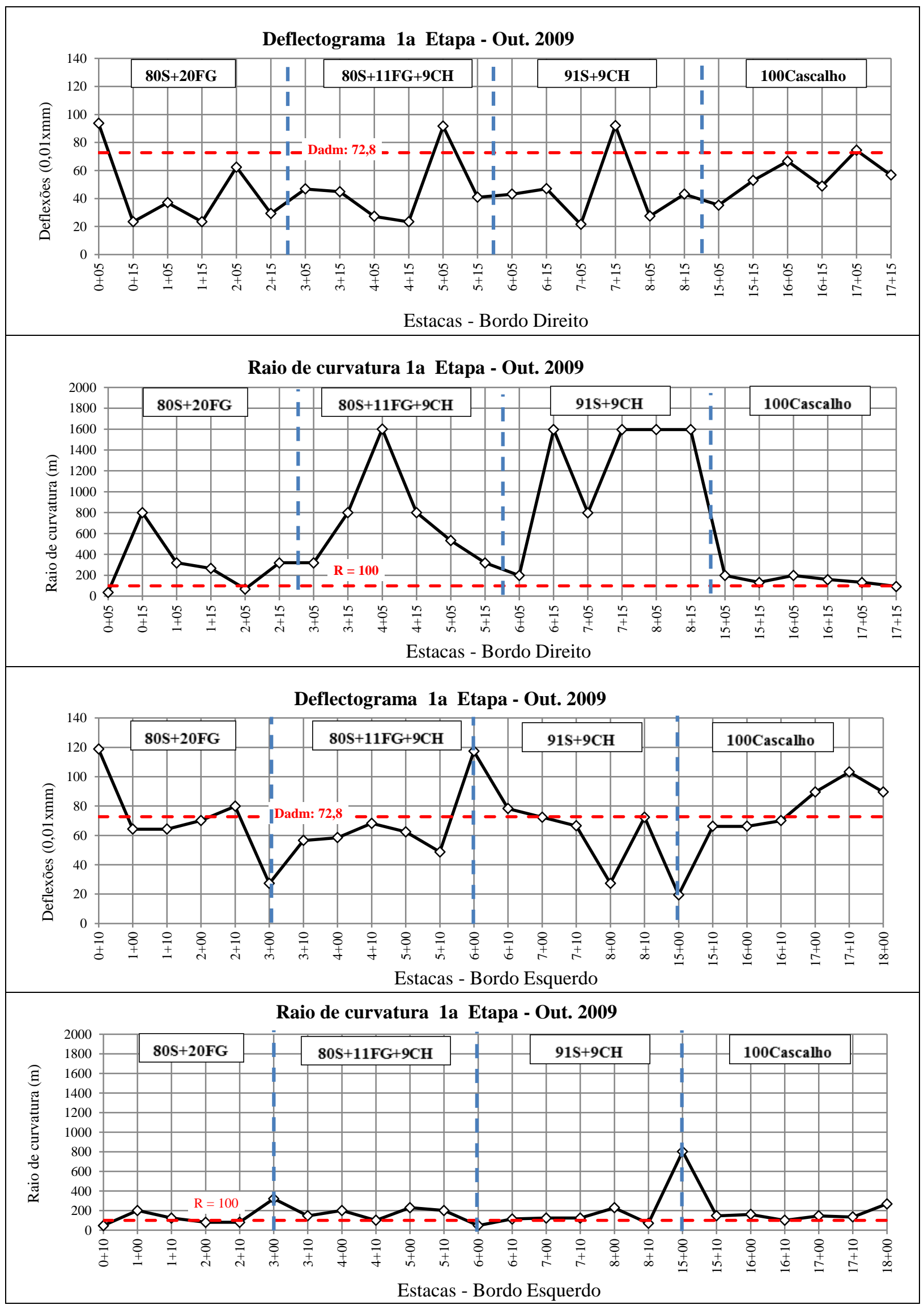

Figura 4.46. Deflectogramas e raios de curvaturas obtidos na $1^{\text {a }}$ Etapa. Outubro de 2009. 


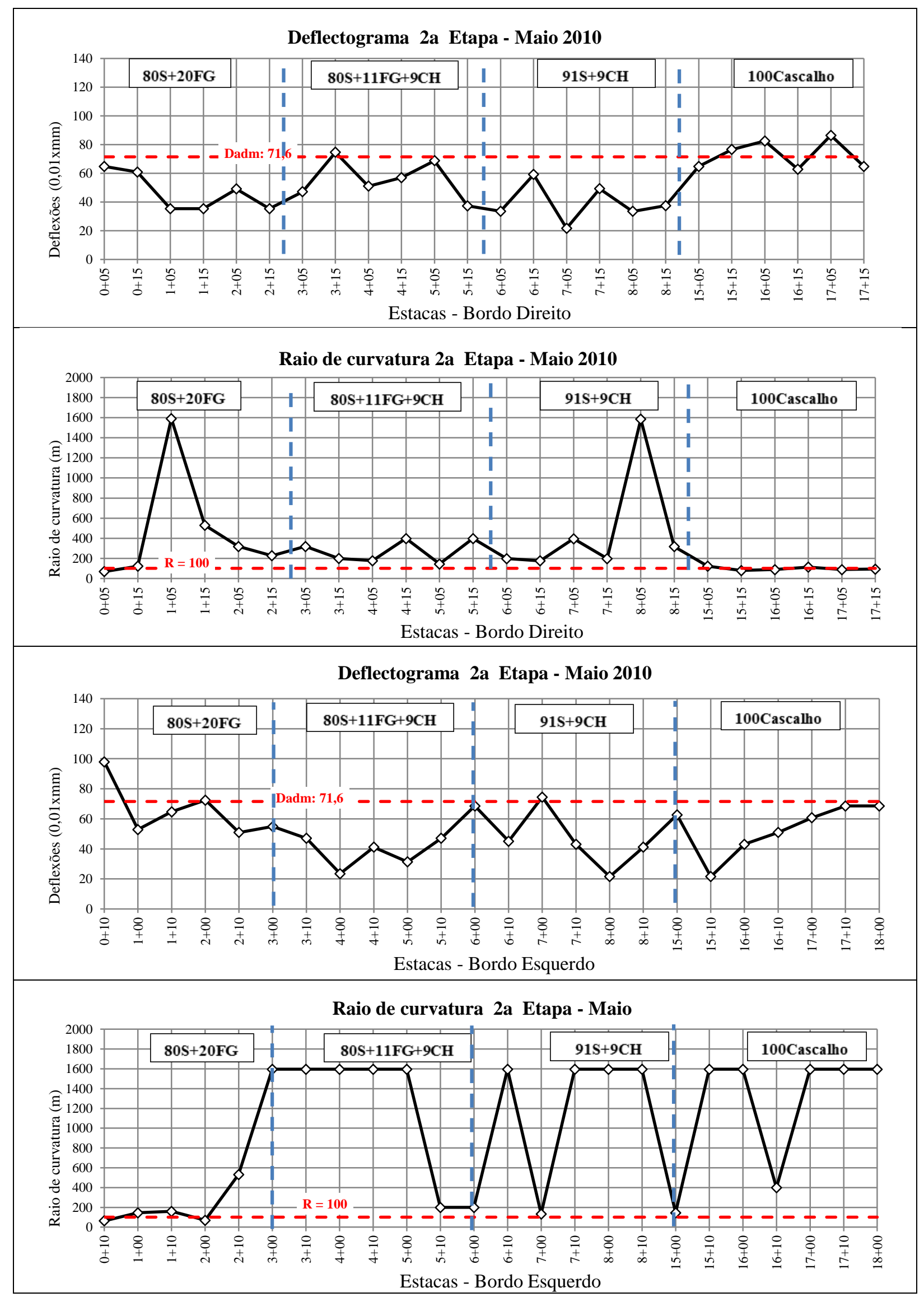

Figura 4.47. Deflectogramas e raios de curvaturas obtidos na $2^{\mathrm{a}}$ Etapa. Maio de 2010. 


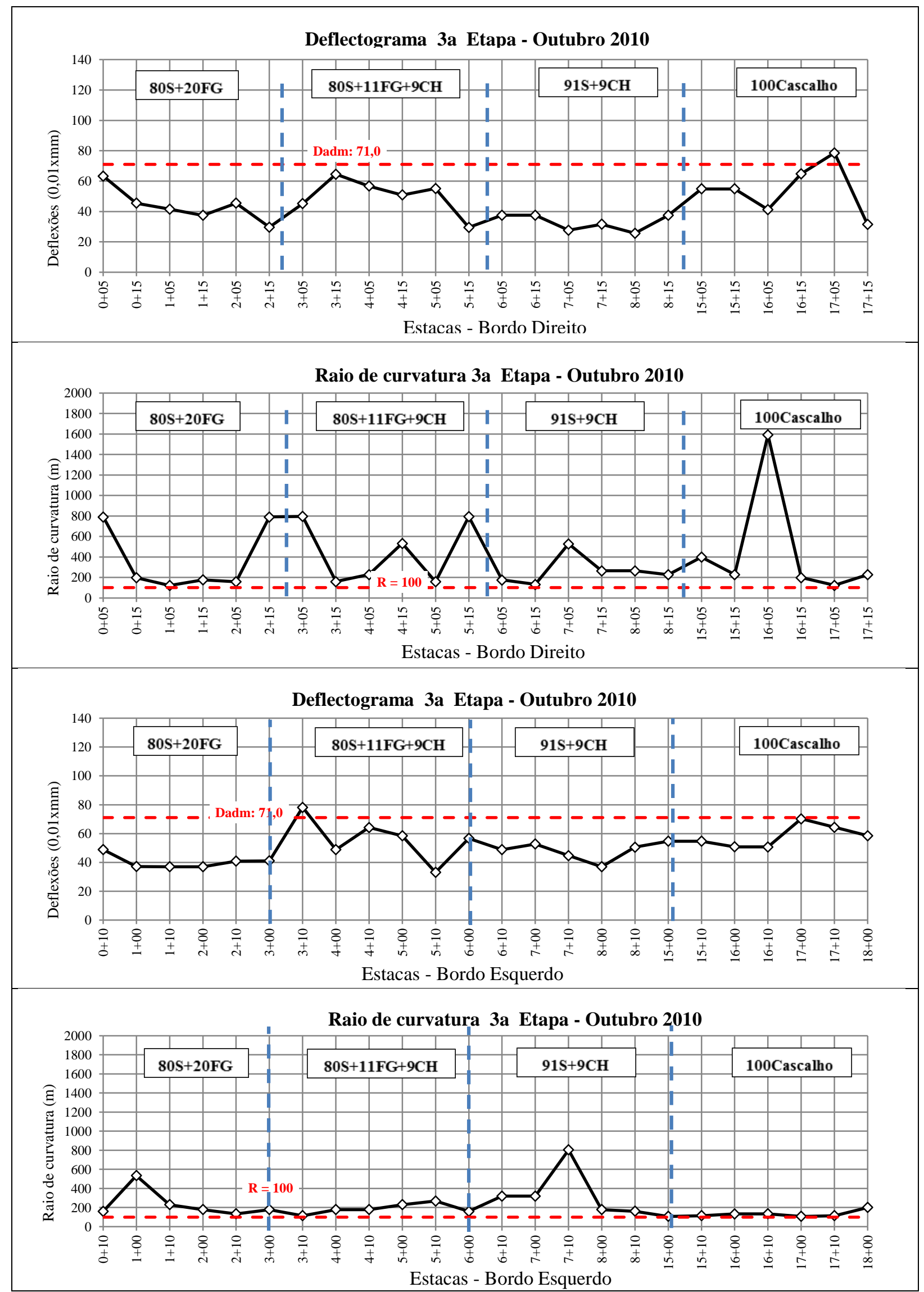

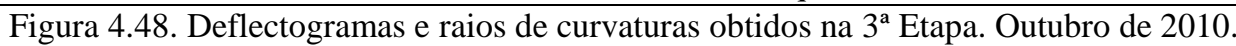




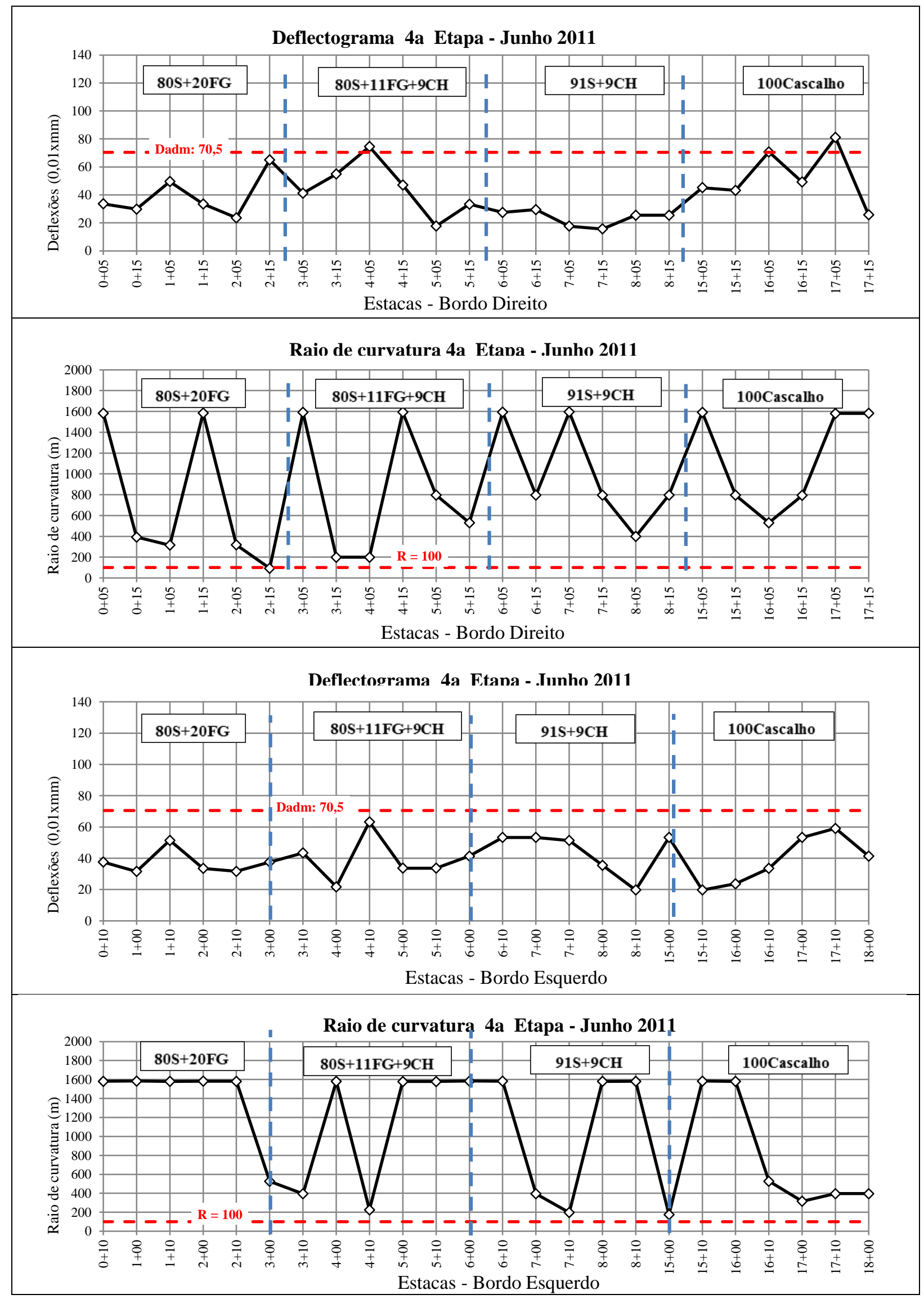

Figura 4.49. Deflectogramas e raios de curvaturas obtidos na $4^{\mathrm{a}}$ Etapa. Junho de 2011. 


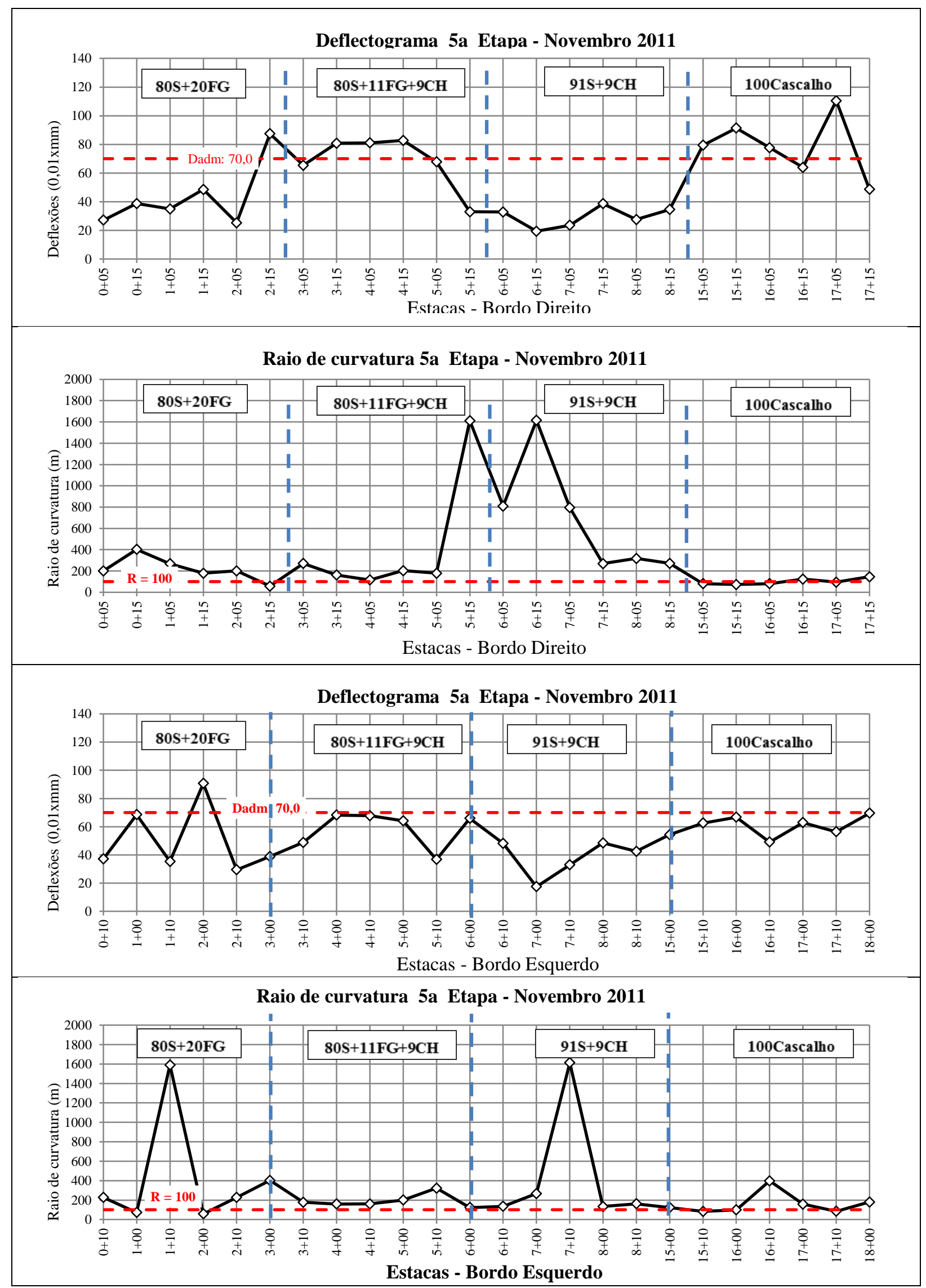

Figura 4.50. Deflectogramas e raios de curvaturas obtidos na $5^{\text {a }}$ Etapa. Novembro de 2011 
Universidade de Brasília

Departamento de Engenharia Civil / FT

Programa de Pós-Graduação em Geotecnia

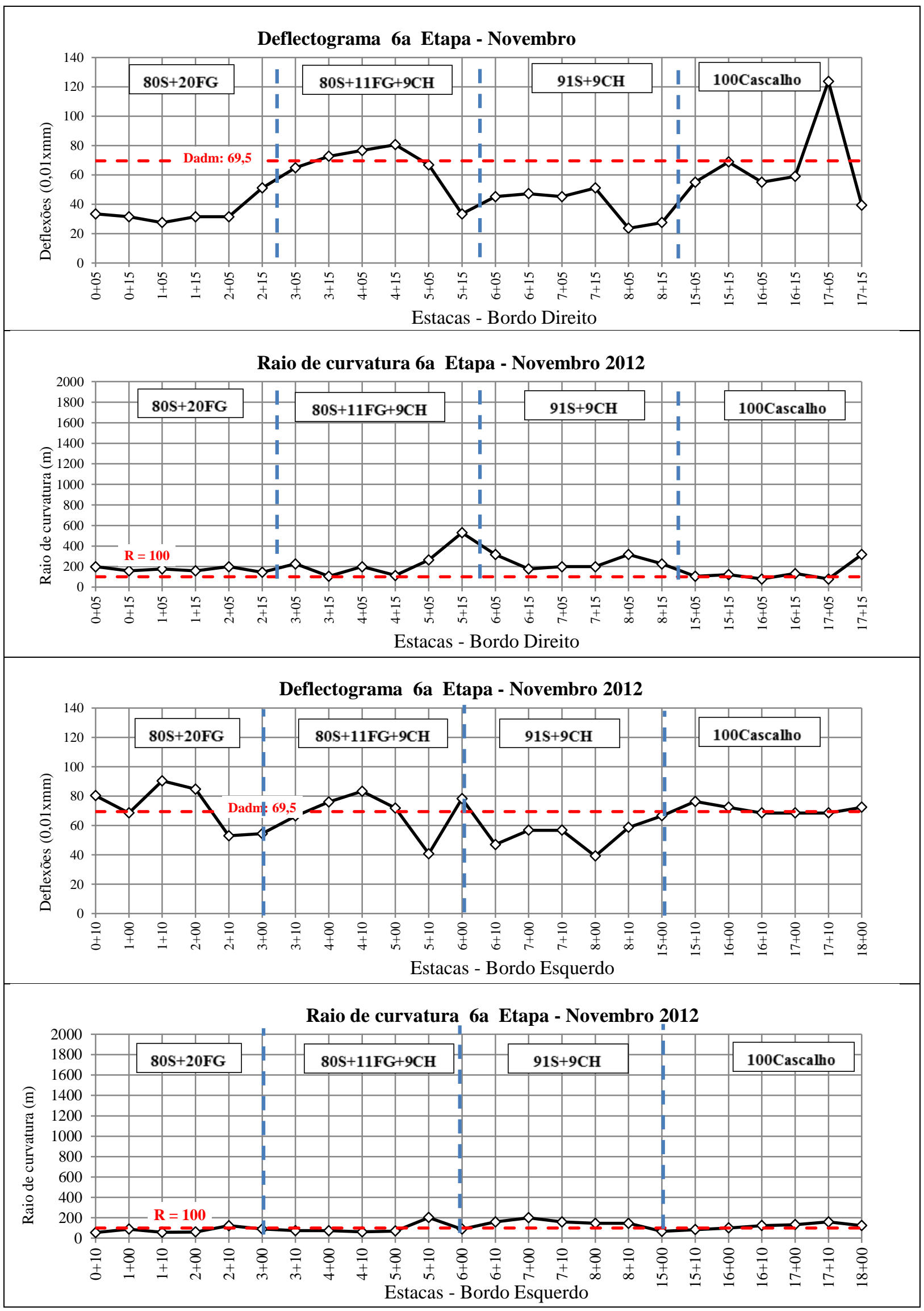

Figura 4.51. Deflectogramas e raios de curvaturas obtidos na $6^{a}$ Etapa. Novembro de 2012. 
Universidade de Brasília

Departamento de Engenharia Civil / FT

Programa de Pós-Graduação em Geotecnia

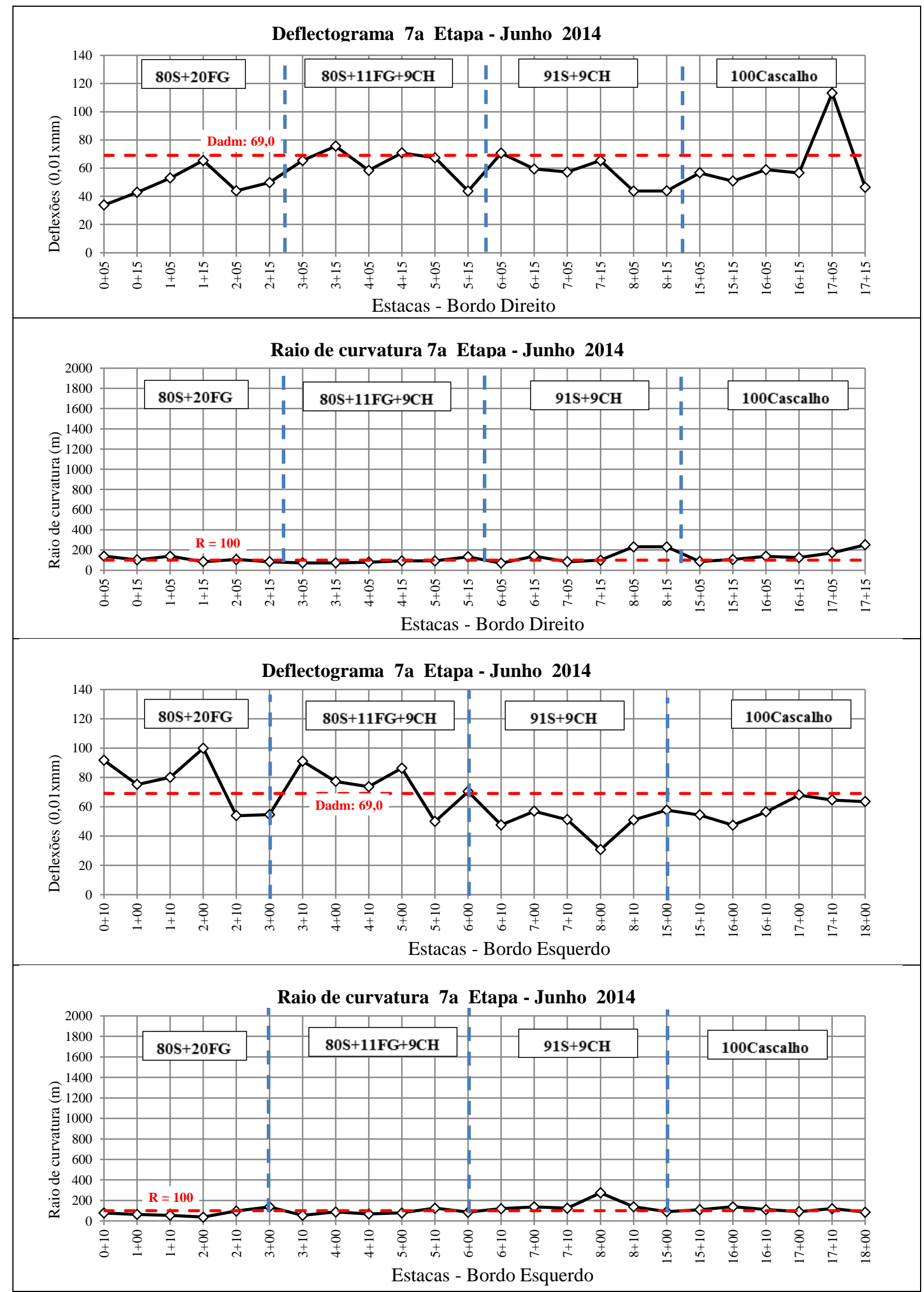

Figura 4.52. Deflectogramas e raios de curvaturas obtidos na $7^{\text {a }}$ Etapa. Junho de 2014. 
Ainda seguindo as orientações da DNER-PRO 11/79 (DNER, 1979), foram determinadas as deflexões de projeto Dp para cada trecho homogêneo, em todas as etapas de avaliação do pavimento. No caso em estudo, por se tratar de trechos com materiais distintos na camada de base, cada um poderia ser considerado inequivocamente um trecho homogêneo. Inicialmente, foram determinadas as médias dos deslocamentos máximos para cada trecho e época, assim como os valores de desvio padrão correspondentes. A partir desses dados, foram determinadas as deflexões características dos trechos, somando a média dos deslocamentos máximos de todas as estacas do trecho considerado e os desvios padrão correspondentes. Em seguida, foram aplicados os fatores de correção sazonal e obteve-se finalmente a deflexão de projeto para cada trecho. Nessa fase, os raios de curvatura dos trechos foram determinados a partir das médias dos deslocamentos máximos $\left(\mathrm{D}_{0}\right)$ e dos deslocamentos para carga localizada a 25 cm do ponto de prova $\left(\mathrm{D}_{25}\right)$. As bacias de deslocamentos médias dos trechos para cada trecho em cada etapa são ilustradas na Figura 4.53.

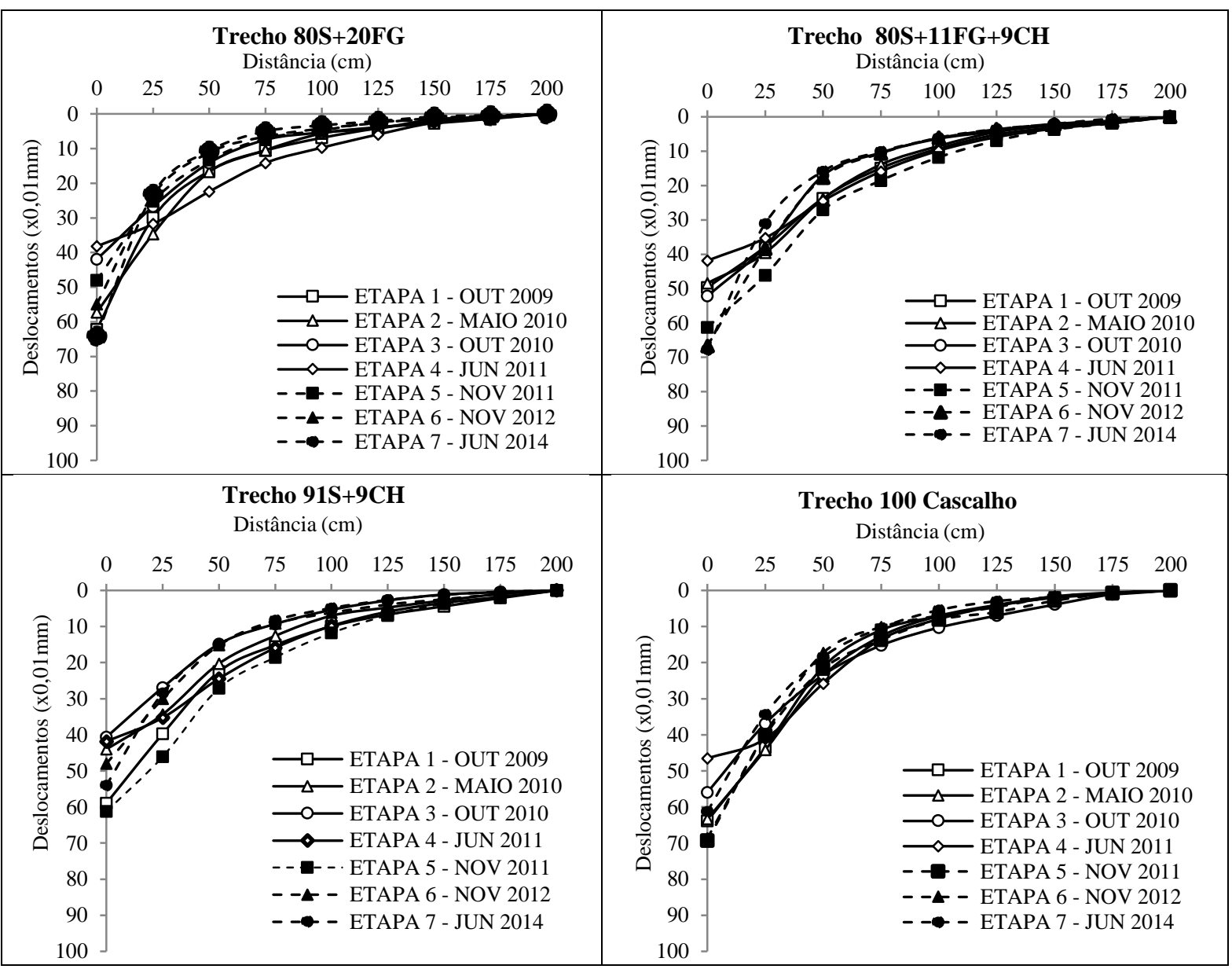

Figura 4.53. Bacias de deslocamentos médias obtidas para cada trecho em todas as etapas de avaliação do pavimento. Nota: BE=Bordo Esquerdo; BD=Bordo Direito. 
Para servir de base para as comparações, foram determinadas as deflexões admissíveis $\mathrm{D}_{\text {adm }}$ conforme define a DNER - PRO 11/79 (DNER, 1979). Para tanto, considerou-se que, por se tratar de um pavimento de baixo custo, espera-se que durante sua vida de projeto de 10 anos, o mesmo receba um número de solicitação de eixo padrão $\mathrm{N}=5.10^{6}$, de acordo com as orientações de Nogami \& Villibor (1995). A partir desta consideração, foi possível estimar o volume de tráfego esperado para cada época de avaliação. Na falta de um estudo detalhado sobre o tráfego na região e na pista experimental, adotou-se uma taxa de crescimento anual de 3\% e uma progressão linear para esta tarefa, em concordância com Balbo (2007). De posse de todos esses dados, foi então possível enquadrar os trechos experimentais dentro dos critérios de avaliação estrutural indicados pela DNER-PRO 11/79 (DNER, 1979). Nas Tabelas 4.15 a 4.18 estão apresentadas sucessivamente os parâmetros estruturais dos trechos solo+fosfogesso, solo+fosfogesso+cal, solo+cal e cascalho em cada etapa de avaliação do pavimento.

Tabela 4.15. Avaliação estrutural do trecho 80Solo+20Fosfogesso em todas etapas de monitoramento.

\begin{tabular}{cccccccccccccc}
\hline \multicolumn{10}{c}{ 80SOLO+20FOSFOGESSO } \\
\hline Etapa & Data & Dmed & D $_{25}$ & $\boldsymbol{\sigma}$ & CV & Dc & FS & N & Dp & Dadm $(\mathbf{0 , 0 1 m m})$ & R (m) & Hipótese & Qualidade Estrutural \\
\hline 1 & out/09 & 61 & 30 & 23 & 29 & 102 & 1,0 & 3.846 .154 & 102 & 71 & 102 & II & REGULAR \\
2 & mai/10 & 56 & 34 & 19 & 28 & 87 & 1,2 & 4.076 .923 & 104 & 70 & 141 & II & REGULAR \\
3 & out/10 & 42 & 27 & 5 & 13 & 45 & 1,0 & 4.192 .308 & 45 & 70 & 206 & I & BOA \\
4 & jun/11 & 38 & 31 & 8 & 22 & 45 & 1,2 & 4.307 .692 & 55 & 70 & 458 & I & BOA \\
5 & nov/11 & 48 & 25 & 26 & 50 & 79 & 1,0 & 4.423 .077 & 79 & 69 & 139 & II & REGULAR \\
6 & nov/12 & 53 & 23 & 15 & 20 & 90 & 1,0 & 4.538 .462 & 90 & 69 & 103 & I & BOA \\
7 & jun/14 & 63 & 33 & 18 & 22 & 98 & 1,2 & 4.653 .846 & 117 & 69 & 105 & II & REGULAR \\
\hline
\end{tabular}

Tabela 4.16. Avaliação estrutural do trecho 80Solo+11Fosfogesso+9Cal em todas etapas de monitoramento.

\begin{tabular}{|c|c|c|c|c|c|c|c|c|c|c|c|c|c|}
\hline \multicolumn{14}{|c|}{ 80SOLO+11FOSFOGESSO+9CAL } \\
\hline Etapa & Data & Dmed & $\mathbf{D}_{25}$ & $\sigma$ & CV & De & FS & $\mathbf{N}$ & Dp & Dadm $(0,01 \mathrm{~mm})$ & $\mathbf{R}(\mathbf{m})$ & Hipótese & Qualidade Estrutural \\
\hline 1 & out/09 & 50 & 38 & 20 & 39 & 69 & 1,0 & 3.846 .154 & 69 & 73 & 264 & I & $\mathrm{BOA}$ \\
\hline 2 & mai/10 & 48 & 40 & 15 & 30 & 63 & 1,2 & 4.076 .923 & 75 & 72 & 354 & II & REGULAR \\
\hline 3 & out/10 & 52 & 38 & 14 & 27 & 66 & 1,0 & 4.192 .308 & 66 & 71 & 218 & I & $\mathrm{BOA}$ \\
\hline 4 & jun/11 & 42 & 35 & 16 & 39 & 58 & 1,2 & 4.307 .692 & 70 & 70 & 476 & I & $\mathrm{BOA}$ \\
\hline 5 & nov/11 & 61 & 46 & 18 & 29 & 79 & 1,0 & 4.423 .077 & 79 & 70 & 206 & II & REGULAR \\
\hline 6 & nov/12 & 66 & 38 & 15 & 24 & 81 & 1,0 & 4.538 .462 & 81 & 69 & 112 & II & REGULAR \\
\hline 7 & jun/14 & 68 & 41 & 14 & 21 & 82 & 1,2 & 4.653 .846 & 99 & 69 & 117 & II & REGULAR \\
\hline
\end{tabular}

Tabela 4.17. Avaliação estrutural do trecho 91Solo+9Cal em todas etapas de monitoramento.

\begin{tabular}{cccccccccccccc}
\hline \multicolumn{10}{c}{ 91SOLO+9CAL } \\
\hline Etapa & Data & Dmed & $\mathbf{D}_{25}$ & $\boldsymbol{\sigma}$ & CV & Dc & FS & N & Dp & Dadm $(\mathbf{0 , 0 1 m m})$ & R (m) & Hipótese & Qualidade Estrutural \\
\hline 1 & out/09 & 59 & 40 & 29 & 49 & 88 & 1,0 & 3.846 .154 & 88 & 71 & 162 & II & REGULAR \\
2 & mai/10 & 44 & 34 & 17 & 38 & 61 & 1,2 & 4.076 .923 & 73 & 70 & 323 & II & REGULAR \\
3 & out/10 & 41 & 27 & 10 & 25 & 51 & 1,0 & 4.192 .308 & 51 & 70 & 228 & I & BOA \\
4 & jun/11 & 33 & 28 & 14 & 42 & 47 & 1,2 & 4.307 .692 & 56 & 70 & 680 & I & BOA \\
5 & nov/11 & 36 & 24 & 14 & 38 & 50 & 1,0 & 4.423 .077 & 50 & 69 & 255 & I & BOA \\
6 & nov/12 & 48 & 30 & 15 & 30 & 63 & 1,0 & 4.538 .462 & 63 & 69 & 174 & I & BOA \\
7 & jun/14 & 54 & 28 & 12 & 22 & 66 & 1,2 & 4.653 .846 & 79 & 69 & 122 & II & REGULAR \\
\hline
\end{tabular}


Tabela 4.18. Avaliação estrutural do trecho 100Cascalho em todas etapas de monitoramento.

\begin{tabular}{|c|c|c|c|c|c|c|c|c|c|c|c|c|c|}
\hline \multicolumn{14}{|c|}{ 100CASCALHO } \\
\hline Etapa & Data & Dmed & $\mathbf{D}_{25}$ & $\sigma$ & $\mathrm{CV}$ & Dc & FS & $\mathbf{N}$ & Dp & $\operatorname{Dadm}(0,01 \mathrm{~mm})$ & $\mathbf{R}(\mathbf{m})$ & Hipótese & Qualidade Estrutural \\
\hline 1 & out/09 & 65 & 44 & 23 & 35 & 87 & 1,0 & 3.846 .154 & 87 & 71 & 154 & II & REGULAR \\
\hline 2 & mai/10 & 63 & 45 & 17 & 27 & 80 & 1,1 & 4.076 .923 & 88 & 70 & 172 & II & REGULAR \\
\hline 3 & out/10 & 56 & 37 & 12 & 21 & 68 & 1,0 & 4.192 .308 & 68 & 70 & 160 & I & $\mathrm{BOA}$ \\
\hline 4 & jun/11 & 46 & 40 & 18 & 39 & 64 & 1,1 & 4.307 .692 & 71 & 70 & 557 & II & REGULAR \\
\hline 5 & nov/11 & 69 & 40 & 18 & 26 & 86 & 1,0 & 4.423 .077 & 86 & 69 & 108 & II & REGULAR \\
\hline 6 & $\operatorname{nov} / 12$ & 69 & 40 & 19 & 28 & 88 & 1,0 & 4.538 .462 & 88 & 69 & 108 & II & REGULAR \\
\hline 7 & jun/14 & 61 & 34 & 17 & 28 & 78 & 1,1 & 4.653 .846 & 86 & 69 & 115 & II & REGULAR \\
\hline
\end{tabular}

Dessas análises, verificou-se que quando apenas são considerados as deflexões máximas apresentados nas bacias deflectométricas e nos deflectogramas, com raras exceções, todas deflexões medidas em campo nos sete períodos de avaliação encontram-se abaixo de $80.10^{-2}$ mm, sendo esse nível de deflexão considerado satisfatório na prática rodoviária. Observa-se também que em todas das etapas de avalição, as médias dos deslocamentos não superam esse valor. Quando adota-se o procedimento da DNER - PRO 11/79 (DNER, 1979) baseado nas deflexões de projeto e nos raios de curvatura, o quadro de bom desempenho do pavimento é confirmado para todos os trechos. Conforme apresentado nas Tabelas 4.15 a 18 , todos os materiais apresentam uma qualidade estrutural boa ou regular em todas as etapas de avaliação. Para os ensaios de viga Benkelman, conclui-se em um comportamento semelhante e satisfatório entre os materiais em estudo.

\subsection{3 - ENSAIOS DE PROVA DE CARGA SOBRE PLACA}

A partir dos ensaios de prova de carga sobre placa, foram determinados os valores médios de deslocamentos máximos de cada trecho em cada período de avaliação e os desvios padrão associados. Também foram obtidos os valores de deslocamentos para um carregamento padrão de $560 \mathrm{kPa}$, as deformações elásticas médias e suas taxas de recuperação de elasticidade em relação à deformação total e, finalmente, os módulos de reação de placa e módulos de reação elástica da placa. Esses últimos dados foram obtidos a partir da relação entre a pressão aplicada na placa e o deslocamento total correspondente, e no segundo caso, com apenas a parcela de deslocamento elástico. A Figura 4.54 ilustra as curvas de deformações médias obtidas desses ensaios para cada trecho e nos sete períodos de monitoramento enquanto os parâmetros dos ensaios estão apresentados nas Tabelas 4.19 a 4.22 respectivamente e suas variações estão ilustradas respetivamente nas Figuras 4.55 a 58 . 
Universidade de Brasília

Departamento de Engenharia Civil / FT

Programa de Pós-Graduação em Geotecnia

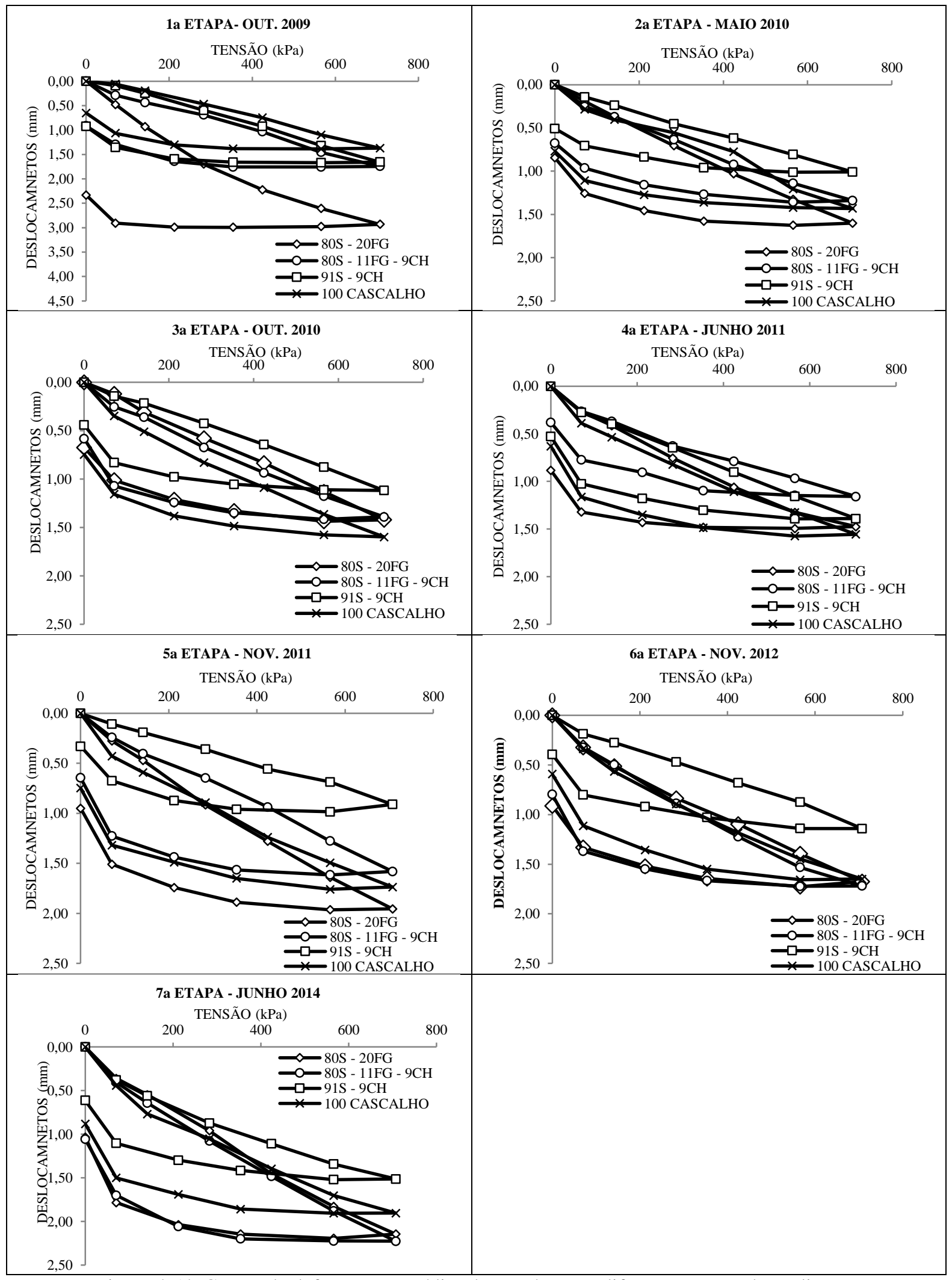

Figura 4.54. Curvas de deformações médias dos trechos nas diferentes etapas de avaliação. 
Universidade de Brasília

Departamento de Engenharia Civil / FT

Programa de Pós-Graduação em Geotecnia

Tabela 4.19. Média dos deslocamentos máximos obtidos dos ensaios de prova de carga.

\begin{tabular}{lccccccccc}
\hline \multirow{2}{*}{ ETAPA } & \multicolumn{2}{c}{$\mathbf{8 0 S - 2 0 F G}$} & \multicolumn{2}{c}{ 80S-11FG-9CH } & \multicolumn{2}{c}{ 91S-9CH } & \multicolumn{2}{c}{ 100 CASCALHO } \\
\cline { 2 - 11 } & $\mathbf{D}_{\max }(\mathbf{m m})$ & $\boldsymbol{\sigma}$ & $\mathbf{D}_{\max }(\mathbf{m m})$ & $\boldsymbol{\sigma}$ & $\mathbf{D}_{\max }(\mathbf{m m})$ & $\boldsymbol{\sigma}$ & $\mathbf{D}_{\max }(\mathbf{m m})$ & $\boldsymbol{\sigma}$ \\
\hline 1a - OUT. 2009 & $\mathbf{2 , 9 9}$ & 0,93 & $\mathbf{1 , 7 6}$ & 0,98 & $\mathbf{1 , 6 7}$ & 0,68 & $\mathbf{1 , 3 9}$ & 0,13 \\
\hline 2a - MAIO 2010 & $\mathbf{1 , 6 3}$ & 0,57 & $\mathbf{1 , 3 6}$ & 0,50 & $\mathbf{1 , 0 1}$ & 0,06 & $\mathbf{1 , 4 3}$ & 0,13 \\
\hline 3a- OUT. 2010 & $\mathbf{1 , 4 4}$ & 0,77 & $\mathbf{1 , 4 1}$ & 0,21 & $\mathbf{1 , 1 2}$ & 0,41 & $\mathbf{1 , 6 0}$ & 0,19 \\
\hline 4a - JUNHO 2011 & $\mathbf{1 , 5 4}$ & 0,59 & $\mathbf{1 , 1 8}$ & 0,31 & $\mathbf{1 , 3 9}$ & 0,56 & $\mathbf{1 , 5 7}$ & 0,38 \\
\hline 5a - NOV. 2011 & $\mathbf{1 , 9 7}$ & 1,05 & $\mathbf{1 , 6 2}$ & 0,49 & $\mathbf{1 , 0 0}$ & 0,22 & $\mathbf{1 , 7 7}$ & 0,11 \\
\hline 6a - NOV. 2012 & $\mathbf{1 , 7 3}$ & 1,18 & $\mathbf{1 , 7 2}$ & 0,19 & $\mathbf{1 , 1 4}$ & 0,19 & $\mathbf{1 , 6 6}$ & 0,15 \\
\hline 7a - JUNHO 2014 & $\mathbf{2 , 1 9}$ & 1,08 & $\mathbf{2 , 2 3}$ & 0,37 & $\mathbf{1 , 5 2}$ & 0,75 & $\mathbf{1 , 9 1}$ & 0,17 \\
\hline
\end{tabular}

Tabela 4.20. Médias dos deslocamentos correspondente a um carregamento de 560kPa.

\begin{tabular}{lccccccccc}
\hline \multirow{2}{*}{ ETAPA } & \multicolumn{2}{c}{ 80S-20FG } & \multicolumn{2}{c}{ 80S-11FG-9CH } & \multicolumn{2}{c}{ 91S-9CH } & \multicolumn{2}{c}{ 100 CASCALHO } \\
\cline { 2 - 10 } & $\mathbf{D}_{560 k P a}(\mathbf{m m})$ & $\boldsymbol{\sigma}$ & $\mathbf{D}_{560 \mathrm{kP}}(\mathbf{m m})$ & $\boldsymbol{\sigma}$ & $\mathbf{D}_{560 \mathrm{kP}}(\mathbf{m m})$ & $\boldsymbol{\sigma}$ & D $_{560 \mathrm{kPa}}(\mathbf{m m})$ & $\boldsymbol{\sigma}$ \\
\hline 1a - OUT. 2009 & $\mathbf{2 , 5 9}$ & 0,78 & $\mathbf{1 , 4 4}$ & 0,94 & $\mathbf{1 , 3 0}$ & 0,54 & $\mathbf{1 , 0 9}$ & 0,05 \\
\hline 2a - MAIO 2010 & $\mathbf{1 , 3 1}$ & 0,50 & $\mathbf{1 , 1 3}$ & 0,44 & $\mathbf{0 , 8 0}$ & 0,06 & $\mathbf{1 , 1 9}$ & 0,18 \\
\hline 3a - OUT. 2010 & $\mathbf{1 , 1 2}$ & 0,68 & $\mathbf{1 , 1 7}$ & 0,18 & $\mathbf{0 , 8 7}$ & 0,31 & $\mathbf{1 , 3 5}$ & 0,20 \\
\hline 4a - JUNHO 2011 & $\mathbf{1 , 3 1}$ & 0,63 & $\mathbf{0 , 9 6}$ & 0,28 & $\mathbf{1 , 1 5}$ & 0,47 & $\mathbf{1 , 3 2}$ & 0,35 \\
\hline 5a - NOV. 2011 & $\mathbf{1 , 6 2}$ & 0,87 & $\mathbf{1 , 2 6}$ & 0,31 & $\mathbf{0 , 6 8}$ & 0,15 & $\mathbf{1 , 4 8}$ & 0,11 \\
\hline 6a - NOV. 2012 & $\mathbf{1 , 3 8}$ & 0,95 & $\mathbf{1 , 5 2}$ & 0,27 & $\mathbf{0 , 8 7}$ & 0,10 & $\mathbf{1 , 4 4}$ & 0,14 \\
\hline 7a - JUNHO 2014 & $\mathbf{1 , 8 1}$ & 0,76 & $\mathbf{1 , 8 6}$ & 0,29 & $\mathbf{1 , 3 3}$ & 0,68 & $\mathbf{1 , 6 9}$ & 0,13 \\
\hline
\end{tabular}

Tabela 4.21. Módulos de reação de placa em MPa/m.

\begin{tabular}{lccccccccc}
\hline \multirow{2}{*}{ ETAPA } & \multicolumn{2}{c}{ 80S-20FG } & \multicolumn{2}{c}{ 80S-11FG-9CH } & \multicolumn{2}{c}{ 91S-9CH } & \multicolumn{2}{c}{ 100 CASCALHO } \\
\cline { 2 - 10 } & $\mathrm{k}_{\text {placa }}$ & $\mathrm{k}_{\text {elastico }}$ & $\mathrm{k}_{\text {placa }}$ & $\mathrm{k}_{\text {elastico }}$ & $\mathrm{k}_{\text {placa }}$ & $\mathrm{k}_{\text {elastico }}$ & $\mathrm{k}_{\text {placa }}$ & $\mathrm{k}_{\text {elastico }}$ \\
\hline 1a - OUT. 2009 & 216 & 1183 & 389 & 857 & 429 & 968 & 516 & 984 \\
\hline 2a - MAIO 2010 & 426 & 936 & 495 & 1065 & 699 & 1408 & 470 & 1068 \\
\hline 3a- OUT. 2010 & 501 & 949 & 480 & 876 & 646 & 1047 & 414 & 830 \\
\hline 4a - JUNHO 2011 & 426 & 1194 & 584 & 907 & 489 & 819 & 426 & 763 \\
\hline 5a - NOV. 2011 & 345 & 703 & 444 & 755 & 823 & 1220 & 378 & 715 \\
\hline 6a - NOV. 2012 & 405 & 928 & 369 & 767 & 646 & 945 & 390 & 669 \\
\hline 7a - JUNHO 2014 & 309 & 637 & 301 & 606 & 420 & 784 & 331 & 691 \\
\hline
\end{tabular}

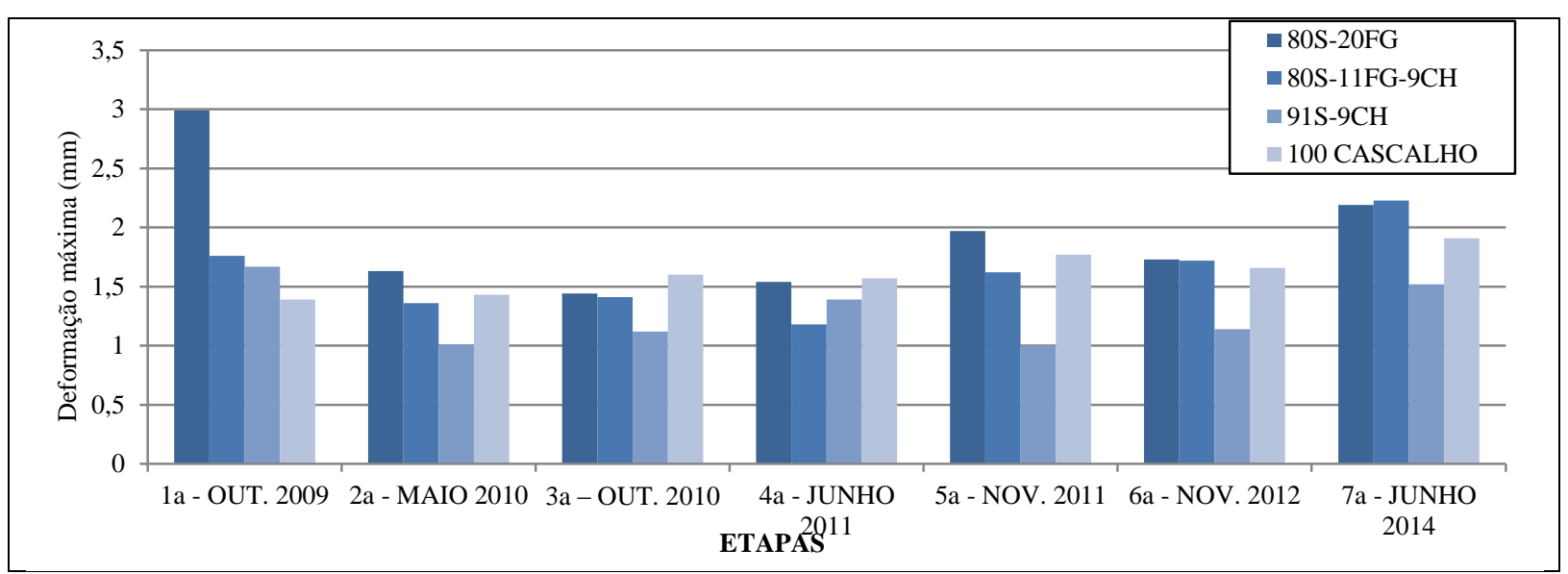

Figura 4.55. Média dos deslocamentos máximos obtidos dos ensaios de prova de carga. 
Universidade de Brasília

Departamento de Engenharia Civil / FT

Programa de Pós-Graduação em Geotecnia

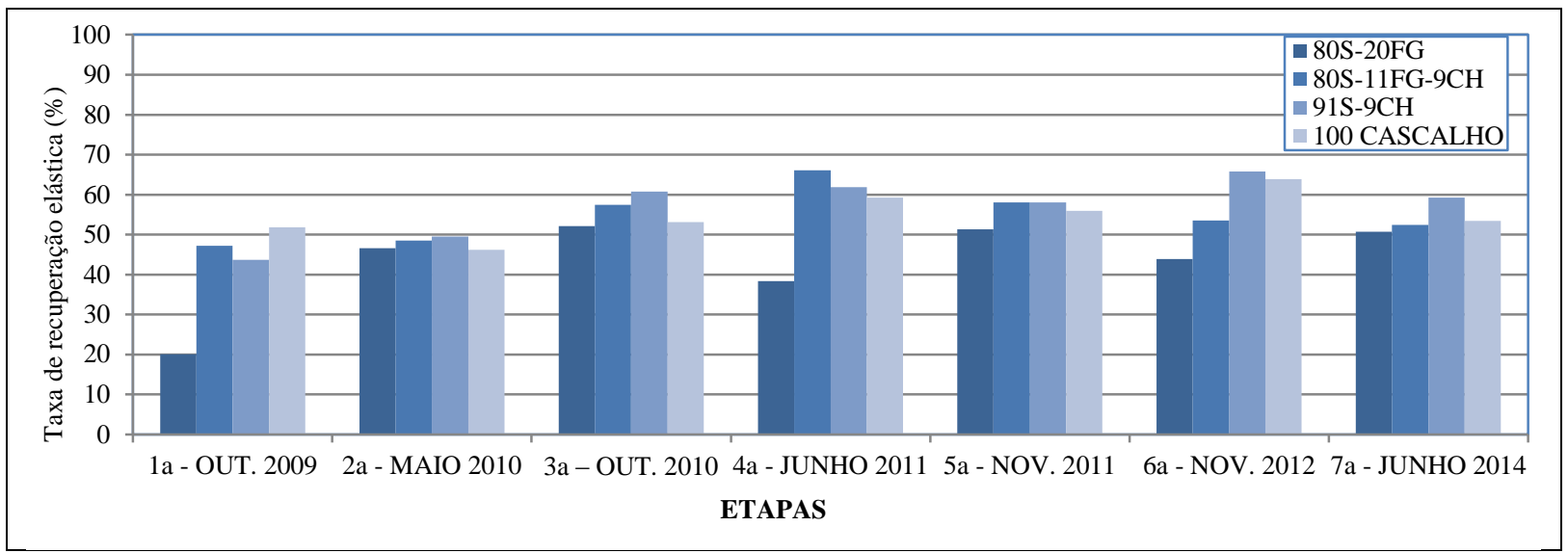

Figura 4.56. Taxas de recuperação elásticas do pavimento em relação a deformação total.

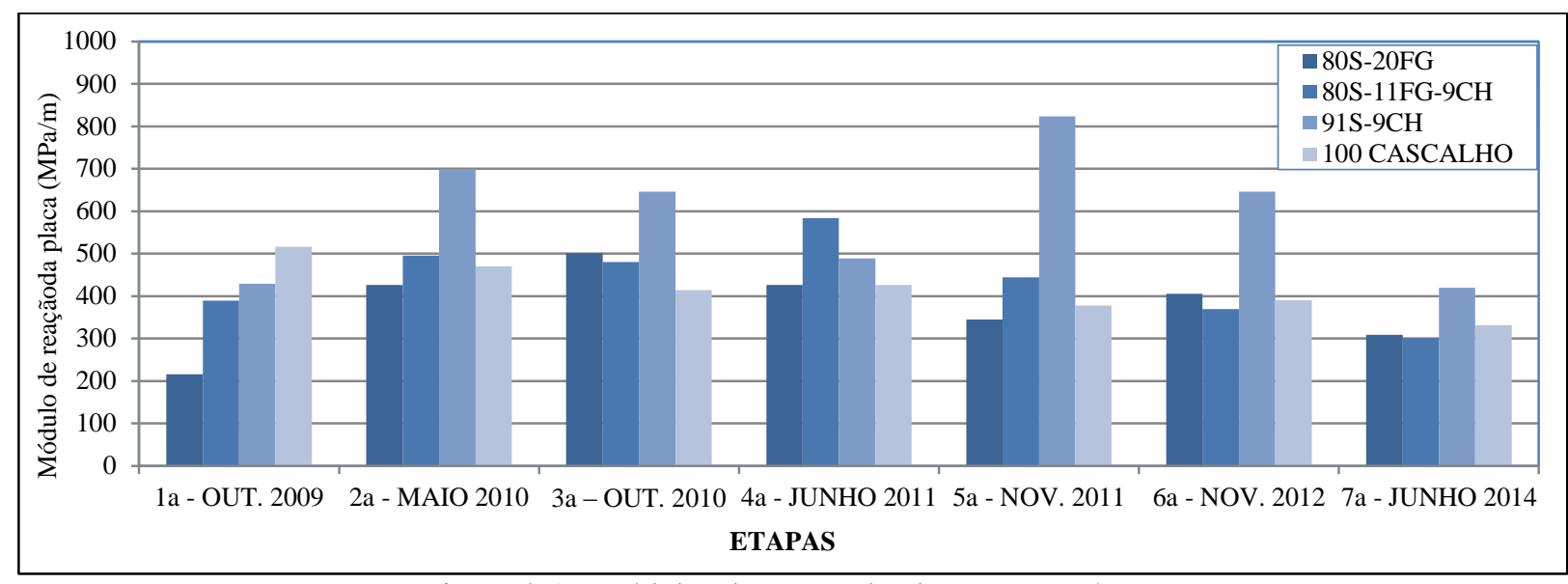

Figura 4.57. Módulos de reação da placa em MPa/m.

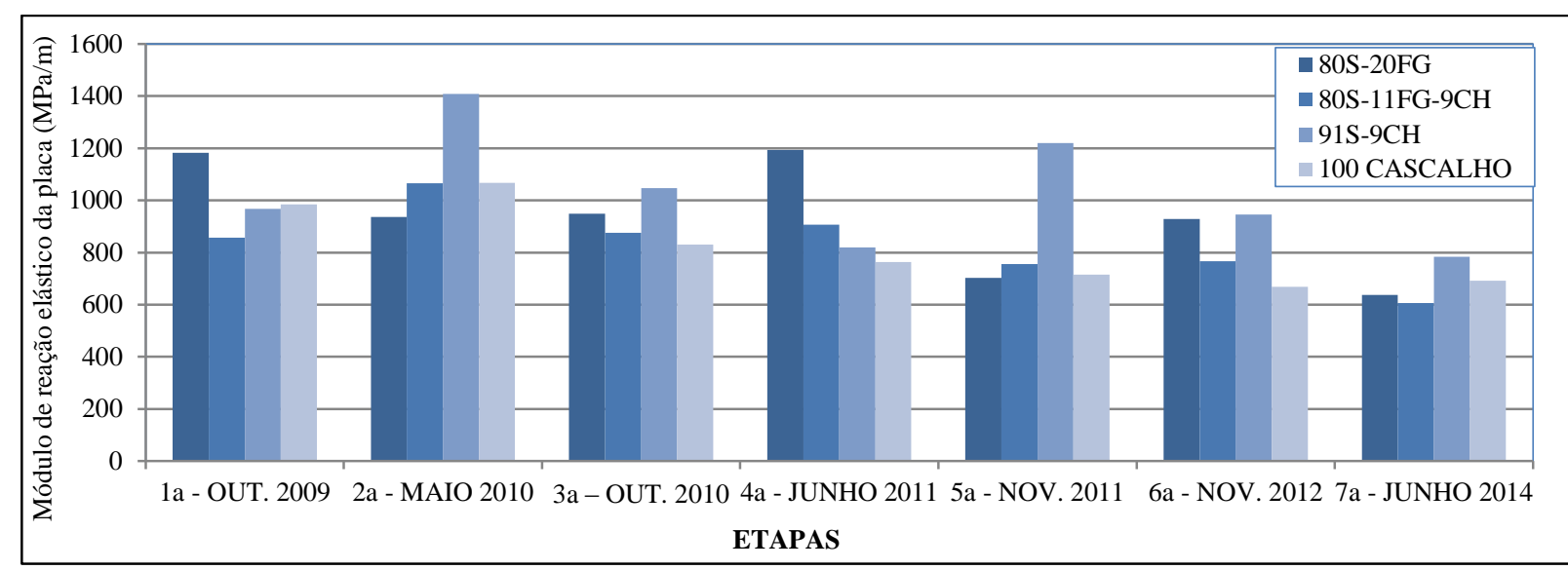

Figura 4.58. Módulos de reação elásticos da placa em MPa/m.

A partir desses dados, observou-se que, com exceção do trecho solo+fosfogesso na primeira etapa de avaliação, todas as médias dos deslocamentos máximos apresentaram valores inferiores a 2,5 mm. De acordo com Rezende (2003), este valor pode ser considerado como limite aceitável de deformação para um pavimento de baixo de volume de tráfego. No 
entanto, conforme salienta Metogo (2010), esse valor elevado de deformação é devido às dificuldades encontradas durante a execução desse trecho na estação chuvosa. Nas campanhas seguintes, esses valores se mantiveram relativamente baixos, variando na ordem de 1,00 a 2,00 mm. Nota-se que a partir da segunda etapa de avaliação, o trecho solo+cal apresentou as menores médias de deslocamentos máximos.

Na mesma lógica, as médias dos deslocamentos obtidos para um carregamento padrão de $560 \mathrm{kPa}$ estão dentro dos limites de deformabilidade aceitáveis de $2,5 \mathrm{~mm}$ em todas as épocas. A partir das taxas de recuperação de elasticidade da Figura 4.56, observou-se que praticamente em todas as etapas de avaliação, esta recuperação dificilmente excedeu os $60 \%$ em relação a deformação total a qual está sujeito o pavimento durante o ensaio. Disso deduzse que os ensaios de prova de carga mobilizam uma parcela importante da parcela plástica dos materiais em campo. Alguns cuidados devem ser tomados quando a esse comportamento, pois as deformações permanentes mobilizadas podem ser a origem de futuros defeitos de pavimentos, entre os quais, as panelas.

No que diz respeito aos módulos de reação da placa, ressalta-se que quando maior esses parâmetros, maior a rigidez da estrutura avaliada e melhor sua capacidade de absorção das deformações. Nesse sentido, observou-se que, no que diz respeito a esses módulos, o trecho solo+fosfogesso apresentou os menores valores na primeira etapa, em função das dificuldades construtivas já mencionadas. Esse quadro, no entanto, foi melhorando com o tempo, aproximando-se dos valores obtidos com os outros trechos. Os maiores valores de módulos de reação foram obtidos nos trechos solo+cal e solo+fosfogesso+cal.

\subsection{4 - ENSAIOS DCP}

Nas Figuras 4.59 a 4.61, os valores e os diagramas de penetrações médias de cada trecho estão ilustrados para cada campanha de ensaios. Na Tabela 4.22 estão apresentadas as espessuras médias das primeiras camadas homogêneas e os valores dos índices de penetração médios $\mathrm{DN}_{\text {med }}$ obtidos a partir dos resultados dos ensaios DCP. Na Figura 4.62 está apresentado um comparativo dos índices de penetração médios dos trechos por etapa. Cabe ressalta-se que, quanto maior o índice de penetração, menor a resistência à penetração da camada. 
Universidade de Brasília

Departamento de Engenharia Civil / FT

Programa de Pós-Graduação em Geotecnia

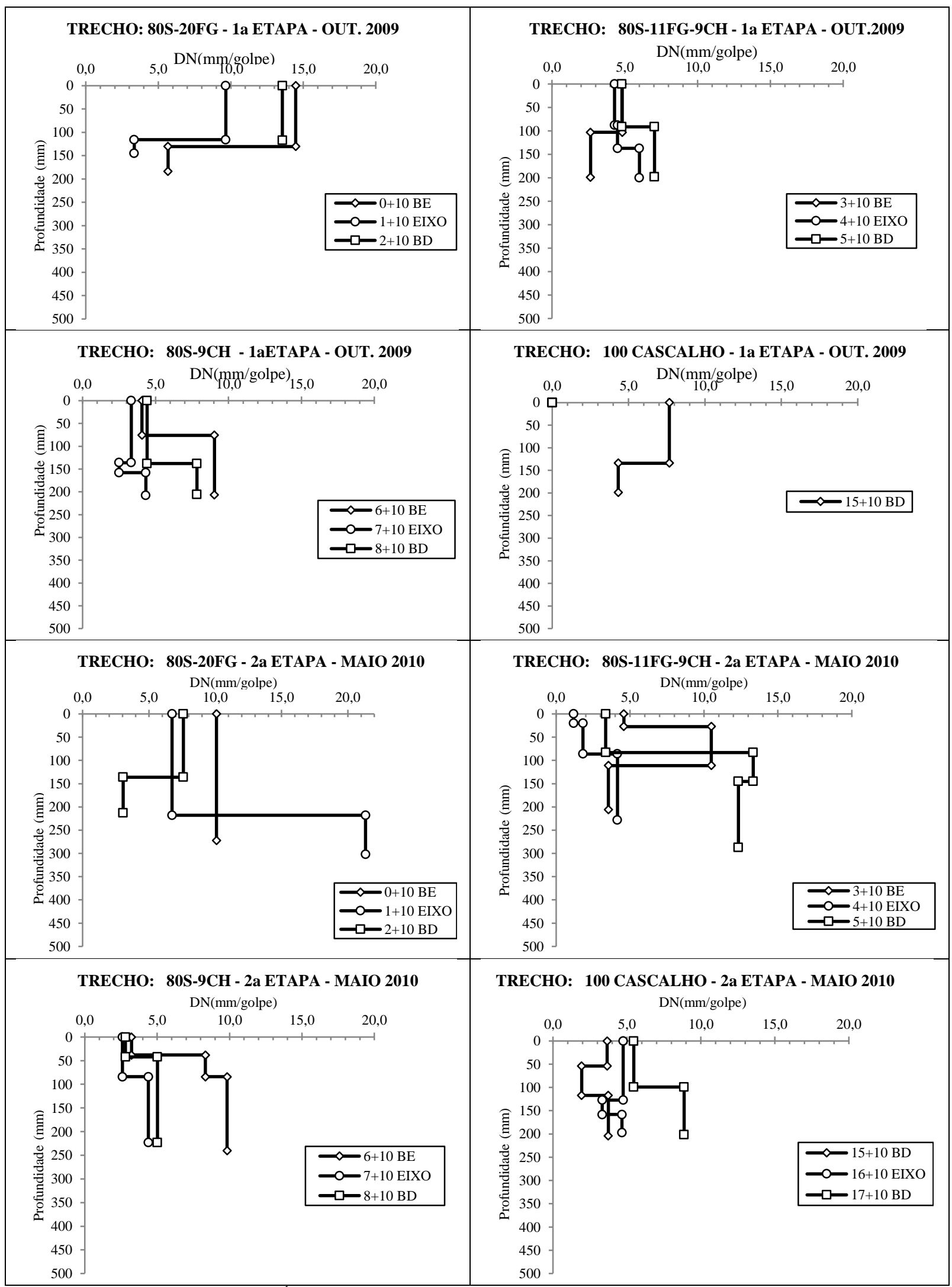

Figura 4.59. Índices de penetração do DCP nos trechos nas $1^{\mathrm{a}}$ e $2^{\mathrm{a}}$ etapas. 
Universidade de Brasília

Departamento de Engenharia Civil / FT

Programa de Pós-Graduação em Geotecnia

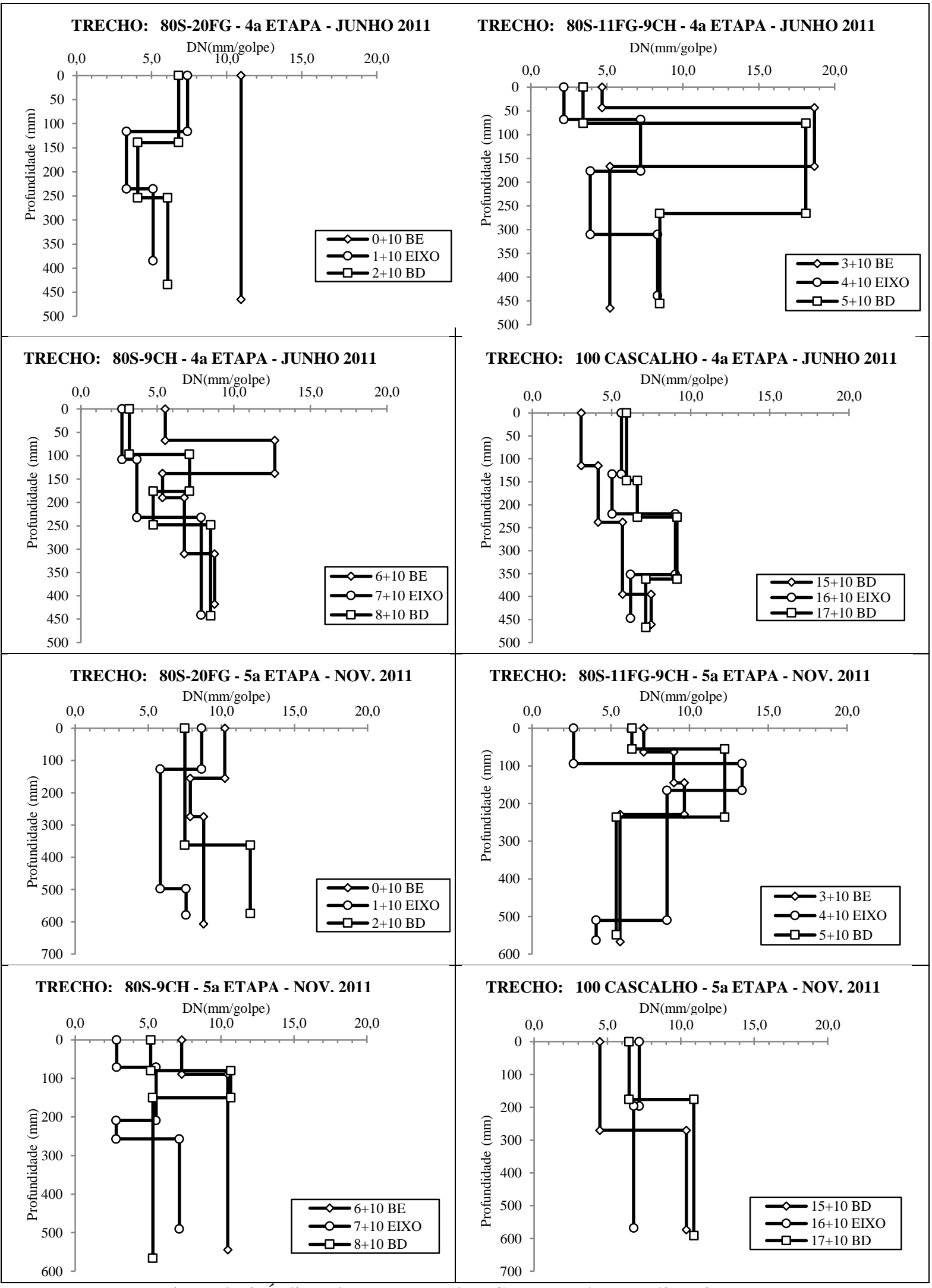

Figura 4.60. Índices de penetração do DCP nos trechos nas $4^{\mathrm{a}}$ e $5^{\mathrm{a}}$ etapas. 
Universidade de Brasília

Departamento de Engenharia Civil / FT

Programa de Pós-Graduação em Geotecnia

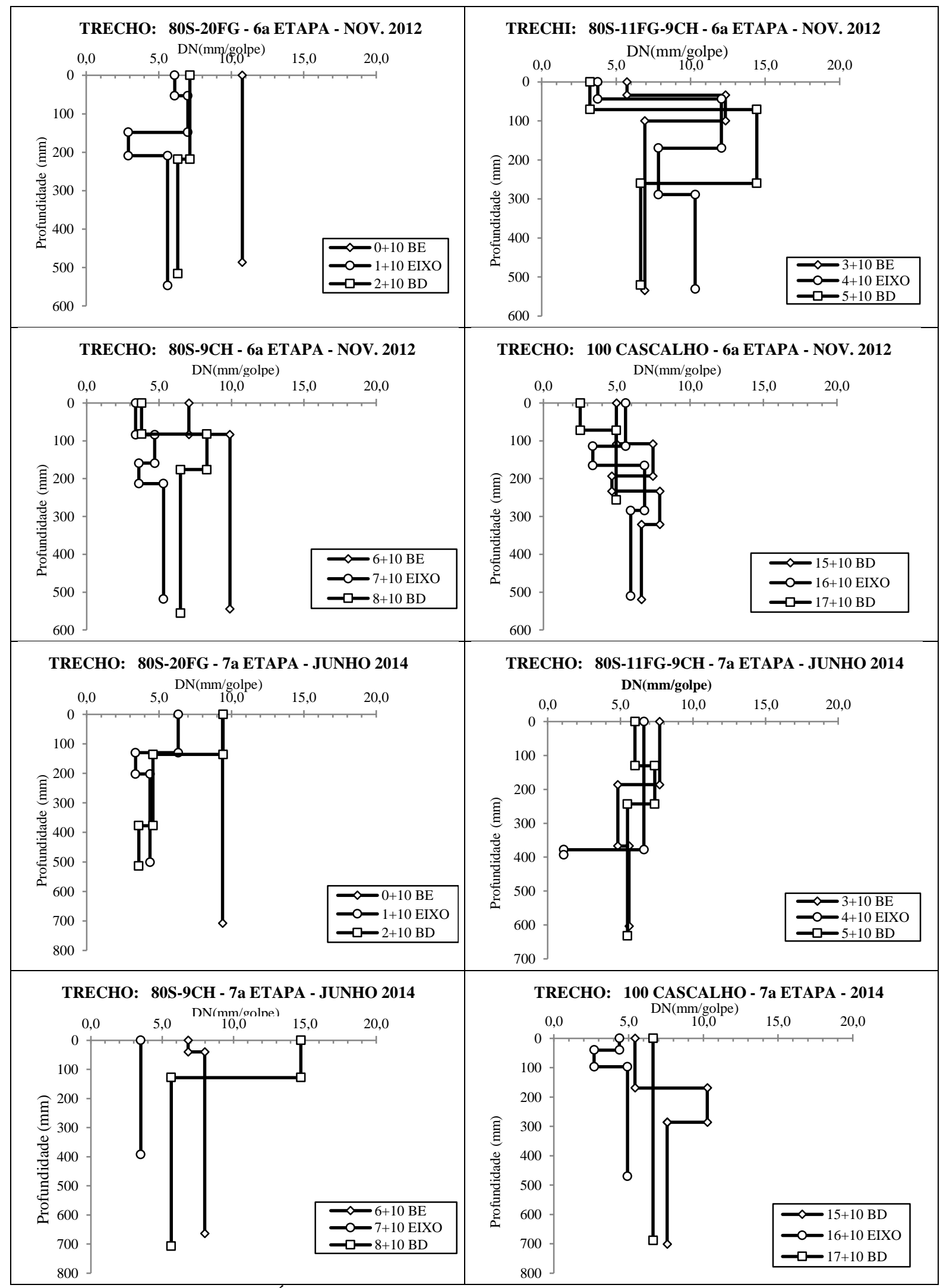

Figura 4.61. Índices de penetração do DCP nos trechos nas $6^{\mathrm{a}}$ e $7^{\mathrm{a}}$ etapas. 
Universidade de Brasília

Departamento de Engenharia Civil / FT

Programa de Pós-Graduação em Geotecnia

Tabela 4.22. Espessuras médias das primeiras camadas e índices de penetração médios correspondentes.

\begin{tabular}{|c|c|c|c|c|c|c|c|c|}
\hline \multirow{2}{*}{ ETAPA } & \multicolumn{2}{|c|}{ 80S-20FG } & \multicolumn{2}{|c|}{ 80S-11FG-9CH } & \multicolumn{2}{|c|}{ 91S-9CH } & \multicolumn{2}{|c|}{100 CASCALHO } \\
\hline & $\begin{array}{c}\text { Esp. Med. } \\
(\mathrm{cm})\end{array}$ & $\begin{array}{c}\text { DNmed. } \\
\text { (mm/golpe) }\end{array}$ & $\begin{array}{c}\text { Esp. Med. } \\
(\mathrm{cm})\end{array}$ & $\begin{array}{c}\text { DNmed. } \\
\text { (mm/golpe) }\end{array}$ & $\begin{array}{c}\text { Esp. Med. } \\
\text { (cm) }\end{array}$ & $\begin{array}{c}\text { DNmed. } \\
\text { (mm/golpe) }\end{array}$ & $\begin{array}{c}\text { Esp. Med. } \\
(\mathrm{cm})\end{array}$ & $\begin{array}{c}\text { DNmed. } \\
\text { (mm/golpe) }\end{array}$ \\
\hline 1a - OUT. 2009 & 12,12 & 12,56 & 9,40 & 4,64 & 11,67 & 3,94 & 13,40 & 2,56 \\
\hline $2 \mathrm{a}-\mathrm{MAIO} 2010$ & 20,88 & 8,14 & 4,33 & 3,04 & 5,47 & 2,88 & 9,33 & 4,63 \\
\hline 4a - JUNHO 2011 & 24,02 & 8,38 & 6,23 & 3,43 & 9,07 & 3,79 & 13,17 & 4,88 \\
\hline 5a - NOV. 2011 & 21,47 & 8,79 & 7,07 & 5,35 & 8,00 & 5,11 & 21,40 & 6,04 \\
\hline 6a - NOV. 2012 & 25,23 & 8,00 & 4,97 & 4,24 & 8,30 & 4,75 & 9,80 & 4,36 \\
\hline 7a - JUNHO 2014 & 32,47 & 8,38 & 23,13 & 6,78 & 18,70 & 5,32 & 29,93 & 5,48 \\
\hline
\end{tabular}

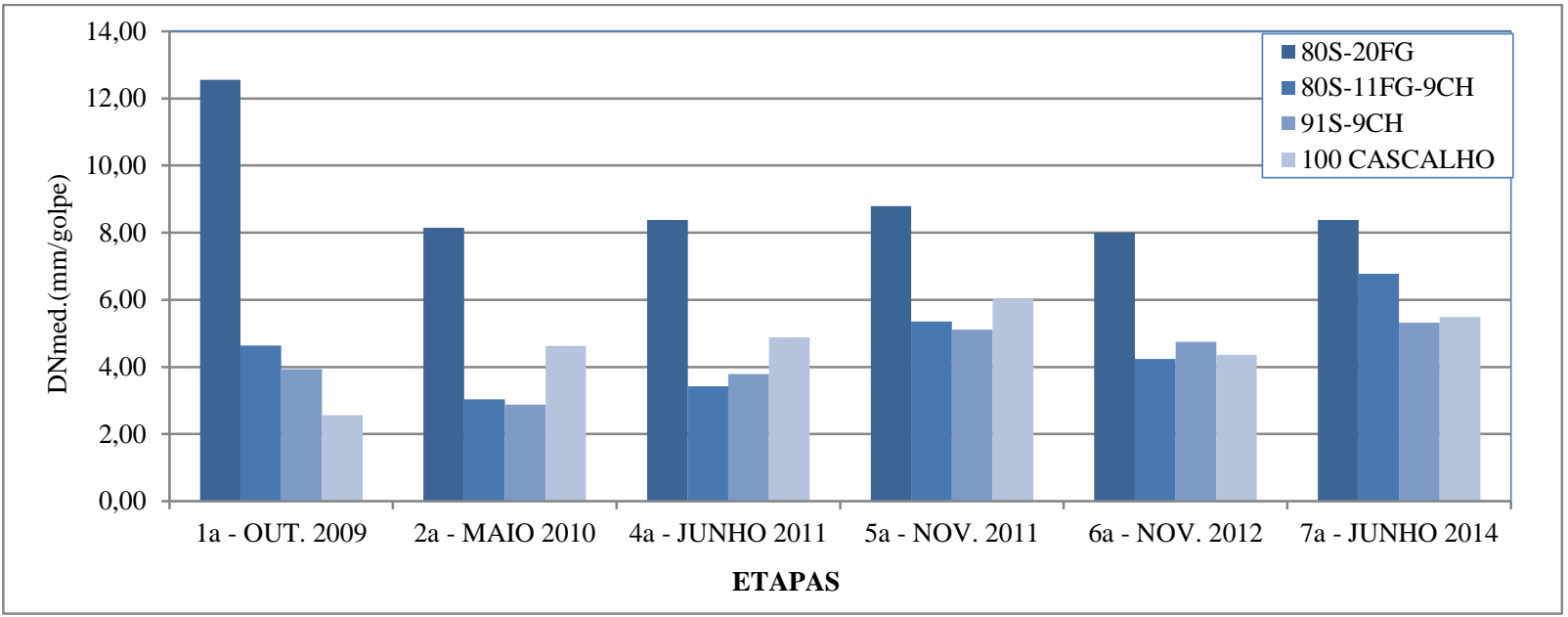

Figura 4.62. Índices de penetração médios dos materiais por etapa.

Com base no que precede, verificou-se um aumento constante da espessura da primeira camada homogênea para os trechos solo+fosfogesso de $12,12 \mathrm{~cm}$ até $32,47 \mathrm{~cm}$. Considerando que a espessura de projeto era de $15 \mathrm{~cm}$, é possível deduzir com o tempo, a camada de base e subleito passaram a apresentar a mesma resistência a penetração do DCP. Para as camadas de solo+fosfogesso+cal e solo+cal a evolução das espessuras das camadas sugere uma consolidação progressiva do próprio material de base até atingir a camada de subleito na última etapa. Para a camada de cascalho, as espessuras homogêneas evoluam de $13,4 \mathrm{~cm}$ no inicio da construção até $29,93 \mathrm{~cm}$ na última etapa sem no entanto apresentar uma sequência lógica nessa evolução. Acredita-se que esse comportamento pode ter sido influenciado pelas presença pedregulhos nessa camada que podem interferir na resistência à penetração do equipamento. Quanto aos índices de penetração, segundo Heyn (1986), é comum observar valores entre 2 e $25 \mathrm{~mm} /$ golpe em camadas de pavimento. Sendo assim, verifica-se que todos os materiais apresentaram resistência dentro dos valores esperados para esses ensaios. Entretanto, nota-se que comparativamente aos demais ensaios, a camada de solo+fosfogesso foi a que apresentou os maiores índices de penetração de DCP em todas as etapas, situando- 
se na faixa de $8 \mathrm{~mm} / g o l p e$. Já para as camadas de solo+fosfogesso+cal, solo+cal e cascalho, verificou-se valores menores e semelhantes em todas as épocas, embora com pequeno aumento desses parâmetros com o tempo.

\subsection{5 - RETROÁNALISE DO PAVIMENTO}

Com base nos dados de deflexão obtidos com os ensaios de viga Benkelman e DCP, foi possível realizar uma retroanálise dos módulos de elasticidade in situ dos materiais estudados. Para tanto, foram consideradas as bacias médias dos trechos durante a última campanha de monitoramento realizada em junho de 2014. Na Tabela 4.23 estão resumidas as deflexões das bacias médias desses trechos.

Tabela 4.23. Resumo das bacias de deslocamentos médias dos trechos na $7^{\mathrm{a}}$ etapa de avaliação-junho/14.

\begin{tabular}{lccccccccc}
\hline Trecho & $\mathbf{D}_{\mathbf{0}}$ & $\mathbf{D}_{\mathbf{2 5}}$ & $\mathbf{D}_{\mathbf{5 0}}$ & $\mathbf{D}_{\mathbf{7 5}}$ & $\mathbf{D}_{\mathbf{1 0 0}}$ & $\mathbf{D}_{\mathbf{1 2 5}}$ & $\mathbf{D}_{\mathbf{1 5 0}}$ & $\mathbf{D}_{\mathbf{1 7 5}}$ & $\mathbf{D}_{\mathbf{2 0 0}}$ \\
\hline 80S+20FG & 63 & 33 & 11 & 5 & 3 & 2 & 1 & 0 & 0 \\
\hline 80S+11FG+9CH & 68 & 41 & 16 & 10 & 6 & 4 & 2 & 1 & 0 \\
\hline $91 \mathrm{~S}+9 \mathrm{CH}$ & 54 & 28 & 15 & 8 & 5 & 3 & 1 & 0 & 0 \\
\hline Cascalho & 60 & 34 & 17 & 11 & 5 & 3 & 2 & 1 & 0 \\
\hline
\end{tabular}

Para realizar esta tarefa, recorreu-se ao programa de retroanálise BAKFAA V.2.0 da Federal Aviation Administration e disponível gratuitamente na internet. Na Figura 4.63 está apresentada a tela inicial desse programa, onde são introduzidos os dados iniciais de retroanálise, como a estrutura do pavimento, os módulos de elasticidade iniciais, as camadas a serem consideradas na retroanálise, o carregamento aplicado no pavimento e seu raio de aplicação, as posições dos sensores e as deflexões de campo. Nos casos em estudo, foi considerada uma camada de revestimento asfáltico de $5 \mathrm{~cm}$ de espessura, por ser o menor valor admissível pelo programa, e de módulo de elasticidade fixo de $3000 \mathrm{MPa}$. Para as camadas de base, foi adotado um módulo de elasticidade inicial de $300 \mathrm{MPa}$. Considerando que nessa etapa as primeiras camadas homogêneas obtidas dos ensaios DCP já apresentam espessuras superiores ao $15 \mathrm{~cm}$ do projeto, essa espessura que foi utilizada. O módulo de elasticidade inicialmente adotado foi de $100 \mathrm{MPa}$ para a camada de subleito. Para essas duas camadas, os valores de módulos de elasticidade são sujeitos a variação durante o processo da retroanálise. 


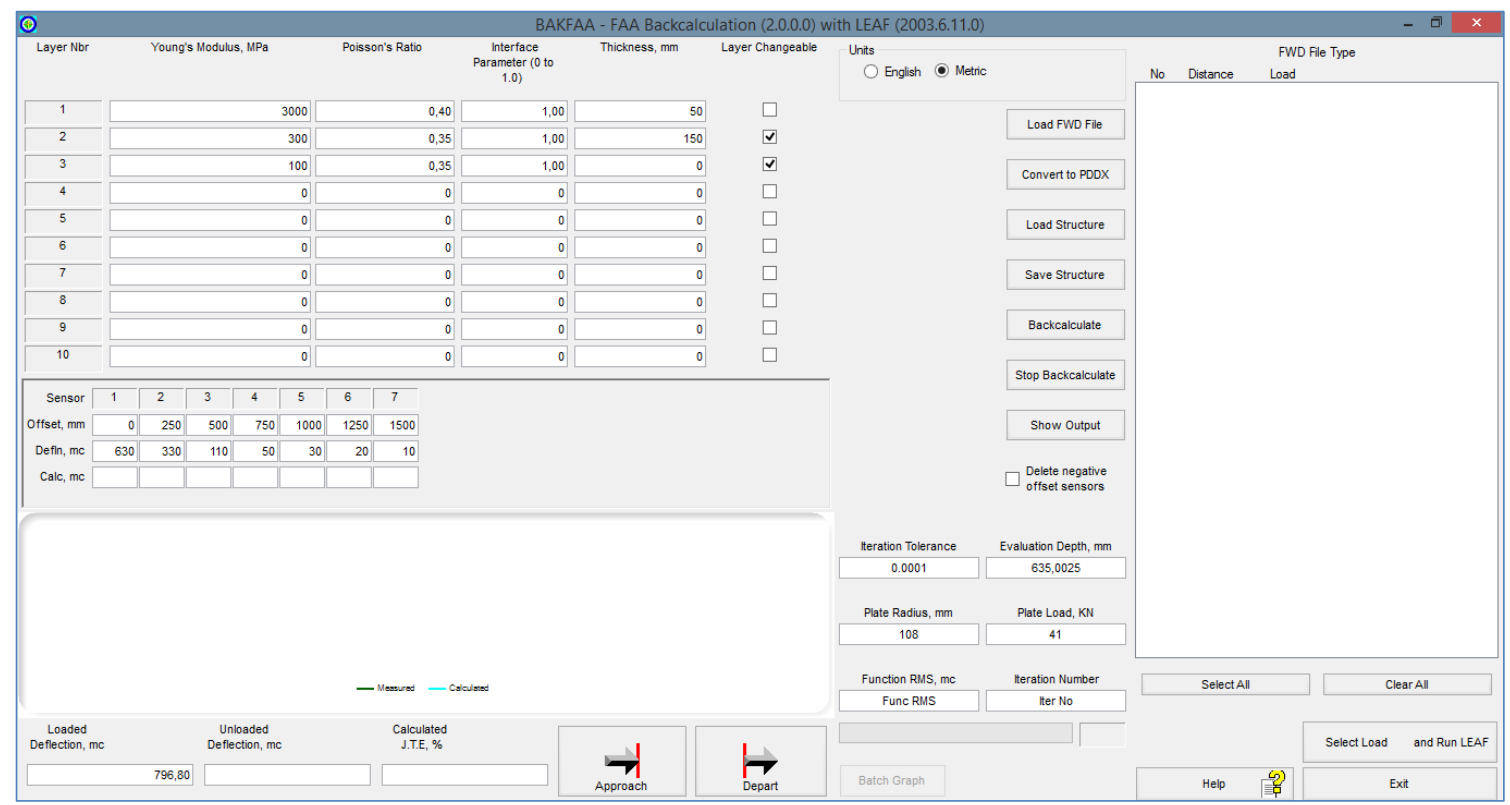

Figura 4.63. Tela de entrada dos dados iniciais para retroanálises no BAKFAA - Caso do trecho 80Solo+20Fosfogesso.

Na Figura 4.64 está apresentada a tela do programa após as iterações de retroanálise. Nesta tela, tem-se os novos módulos de elasticidade, as bacias de deslocamentos calculadas e a raiz do valor quadrático médio - RMS para verificação da acurácia do processo. Na Figura 4.65 estão apresentadas as telas de saídas e na Tabela 4.24 estão resumidos os resultados obtidos da retroanálise dos trechos solo+fosfogesso, solo+fosfogesso+cal, solo+cal e cascalho.

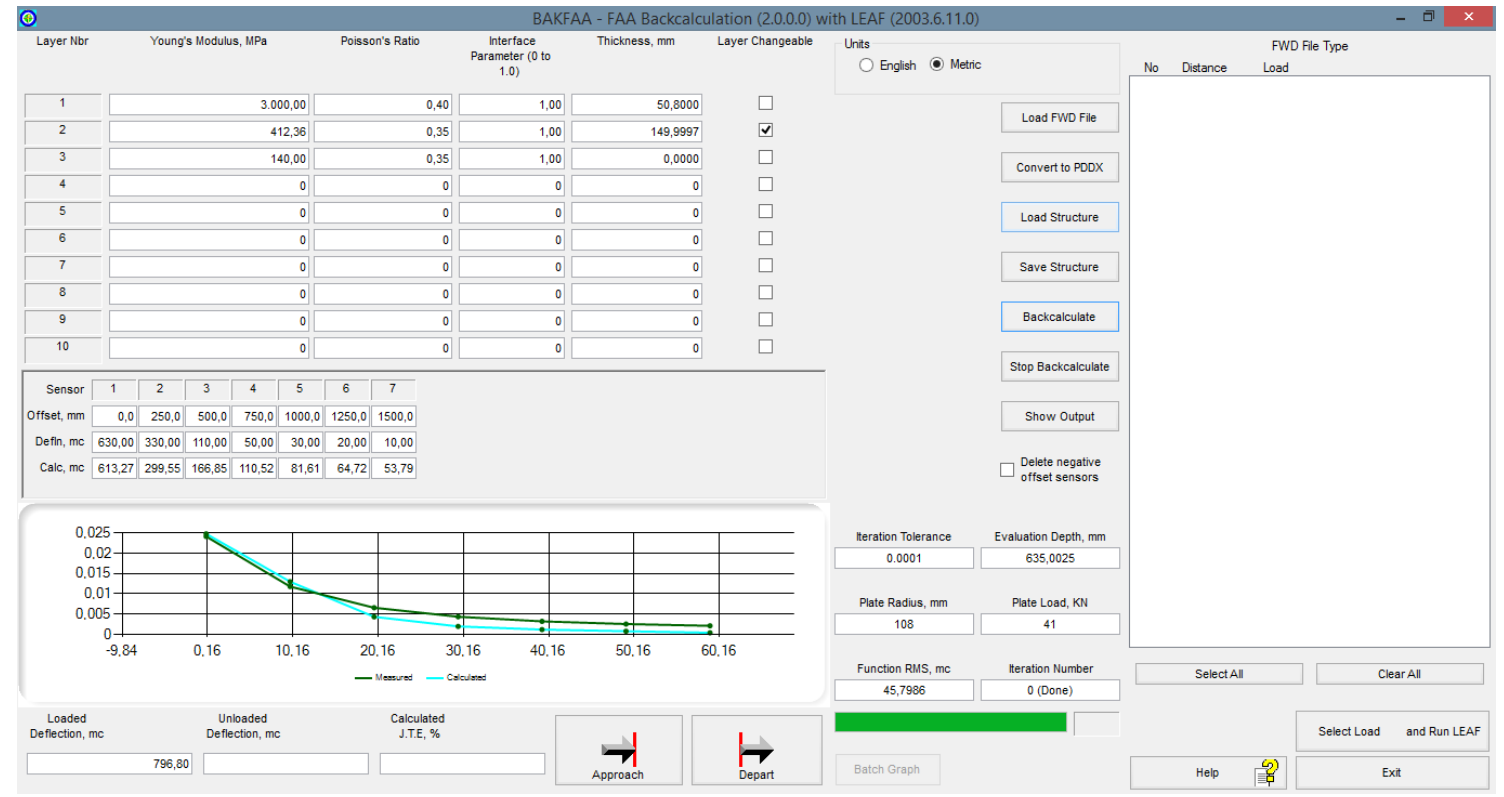

Figura 4.64. Tela do BAKFAA com os resultados da retroanálise - Caso do trecho 80Solo+20Fosfogesso. 

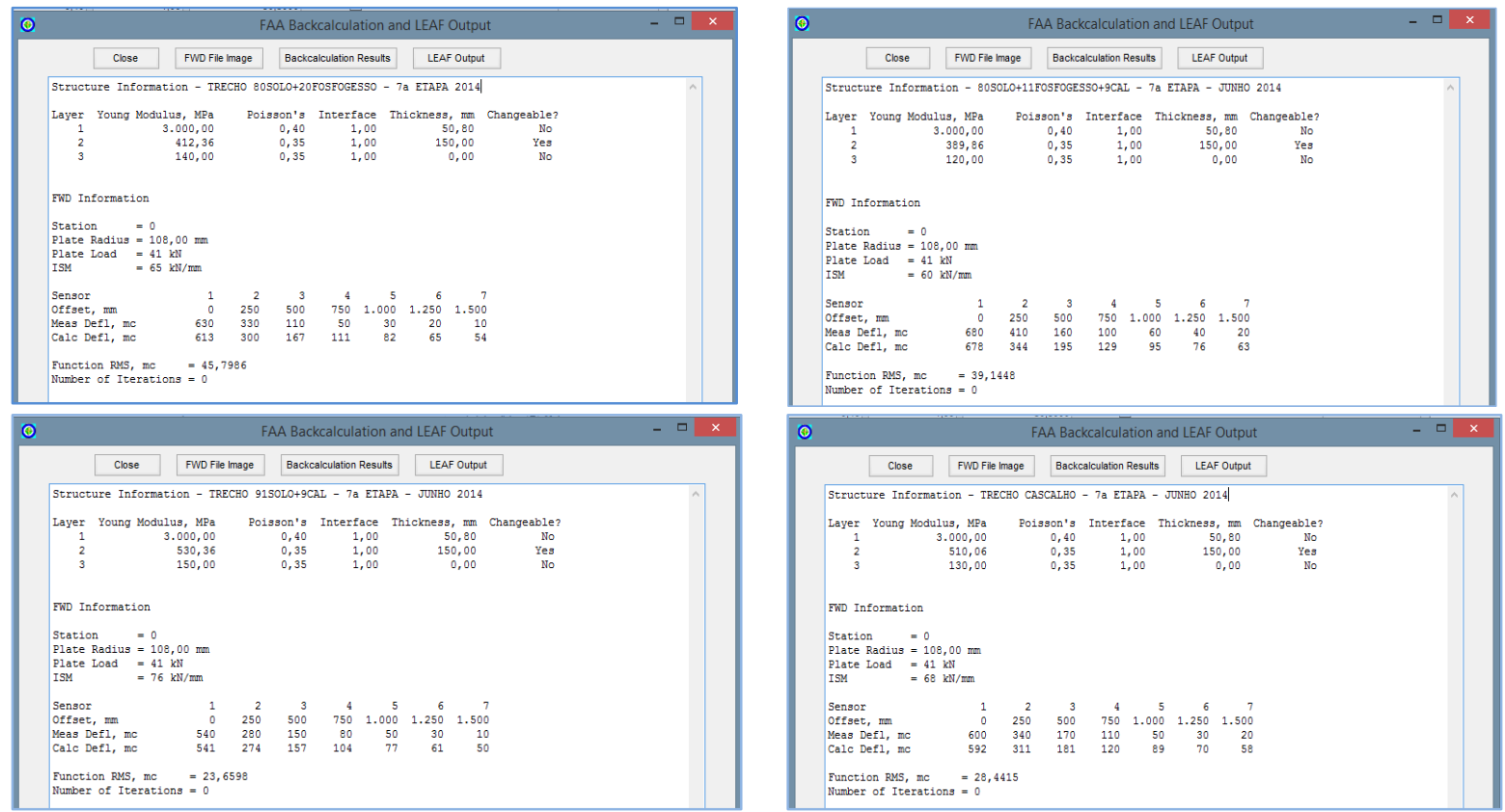

Figura 4.65. Resultados obtidos das retroanálises com o programa BAKFAA para os trechos em estudo.

Tabela 4.24. Módulos retronalisados com o programa BAKFAA para os trechos em estudo.

\begin{tabular}{lccccccc}
\hline \multirow{2}{*}{ Camadas } & \multicolumn{3}{c}{ Dados de entrada } & \multicolumn{3}{c}{ Módulos retroanalisados (MPa) } \\
\cline { 2 - 9 } & E (MPa) & Espessura(cm) & Poisson & Solo+FG & Solo+FG+Cal & Solo+Cal & Cascalho \\
\hline Resvetimento & 3.000 & 5 & 0,40 & - & - & - & - \\
\hline Base & 300 & 15 & 0,35 & $\mathbf{4 1 2}$ & $\mathbf{3 9 0}$ & $\mathbf{5 3 0}$ & $\mathbf{5 1 0}$ \\
\hline Subleito & 100 & 0 & 0,35 & $\mathbf{1 4 0}$ & $\mathbf{1 2 0}$ & $\mathbf{1 5 0}$ & $\mathbf{1 3 0}$ \\
\hline RMS & - & - & - & 45,80 & 39,14 & 23,66 & 28,44 \\
\hline
\end{tabular}

Obs. RMS = Raiz do valor quadrático médio.

A partir dessas retroanálises, observa-se que os módulos de elasticidade do subleito variam entre 120 e 150MPa. Embora ligeiramente acima dos valores de módulos de 100MPa geralmente esperados para o subleito, esses valores são aceitáveis. Para as camadas de base, observou-se também um aumento dos valores de módulos de elasticidade quando comparado com o valor de entrada de 300MPa geralmente aceito para as camadas de base. Na ordem crescente dos módulos obtidos, tem-se a camada de solo+fosfogesso+cal com 390MPa, solo+fosfogesso com 412MPa, cascalho com 510MPa e finalmente, a camada de solo+cal com 530MPa. Verifique-se que esses valores são compatíveis com aqueles encontrados em laboratório para as misturas GII-4 (78\%solo+20\%fosfogesso+2\%cal) e GII-10 $(76 \%$ solo+20\%fosfogesso+4\%cal) e cujos valores eram de $366 \mathrm{MPa}$ e $678 \mathrm{MPa}$ respetivamente. As raízes dos valores quadráticos - RMS são relativamente baixos, sendo todos inferiores a 50, caracterizando uma boa acurácia das retroanálises. 


\subsection{6 - AVALIAÇÃO FUNCIONAL DO PAVIMENTO}

Os resultados do levantamento de defeitos de superfície do pavimento realizado na campanha de ensaios de junho de 2014 estão apresentados nas Tabelas 4.25 e 4.26. Nessas tabelas, ainda é possível acompanhar o cálculo dos índices de gravidade global - IGG de cada trecho. Embora perceptíveis em campo, as profundidades dos afundamentos das trilhas de rodas não foram consideradas nos cálculos pois, por falta do tripé padronizado em campo, não foi possível medir esses parâmetros da forma recomendada pela norma. A partir das informações coletadas, verificou-se que na época do levantamento, os trechos $80 \%$ solo+ $20 \%$ fosfogesso e $80 \%$ solo $+11 \%$ fosfogesso+9\%cal apresentavam um elevado índice de gravidade global, nos dois casos superiores a 80 e inferior a 180. De acordo com a norma DNIT 06/2003-PRO (DNIT, 2003) esses trechos poderiam então ser classificados como ruim do ponto de vista funcional. Ressalta-se no entanto que esses resultados são em grande parte devidos à presença de vários remendos nesses trechos, particularmente nos bordos do pavimento e, aos afundamentos plásticos oriundos das trocas de materiais durante as atividades de instalações de sistema público de esgoto sanitário. Para o mesmo período, os trechos com 91\%solo+9\%cal e com cascalho apresentaram um estado de superfície bom ou regular em decorrência em grande parte, de uma menor ocorrência dessas atividades. 
Universidade de Brasília

Departamento de Engenharia Civil / FT

Programa de Pós-Graduação em Geotecnia

Tabela 4.25 Levantamento do estado de superfície e cálculo dos índices de gravidade global pelas normas DNIT-005/2003-TER e DNIT 006/2003-PRO nos trechos solo+fosfogesso e solo+fosfogesso+cal.

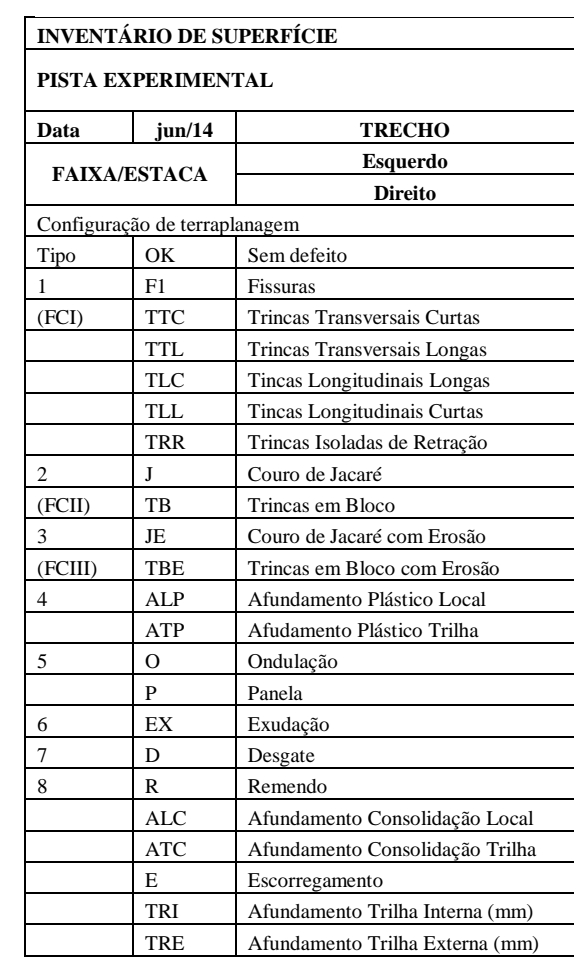

Faixa de levantamento dos defeitos.

\begin{tabular}{|c|c|c|c|c|}
\hline $0+00$ & & $0+10$ & & $1+00$ \\
\hline & $0+05$ & & $0+15$ & \\
\hline & A & & & A \\
\hline & & & & \\
\hline & $X$ & & & $\mathrm{X}$ \\
\hline & & & & \\
\hline & $X$ & & & $\mathrm{X}$ \\
\hline & $x$ & & & \\
\hline & & & & \\
\hline & & & & \\
\hline & & & & $X$ \\
\hline & & & & \\
\hline & & & & \\
\hline & & & & \\
\hline & & & & $x$ \\
\hline & & & & \\
\hline & & & & \\
\hline & 0 & & & 0 \\
\hline & 0 & & & 0 \\
\hline
\end{tabular}

\section{(2)}

\begin{tabular}{|c|l|}
\hline TIPO & Natureza do defeito \\
\hline 1 & (FCI) F, TTC, TTL, TLC, TLL,TER \\
\hline 2 & (FCII) J,TB \\
\hline 3 & (FCII) JE, TBE \\
\hline 4 & ALP, ATP \\
\hline 5 & $\mathrm{O}, \mathrm{P}, \mathrm{E}$ \\
\hline 6 & $\mathrm{Ex}$ \\
\hline 7 & $\mathrm{D}$ \\
\hline 8 & $\mathrm{R}$ \\
\hline 9 & $\mathrm{~F}=(\mathrm{TRI}+\mathrm{TRE}) / 2 \mathrm{em} \mathrm{mm}$ \\
\hline 10 & $\mathrm{FV}=($ TRIv+TREv)/2 \\
\hline \multicolumn{2}{|l}{ Número de estações inventoríadas } \\
\hline Ím
\end{tabular}

\begin{tabular}{|c|c|}
\hline Frequência Abs. \\
4 \\
1 \\
\hline 0 \\
\hline 0 \\
\hline 0 \\
\hline 0 \\
3 \\
0 \\
\hline 0 \\
\hline 4 \\
\hline $\mathbf{1 2 2 5}$
\end{tabular}

\begin{tabular}{|c|c|c}
\hline Frequência Rel. & \\
\hline $100 \%$ & \\
\hline $25 \%$ & \\
\hline $0 \%$ & \\
\hline $50 \%$ & \\
$0 \%$ & \\
\hline $0 \%$ & \\
\hline $0 \%$ & \\
$75 \%$ & \\
\hline 0 & \\
\hline IGI=(Fx4/3) quando $\mathrm{F} \leq 30$ \\
\hline
\end{tabular}

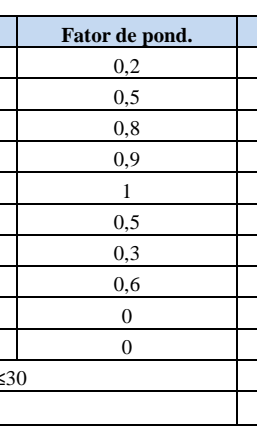

\begin{tabular}{|c|c|}
\hline Índice de Gravidade Ind. & | \\
\hline 20,0 \\
\hline 12,5 \\
\hline 0,0 \\
\hline 45,0 \\
\hline 0,0 \\
\hline 0,0 \\
\hline 0,0 \\
\hline 45,0 \\
\hline 0 \\
\hline 0 \\
\hline IGI=FV quando F $\leq 50$ \\
\hline IGE \\
\hline
\end{tabular}

IGII=50 quando $\mathrm{F}>50$

\begin{tabular}{|c|c|c|}
\hline $3+00$ & & $3+10$ \\
\hline & $3+05$ & \\
\hline & A & \\
\hline & & \\
\hline & & \\
\hline & & \\
\hline & & \\
\hline & & \\
\hline & & \\
\hline & & \\
\hline & $x$ & \\
\hline & & \\
\hline & & \\
\hline & & \\
\hline & $\mathrm{X}$ & \\
\hline & & \\
\hline & & \\
\hline & 0 & \\
\hline
\end{tabular}

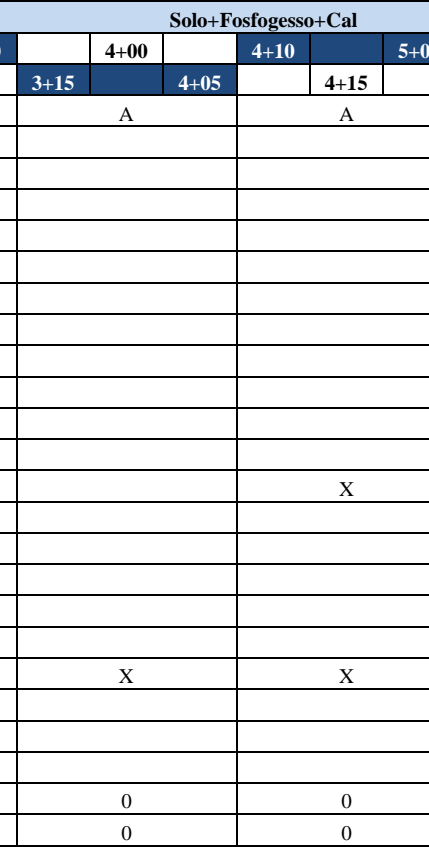

\begin{tabular}{|c|}
\hline \\
\hline \\
\hline \\
\hline \\
\hline \\
\hline \\
\hline \\
\hline \\
\hline \\
\hline \\
\hline \\
\hline \\
\hline \\
\hline \\
\hline \\
\hline \\
\hline
\end{tabular}

Î́ndice de Gravidade Global IGG

IGI $=40$ quando $F>30$

\begin{tabular}{|c|c|}
\hline Frequência Abs. & \\
\hline 1 \\
0 \\
0 \\
\hline 3 \\
0 \\
\hline 0 & \\
\hline 0 & \\
\hline 4 & \\
\hline 0 & \\
\hline 0 & \\
\hline 4 & \\
$\mathbf{1 3 2 , 5}$ & \\
\end{tabular}

\begin{tabular}{|c|c|}
\hline Frequência Rel. & Fator de pond. \\
\hline $25 \%$ & 0,2 \\
\hline $0 \%$ & 0,5 \\
\hline $0 \%$ & 0,8 \\
\hline $75 \%$ & 0,9 \\
\hline $0 \%$ & 1 \\
\hline $0 \%$ & 0,5 \\
\hline $0 \%$ & 0,3 \\
\hline $100 \%$ & 0,6 \\
\hline 0 & 0 \\
\hline 0 & 0 \\
\hline \multicolumn{2}{|c|}{ uando $F \leq 30$} \\
\hline
\end{tabular}

Índice de Gravidade Ind. 
Universidade de Brasília

Departamento de Engenharia Civil / FT

Programa de Pós-Graduação em Geotecnia

Tabela 4.26 Levantamento do estado de superfície e cálculo dos índices de gravidade global pelas normas DNIT-005/2003-TER e DNIT 006/2003-PRO nos trechos solo+cal e cascalho.

\begin{tabular}{|l|}
\hline INVENTÁRIO DE SUPERFÍCIE \\
\hline PISTA EXPERIMENTAL
\end{tabular}

\begin{tabular}{|c|c|c|c|c|c|c|c|c|c|c|c|c|c|c|c|c|c|c|c|c|c|c|c|c|c|}
\hline \multirow{3}{*}{\multicolumn{2}{|c|}{\begin{tabular}{l|l} 
Data & jun/14 \\
FAIXA/ESTACA
\end{tabular}}} & TRECHO & \multicolumn{12}{|c|}{ Solo+Cal } & \multicolumn{11}{|c|}{ Cascalho } \\
\hline & & Esquerdo & $6+00$ & & $6+10$ & & $7+00$ & & $7+10$ & & $8+00$ & & $8+10$ & & $15+00$ & & $15+10$ & & $16+00$ & & $16+10$ & & $17+00$ & & $17+10$ \\
\hline & & Direito & & $6+05$ & & $6+15$ & & $7+05$ & & $7+15$ & & $8+05$ & & $8+15$ & & $15+05$ & & $15+15$ & & $16+05$ & & $16+15$ & & $17+05$ & $17+15$ \\
\hline \multicolumn{3}{|c|}{ Configuração de terraplanagem } & \multicolumn{3}{|c|}{ A } & \multicolumn{3}{|c|}{ A } & \multicolumn{3}{|c|}{ A } & \multicolumn{3}{|c|}{$\mathrm{A}$} & \multirow{2}{*}{\multicolumn{3}{|c|}{$\mathrm{A}$}} & \multirow{2}{*}{\multicolumn{3}{|c|}{ A }} & \multicolumn{3}{|c|}{ A } & \multirow{2}{*}{\multicolumn{2}{|c|}{ A }} \\
\hline \begin{tabular}{|l|l|} 
Tipo \\
\end{tabular} & $\mathrm{OK}$ & Sem defeito & & & & & $\mathrm{x}$ & & & $\mathrm{x}$ & & & & & & & & & & & & & & & \\
\hline \begin{tabular}{|c|c|c|c|}
1 \\
\end{tabular} & F1 & \begin{tabular}{|l|} 
Fissuras \\
\end{tabular} & & & & & & & & & & & & & & & & & & & & & & & \\
\hline \multirow[t]{5}{*}{ (FCI) } & TTC & \begin{tabular}{|l|} 
Trincas Transversais Curtas \\
\end{tabular} & & & & & & & & & & & & & & & & & & & & & & & \\
\hline & TTL & Trincas Transversais Longas & & & & & & & & & & & & & & & & & & & & & & & \\
\hline & TLC & \begin{tabular}{|l|} 
Tincas Longitudinais Longas \\
\end{tabular} & & $\mathrm{x}$ & & & & & & & & & & & & & & & $\mathrm{x}$ & & & $\mathrm{x}$ & & & \\
\hline & TLL & \begin{tabular}{|l|} 
Tincas Longitudinais Curtas \\
\end{tabular} & & & & & & & & & & & & & & & & & & & & & & & \\
\hline & TRR & Trincas Isoladas de Retração & & & & & & & & & & & & & & & & & & & & & & & \\
\hline 2 & $\mathrm{~J}$ & Couro de Jacaré & & & & & & & & & & & & & & & & & & & & & & & \\
\hline (FCII) & $\mathrm{TB}$ & Trincas em Bloco & & & & & & & & & & & & & & & & & & & & & & & \\
\hline 3 & $\mathrm{JE}$ & Couro de Jacaré com Erosão & & & & & & & & & & & & & & & & & & & & & & & \\
\hline \begin{tabular}{|l} 
(FCIII) \\
\end{tabular} & TBE & Trincas em Bloco com Erosão & & & & & & & & & & & & & & & & & & & & & & & \\
\hline \multirow[t]{2}{*}{4} & ALP & Afundamento Plástico Local & & & & & & & & & & & & & & & & & & & & & & & \\
\hline & ATP & Afudamento Plástico Trilha & & $\mathrm{x}$ & & & & & & & & & & & & & & & & & & & & & \\
\hline \multirow[t]{2}{*}{5} & $\mathrm{O}$ & Ondulação & & & & & & & & & & & & & & & & & & & & & & & \\
\hline & $P$ & Panela & & & & & & & & & & & & & & & & & & & & & & & \\
\hline 6 & EX & Exudação & & & & & & & & & & & & & & & & & & & & & & & \\
\hline 7 & D & Desgate & & & & & & & & & & & & & & & & & & & & & & & \\
\hline \multirow[t]{6}{*}{8} & $\mathrm{R}$ & Remendo & & $\mathrm{x}$ & & & & & & & & & & & & $\mathrm{x}$ & & & $\mathrm{x}$ & & & $\mathrm{x}$ & & & $\mathrm{x}$ \\
\hline & ALC & \begin{tabular}{|l} 
Afundamento Consolidação Local \\
\end{tabular} & & & & & & & & & & & & & & & & & & & & & & & \\
\hline & ATC & Afundamento Consolidação Trilha & & & & & & & & & & & & & & $\mathrm{x}$ & & & & & & & & & \\
\hline & $\mathrm{E}$ & \begin{tabular}{|l|} 
Escorregamento \\
\end{tabular} & & & & & & & & & & & & & & & & & & & & & & & \\
\hline & TRI & Afundamento Trilha Interna $(\mathrm{mm})$ & & 0 & & & 0 & & & 0 & & & 0 & & & 0 & & & 0 & & & 0 & & & 0 \\
\hline & TRE & Afundamento Trilha Externa (mm) & & 0 & & & 0 & & & 0 & & & 0 & & & 0 & & & 0 & & & 0 & & & 0 \\
\hline
\end{tabular}

\begin{tabular}{|c|c|c|c|c|c|c|c|c|c|}
\hline TIPO & Natureza do defeito & Frequência Abs. & Frequência Rel. & Fator de pond. & Índice de Gravidade Ind. & Frequência Abs. & Frequência Rel. & Fator de pond. & Índice de Gravidade Ind. \\
\hline 1 & (FCI) F, TTC, TTL, TLC, TLL,TER & 1 & $25 \%$ & 0,2 & 5,0 & 2 & $50 \%$ & 0,2 & 10,0 \\
\hline 2 & (FCII) J,TB & 0 & $0 \%$ & 0,5 & 0,0 & 0 & $0 \%$ & 0,5 & 0,0 \\
\hline 3 & (FCII) JE, TBE & 0 & $0 \%$ & 0,8 & 0,0 & 0 & $0 \%$ & 0,8 & 0,0 \\
\hline 4 & ALP, ATP & 1 & $25 \%$ & 0,9 & 22,5 & 0 & $0 \%$ & 0,9 & 0,0 \\
\hline 5 & $\mathrm{O}, \mathrm{P}, \mathrm{E}$ & 0 & $0 \%$ & 1 & 0,0 & 0 & $0 \%$ & 1 & 0,0 \\
\hline 6 & Ex & 0 & $0 \%$ & 0,5 & 0,0 & 0 & $0 \%$ & 0,5 & 0,0 \\
\hline 7 & $\mathrm{D}$ & 0 & $0 \%$ & 0,3 & 0,0 & 0 & $0 \%$ & 0,3 & 0,0 \\
\hline 8 & $\mathrm{R}$ & 1 & $25 \%$ & 0,6 & 15,0 & 4 & $100 \%$ & 0,6 & 60,0 \\
\hline 9 & $\mathrm{~F}=(\mathrm{TRI}+\mathrm{TRE}) / 2 \mathrm{em} \mathrm{mm}$ & 0 & 0 & 0 & 0 & 8 & 0 & 4 & 3 \\
\hline 10 & $\mathrm{FV}=(\mathrm{TRIV}+\mathrm{TREv}) / 2$ & 0 & 0 & 0 & 0 & 16 & 0 & 8 & 8 \\
\hline \multicolumn{2}{|c|}{ Número de estações inventoríadas } & 4 & \multicolumn{2}{|c|}{$\mathrm{IGI}=(\mathrm{Fx} 4 / 3)$ quando $\mathrm{F} \leq 30$} & IGI=FV quando $\mathrm{F} \leq 50$ & 4 & \multicolumn{2}{|l|}{$\mathrm{IGI}=(\mathrm{Fx} 4 / 3)$ quando $\mathrm{F} \leq 30$} & IGI=FV quando $\mathrm{F} \leq 50$ \\
\hline \multicolumn{2}{|c|}{ Îndice de Gravidade Global IGG } & 42,5 & $\mathrm{IGI}=40$ quando $\mathrm{F}>30$ & & $\mathrm{IGI}=50$ quando $\mathrm{F}>50$ & 70,0 & IGI $=40$ quando $F>30$ & & IGI $=50$ quando $\mathrm{F}>50$ \\
\hline
\end{tabular}




\section{5 - CONSIDERAÇÕES FINAIS}

Neste capítulo estão apresentados as principais conclusões sobre os estudos de laboratório e de campo de misturas de solos tropical, fosfogesso e cal desenvolvidos nesta tese. Por fim, são propostas novas perspectivas para o estudo e a utilização do fosfogesso em pesquisas e projetos futuros.

\section{1 - CONCLUSÕES}

\subsection{1 - ENSAIOS DE LABORATÓRIO}

Com os resultados obtidos a partir dos ensaios de laboratório verificou-se que:

- O solo utilizado e proveniente da cidade de Catalão apresenta o comportamento típico de um solo tropical, tendo suas concreções desfeitas pela ação do defloculante hexametafosfato de sódio.

- Sem uso de defloculante nem de ultrassom nos ensaios granulométricos a laser, tanto o solo como o fosfogesso apresentaram uma predominância da fração arenosa.

- Com o aumento do teor de fosfogesso há diminuição da fração de areia média e aumento da fração silte nas misturas.

- Em função dos valores de coeficientes de uniformidade e coeficiente de curvatura, todos os materiais analisados apresentam uma boa graduação.

- Tanto o solo como as misturas apresentaram valores de limites de liquidez médios. Entretanto, esse parâmetro aumenta significativamente com a adição do fosfogesso, enquanto com a adição da cal não se observa variação marcante. Essa tendência se reflete nos índices de plasticidade das misturas.

- No que diz respeito a classificação TRB, existe pouca variação dentre dos subgrupos, as amostras pertencem ao grupo A-2 correspondendo aos solos arenosos siltosos. Nesse grupo se encaixa também o fosfogesso. Nota-se, entretanto, predominância do grupo A-24. 
- De acordo com o SUCS, todos os materiais são classificados no grupo CL das argilas inorgânicas de baixa a média plasticidade ou argilas pedregulhosas, arenosas e siltosas. $\mathrm{O}$ fosfogesso por sua vez é classificado como areia fina siltosa (ML) nesse sistema devido particularmente a sua não plasticidade.

- De acordo com a metodologia MCT, o solo estudado apresenta um comportamento tecnológico de solos lateríticos arenosos (LA').

- A cal apresentou a menor massa específica dos grãos. Sendo assim, observou-se uma diminuição dos valores desse parâmetro para as misturas, à medida que aumentava-se a quantidade de cal.

- O aumento do teor de fosfogesso gera aumento da umidade ótima e diminuição do peso específico seco aparente máximo.

- Existe um ponto de equilíbrio dos valores das umidades ótimas e massas específicas aparentes secas na mistura com $6 \%$ de cal e $15 \%$ de fosfogesso, o que poderia indicar uma mistura de comportamento tecnológico estável ou ótimo.

- O aumento do teor de fosfogesso aumenta os valores de mini-CBR com imersão em relação aos valores obtidos para o solo puro. A presença do fosfogesso nas misturas com o solo melhora também perda de suporte mini-CBR por imersão (PSI).

- A cura de 7 dias dos materiais proporcionou ganhos de resistência.

- Pelo critério de resistência indicado pela metodologia MCT, o uso de todas as misturas pode ser considerado adequado em camadas de pavimentos de baixos custos.

- Para as misturas com até $20 \%$ de fosfogesso e $6 \%$ de cal, a expansão das misturas diminui significativamente com 7 dias de cura, permitindo sua utilização bastante segura em campo quando o pavimento for executado em estação seca. Essa redução não é verificada para misturas com teores maiores.

- A adição da cal aumenta significativamente o $\mathrm{pH}$ das misturas. Com o fosfogesso, as variações desse parâmetro são insignificativas. Isso sugere que a cal tem uma maior contribuição nas reações de troca catiônica nas misturas do que o fosfogesso e consequentemente maior contribuição no aumento de resistência.

- Os ensaios de difratometria de raio-x realizados sobre as misturas mostraram que a formação da etringita ocorre efetivamente nas misturas com teores de fosfogesso e cal acima de $20 \%$ e $6 \%$, respetivamente. Isto corrobora as observações realizadas com os ensaios de expansão. 
- A adição de $20 \%$ de fosfogesso gera uma variação pouco significativa na resistência à compressão do solo. Como esperado também, não se verificou ganho significativo de resistência com o tempo de cura para as misturas com fosfogesso e sem cal. Isso mostra que o fosfogesso por si só não desenvolve reações pozolânicas importantes quando misturado com solo.

- Observa-se um constante ganho de resistência à compressão simples com a adição da cal e o aumento do tempo de cura, superando o valor de $1200 \mathrm{kPa}$ requerido para solos melhorados com cimento.

- As simulações realizadas com os módulos de resiliência obtidos dos ensaios apresentaram deflexões elásticas e deformações verticais no topo do subleito satisfatórias para um pavimento de baixo custo, com destaque para as misturas GII-4 (78\%solo+20\%fosfogesso+2\%cal) e GII-10 (76\%solo+20\%fosfogesso+4\%cal), cujos valores de módulos de resiliência no estado de tensões considerado foram de $366 \mathrm{MPa}$ e $678 \mathrm{MPa}$ respetivamente.

\subsection{2 - ENSAIOS DE CAMPO}

Com os resultados obtidos das sete baterias de ensaios de campo, verificou-se que:

- Todos os trechos analisados apresentaram deslocamentos máximos médios semelhantes e satisfatórios em todas as etapas de avaliação com a viga Benkelman.

- O bom desempenho dos trechos foi confirmando pela metodologia DNER - PRO 11/79 que considera as deflexões de projeto e os raios de curvatura do pavimento.

- Com exceção do trecho solo+fosfogesso na primeira etapa de avaliação, todas as médias dos deslocamentos máximos obtidos a partir dos ensaios de campo apresentaram valores inferiores a 2,5mm, valor este considerado limite aceitável de deformação para um pavimento de baixo volume de tráfego. No entanto, conforme ressalva Metogo (2010), esse valor elevado de deformação pode ser atribuído às dificuldades encontradas durante a execução desse trecho em estação chuvosa. Nas campanhas seguintes, esses valores se mantêm relativamente baixos, variando entre 1,00 a 2,00mm.

- Em todas etapas de avaliação, a recuperação elástica do pavimento dificilmente excede os $60 \%$ em relação a deformação total a qual está sujeito durante o ensaio. Deduz-se que os ensaios de prova de carga sobre pavimento mobilizam uma parcela importante da parcela 
plástica dos materiais em campo. Sendo assim, alguns cuidados devem ser tomados quando a isto pois as deformações permanentes mobilizados podem ser a origem de futuros defeitos de pavimento, entre os quais, as panelas.

- O trecho solo+fosfogesso apresenta os menores valores de módulos de reação na primeira etapa. Esse quadro no entanto melhorou com o tempo, aproximando-se dos valores obtidos com os outros trechos. Os maiores valores de módulos de reação são obtidos nos trechos solo+cal e solo+fosfogesso+cal.

- Todos os materiais apresentaram índices de penetração do DCP dentro dos valores esperados para um pavimento. No entanto, a camada de solo+fosfogesso apresentou os maiores índices em todas as etapas, situando-se na faixa de $8 \mathrm{~mm} / g o l p e$. Já para as camadas de solo+fosfogesso+cal, solo+cal e cascalho, verificou-se índices menores e semelhantes em todas os períodos, embora com pequeno aumento com o tempo.

- As retroanálises realizadas com o programa BAKFAA situaram os valores de módulos de elasticidade do subleito entre 120 e 150MPa. Embora ligeiramente acima dos valores de módulos de 100MPa geralmente esperados para o subleito, esses valores são aceitáveis.

- Para as camadas de base, observou-se valores de módulos de elasticidade quando comparado com o valor de entrada de $300 \mathrm{MPa}$ geralmente aceito para as camadas de base. Na ordem crescente, tem-se a camada de solo+fosfogesso+cal com 390MPa, solo+fosfogesso com 412MPa, cascalho com 510MPa e finalmente, a camada de solo+cal com 530MPa. Isso mostram de forma geral, bom comportamento elástico de todos os materiais.

- Seis anos após a abertura ao tráfego, já são perceptíveis algumas degradações no pavimento, indiferentemente dos trechos. Estas são não só inerentes aos processos próprios de degradação do pavimento, como também são resultados de diversas intervenções humanas sobre esse pavimento. Sendo assim recomenda-se que um melhor acompanhamento das degradações desse trecho pelas autoridades do município de Aparecida de Goiânia.

Deste estudo, é possível concluir que a utilização do fosfogesso em pavimento de baixo custo é viável desde que misturado com o solo até $20 \%$. Acima desse valor, já se verifica queda nas resistências além de dificuldade de manuseio. Quando adiciona-se teor de cal com até $8 \%$, verifica-se um ganho constante de resistência. No entanto, com esse tipo de mistura, deve-se redobrar os cuidados em função da possibilidade de formação da etringita tendo em vista que 
pode provocar expansões indesejáveis. Para limitar a formação desse mineral, recomenda-se que misturas de solo, fosfogesso e cal não ultrapassem teores de fosfogesso e cal de 20 e $6 \%$ respectivamente e que, uma vez aplicado em campo, esses materiais não estejam sujeitos a intensa molhagem por aproximadamente uma semana, tempo necessário para a efetivação da cura. Em campo, todos os materiais apresentaram comportamentos estruturais semelhantes e satisfatórios podendo substituir o cascalho laterítico em pavimentação de vias vicinais. No entanto, maior atenção deve-se tomar com a mistura solo+fosfogesso, sobretudo durante a construção pelo fato desse material reter bastante água, fato que pode prejudicar seu desempenho durante sua vida de serviço.

\section{2 - SUGESTÕES PARA PESQUISAS FUTURAS}

Para pesquisas futuras, sugere-se que:

- Estudos semelhantes sejam realizados com o fosfogesso do tipo hemi-hidratado e anidro.

- Sejam testados outros estabilizantes como o cimento.

- Verifica-se a possibilidade de utilizar o fosfogesso como fíler em misturas asfálticas.

- Verificar a viabilidade do uso do fosfogesso em obras de aterro. 


\section{REFERÊNCIAS BIBLIOGRÁFICAS}

AASHTO (2003): American Association of State Highway and Transportation Officials, T 307-99: Determining the Resilient Modulus of Soils and Aggregate Materials, standard Method of Test. Washington DC. 46p.

Abitrante, E.;Trichês, G. \& Striani, C.S. (2009).Controle de compactação de solos com uso do DCP. Ed. Universidade Federal de Santa Catarina, Florianópolis. 91p.

ABNT (1983): Associação Brasileira de Normas Técnicas, NBR 7170: Tijolo maciço cerâmico para alvenaria. Rio de Janeiro. 4p.

ABNT (1984): Associação Brasileira de Normas Técnicas. NBR 6459: Solo - Determinação do limite de liquidez. Rio de Janeiro. 6p.

ABNT (1984): Associação Brasileira de Normas Técnicas. NBR 7180: Solo - Determinação do limite de plasticidade. Rio de Janeiro. 3p.

ABNT (1984): Associação Brasileira de Normas Técnicas. NBR 7181: Solo - Análise granulométrica. Rio de Janeiro. 13p.

ABNT (1992): Associação Brasileira de Normas Técnicas, NBR 12770: Solo coesivo Determinação da resistência à compressão não confinada. Rio de Janeiro. 4p.

ABNT (2004): Associação Brasileira de Normas Técnicas. NBR 10004: Resíduos sólidos Classificação. Rio de Janeiro. 71p.

ABNT (2004): Associação Brasileira De Normas Técnicas. NBR 10005: Procedimento para obtenção de extrato lixiviação de resíduos. Rio de Janeiro. 16p.

Afès, M.\& Didier, G. (2000) Stabilisation des sols gonflants : cas d'une argile en provenance de Mila. Bul Eng Geol Env, Algérie,v59, p 75 - 83.

Afifi, E. E.M., Hilal, M.A., Attallah, M.F. \& El-Reefy,(2009) S.A. Characterization of phosphogypsum wastes associated with phosphoric acid and fertilizers production. Journal of Environmental Radioactivity v100, p407-412.

Afnor - XP P 94-105. (2000) Sols : Reconnaissance et essais. Contrôle de la qualité du compactage. Méthode au pénétromètre dynamique à energie variable - Principe et méthode d'étalonnage du pénétromètre - Exploitation des résultats - Interpretation. France. 36p.

Ajam, L.; Ouezdou, M. B.; Felfoul, H. S. \& Mensi, R.E., (2009). Characterization of the Tunisian Phosphogypsum and its valorization in clays bricks, Construction and Building Materials, 8p.

Alves, A.B.C. (2002). Avaliação da Capacidade de Suporte e Controle Tecnológico de Execução da Camada Final de Terraplanagem Utilizando o Penetrômetro Dinâmico de Cone. Dissertação de Mestrado. PPGEC/UFSC, Florianópolis, SC. 
Angelim, R. R. (2005). Influência do procedimento de mistura da cal hidratada ao solo no comportamento do solo estabilizado para fins de pavimentação rodoviária. In: II Simpósio Sobre Solos Tropicais e Processos Erosivos no Centro-Oeste, UFG, p. 195-199.

ASTM (2003): American Society for Testing And Material, D6951-03: Standard test method for use of the dynamic cone penetrometer in shallow pavement applications. West Conshohocken, United State.7p.

ASTM (2006): American Society for Testing and Material D5550-06: Standard Standard Test Method for Specific Gravity of Soil Solids by Gas Pycnometer.West Conshohocken, United State.5p.

ASTM (2015): American Society for Testing and Material. D5858-96: Standard Guide for Calculating In Situ Equivalent Elastic Moduli of Pavement Materials Using Layered Elastic Theory. West Conshohocken, United State.7p.

Azouazi, M.; Ouahidi, Y.; Fakhi, S.; Andres, Y.; Abbe, J.CH. \& Benmansour, M.(2001) Natural radioactivity in phosphates, phosphogypsum and natural waters in Morocco, Journal of Environmental Radioactivity V 54, p231-242.

Balbo, J.T. (2007) Pavimentação Asfáltica - Materiais, Projeto e Restauração. Oficina de Textos, São Paulo, Brasil, 560p.

Bell, F.G,(1996) Lime stabilization of clay minerals and soils. Engineering Geology, South Africa, v42, p $223-237$.

Berish, C.W. (1990) Potential environmental hazards of phosphogypsum storage in central Florida. In: $3^{\text {rd }}$ International Symposium on Phosphogypsum, 1990, Miami, Florida. Proceedings... Bartow, Florida: Florida Institute of Phosphate Research, publication $\mathrm{N}^{\mathrm{O}} 01$ 060-083, v1, P.1-29.

Bernucci, L.B.; Motta, L.M.G; Ceratti, J.A.P \& Soares, J.B., (2008) Pavimentação asfáltica Formação básica para engenheiros. Petrobrás, Abeda. Rio de Janeiro. 504p.

Better ,C. (1999) World Production of Phosphate Rock, Better Crops, v.83, No. 1, p.4-7.

Borges, C. B. S.(2001), Estudo comparativo entre medidas de deflexão com viga Benkelman e FWD em pavimentos da malha rodoviária estadual de Santa Catarina. Dissertação de mestrado. Programa de Pós-Graduação em Engenharia, Universidade Federal de Santa Catarina, Florianópolis. 197p.

Burnett, W.C.\& Elzermanb, A.W. (2001) Nuclide migration and the environmental radiochemistry of Florida phosphogypsum. Journal of Environmental Radioactivity v54. p2751.

Camichael, J. B. (1998), World production and utilization of phosphogypsum. In: $2^{\text {nd }}$ International Symposium on Phosphogypsum, Miami, Florida. Proceedings... Bartow, Florida: Florida Institute of Phosphate Research, 1988, publication $\mathrm{N}^{\mathrm{o}}$ 01-037-055, v1, p 105110. 
Castilhos JR, A.B.; Roman, H.R.; Rocha, J.C.; Cheriaf, M.; Maccarini, M.; Castro, M. L. M. M.; Silveira, P. B. M.; Pressinotti, Q. S. H. C.\& Guardani, R., (2006). Tecnologia de Produção de fertilizantes. Instituto de pesquisa tecnológica - IPT. São Paulo, SPX.

Cekinski, E.; Calmanovici, C. E. ; Bichara, J. M.; Fabiani, M.; Giulietti, M.; Castro, M. L. M. M.; Silveira, P. B. M.; Pressinotti, Q. S. H. C.; Guardani, R., (1990) Tecnologia de Produção de fertilizantes. Instituto de pesquisa tecnológica - IPT. São Paulo, SP.

Chang, W. F.; Ching, D. A. \& Ho, R.(1989) Phosphogypsum for secondary road construction. Bartow Florida, University of Miami, Florida Institute of Phosphate Research, 1989, 181p.

Claude, K.W.F.,(2005) Chimie générale pour ingénieur. Presses polytechnique et universitaires romandes. 739p. Disponível em:http://books.google.com/books?id=xprJcdHNiggC\&printsec=frontcover\&dq=chimie+gén érale+ingenieur\&ei=HjDOS7WCM6KeygTNwYn1AQ\&hl=fr\&cd=1\#v=onepage \&q=phosph ate $\& \mathrm{f}=$ false Acesso em 20 de novembro de 2010.

CNEN (2014): Comissão Nacional de Energia Nuclear, Resolução Cnen179/14 - Uso do fosfogesso na agricultura e na indústria cimenteira. Ministério da Ciência, Tecnologia e Inovação.

CNEN (2015): Comissão Nacional de Energia Nuclear, Resolução CNEN189/15 - Nível de dispensa para o uso do fosfogesso na construção civil. Ministério da Ciência, Tecnologia e Inovação.

Cuadri, A.A. ; Navarro, F.J. ; Morales, M.G. \& Bolivar, J.P.,(2014) Valorization of phosphogypsum waste as asphaltic bitumen modifier. Journal of Hazardous Materials. 6p.

Cunha, N. L. (2011), Uso de materiais não convencionais para base de pavimentos asfálticos no município de Aparecida de Goiânia - GO. Dissertação de mestrado. Programa de PósGraduação em Geotecnia e Construção Civil, Universidade Federal de Goiás, Goiânia, Brasil. $231 \mathrm{p}$.

Degirmenci, N.; Okucu, A.\& Turabi (2007) A.Application of phosphogypsum in soil stabilization. BuildingandEnvironment v 42. p 3393-3398.

DER-PR (2005): Departamento de Estradas e Rodagem do Estado do Paraná, ES-P 11. Pavimentação: Solo-cimento e solo tratado com cimento. Especificação de Serviços Rodoviários.19p.

DER-SP (2006): Departamento de Estradas e Rodagem do Estado do São Paulo, IP-DE$\mathrm{P} 00 / 003$. Avaliação funcional e estrutural de pavimento. Instrução de projeto. 29p.

DER-SP (2006): Departamento de Estradas e Rodagem do Estado do São Paulo, IP-DEP00/001. Projeto de pavimentação. Instrução de projeto. 53p.

DNER (1979): Departamento Nacional de Estradas de Rodagem, Pro 011/79: Avaliação estrutural dos pavimentos flexíveis. Procedimento B, Rio de Janeiro. 16p. 
DNER (1994): Departamento Nacional de Estradas de Rodagem, ME 228: SolosCompactação em equipamento miniatura - Método de Ensaio. Rio de Janeiro.14p.

DNER (1994): Departamento Nacional de Estradas De Rodagem, ME 24: Pavimento Determinação das deflexões pela viga Benkelman - Método de Ensaio, Rio de Janeiro. 6p.

DNER (1994): Departamento Nacional de Estradas de Rodagem, ME 256: Determinação de perda de massa por imersão em água - Método de Ensaio. Rio de Janeiro. 6p.

DNER (1994): Departamento Nacional de Estradas de Rodagem, ME 258: Solos compactados em equipamento miniatura - Mini - MCV, Método de Ensaio. Rio de Janeiro, 1994a. 14p.

DNER (1994): Departamento Nacional de Estradas de Rodagem, PRO 175: Aferição de viga Benkelman. Rio de Janeiro. 11p.

DNER (1996): Departamento Nacional de Estradas de Rodagem, PRO 273: Determinação de deflexões utilizando deflectômetro de impacto tipo "Failling Weight Deflectometer (FWD)", Procedimento. Rio de Janeiro. 4p.

DNER (1997): Departamento Nacional de Estradas de Rodagem, ME 254: Solos compactados em equipamento miniatura - Mini-CBR e expansão - Método de Ensaio. Rio de Janeiro,14p.

DNIT (2003): Departamento Nacional de Infraestrutura de Transporte, PRO 008: Levantamento visual contínuo para avaliação da superfície de pavimentos flexíveis e semirígidos - Procedimento. Rio de Janeiro.11p.

DNIT (2003): Departamento Nacional de Infraestrutura de Transporte, PRO 007: Levantamento para avaliação da condição de superfície de subtrecho homogêneo de rodovias de pavimentos flexíveis e semi-rígidos para gerência de pavimentos e estudos e projetos Procedimento. Rio de Janeiro, 2003.11p.

DNIT (2003): Departamento Nacional de Infraestrutura de Transporte, PRO 006: Avaliação objetiva da superfície de pavimentos flexíveis e semi-rígidos - Procedimento. Rio de Janeiro.10p.

DNIT (2003): Departamento Nacional de Infraestrutura de Transporte, PRO 009: Avaliação subjetiva da superfície de pavimentos flexíveis e semi-rígidos - Procedimento Terminologia. Rio de Janeiro, 2003.6p.

DNIT (2003): Departamento Nacional de Infraestrutura de Transporte, PRO 006: Avaliação objetiva da superfície de pavimentos flexíveis e semi-rígidos - Procedimento. Rio de Janeiro, 2003.10p.

DNIT (2004): Departamento Nacional de Infraestrutura de Transporte, ME 055: pavimento rígido - prova de carga estática para determinação do coeficiente de recalque de subleito e sub-base em projeto e avaliação de pavimentos - Método de ensaio. Rio de Janeiro.6p. 
Dudas M. J., Arocena J. M., \& Rutherford P. M., (1995). Heterogeneous distribution of trace elements and fluorine in phosphogypsum by-product. The Science of the Total Environment, vol.162, pp. 149-160.

Dueñas, C.; Liger, E.; Cañete, S.; Pérez, M. \& Bolívar, J.P., (2007) Exhalation of ${ }^{222}$ Rn from phosphogypsum piles located at the Southwest of Spain. Journal of Environmental Radioactivity v95 p 63-74.

Faria, L. F. Ensaios laboratoriais com mistura de solo, fosfogesso e cal. (2007). Relatório final. Projeto de iniciação científica em Engenharia Civil - Escola de Engenharia Civil, Universidade Federal de Goiás. 34p.

Farias C. E. G. \& Coelho, J. M. (2002) Mineração e Meio Ambiente no Brasil. PNUD, Contrato 2002/001604. 42p

Felfoul, H. S.; Clastres, P.; Ouezdou, M. B. \& Gibergues, C. A (2002). Propriétés et perspectives de valorisation du phosphogypse l'exemple de la Tunisie. In: International Symposium on Environmental Pollution Control and Waste Management, Tunis, Tunisia. Proceedings...Tunis, Tunísia: EPCOWM 2002, p.510-520, 7-10.

Fernandes, F. R. C.; Luz, A. B. \& Castilhos, Z. C. (2010) Agrominerais para o Brasil. CETEM/MCT. Rio de Janeiro. 30p.

Ferrari, F. O. S.(2012), Utilização de fosfogesso, resíduos da produção de cal e areia da extração de ouro para produção de materiais da construção civil. Dissertação de mestrado. Programa de Pós-Graduação em Engenharia, Universidade Federal do Paraná, Curitiba. 84p.

Ferreira, C.M. (2007) Trabalhando com Viga Benkelman. 87p.

França, F. C., (2003) Estabilização química dos solos para fins rodoviários: estudo de caso com produto "RBI Grade 81". 2003. Dissertação de Mestrado em Engenharia Civil, Universidade Federal de Viçosa, Viçosa. 129p.

Franco, F. A. C. P., (2007) Método de dimensionamento mecanístico-empírico de pavimentos asfálticos - Sispav. Tese de doutorado. Coppe, Universidade Federal de Rio de Janeiro. Rio de Janeiro. 294p.

Gleize, P.; Lamberts, R. \& Soares, S.R.(1998) Valorização do fosfogesso na construção civil, Universidade Federal de Santa Catarina-UFSC, Centro Tecnológico - CTC, Núcleo de Pesquisas em construção - NPC \& Laboratório em Resíduos Sólidos, 151p.

Gourvès, R. ; Barjot, R., (1996) Le pénétromètre dynamique léger Panda. Seminaire : De la geologie au calcul des ouvrages. Grenoble, France.6p.

Haridasan, P.P.; Maniyan, C.G.; Pillai, P.M.B.; Khan, A.H., (2002). Dissolution characteristics of ${ }^{226} \mathrm{Ra}$ from phosphogypsum. Journal of Environmental Radioactivity v62. 287-294. 
Heyn, A.T. (1986) Aplicações do penetrômetro dinâmico de ponta cônica na avaliação de estruturas de pavimento. $21^{a}$ Reunião Anual de Pavimentação, Salvador, BA, Brasil, Vol.2, p $139-149$.

Ho, R.K.H.; Williams, R.W.; Cogdill, L.L.; Chang, W.F. (1988) Columbia county experimental road. In: $2^{\text {nd }}$ International Symposium on Phosphogypsum, Miami, Florida. Proceedings... Bartow, Florida: Florida Institute of Phosphate Research, publication $\mathrm{N}^{\mathrm{O}}$ 01037-055, v2, p.398-416.

Huang, Pavement Analysis and Design (2004). 2nd Ed. 792p.

Idalíria, M.D., (2007) Estudo de solos tropicais para uso em pavimentação a partir de ensaios triaxiais estáticos. 2007.139f. Dissertação de Mestrado em Engenharia Civil. Escola de Engenharia de São Carlos, Universidade de São Paulo, São Carlos.

Jang, M.; Kang C.S. \& Moon, J.H.,(2005) Estimation of ${ }^{222} \mathrm{Rn}$ release from the phosphogypsum board used in housing panels. Journal of Environmental Radioactivity v80, p153-160.

Jasinski, S.M., (2006) Phosphate rock, Minerals Yearbook, U.S. Geological Survey, 11p.

Kacimi, L.; Masseron, S. A.; Ghomari, A.; Derriche, Z. \& Salem, S., (2006) Valorization of phosphogypsum by using it in cement manufactory. COVAPHOS II v4, p. 217, 2006.

Kanno, W.M.; Rosseto, H.L \& Ferreira, M.S. Fosfogesso é usado em habitações populares. Universidade de São Paulo, (2008) Disponível em: http://www.saocarlos.usp.br/index.php?option=com_content\&task=view\&id=260\&Itemid=10 $\underline{8}$ Acesso em: 29 de Janeiro 2009.

Kenley, W.C.\&Chang, W.F., Polk county experimental road. (1988). In: $2^{\text {nd }}$ International Symposium on Phosphogypsum, Miami, Florida. Proceedings... Bartow, Florida: Florida Institute of Phosphate Research, publication $\mathrm{N}^{\mathrm{o}}$ 01-037-055, v2,p.353-359.

Kouloheris, A.P., (1980)Chemical nature of phosphogypsum as produced by various wet process phosphoric acid processes. In: INTERNATIONAL SYMPOSIUM ON PHOSPHOGYPSUM, Miami, Florida. Proceedings... Bartow, Florida: Florida Institute of Phosphate Research, publication N01-001-017, p.7-34.

Kumar, S. (2002) A perspective study on fly ash - lime - gypsum bricks and hollow blocks for low cost housing development. Construction and Building Materials v.16. p519-525.

Lima, D. C.; Bueno, B. S. \& Fontes, M. P. F.,(2000) Resultados de ensaios triaxiais de misturas de solo-cal. In: VII Congresso Nacional de Geotecnia. P. 523 - 529.

Little, D. N. (1999). Evaluation of strutural properties of lime stabilized soils and aggregates.Volume 1 : Summary of findings. $89 \mathrm{p}$. 
Lloyd, JR. G.M., (1985) Phosphogypsum. A review of the Florida institute of phosphate Research Programs to develop uses for phosphogypsum, Florida Institute of Phosphate Research. Publication $\mathrm{N}^{\mathrm{o}}$ 01-000-035. 16p.

Lovato, R. S. (2004) Estudo do comportamento mecânico de um solo laterítico estabilizado com cal, aplicado à pavimentação. 2004.164f. Dissertação (Mestrado em Engenharia Civil), Programa de Pós-Graduação em Engenharia Civil, Escola de Engenharia Civil, Universidade Federal do Rio Grande do Sul, Porto Alegre.

Luz, M. P. (2008) Aproveitamento de filer de pedreiras da região metropolitana de Goiânia em pavimentos flexíveis urbanos: avaliação técnica e sócio-ambiental. Tese de Doutorado em Ciências do Ambiente. Programa de Doutorado em Ciências Ambientais, Universidade Federal de Goiás, Goiânia. 103p.

Macêdo, J.A.C.(1996) Interpretação de ensaios defletométricos para avaliação estrutural de pavimentos flexíveis. Tese (Doutorado). Universidade Federal do Rio de Janeiro - Coppe, Rio de Janeiro.477p.

Máduar, M.F, ; Campos, M.P. ; Mazzilli \& Vilaverde, F.L.,(2011). Assessment of external gamma exposure and radon levels in a dwelling constructed with phosphogypsum plates. Journal of Hazardous Materials. 5p.

Marques, M. O., (2012), Monitoramento de Trechos de Pavimentos Experimentais com Materiais Alternativos na Região Metropolitana de Goiânia. Dissertação de mestrado. Programa de Pós-Graduação em Geotecnia e Construção Civil, Universidade Federal de Goiás, Goiânia, Brasil.

Masri, A. M.S.; Amin, Y.; Ibrahim, S.\& Al-Bich, F. (2004). Distribution of some trace metals in Syrian phosphogypsum. Applied Geochemistry v19. p.747-753.

Matos, T.H.C. (2011) Caracterização hidro-mecânica do fosfogesso e das misturas solofosfogesso. 2011. 118f. Dissertação de Mestrado em Geotecnia. Programa de Pós-graduação em Geotecnia, Universidade de Brasília, Brasília.

Mazzilli, B.; Saueia, C.H.R., (1997) Implicações radiológicas da utilização do fosfogesso como material de construído. Ambiente Construção, São Paulo,v.1, N 2, p.17-22.

McClellan, G.H.; Kauwenbergh, S.J.V., (2004) Les gisements de phosphates du monde, utilisation des phosphates naturels pour une agriculture durable In: Zapata, F; Roy, R.N., (Org.) Utilisation des phosphates naturels pour une agriculture durable. Bulletin FAO engrais et nutrition végétale 13. Organisation des Nations Unies pour l'Alimentation et l'Agriculture (FAO), Rome. Disponível em: http://www.fao.org/docrep/007/y5053f/y5053f06.htm\#bm06, Acesso em: 3 de novembro de 2010.

Medina, J. \& Motta,L. (2015) Mecânica dos pavimentos, Rio de Janeiro, Editora Interciênca.640p. 
Mesquita, G.M. (2007) Aplicação de misturas de fosfogesso e solos tropicais finos na pavimentação. 2007. Dissertação Mestrado em Engenharia do Meio Ambiente - Escola de Engenharia Civil, Universidade Federal de Goiás, Goiânia, 2007. 144p.

Metogo, D. A. N. (2010) Construção e avaliação inicial de um trecho de pavimento asfáltico executado com misturas de solo tropical, fosfogesso e cal. Dissertação de Mestrado em Geotecnia - Escola de Engenharia Civil, Universidade Federal de Goiás, Goiânia. 195p.

Metogo, D. A. N. (2009)Resultados preliminares de estudos laboratoriais com misturas de solos tropicais finos, fosfogesso e estabilizantes químicos, Congresso de Pesquisa, Ensino e Extensão, Universidade Federal de Goiás.7p.

Min, Y.; Jueshi Q. \& Ying, P., (2008) Activation of fly ash - lime systems using calcined phosphogypsum. Construction and Building Materials v22, p 1004-1008.

Moughli, L. (2000) Transfert de technologie en agriculture. Bulletin mensuel d'information et de liaison du PNTTA, $\mathrm{N}^{\mathrm{o}}$ 72, p.1-4.

Mun, K.J.; Hyoung, W. K.; Lee, C.W.; So, S.Y. \& Soh, Y.S., (2007) Basic properties of nonsintering cement using phosphogypsum and waste lime as activator. ConstructionandBuildingMaterialsv21 p.1342-1350.

Nifong, G. D. \& Harris, J.K. (1993) Environmental monitoring of Polk and Columbia countries experimental phosphogypsum roads. Final report. Florida Institute of phosphate research, Miami, Florida, Publication N ${ }^{\mathrm{o}}$ 05-033-101, 129 p.

Nogami, J. S.; Villibor, D. F. (1995) Pavimentação de baixo custo com solos lateríticos, São Paulo, Vilibor. 240p.

Norfalco, (2007) Manuel sur l’acide sulfurique. 36p.

Oliveira, J. C. ( 2007) Indicadores de potencialidades e desempenho de agregados reciclados de resíduos sólidos da construção civil em pavimentos flexíveis. Tese de Doutorado em Geotecnia. Faculdade de Tecnologia, Departamento de Engenharia Civil e Ambiental, Universidade de Brasília, Brasília. 167p.

Ouhadi, V. R. \& Yong, R. N. (2008) Ettringite formation and behaviour in clayey soils.Applied Clay Science, v42, p.258-265.

Palmer, C. S., (1986) Virginia's lime industry. Virginia Mineral, United State of America v.32. No2, p.33-44, November 1986.

Parreira, A.B.; Kobayashi, A.R.K.; Silvestre JR, O.B., (2003) Influence of Portland cement type on unconfined compressive strength and linear expansion of cement-stabilized phosphogypsum, Journal of Environmental Engineering, v129, p.956-960.

Perera, R.W. \& Kohn, S. D. (2002) Issues in Pavement Smoothnes: A summary report. National Cooperative Highway Reseach Programa. Transportation Research Board. 164p. 
Pessoa, F. H. C. (2012), Avaliações Funcional e Estrutural de Trechos de Rodovias no Distrito Federal Construídos com Diferentes Materiais. Tese de doutorado. Programa de PósGraduação em Geotecnia, Universidade de Brasília. Brasília. 210p.

PORMIN: Portal de Apoio ao Pequeno Produtor Mineral, Beneficiamento de Minérios. Ministério de Minas e Energia, Brasília, 10p. 2008.

Rabi J.A. \& Mohamad A.A., (2006) Parametric modeling and numerical simulation of natural-convective transport of radon - 222 from a phosphogypsum stack into open air. Applied Mathematical Modeling v30, p1546-1560.

Rauber, C.H. \& Kupferschmidt, H. (2006) Acide fluorhydrique: intoxications et brûlures, 4p.

Rezende, L. R., (2003) Estudo de comportamento de materiais alternativos utilizados em estruturas de pavimentos flexíveis. Tese de Doutorado em Engenharia Civil. Faculdade de Tecnologia, Departamento de Engenharia Civil e Ambiental, Universidade de Brasília, Brasília. 372p.

Rezende, L. R., (1999) Técnicas alternativas para construção de bases de pavimentos rodoviárias. Dissertação de Mestrado em Engenharia Civil. Faculdade de Tecnologia, Departamento de Engenharia Civil e Ambiental, Universidade de Brasília, Brasília, 1999. $172 \mathrm{p}$.

Roessler, C.E., (1990) Radon emanation from roads constructed with phosphogypsum aggregates. In: $3^{\text {rd }}$ International Symposium on Phosphogypsum, Miami, Florida. Proceedings... Bartow, Florida: Florida Institute of Phosphate Research, publication $\mathrm{N}^{\mathrm{o}}$ 01060-083, v1, p.30-43.

Rouis, M.J.; Ballivy, G. \& Bensalah, A., (1990) Phosphogypsum Management in Tunisia: Environmental Problems and Required Solutions. In: $3^{\text {rd }}$ International Symposium on Phosphogypsum, Miami, Florida. Proceedings... Bartow, Florida: Florida Institute of Phosphate Research, publication N $\mathrm{N}^{\mathrm{0}}$ 01-060-083, v1, p.87-94.

Rufo, R. C. (2009) Estudo laboratorial de misturas de fosfogesso, solo tropical e cal para fins de pavimentação. 2009. Dissertação de Mestrado em Engenharia do Meio Ambiente - Escola de Engenharia Civil, Universidade Federal de Goiás, Goiânia. 152p.

Rutherford, P.M.; Dudas, M.J. \& Arocena, J.M., (1995) Radioactivity and elemental composition of phosphogypsum produced from three phosphate rock sources. Waste Management and Research v13, p407- 423.

Sayers,M.W ; Gillespie, T.D. \& Paterson, W. D. O., (1986) Guidelines for Conducting and Calibrating Road Roughness Measurements. The International Bank for Reconstruction and development. World Bank. 96p.

Shen, W.; Zhou, M. \& Zhao, Q., (2007) Study on lime - fly ash - phosphogypsum binder. Construction and Building Materials v21, p1480-1485. 
Shirley, M. F. (2005) Estudo do comportamento mecânico de misturas de fosfogesso e cal para utilização na construção de rodoviárias. Dissertação de mestrado. Escola de Engenharia de São Carlos, Universidade de São Paulo, São Paulo, SP. 210p.

Silva Júnior, F. A. (2005). Cone de Penetração Dinâmica (DCP): Uma Alternativa Ao Dimensionamento De Pavimentos Urbanos. Dissertação (Mestrado Em Engenharia Civil) Universidade Federal de Campina Grande, 109p.

Silva, N.C.D.; Cipriani, M.; Taddei, M. H. T., (2002) Estudo da exalação de radônio, dos processos de lixiviação de metais pesados e radionuclídeos e das características físicas, químicas e radiométricas do fosfogesso da Ultrafértil e da Copebrás, visando sua utilização na construção de aterros.ComissãoNacional de Energia Nuclear, 60p.

Singh, M., (2005) Role of phosphogypsum impurities on strength and microstructure of selenite plaster. Construction and Building Materials, v19, p480-486.

Souza, (2001) A.E. Fosfato. Balanço mineral Brasileiro p1-31.

Straaten, P.V. (2002) Rocks for Crops: Agrominerals of sub-Saharan Africa. ICRAF, Nairobi, Kenya, 338p.

Sumner, M.E.; Miller, W.P.; Radcliffe, D.E. \& Mccray, M., (1986) Use of phosphogypsum as an amendment for highly weathered soils.In: $3^{\text {rd }}$ Workshop on By-Products of Phosphate Industries. Proceedings... Bartow, Florida: Florida Institute of Phosphate Research, publication $\mathrm{N}^{\mathrm{o}}$ 01.031.046, p.111-136.

Tayibi, H.; Choura, M.; López, F.A.; Lguacil, F.J.; Delgado, L. A., (2009) Environmental impact and management of phosphogypsum.Journal of Environmental Management v90.p2377-2386.

Technologies nouvelles. (2012) Analyseur de profil en long APL. Disponível em: http://www.technologiesnouvelles.fr/wp-content/uploads/2012/09/01_Fiche-

Moyen_APL_V1.pdf. Acesso : 15/07/2015.

Tosaka, (2008) Decay chain 4n+2, Uranium series. Disponível em: http://en.wikipedia.org/wiki/File:Decay_chain(4n\%2B2,_Uranium_series).PNG, Acesso em: 15 de novembro 2010.

UNIDO; IFCD (1998) - United Nation Industrial Development Organization; International Fertilizer Development Center, Fertilizer manual, Netherland, 615p. 1998.

UNSCEAR (2000): United Nations Scientific Committee on the Effects of Atomic Radiation, Annex B: Exposures from 84 natural radiation sources. UNSCEAR Report to the General Assembly, with scientific annexes Vienna, AUSTRIA, 2000. v1, 74p.

USEPA (2009): U.S. Enviromental Protection Agency, Hazardous Waste Characteristics: A User-Friendly Reference Document. Washington D.C., 2009, 30p. Disponível em: http://www.epa.gov/wastes/hazard/wastetypes/wasteid/char/hw-char.pdf, Acesso em: 25 de novembro de 2010. 
Villibor, D. F.; Nogami J. S.; Cincere J. R.; Serra P. R. M. \& Neto A. Z., (2009). Pavimentos de baixo custos para vias urbanas: Bases alternativas com solos lateríticos, gestão de manutenção de vias urbanas. Arte \& Ciência Editora, $2^{a}$ edição - ampliada. São Paulo 196p. Il.; 23cm. ISBN - 978-85-61165-29-1

Villibor, D.F.; Nogami, J.S. (2009). Pavimentos econômicos: Tecnologia de uso dos solos finos lateríticos. 1ed. São Paulo:Editora Arte \&Ciência.. 292p.

Windham, S. T. \& Horton, T.R., (1980). Assessment of radon exhalation from phosphate gypsum piles. In: International Symposium on Phosphogypsum. Proceedings... Bartow, Florida: Florida Institute of Phosphate Research , publication Nº1-001-017, 1980 P.84-100.

Wolicka, D., (2008) Biotransformation of phosphogypsum in wastewaters from the dairy industry. Bioresource Technology v99 p.5666 - 5672 .

Yang, L.; Yan, Y. \& Hu, Z. (2013). Utilization of phosphogypsum for preparation of nonautoclaved aerated concrete. Construction and Building Materials. 7p.

Zapata, F \& Roy, R.N., (2004). Utilisation des phosphates naturels pour une agriculture durable. Bulletin FAO engrais et nutrition végétale 13. Organisation des Nations Unies pour l'Alimentation et l'Agriculture Rome. Disponível em: http://www.fao.org/docrep/007/y5053f/y5053f05.htm\#bm05, Acesso em : 3 de novembro de 2010.

Zhou, J.; Gao, H.; Shu, Z.; Li, T.; Wang, Y. \& Yan, C. (2012). Utilization of waste phosphogypsum to prepare non-fired bricks by a novel hydratation-recrystallization process. Construction and Building Materials. 6p.

Zhou, J.; Yu, D.; Shu, Z.; Li, T.; Chen, Y. \& Wang, Yanxin (2014). A novel two-step process of preparing cement-free non fired braicks from waste phophogypsum. Construction and Building Materials. 7p. 